Portland State University

PDXScholar

Summer 7-16-2018

\title{
Principal and Teacher Beliefs About the Impact of CBAs on School Performance: Five High Performing High Schools in Oregon
}

Kevin Jon Ricker

Portland State University

Follow this and additional works at: https://pdxscholar.library.pdx.edu/open_access_etds

Part of the Educational Administration and Supervision Commons, and the Educational Leadership Commons

Let us know how access to this document benefits you.

\section{Recommended Citation}

Ricker, Kevin Jon, "Principal and Teacher Beliefs About the Impact of CBAs on School Performance: Five High Performing High Schools in Oregon" (2018). Dissertations and Theses. Paper 4508.

https://doi.org/10.15760/etd.6392

This Dissertation is brought to you for free and open access. It has been accepted for inclusion in Dissertations and Theses by an authorized administrator of PDXScholar. Please contact us if we can make this document more accessible: pdxscholar@pdx.edu. 
Principal and Teacher Beliefs About the Impact of CBAs on School Performance: Five High Performing High Schools in Oregon

by

Kevin Jon Ricker

A dissertation submitted in partial fulfillment of the requirements for the degree of

\author{
Doctor of Education \\ in \\ Educational Leadership: Administration
}

Dissertation Committee:

Deborah Peterson, Chair

Pat Burk

Rana Houshmand

Jose Padin

Portland State University

2018 
(C) 2018 Kevin Jon Ricker 


\begin{abstract}
This qualitative study examined how school leaders work within the structure of individual district collective bargaining agreements to improve student achievement. The study examines real or perceived barriers to improving student achievement within educational organizations from the perspective of the principals and teacher-leaders.

This study included two qualitative instruments, one for building principals and one for the building teachers, administered in five Oregon high schools recognized as successful by the Oregon Department of Education in 2014-2015. This dissertation determined the impact collective bargaining agreements had on the ability of high school principals to reduce educational disparities and close the achievement gap from both the perspective of themselves and teacher-leaders. The dissertation concluded with a brief summary of the collective findings from the study, as well as the implications for practice specific to building principals and teacher-leaders in the context of their school, and agreement about strategies that work to overcome barriers to school performance.
\end{abstract}




\section{Dedication}

I dedicate my dissertation studies to my best friend and wife, Keri. Thank you for the love, patience, and support you provide and give to me on a daily basis. The commitment to this work is something that was shared by both of us, and only with her continual encouragement, assistance and unconditional love, was this possible. We both made a great number of sacrifices during some incredibly difficult times to make this happen, and it will always be a reminder that we can accomplish anything together.

This dissertation is also dedicated to my Grandmother Margaret Ricker, who passed April $3^{\text {rd }}, 2018$. No one, including me, was more interested in the completion of this dissertation than my Grandmother. She questioned me about my progress on every single one of our phone calls together for the last few years. I am sorry Grandma that it took me so long, but I hope you can see that I finally did it. I miss you.

I dedicate this work to my family. Thank you, mom and dad, for providing me the opportunity to access a quality education and the gifts of a safe, stable and happy home shared with a generous, loving and supportive family. There is nothing more a child could ask from his parents. Thank you to my brother Matt Ricker and his family; wife Mari and daughters, Elsa and Gemma, for the kindness you have shown and the strength and courage you have given to me. Thank you, Rick and Susan Pilgrim, for welcoming me into your family and for your unwavering support in anything I do. Thank you, Carol, for keeping me company in the office all those hours I worked late, never once complaining, and most importantly for being my friend. 
I dedicate my studies to the students I had the opportunity to work with and serve over the course of my career. Last, I dedicate this to my good friend Justin Rosenblad, an exceptional educator and father. You will always be remembered. 


\section{Acknowledgements}

I want to first and foremost extend my deepest gratitude to my advisor Dr. Deborah Peterson. Her support is the reason why I am currently typing these words. She is simply an exceptional advisor, a true mentor, and constant source of inspiration and motivation. I do not have the words to express the level of gratitude and respect I have for you. Thank you. I would like to thank my committee members, Dr. Pat Burk, Dr. Alan Cabelly, and Dr. Rana Houshmand and Dr. Jose Padin for their flexibility, humor and most import, tremendous patience! I am so grateful for your time, your commitment, and your guidance in this process. I am a better educator because of what I have learned from all of you.

Thank you, Dr. Tom Chenoweth, for providing me the opportunity to connect with Portland State University and to complete what was left unfinished. Thank you, Dr. Daniel Duke, for believing in me, and helping me start this work a long time ago. A special acknowledgement goes to Stefanie Randol. I simply would not be here without you. Thank you for your kindness, your patience and your continual support.

I would like to extend my sincerest gratitude to a number of my colleagues that have provided immeasurable support during this dissertation work: Dr. Simon Driver, Dr. Drew Hinds, Dr. Zach Ramberg, Andrea Wallace, Tami Burton, Dr. Danielle Hudson, Dave Collins, and Dr. Charles Martinez. Furthermore, I would like to thank James Barlow, a true mentor, and many of my old friends and colleagues at Mills E. Godwin, Fluvanna, Molalla, and Centennial High Schools, as well as those in Springfield Public 
Schools and COSA that have provided so much support, guidance, and often patience, in our work together. 
Table of Contents

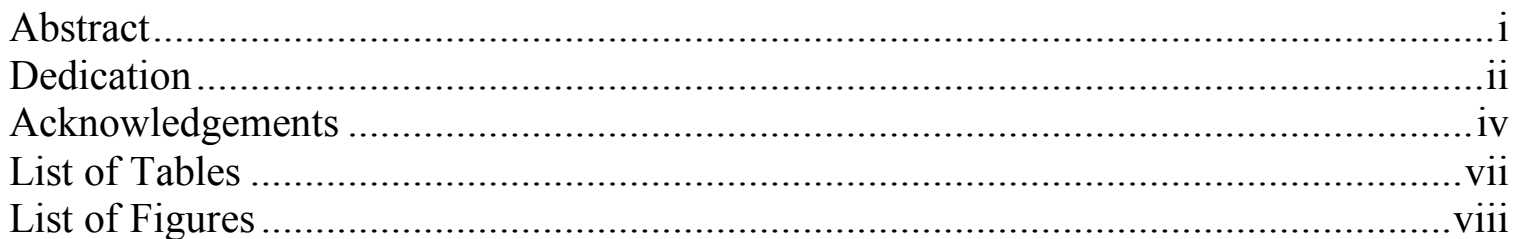

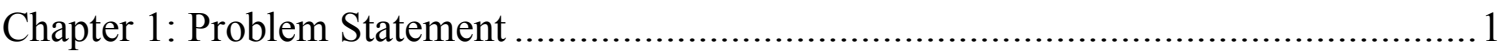

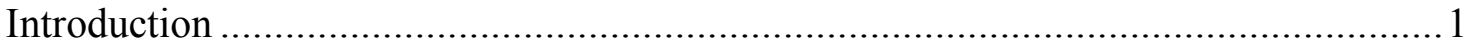

Background of the Problem................................................................................. 3

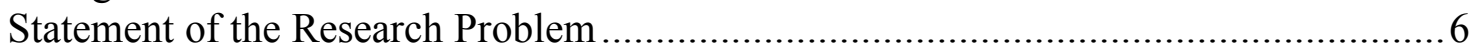

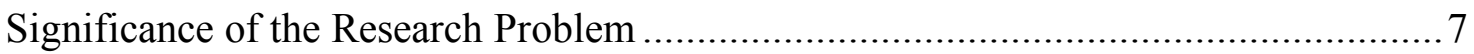

Presentation of Methods and Research Question .................................................... 10

Definition of Key Concepts.............................................................................. 11

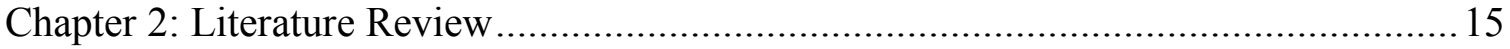

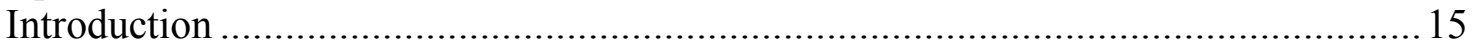

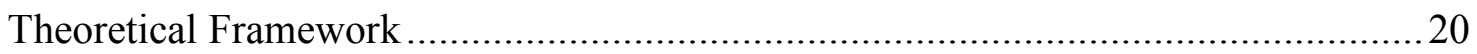

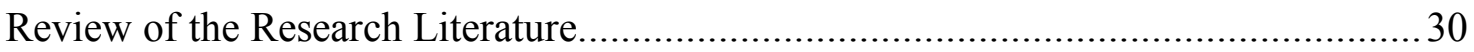

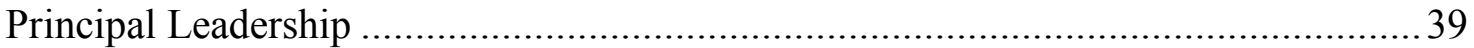

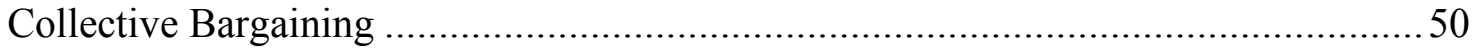

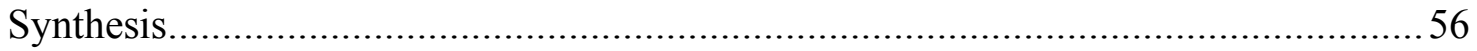

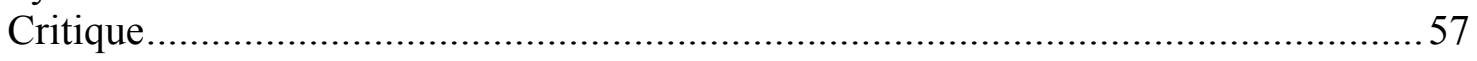

Review of the Methodological Literature …………..........................................5

Summary of the Research Literature and Application to the Study .............................58

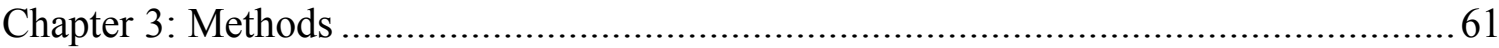

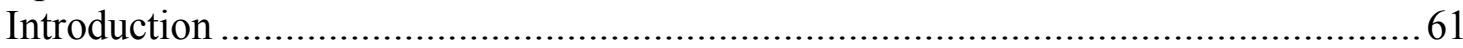

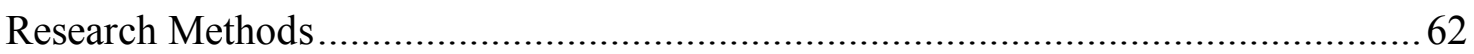

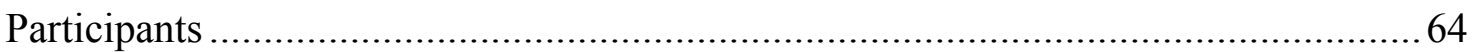

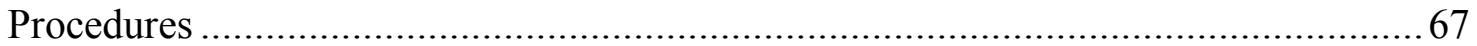

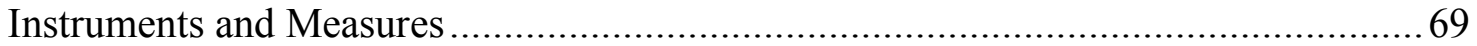

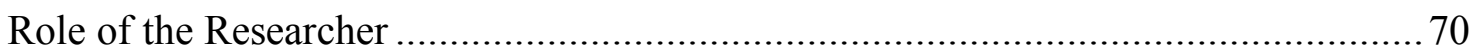

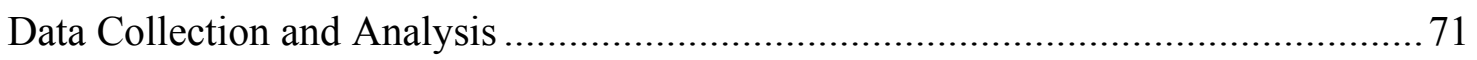

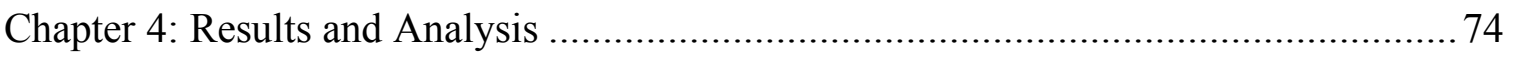

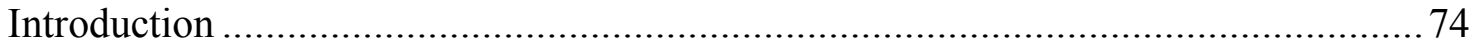

Analysis of Data and Presentation of the Results.................................................. 75

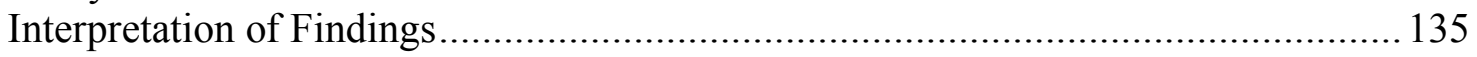

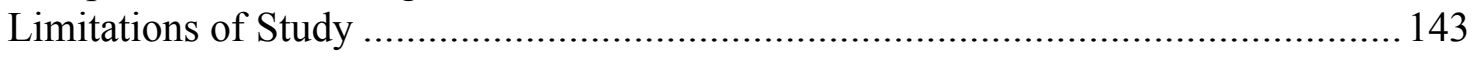

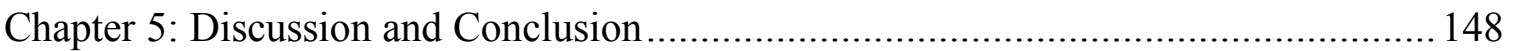

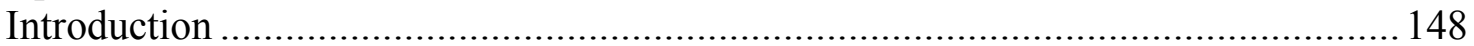

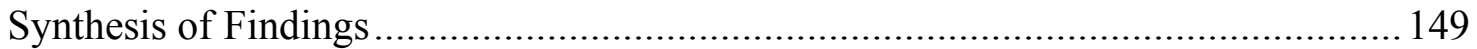

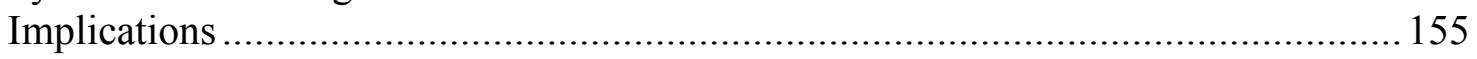

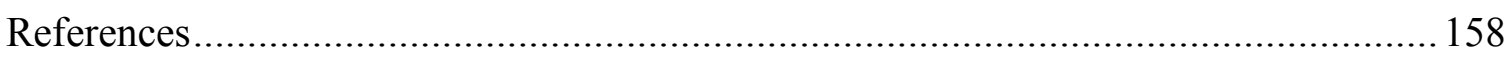


List of Tables

Table $\quad$ Page

1 A Summary of Principal Ratings of How Much Control They Have in Making Decisions ................................................................... 47

2 Number of Categories of Responses Per Question .................................... 146 
List of Figures

Figure $\quad$ Page

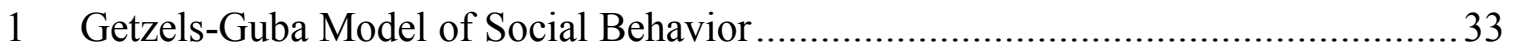

2 Visual Summary of the Qualitative Data on Principal Attitudes About the Job of the Principal ......................................................................................... 44

3 Summary of Collective Principal Responses to Question 1 ............................... 77

4 Summary of Collective Principal Responses to Question 2 ............................... 78

5 Summary of Collective Principal Responses to Question 3 ................................ 79

6 Summary of Collective Principal Responses to Question 4 ................................. 80

7 Summary of Collective Principal Responses to Question 5 ............................... 81

8 Summary of Collective Principal Responses to Question 6 ................................. 82

9 Summary of Collective Principal Responses to Question 7 .............................. 83

10 Summary of Collective Teacher Responses from Buildings A-E to Question 1 .......84

11 Summary of Collective Teacher Responses from Buildings A-E to Question 2 „......85

12 Summary of Collective Teacher Responses from Buildings A-E to Question 3 .......86

13 Summary of Collective Teacher Responses from Buildings A-E to Question 4 ......87

14 Summary of Collective Teacher Responses from Buildings A-E to Question 5 .......88

15 Summary of Collective Teacher Responses from Buildings A-E to Question 6......89

16 Summary of Collective Teacher Responses from Buildings A-E to Question 7 .......91

17 Summary of Collective Teacher Responses from Building A to Question 1 ...........92

18 Summary of Collective Teacher Responses from Building A to Question 2 ...........93

19 Summary of Collective Teacher Responses from Building A to Question 3 ...........93

20 Summary of Collective Teacher Responses from Building A to Question 4 ...........94

21 Summary of Collective Teacher Responses from Building A to Question 5 ...........94 
22 Summary of Collective Teacher Responses from Building A to Question 6 ...........95

23 Summary of Collective Teacher Responses from Building A to Question 7 ...........95

24 Summary of Collective Teacher Responses from Building B to Question 1 ...........96

25 Summary of Collective Teacher Responses from Building B to Question 2 ...........97

26 Summary of Collective Teacher Responses from Building B to Question 3 ...........97

27 Summary of Collective Teacher Responses from Building B to Question 4 ...........98

28 Summary of Collective Teacher Responses from Building B to Question 5 ...........98

29 Summary of Collective Teacher Responses from Building B to Question 6 ...........99

30 Summary of Collective Teacher Responses from Building B to Question 7 ...........99

31 Summary of Collective Teacher Responses from Building C to Question 1 ......... 101

32 Summary of Collective Teacher Responses from Building C to Question 2 .......... 101

33 Summary of Collective Teacher Responses from Building C to Question 3 ......... 102

34 Summary of Collective Teacher Responses from Building C to Question 4 ......... 102

35 Summary of Collective Teacher Responses from Building C to Question 5 .......... 103

36 Summary of Collective Teacher Responses from Building C to Question 6 .......... 103

37 Summary of Collective Teacher Responses from Building C to Question 7 .......... 104

38 Summary of Collective Teacher Responses from Building D to Question 1 ......... 105

39 Summary of Collective Teacher Responses from Building D to Question 2 ......... 105

40 Summary of Collective Teacher Responses from Building D to Question 3 ......... 106

41 Summary of Collective Teacher Responses from Building D to Question 4 ......... 106

42 Summary of Collective Teacher Responses from Building D to Question 5 ......... 107

43 Summary of Collective Teacher Responses from Building D to Question 6 ......... 107

44 Summary of Collective Teacher Responses from Building D to Question 7 ......... 108

45 Summary of Collective Teacher Responses from Building E to Question 1.......... 109 
46 Summary of Collective Teacher Responses from Building E to Question 2.......... 110

47 Summary of Collective Teacher Responses from Building E to Question 3.......... 110

48 Summary of Collective Teacher Responses from Building E to Question 4........... 111

49 Summary of Collective Teacher Responses from Building E to Question 5.......... 111

50 Summary of Collective Teacher Responses from Building E to Question 6........... 112

51 Summary of Collective Teacher Responses from Building E to Question 7.......... 112

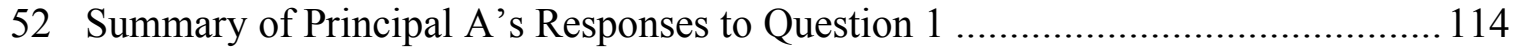

53 Summary of Principal A's Responses to Question 2 ..................................... 114

54 Summary of Principal A's Responses to Question 3 .................................... 115

55 Summary of Principal A’s Responses to Question 4 ...................................... 115

56 Summary of Principal A's Responses to Question 5 .................................... 116

57 Summary of Principal A's Responses to Question 6 ......................................... 116

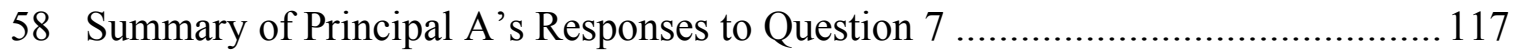

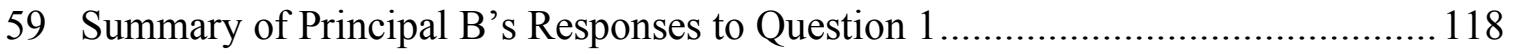

60 Summary of Principal B's Responses to Question 2 ...................................... 119

61 Summary of Principal B's Responses to Question 3 ......................................... 119

62 Summary of Principal B's Responses to Question 4 ....................................... 120

63 Summary of Principal B's Responses to Question 5 .................................... 120

64 Summary of Principal B's Responses to Question 6...................................... 121

65 Summary of Principal B's Responses to Question 7 ....................................... 121

66 Summary of Principal C's Responses to Question 1 ...................................... 123

67 Summary of Principal C's Responses to Question 2 ...................................... 123

68 Summary of Principal C's Responses to Question 3 ...................................... 124

69 Summary of Principal C's Responses to Question 4 ..................................... 124 
70 Summary of Principal C's Responses to Question 5...................................... 125

71 Summary of Principal C's Responses to Question 6..................................... 125

72 Summary of Principal C's Responses to Question 7 .................................... 126

73 Summary of Principal D's Responses to Question 1 ....................................... 127

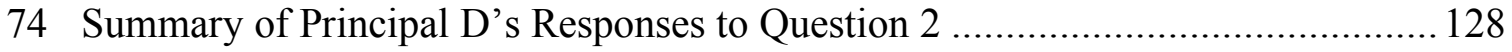

75 Summary of Principal D's Responses to Question 3 ........................................ 128

76 Summary of Principal D's Responses to Question 4 ...................................... 129

77 Summary of Principal D's Responses to Question 5 ...................................... 129

78 Summary of Principal D’s Responses to Question 6 .................................... 130

79 Summary of Principal D's Responses to Question 7 ...................................... 130

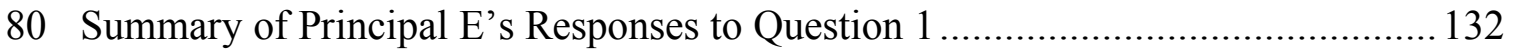

81 Summary of Principal E's Responses to Question 2 ................................... 132

82 Summary of Principal E's Responses to Question 3 ........................................ 133

83 Summary of Principal E's Responses to Question 4 ....................................... 133

84 Summary of Principal E's Responses to Question 5 ...................................... 134

85 Summary of Principal E's Responses to Question 6 ......................................... 134

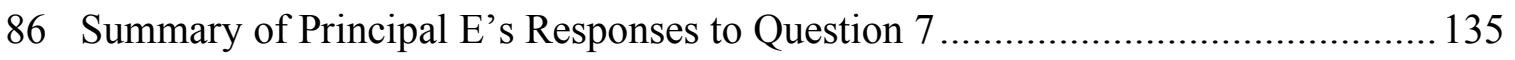




\section{Chapter 1: Problem Statement}

\section{Introduction}

"Accountability" is a word that defines the current public education system at every level. With the release of $A$ Nation at Risk (National Commission on Excellence in Education, 1983), subsequent educational reform and policy at the state and national level have focused on improving student academic performance and reducing persistent racial and socio-economic achievement gaps. This focus on accountability is echoed by McGuinn (2010): “The creation of state accountability systems has created greater transparency about school performance and held politicians and school leaders responsible for the academic achievement of students as never before" (p. 26).

The No Child Left Behind Act of 2001 (NCLB) explicitly recognized the role of collective bargaining in education (Section 1116d) and is also the first clear representation of the diminishing level of authority and autonomy for our public-school leaders. This diminished level of authority and autonomy raises the question of whether decreased authority and autonomy negatively impact student achievement universally. Although collective bargaining and labor agreements are prevalent in almost every public-school district in the country, they are neither uniform nor systemic, but individual and specific to the local level. There is very little research measuring how much variability there is in collective bargaining agreements (CBAs) from district to district. The lack of research begs the question of whether our educational leaders are universally restricted in their ability to lead based on CBAs or is the impact of CBAs on ability to 
lead dependent upon the locale and the individual labor agreement. According to Hess and Loup (2008), this question is significant because

At least in some communities, labor agreements may not bear as much responsibility for enervated management ... some scholarly accounts have suggested that the failure to aggressively pursue effective teachers, remove ineffective teachers, find ways to assign teachers where they are needed most, or rethink school routines cannot be attributed solely to contractual constraints. (p. 11)

A significant factor in the level of authority and autonomy that can be exercised by school leaders is dictated by the individual terms of school district collective bargaining and labor agreements. Collective bargaining is not a practice that is limited in scope to a few isolated school districts; rather collective bargaining is mandated by law in the vast majority of the United States. The National Education Association has defined 45 states as collective bargaining states: 31 as mandatory, 14 as permissible and 5 states as non-collective bargaining states (Hess \& Loup, 2008). The labor agreements resulting from CBAs are, therefore, a common and integral part of the public education system. As a result of the commonplace in practice, there is little comparative student achievement data between the two types, collective and non-collective, states.

In 2012, Winkler, Scull, and Zeehandelaar concluded that as a state, Oregon was ranked second in relative strength of state-level teacher unions among the 50 states (plus Washington, DC) as compared to one another, noting that "Oregon's teacher unions have substantial internal resources, are active donors to politicians and parties, and enjoy highly favorable bargaining rules" (p. 284). Conversely, Oregon is ranked number 40 among states in academic achievement (Oregon Department of Education [ODE], 2014a). The significant difference in the state of Oregon between the identified strength of the 
teacher union and the reciprocal lack of student achievement provides a unique opportunity to examine the relationship, if any, between the two.

\section{Background of the Problem}

As far back as the publication of $A$ Nation at Risk (National Commission on Excellence in Education, 1983), which warned us of a "rising tide of mediocrity," public schools have functioned under a veil of criticism and pressure to increase student achievement. President Clinton instituted the first national formulation of educational policy focused on accountability through the Goals 2000 program, which included a process of national teacher certification. It was followed by the most significant adoption of educational policy in the last decade, the NCLB, which formally imposed "for the first time, a national accountability system of annual testing and performance-based rewards and sanctions" (Moe, 2002, p. 2).

According to McEachin and Strunk (2011), the theoretical framework behind the use of accountability policies holds that "the threat (and use) of sanctions will incentivize teachers, principals, superintendents and other school staff to implement reforms that will increase student achievement" (p. 872). Implicit to this theory of action is the assumption that schools and school districts have the authority and ability to allow and implement change that will positively impact student learning. CBAs control the flexibility of district and school administrators to implement change in response to accountability policies, and thus have a negative impact on student performance (McEachin \& Strunk, 2011). Examples of such restrictions are provided by Hess and Loup (2008):

Labor agreements ... now regulate virtually all aspects of school district operations, from how teachers are paid and assigned to schools to how they can 
be evaluated, how or whether they can be disciplined or fired, when and where they receive professional development, and how much time off they get for union activities. (p. 10)

The current educational environment is defined by organizational accountability practices intended to increase the level of student achievement in the public-school system. The ability of states to apply for waivers to NCLB represents the latest attempt to address the crisis facing our schools, and ultimately may change the way we discuss student achievement. In order to understand how CBAs impact student achievement through educational policy, we can follow the most significant educational policy, NCLB, through the stage model. The identified issue, the effectiveness of the system of public education, is not a new policy problem. It has been identified at the political level as far back as the publication of $A$ Nation at Risk (National Commission on Excellence in Education, 1983), which effectively focused the attention of our country on the outcomes of our public-school system. As a result of the questions raised about the effectiveness of our public education system, educational reform has been represented on the agendas of almost every politician, political interest group or legislative committee since the turn of the century, the most powerful being the American Federation of Teachers and the National Education Association. According to Lieberman (1999), the National Education Association and the American Federation of Teachers are the most powerful organizations in American education

With over three million members paying dues in excess of one billion dollars a year, they help choose presidential candidates, and make national educational policy. With more than 6,000 full time officers and staff, these unions have more operatives than the Democrat and Republican parties combined. (p. 1) 
Most recently, school accountability has been at the forefront of the legislative agenda in many states (Moe, 2002). The message is clear: public schools will have strong academic standards, measured by standardized assessments, and the teachers and administrators, incentivized by performance consequences, are accountable for the results.

The implementation of NCLB was bureaucratically ensured by attaching compliance to federal funding. In order to receive federal monies, states were required to establish a system of progress monitoring, called Adequate Yearly Progress which would provide ratings for individual schools. In order to receive federal dollars distributed through the state departments of education, participation is required. Failure to meet the prescribed standards results in a series of incremental consequences for schools and school administrators up to and including removal and receivership of the individual school. Classroom teachers, who according to Danielson (2009) have the single largest impact of any variable on student achievement under the control of the school, are protected from individual consequence by CBAs.

Although the strength of teacher unions and the restrictions imposed by CBAs are often cited as significant barriers to meeting progressive accountability measures, not all employee organizations in the 50 states have the right to collectively bargain. There are considerable differences, dependent upon the individual state, the type of bargaining status, and the context of the relationship it maintains with the district, when attempting to identify or generalize direct correlations related to CBAs and school performance. Recent work stoppages in states that permit bargaining such as Arizona, Oklahoma and 
West Virginia demonstrate the importance of relationships between individual district leaders and teachers, regardless of the individual strengths of the CBAs. In these states, the district is the sole authority on whether CBAs are allowed; they may choose to grant individual employee organizations bargaining rights, the opportunity to enter into a meetand-confer agreement, or not to recognize the employee organization at all (Winkler et al., 2012).

The final step in the systems model is evaluation. NCLB required that all students and schools show $100 \%$ compliance by 2014 , a target missed by all schools. However, new federal legislation has provided state education agencies the opportunity to apply for waivers from the accountability structures imposed in the previous policy, which may be an indication to the ineffectiveness of the original legislation. The failure of accountability policies in education comes as no surprise to Moe (2002):

We should expect that many authorities will not be motivated to design an accountability system that actually works. Their goals are endogenous to the political process, shaped by the constituencies and groups that can most affect their reelection. The most powerful of the groups are the teachers' unions, whose own interests are very much opposed to what reformers, are trying to get the (same) authorities to do. (p. 20)

\section{Statement of the Research Problem}

Many issues need to be examined regarding the relationship of CBAs on the ability of school leaders to impact educational disparities. First, the role of labor agreements in public education must be examined. Next, the impact of CBAs on the autonomy and authority of building leadership must be explored. In a system where teacher quality, one of the most significant variables affecting student achievement, can be regulated by individual district labor agreements, additional variables such as local 
context may impact implementation of the CBA. Therefore, additional research is needed to examine the impact of CBAs, as well as the perceived impact of the CBA and the ability of school administrators and teacher-leaders to pursue educational reform in support of improved student achievement and overall school performance. Therefore, this study examines the impact of CBAs on school performance in five high performing schools in Oregon. This study does not intend to examine other characteristics of the schools, characteristics such as school climate, community characteristics, district leadership, or other phenomena that impact the ability of schools to improve (Gunal, \& Demirtasil, 2016).

\section{Significance of the Research Problem}

The NCLB reaffirmed a commitment to strong educational accountability systems, by requiring every state accepting federal funding to meet yearly, increasing performance targets until all students were achieving grade level educational standards by 2014. The outcome was the nationwide inability and failure of public schools to meet the performance targets and resulted in a letter penned in 2011 from the United States Secretary of Education, Arnie Duncan, to each Chief State School Officer in the country providing flexibility to the NCLB through a "waiver" application:

Over the past few years, States and districts have initiated groundbreaking reforms and innovations to increase the quality of instruction and improve academic achievement for all students ... Many of these innovations and reforms, however, were not anticipated when the No Child Left Behind Act of 2001 (NCLB) was enacted nearly a decade ago. While NCLB helped State and local educational agencies (SEAs and LEAs) shine a bright light on the achievement gap and increased accountability for groups of high-need students, it inadvertently encouraged some States to set low academic standards, failed to recognize or reward growth in student learning, and did little to elevate the teaching profession or recognize the most effective teachers. Instead of fostering progress and 
accelerating academic improvement, many NCLB requirements have unintentionally become barriers to State and local implementation of forwardlooking reforms designed to raise academic achievement. Consequently, many of you are petitioning us for relief from the requirements of current law ... For these reasons, I am writing to offer you the opportunity to request flexibility on behalf of your State, your LEAs, and your schools, in order to better focus on improving student learning and increasing the quality of instruction. (U.S. Department of Education, 2011, p. 1)

The state of Oregon applied for an initial waiver, initially identifying 92 "priority" and "focus" schools. The rationale for the waiver application was as stated:

Educators across the state have, for some time, seen a need to revisit the expectations and consequences found in ESEA. As expectations under this federal legislation escalated, a larger number of schools were identified as failing each year. This increasing identification of schools highlighted problems in the model used for identification of schools more than it identified actual failure on the part of schools. The authors of ESEA anticipated that the law would need to be revisited and included a clause calling for reauthorization of the law in 2005. Congress has not yet reauthorized this law, however, and USED has moved to provide some relief to states, districts, and schools through the waiver process. (ODE, 2014b, p. 8)

The significance of the educational problem and the need for the research is identified in the rationale written by the ODE (2014b): "We anticipated ESEA would fail; therefore, we built in a safety clause" (p. 2). Hess and West (2006) believed that the CBAs represent the most significant barrier to addressing the achievement gap and overall poor student performance:

The most daunting impediments to (retooling American schools for the $21^{\text {st }}$ century) are the teacher collective bargaining agreements that regulate virtually all aspects of school district operations. These agreements are a critical part of the problem, and the solution, to the educational challenges we now face. (p. 2)

The commitment to closing the achievement gap and addressing the educational inequities that currently exist and are continually increasing for our most disadvantaged students should be our highest priority for teaching and learning (ODE, 2014a). 
Statistically, Oregon has inequitable achievement gaps among different student demographics. In 2014, the ODE (2014a) conducted an audit that found

Significant achievement gaps for economically disadvantaged, Hispanic, black, and Native American 8th grade students in the 2011-12 school year. We compared test scores for these student groups to the test scores of reference groups of other students. The difference in test scores between two groups is the achievement gap. An achievement gap for a specific group indicates they are falling behind in learning. According to research, a five-point gap in test scores as measured by the Oregon Assessment of Knowledge and Skills (OAKS) test is equal to one year of learning. By that measure, Hispanic, black, and Native American 8th graders were at least one year behind in math and reading, having scored on average at least five points lower on the OAKS math and reading tests than other students. Economically disadvantaged 8th graders were one year behind in math, having scored on average at least five points lower on the OAKS math test than non-disadvantaged students. (p. 1)

In addition, Adamowski, Therriault, and Cavanna (2007) reported similar findings that showed CBAs negatively impact the ability of principals to increase student achievement: "it is not clear that school leaders have the flexibility they need to get the results demanded by state and federal accountability systems" (p. 5). However, under the same accountability measures and CBAs, some schools with the most challenging socioeconomics status and demographics improved graduation rates and closed their academic achievement gaps, demonstrating that it is possible to lead within restrictive CBAs and increase student achievement. Because evidence exists to support opposing viewpoints, additional research is needed to more deeply explore the conditions under which CBAs impact the ability of school leaders to improve student achievement.

\section{Presentation of Methods and Research Question}

The study involves collecting data around the characteristics of successful leaders in Oregon high schools from the perspectives of teacher leaders and principals. Data from the principal of each of the identified five high performing high schools were collected 
using an online questionnaire consisting of seven approved study questions. Principal interviews or data collection was conducted via an online media or qualitative tool. Additionally, this study obtained data from teacher participants using an online questionnaire consisting of the seven approved study questions which intended to include five teacher leaders at each of the identified five high performing high schools.

The research questions to be studied are as follows:

1. What do principals and teacher leaders believe about the effect of CBAs on school performance?

2. How do principals and teachers in high performing schools describe authority and autonomy of leadership in effective schools?

Our public schools have not met the accountability standards set by the NCLB.

Oregon is a low performing state, with the second strongest teacher union in the country. Principal leadership is proven to have a positive correlation to academic achievement and there are significant educational achievement disparities among schools in Oregon. The purpose of the research is to understand how both school administrators and teacherleaders believe labor agreements impact school performance, as well as how they describe what impact it may have on level of authority and autonomy of the principal to do what is necessary to ensure that your school meets the expectations for student achievement and improving graduation rates?

\section{Definition of Key Concepts}

Accountability: In the context of the current public education system, accountability refers to educational reform and policy at the state and national level that has focused on improving student academic performance and reducing persistent racial and socio-economic achievement gaps. For public school principals, failure to 
demonstrate improvements in student achievement on standardized assessments can result in consequences up to and including the loss of employment as mandated by state and federal policy (NCLB).

Achievement Gap: The achievement gap in education refers to the disparity in academic performance between sub groups of students, specifically students in underrepresented groups.

Collective Bargaining: The performance of the mutual obligation of a public employer and the representative of its employees to meet at reasonable times and confer in good faith with respect to employment relations for the purpose of negotiations concerning mandatory subjects of bargaining, to meet and confer in good faith in accordance with law with respect to any dispute concerning the interpretation or application of a CBA, and to execute written contracts incorporating agreements that have been reached on behalf of the public employer and the employees in the bargaining unit covered by such negotiations. The obligation to meet and negotiate does not compel either party to agree to a proposal or require the making of a concession. This subsection may not be construed to prohibit a public employer and a certified or recognized representative of its employees from discussing or executing written agreements regarding matters other than mandatory subjects of bargaining that are not prohibited by law as long as there is mutual agreement of the parties to discuss these matters, which are permissive subjects of bargaining (ORS 243.650, 2017).

CBA (Collective Bargaining Agreement): A CBA is a binding contract between a union and a school district or other employing entity. The contract can contain only 
certain provisions, as defined by state law (or allowed by virtue of silent state law), and is open for negotiation only at certain times, typically every three years. Disputes over the contract are settled by outside arbitration. Only unions can negotiate CBAs — although some may choose not to (Winkler et al., 2012).

Mandatory Bargaining State: In Mandatory Bargaining States, all employee organizations have bargaining rights. In these states, it is up to the employees if they want to organize; if they want to be a union or an association; and if they want to negotiate a CBA, enter into a meet-and-confer agreement, or work under no agreement at all. The law requires that if employees wish to organize and use their bargaining rights to negotiate a contract, the district must recognize them as a union-and bargain with them. The employer must accept the employees' choice. A Mandatory Bargaining State is sometimes referred to as a Collective Bargaining State (Winkler et al., 2012).

Learning Organization: For the purpose of this paper, I have chosen to use the definition of a "learning organization" from the text, The Fifth Discipline: The Art and Practice of the Learning Organization by Senge (1990). A learning organization is one where, "people continually expand their capacity to create the results they truly desire, where new and expansive patterns of thinking are nurtured, where collective aspiration is set free, and where people are continually learning how to learn together" (p. 3). I believe that this definition most accurately represents the purpose of the "organization" of public education, as well as the overall belief of the general public about what public education should be for our children. 
Labor Organization: Any organization that has as one of its purposes representing employees in their employment relations with public employers (ORS 243.650, 2017).

Meet-and-Confer Agreement: A meet-and-confer agreement is a non-binding memorandum of understanding between an employee organization and a district. Under its terms, a dispute must get worked out locally, and the district can override the agreement in the event of a conflict. The agreement can be discussed, and altered, at any time, and the contents are not limited to certain provisions. Both unions and associations can enter into meet-and-confer agreements (Winkler et al., 2012).

NCLB (No Child Left Behind Act of 2001): The NCLB, a United States Act of Congress that is a reauthorization of the Elementary and Secondary Education Act. NCLB supports standards-based education reform based on the premise that setting high standards and establishing measurable goals can improve individual outcomes in education. NCLB requires states to develop assessments in basic skills. States must give these assessments to all students at select grade levels in order to receive federal school funding.

Permitted Bargaining State: In permitted bargaining states, districts may decide to grant employee organizations bargaining rights, to enter into a meet-and-confer agreement, or not recognize the employee organization at all. In these states it is still up to employees whether to organize. If they then wish to negotiate a CBA, they must first request recognition as a union— - but districts are not obligated to recognize them as such. Even if the employees seek a non-binding meet-and-confer agreement, the district is not required to grant that request. The employees must accept the district's choice. A 
Permitted Bargaining State is sometimes referred to as a Non-Collective Bargaining State (Winkler et al., 2012).

Prohibited Bargaining State: In prohibited bargaining states, districts may not grant bargaining rights to employee organizations. Employees may still organize, but those organizations are associations, not unions. In such states, a district may still enter into non-binding meet-and-confer agreements with the association if it wishes to; the employees must accept the employer's choice (Winkler et al., 2012).

Role: The behavior of an individual in the organization and social system in which they participate. 


\section{Chapter 2: Literature Review}

\section{Introduction}

The following literature review explores the relationship among three areas of educational literature: (a) role theory (educational administration), (b) organizational theory, and (c) principal leadership. I also discuss the impact of collective bargaining and labor agreements on school leadership and achievement in the public schools of the state of Oregon. The purpose of this literature review is not to create or define a new problem or area for educational research, but rather to extend and build upon previous research, more specifically to the state of Oregon. The selected literature is intended to frame the problem statement in an existing design with the intention of addressing more local and regional concerns, issues and problems that may or may not have been accounted for or adequately addressed in the previous study. More important, the literature supporting the research makes the conclusions more useful to practitioners, especially in Oregon, and in turn add to the larger body of educational research in the field.

The most accurate way to connect collective bargaining and labor agreements to educational policy and politics and the impact it has on student achievement is to view it historically. According to Lieberman (1999)

The most significant feature of the growth of collective bargaining is that it has occurred directly alongside of reported declines in student achievement and huge increases in expenditures in public education that have grown faster than the rate of inflation, reflecting a significant decline in educational productivity. (p. 2)

More significantly, collective bargaining in public education circumvents the political

definition of a democratic society by negotiating with public officials (i.e., school boards 
and school districts) singularly and exclusionary of all other interest groups (Lieberman, 1999). There is no greater political power than to be immune from competition in a democratic and capitalistic society. Although the political process seems to support the position interest of the teacher unions, their inception was a result of a societal need to provide protection, support and guidance for individuals in the workplace. There is a continued need for this type of presence and it can coexist in a frame where the political and organizational outcomes do not come into conflict. A focused system of accountability was "designed to spur academic improvement (student achievement), but also to spotlight the achievement gap and insist on efforts to close it" (Peterson \& West, 2003). In response, our public schools have changed their focus; placing priority on instructional leadership, professional collaboration, and high-quality standards-based professional development.

The responsibility to meet these constant challenges universally resides within our public-school systems, but instructionally rests in the hands of our teachers, and on the shoulders of our principals for leadership and management. In The Practice of Management, Drucker (1954) found that the first principle of effective management is defined as having an alignment between authority and responsibility. Using the first principle of effective management as our frame, it would then be logical to assume that if it is the responsibility of our individual public schools to increase student academic achievement, that public school leaders would also have the equivalent aligned authority to identify and implement improvement strategies where necessary. The current reality in our public education system is that nearly everything public schools and school principals 
do is dictated by CBAs. In fact, labor agreements often stipulate the terms of almost every other educational variable available to educational leaders in the operation of a public school: length of the day and year, student schedules, salaries, assignments and even the conditions in which employees may be disciplined and removed, is regulated by labor agreements (Hess \& West, 2006).

Labor agreements by their very nature restrict the authority and autonomy of public school districts and site-based educational administrators (Eberts, 2007).

According to Moe (2009) of Stanford University, teacher unions are

Centrally concerned with their membership base and financial resources, and thus with protecting teacher jobs, attracting members and for representing the occupational interests of their members: in better pay and benefits, more autonomy, less threatening methods of evaluation, smaller classes, prohibitions on non-classroom duties, fewer course preparations, and other rights and protections. The unions secure these objectives through formal contract rules that require or prohibit certain behaviors on the part of management, and most generally place restrictions on top-down control. (p. 158)

The conundrum facing public education today exists in the conflict of purpose between the public-school system and labor agreements that control the structure and flexibility of organization. The problem in practice is most accurately defined by Barkley (2005), former executive director of the Ohio Education Association, "The fundamental and legitimate purposes of unions [are] to protect the employment interests of their members. It is the primary function of management to represent the basic interests of the enterprise: teaching and learning” (p. 38). In summary, Hess and Loup (2008) identified the inherent conflict of purpose between the outcomes of the educational system and labor agreements. If the organizational purpose is to promote student learning and academic achievement as directed by federal and state legislation, "Do the labor 
agreements negotiated by school districts and teachers' unions contain provisions that make it harder for public schools to be smart, flexible, high-performing organizations?" (Hess \& Loup, 2008, p. 12). More specifically, do labor agreements have an impact on the ability of educational leaders to increase student achievement and overall school performance?

An analysis of the educational problem in practice can be made by viewing it from a socio-political framework using the classic agency model. The agency model is built on the principal-agent relationship, in which a principal hires or delegates an agent to perform work or act on the principal's behalf. According to Moe (2002), the principalagent relationship is beneficial and necessary in our system of education

Principals of all kinds lack the time or capacity to do everything for themselves; often their agents have expertise and experience that enable them to do a far better job of pursuing the principals' goals than the principals themselves could do. (p. 3)

Although largely beneficial, there are drawbacks to these relationships that inherently place the principals at a disadvantage when working to reduce educational disparities. For example, the agent may not act efficiently in pursuit of the goals of the principal because they may have their own competing interests, distinct from those to whom they are accountable. In order to minimize noncompliance and asymmetry, principals have sought methods to hold agents accountable. These mechanisms are controlled by outside interest groups, such as teachers' unions and their CBAs, resulting in a process of negotiation and bargaining with the purpose of accumulating decision-making (policy) power. In summary, the principal-agent relationship is political, often imperfect, representing a 
constant struggle for control and power for interests that may or may not be congruent with the original goal.

Applying this theory to the system of public education, there are a number of principal-agent relationships working simultaneously inside of the organization, with the associated individuals or interest groups sometimes acting as principals and sometimes acting as agents. In the educational hierarchy, state and federal authorities are the principals, whose goal is to provide a free and appropriate public education and to promote student learning and achievement in our public schools. Administrators and teachers are the agents, acting on behalf of the principals, educating students under the accountability systems created by democratic public agencies. At the local level, administrators and teacher unions are the principals, with classroom teachers acting as the agents for both interest groups. This sets up a basic problem of control; teachers directly serve as agents in two principal-agent relationships, and these two relationships do not have the same desired outcome.

The rules imposed by labor agreements created through the collective bargaining process mandated in the vast majority of our public-school districts across the country impact school leadership decisions. Given these conditions, how do individual school districts and administrators transform our schools into organizations focused on student learning in the $21^{\text {st }}$ century? More specifically, what is the impact of flexibility of the district labor agreement and the process of collective bargaining on student achievement? Variables such as teacher quality and instructional time are known to directly impact student achievement. Some of these options may be severely limited based on local CBA 
requirements. The majority of these variables, and the ability to manipulate them, are often managed by labor agreements (which include both CBAs and board policies in noncollective bargaining states) that limit the authority and autonomy of site-based leaders to invoke the change required and that are expected by local education agencies and ultimately by the state and federal Departments of Education. If labor agreements inhibit the ability of educational leaders to impact variables, such as teacher quality, and teacher quality affects student outcomes, could CBAs be considered a universal obstacle in pursuit of federally mandated minimum levels of student achievement?

\section{Theoretical Framework}

In this section I examine the impact of labor agreements on school leadership and student performance through the lens of the four major frames of an organization (a) the structural approach, (b) the human resource lens, (c) the political frame, and (d) the symbolic frame, as defined by Bolman and Deal (2008). For the purpose of this paper, I have chosen to use the definition of a "learning organization" from the text, The Fifth Discipline: The Art and Practice of the Learning Organization by Senge (1990). Senge defined a learning organization as one where "people continually expand their capacity to create the results they truly desire, where new and expansive patterns of thinking are nurtured, where collective aspiration is set free, and where people are continually learning how to learn together" (p. 3). I believe that this definition most accurately represents the purpose of the "organization" of public education, as well as the overall belief of the general public about what public education should be for our children. 
The structural frame focuses on the formal arrangement of an organization (i.e., social architecture) and the relationship of individuals inside of definitive roles to maximize efficiency (Taylor, 1911). The structural frame exists under the following six assumptions:

1. Organizations exist to achieve established goals and objectives.

2. Organizations increase efficiency and enhance performance through specialization and appropriate division of labor.

3. Suitable forms of coordination and control ensure that diverse efforts of individuals and units mesh.

4. Organizations work best when rationality prevails over personal agendas and extraneous pressures.

5. Structures must be designed to fit an organization's current circumstances (including its own goals, technology, workforce and environment).

6. Problems arise and performance suffers from structural deficiencies, which can be remedied through analysis and restructuring (Bolman \& Deal, 2008).

There is no structure that universally defines an organization; every group or organization develops its own unique structure, defined by the variables inherent to the organization. Public education, however, has been traditionally, and almost uniformly, defined in a structural frame mired in conflict between a "structural looseness," characterized by an inordinate lack of coordination, control, consensus, and accountability; and a centralized undemocratic bureaucracy that is highly rigid, stultifying and unresponsive (Ingersoll, 1994). The inability of our public-school systems to restructure in response to increased accountability structures is partially a result of restrictive labor agreements. According to McEachin and Strunk (2011), not all schools and districts (i.e., complex organizations) that "face accountability pressures have the 
ability to change their structures and practices; they do not have sufficient autonomy and flexibility to make changes they believe will have the most impact on student achievement" (p. 872). The ability to remove ineffective educators, change the schedule of the workday, and require participation in professional development, are all examples of limitations imposed by the structure of the labor agreement.

Organizations themselves have become increasingly more complex as they try to adapt and keep pace in a more global society. In contrast, our public-school systems have resisted significant organizational change. Current educational policy focuses on accountability and demands an increase in student performance and achievement. In a stagnant and non-responsive structural frame, school, and specifically, principal leadership has emerged to the forefront of public and political conversations. According to Lunenburg and Ornstein (2008), "a number of observers have suggested that the increasing complexity of modern organizations puts a greater premium on leaders' possession of a repertoire of styles and strategies" (p. 26). These observations echo the thoughts of Bolman and Deal (2008) who argued that modern leadership is defined by the ability to reframe or view a problem or issue from a multitude of perspectives. In the organization of public education, such conclusions serve to emphasize the critical importance of effective educational leadership and the capacity of building level administrators to implement reform inside an increasingly modern and complex organizational structure that is stringently defined by traditional industrial age policy, represented in the form of collective bargaining, and that is intentionally non-flexible in an effort to maintain the status quo. The best example of a policy that has intentionally 
forced the status quo is the process and method of teacher evaluation and supervision, more specifically, the refusal to support a link between teacher evaluation and student achievement.

The human resource frame is defined by the relationship between people and the organization. The human resource frame is built on the following core assumptions (Bolman \& Deal, 2008):

1. Organizations exist to serve human needs rather than the converse.

2. People and organizations need each other. Organizations need ideas, energy, and talent; people need careers, salaries, and opportunities.

3. When a fit between the individual and the system is poor, one or both suffer. Individuals are exploited or exploit the organization - or both become victims.

4. A good fit, benefits both. Individuals find meaningful and satisfying work, and organizations get the talent and energy they need to succeed.

The human resource frame describes the individual and organizational relationship based on the concept of need. The need of the individual is best described by Maslow (1954) in his theory termed the hierarchy of needs. According to Maslow, we satisfy our basic physiological needs first: food, water and shelter. When those needs are filled or satisfied, we are motivated progressively for our needs for safety, social or belonging, esteem and finally self-actualization (Maslow, 1954). When the needs of the individual inside of an organization are not met, one or both may become ineffective. A successful organization is one that satisfactorily meets the needs of the individual, resulting in an efficient and productive organization.

Applying the human resource frame to public education characterizes a system that has gradually moved from cohesive and successful, to one in conflict; where the 
needs of the individuals are incongruent and detrimental to the needs of the larger organization. The greater goal of our current system of public education as defined by the reauthorization of the Elementary and Secondary Education Act (ESEA), termed No Child Left Behind, is "to ensure that all children have a fair, equal, and significant opportunity to obtain a high-quality education and reach, at a minimum, proficiency on challenging State academic achievement standards and state academic assessments" (NCLB, 2002, Sec. 1001). On the contrary, according to Moe (2006), the individuals (i.e., teachers) in the organization (i.e., public school system), "expect their unions to press for more benefits, to get more time off, to protect them from administrators, to impose restrictive work rules, and in a host of other ways to promote their job-related interests and none of this is premised on what is best for children" (p. 232). Systemically, the result of this conflict is articulated by Bolman and Deal (2008), "when a fit between the individual and the system is poor, one or both suffer. Individuals are exploited or exploit the organization —or both become victims" (p. 122), which some would describe as the current status of our public-school system. Historically, collective bargaining helped preserve the needs of individuals who were exploited, most notably during the industrial revolution, and preserve the balance or "fit." In the modern educational organization, collective bargaining no longer regulates "needs"; rather it serves to unbalance the equation pitting the needs of the organization versus the employees, ultimately resulting in what can be characterized as the exploitation of our students. 
Bolman and Deal (2008) stated that the political frame characterizes organizations as "rolling arenas hosting ongoing contests of individual and group interests" (p. 194). The five basic assumptions of the political frame are:

1. Organizations are coalitions of assorted individuals and interest groups.

2. Coalition members have enduring differences in values, beliefs, information, interests, and perceptions of reality.

3. Most important decisions involve allocating scare resources.

4. Scarce resources and enduring differences put conflict at the center of day-today dynamics and make power the important asset.

5. Goals and decisions emerge from bargaining and negotiation among competing stakeholders jockeying for their own interests.

The political frame challenges the traditional view of the organization, described as created by "legitimate authorities" to ensure the pursuit of the correct objectives, and instead presents one that is marred by conflict and competition. Competition is driven by the scarcity of resources, pitting individuals and groups inside of the organization with differing desires into a struggle to meet their individual or collective needs. The concept of "power" is central to the political frame, representing decision-making authority in the cyclical and repetitive pursuit to acquire the limited resources that are available. The acquisition of power results from a perpetual process of negotiation and bargaining between the significant interest groups and the decision-makers. As a result, the organization will support the interests of the individual or group that has secured the most power, and ultimately may or may not serve the original values of the organization.

For the sole purpose of describing how labor agreements impact school performance in the political frame, I am using student achievement as the representative 
outcome of the public education system (i.e., organization). The major coalitions inside of the public education system are the students, parents, teachers, administrators, and the school board. The purpose, as defined, ultimately serves the students, who conversely hold the least amount of power. Structurally, the schools board holds the most decisionmaking power, which is often conferred to the administration who in turn, manages the teacher work force. By law, the vast majority of states allow teachers to collectively bargain, which places teachers as the largest interest group in the system. The majority of conflict in the organization comes from the power struggle between the teacher union and the school district (i.e., school board) as they compete for the limited resources that are available. An excellent example of this would be the conundrum represented in our current economic climate, pitting union interests against educational interests.

Advocating for and accepting raises at the cost of firing the least senior teachers results in raised class sizes, which is a variable that negatively impacts our students, their achievement, and overall school performance. The competition for resources is a constant struggle dependent upon the specific needs served by each interest group, sometime collaborative and sometime conflicted, and as is symptomatic of the political frame, is in disregard to the organizational objective.

The symbolic frame focuses on the how individuals make meaning of the ambiguity in the environment in which they exist. Meaning is constructed through belief systems, faith and culture. Symbols are the "building blocks" of our meaning and represent our own representations of reality (Bolman \& Deal, 2008). The five basic assumptions of the symbolic frame are: 
1. What is most important is not what happens but what it means.

2. Activity and meaning are loosely coupled; events and actions have multiple interpretations as people experience life differently.

3. Facing uncertainty and ambiguity, people create symbols to resolve confusion, find direction, and anchor hope and faith.

4. Events and processes are often more important for what is expressed than for what is produced. Their emblematic form weaves a tapestry of secular myths, heroes and heroines, rituals, ceremonies, and stories to help people find purpose and passion (Bolman \& Deal, 2008).

The symbolic frame emphasizes culture and perception. It is the "feeling" of an organization, a unique identity, built over time on tradition and value. The symbolic frame is defined by the emotions and rituals, cultivated over time, that drive the norms and decisions of the organization. It does not represent the structure, rigidity and rationality traditionally associated with organizational frameworks. The purpose of an organization, as well as the intended outcome, can be significantly different when viewed through the symbolic frame. Appearance or feeling may outweigh data, and traditions, regardless of efficiency, cost or productivity, may be valued more than modernization or any change in practice that deviates from the "way we always do it."

The public-school system, specifically district labor agreements, provides numerous examples that represent the symbolic frame throughout an organization. The evaluation process that was used to determine teacher quality is symbolic in that it relies more on subjective than objective data, is unproductive in providing substantive instructional change, and disagreements between the association and administration can divert already limited resources away from students and take years to resolve. The 
process of collective bargaining is another example of the symbolic frame in action. Lee, Bolman, and Deal (2008) stated:

On the surface, the negotiation process appears as a strife-ridden political brawl where persistence and power determine the distribution of scarce resources. On a deeper plane, negotiation is a carefully crafted ritual that delivers the performance various audiences demand .... The bargaining drama is designed to convince each side that the outcomes were the result of a heroic battle-often underscored by desperate, all-night, after the deadline rituals of combat that produce a deal just when hope seems lost. (p. 305)

Organizationally, the public education system is defined by theory in all four areas that is representative of an era that has long passed. In an environment that has become more modernized and global, education has failed to keep pace organizationally. Current educational theory holds that accountability policies will help to implement reform that will increase overall student achievement (Figlio \& Ladd, 2008). In order to meet those demands, educators must have the ability to provide effective and efficient leadership, but they must also have the ability to change their organizational structures and practices. A significant impediment to the autonomy and flexibility needed for educational reform and improved student performance is the restrictiveness of CBAs that exist in the majority of our public-school districts and dictate the organizational characteristics of the entire system. McEachin and Strunk (2011) concluded that organizational flexibility is imperative for educational reform and it is the responsibility of our state legislation to take action. They specifically suggested, "if research continues to indicate that restrictive contracts or restrictive elements of contracts inhibit district and school administrators from enacting important reforms or educational strategies, there may be a role for state regulation of certain elements of collective bargaining" (McEachin \& Strunk, 2011, p. 900). 
Looking at organizational leadership through the question of what impact do district labor agreements have on school leadership measured by school performance identifies an organization defined by outdated tradition in the structural, symbolic and human resources frames, and driven by a political process that inhibits change toward a more modern organization. Structurally, labor agreements intentionally work toward the status quo in order to protect the interests of its members, resulting in our system of public education that as an organization that has changed very little over time. However, the needs and outcomes of the organization have changed in response to systemic accountability, leaving public education mired in a structural system that is inadequate to meet more modern and global educational outcomes.

The impact of labor agreements through the symbolic and human resource frame is defined by the competition for limited resources. Collective bargaining has created a separation between the needs of the organization and the needs of the individual.

Whereas the goal of the educational organization is universally determined by state and federal legislation around performance, labor agreements serve the purpose of membership interest and stability, resulting in a perpetual conflict between individual and organizational needs. Examples of this conflict are represented symbolically through the repetitive process of negotiations, seniority in compensation and evaluation practices, and the resistance to measure teacher quality using student performance. All of these symbolic practices consume and divert already limited resources away from students, and potentially limit the effectiveness of school leadership and diminish school performance. Definitively, the political frame is represented through the acquisition of power inside of 
the organization. Politically, collective bargaining is almost universally supported through legislation in the United States and is explicitly referenced in NCLB. Financially teacher unions support many of our legislators and are considered one of the most powerful political action committees in the United States. Through the political frame, the individuals inside of the organization possess more power than the organization itself, which helps to logically conclude that labor agreements impact effective school leadership and overall school performance.

\section{Review of the Research Literature}

Role theory. Role theory is an offspring of the literature of social psychology, and there exists a significant debate over how to accurately define the entire concept of role. This study is centered on the definition of role that believes the behavior of an individual is not random, but a product of the individual's own learned expectations and the influences of the organization and social system in which they participate. This portion of the literature review discusses the historical development of a limited area of role theory, the importance of individuals and their experiences inside of a social system, and how it translates into leadership inside an educational organization.

A review of the history of role theory and the definition of role indicates a number of definitive characteristics. First, role theory is a new field of study. Although it is relatively young, it "shares with more mature fields of behavioral science the fact that it possesses an identifiable domain of study, perspective, and language; and that it has a body of knowledge, some rudiments of theory, and characteristic methods of inquiry" (Biddle \& Thomas, 1966, p. 17). Second, it has undergone a continual evolution in 
definition and range of study. It started as a small slice of unexplored territory in social psychology, limited to the status of a single individual, and now is a method of considerable importance in explaining human behavior. Currently, it is regarded as one of the most popular ideas in the social and behavioral sciences. Because of the broad applicability of its principles and concepts, role has become a "fundamental tool of analysis that helps explain apparent regularities of behavior and the structure of social systems" (Flynn \& Lemay, 1999, p. 225). According to Biddle and Thomas, (1966) perhaps the most significant characteristic of role study is the value it holds as a concept of organization:

Role theory concerns one of the most important features of social life, characteristic behavior patterns or roles. It explains roles by presuming that persons are members of social position and hold expectations for their own behaviors and those of other persons. (p. 67)

A number of studies specific to role theory in the area of administration have been conducted (Getzels, 1952; Getzels \& Guba, 1957; Getzels, Lipham, \& Campbell, 1968). The studies were not specifically dedicated to the concept of role, but how role was defined in the larger context of an organizational setting. The researchers were seeking to develop a "framework for the systematic study of administration, to report a number of research studies undertaken in the terms of the framework, and to examine the implications of the framework for practice" (Getzels et al., 1968, p. 23). The researchers believed that previous research had failed to adequately identify the concept of role and the individual in the context of an organization. In order to more adequately understand this concept, they developed a theory of administration. 
The theory was based on the premise that administration was a social process defined by the context of a social system. In their work in 1968, Getzels et al. more thoroughly defined the social process through three lenses: structural, functional, and operational:

Structurally, administration was seen as "the hierarchy of superordinatesubordinate relationships within a social system" The structure contains any number of positions defined as higher, lower, or parallel used for asserting influence over each other within the system. Functionally, the identified hierarchy of relationships "is the locus for allocating and integrating roles and facilities in order to achieve the goals of the system" Status, procedure, regulation, and evaluation are all pieces of this lens. Operationally, "the administrative process takes effect in situations involving person-to person interactions. (pp. 3-4)

Thus, the network of relationships and interactions of the members, driven by their individual role, defines the social process.

The context in which the social process takes placed is defined as the social system; "the most general context of interpersonal or social behavior" (Getzels, 1952, p. 240). According to Getzels (1952), the social system is comprised of:

Two classes of phenomena which are at once conceptually independent and phenomenally interactive: (1) the institutions, with certain roles and expectations, that will fulfill the goals of the system; and (2) the individuals, with certain personalities and dispositions, inhabiting the system, whose observed interactions comprise what we call social behavior. We shall assert that this behavior may be understood as a function of these major elements: institution, role, and expectation, which together constitute the nomothetic or normative dimension of activity in a social system; and individual, personality, and need-disposition, which together constitute the idiographic or personal dimension of activity in a social system. (p. 56)

A visual representation of the model is provided in Figure 1. Figure 1 provides a clear indication of the function of role inside of the Getzels (1957) model of social behavior. The role of the individual inside of a social system is defined by the interaction of the two components of the social system: the institution and the individual. 
Structurally, an institution is comprised of parts, governed by rules, specified by tasks, in an effort to meet the institutional goals. Each role is "assigned certain responsibilities and concomitant resources, including authority, for implementing the tasks" (Getzels et al., 1968, p. 58). Each role is in turn defined by a set of expectations, or the "prescriptions that delineate what a person should and should not do under various circumstances as the incumbent of a particular role in the social system" (p. 64). Conclusively, it is the combination of the normative, or nomothetic, components (institution and role expectation), and the interaction of the personal, or idiographic, dimension (individual, personality and need disposition), that define the concept of role in the social system.

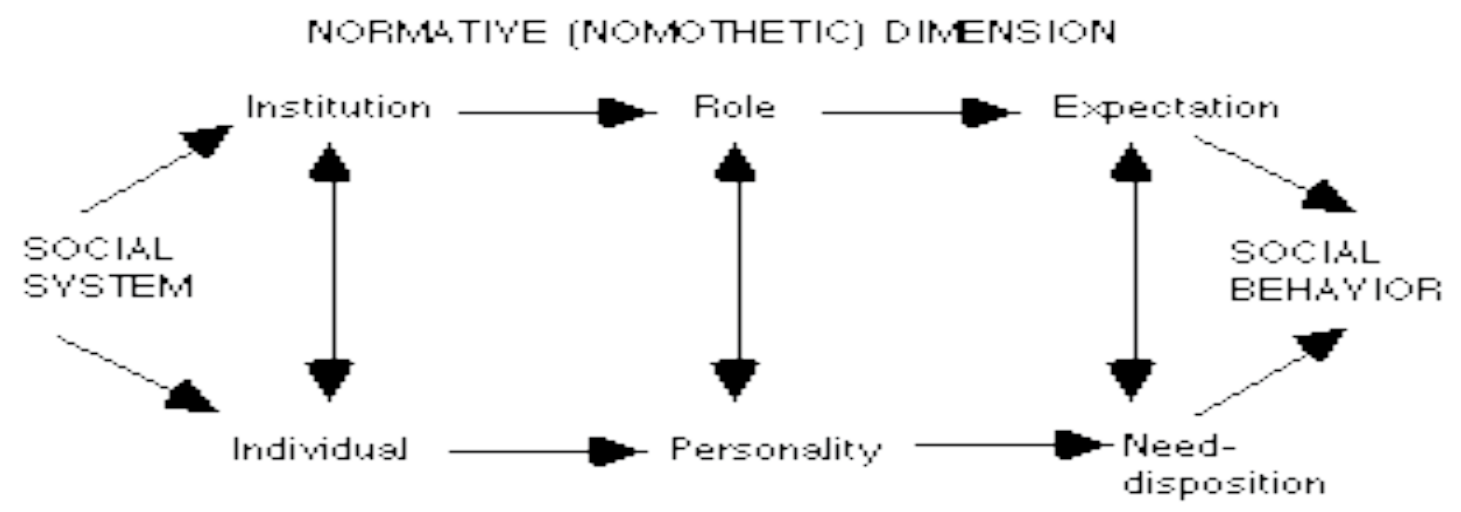

PEFSONAL [IDIOGFA, FHIO] DIMENSION

figure 1

Figure 1. Getzels-Guba model of social behavior. Source: Getzels and Guba (1957, p. 429).

The conceptual view of role inside of the social system is defined by six characteristics. Each characteristic provides a more specific identity to the function and 
importance that roles play in the defined institution and the overall social system. The six characteristics of roles include the following:

(1) Roles represent positions, offices, or statuses within an institution. This implies that any individual inside the framework of a particular social system finds their behavior partially dictated by the role structure of that particular system.

(2) Roles are defined in terms of role expectations. Role expectations are the normative rights and duties attached to a particular role, which define the actions of that individual while occupying that particular role.

(3) Role expectations are institutional givens. Role expectations are attached to a role and are "ordinarily" formulated prior to the individual occupying the role. They are the "blueprints" of what should be done in that role for that institution.

(4) Roles are more or less flexible. The "exact nature of a role is a function" of the particular individual, and a "certain range of variability" is expected.

(5) Roles are complementary. Roles are interdependent with other related roles within the institution.

(6) Roles vary in scope. This describes the "number and quality of the rights and obligations legitimately included as matters for allocation and interaction" among the individuals. (Getzels et al., 1968, pp. 59-64)

A given role inside of the Getzels-Guba (1957) model is a result of the interaction between the idiographic and nomothetic dimensions. This is most easily recognized in the definition of a social system provided by Getzels, "two classes of phenomena (institution and individual) ... phenomenally interactive" (Getzels \& Guba, 1957, p. 424). This is also represented visually in Figure 1 as the arrows moving between the two separate dimensions. The observed behavior of the Getzels-Guba model is therefore described as, "a social act resulting from the individual's attempts to cope with an environment composed of patterns of expectations for his behavior in ways consistent with his own pattern of needs and dispositions." (Getzels \& Guba, 1957, p. 429). The major question 
then becomes how much organizational behavior is dictated by the role and role expectations prescribed by the institution and how much is dictated by the personality and needs-disposition of the individual?

In the Getzels-Guba (1957) model, role problems occur when the outcomes (social behaviors) do not represent the fulfillment of both dimensions of the social systems model. In the administrative setting this is represented by the desire to meet the demands of the organization or institution (school or school district), and the demands of the individual in a way that is "organizationally productive and individually fulfilling" (p. 430). Theoretically, the ideal role is achieved when the individual fulfills both the nomothetic and idiographic dimensions, this condition would only occur if both the institutional expectations and the personal needs were absolutely congruent. But absolute congruence of expectations and needs are seldom, if ever, found in practice, and as a consequence there is inevitably a greater or lesser amount of strain or conflict for the individual and the institution. In the present context, this strain or conflict may be defined simply as the "mutual interference of adjective and integrative reactions" (p. 431).

The model identifies three primary areas of conflict or "problems" specific to the administrative setting. Role-personality conflicts "occur as a function of the discrepancies between the pattern of expectations attaching to a given role and the pattern of needdispositions characteristic of the incumbent of the role" (Getzels \& Guba, 1957, p. 431). In this type of conflict, the individual is forced to choose between fulfilling institutional expectations or individual needs. Role-conflicts “occur whenever a role incumbent is required to conform simultaneously to a number of expectations which are mutually 
exclusive, contradictory, or inconsistent, so that the adjustment to one set of requirements makes adjustment to the other impossible or at least difficult” (p. 432). This type of conflict is therefore defined by the situation of the role, and independent from the personality and needs of the individual. Personality conflicts "occur as a function of opposing needs and dispositions within the personality of the role incumbent” (p. 432). This type of conflict is therefore defined by the individual, and independent from the specific role or role expectations of the institution.

The Getzels-Guba (1954) formulation served to clarify the major types of conflict that may occur in an administrative setting, which I have collectively deemed role problems. The most distinctive and widely recognized term from this literature, although it is not universally defined, is role conflict. In its broadest definition, role conflict is "any situation in which the incumbent of a position perceives that he is confronted with incompatible expectations" (Gross, Mason, \& McEachern, 1958). A more specific definition is the "exposure of the individual to conflicting sets of legitimized role expectations such that complete fulfillment of both is realistically impossible" (Parsons, 1951, p. 280). Both of these definitions indicate that individual behavior is dictated by organizational expectations. Specific examples of role conflict in the educational environment and the effects it can have on organizational effectiveness have been measured through a number of empirical studies. Two such studies are of specific importance to the purposes of this paper.

The first study, conducted in 1954 by Getzels and Guba at the University of Chicago, was explicitly designed to provide empirical data for a "number of hypotheses 
implicit in the indicated role theory" (p. 164). From these studies, they concluded that were two sufficient conditions necessary for role effectiveness in a situation of role conflict. First, that it is necessary to determine the relative congruence of role expectations and need dispositions, which they previously defined in the theory of administration. Second, and more important, that the choice of a major role and the legitimacy of role expectations within the situation are the major factors that determine individual behavior when faced with role conflict (p. 175).

In 1957, Gross et al. (1958) conducted a study of school superintendents in the state of Massachusetts and the exposure of their position (role) to role conflict. In their study, they were able to predict, with a $91 \%$ rate of success, the behavior responses of the superintendents to role conflict via the application of their theory. This finding is important because it supports the idea presented by Getzels and Guba (1954) that role conflict is independent of the individual and dependent upon the situational context of the institution.

Another term used widely in the literature is role strain. In 1960, Goode defined role strain as "a felt difficulty in meeting the norms of the roles that one accepts" (p. 487). This definition indicates that role strain describes areas of conflict between the individual and the institution, much like formal term role-personality defined by Getzels and Guba (1954). One specific type of role strain is defined as role ambiguity. This type of role conflict is identified by an individual's inadequate preparation or lack of role knowledge and is sometimes referred to as role inadequacy. Role ambiguity is the result of one of two problems: ineffective or improper socialization, or a lack of clear 
institutional and individual expectations. Improper socialization is defined as a lack of experience or skill in the personality of the individual needed to perform the role (Bertrand, 1972, p. 174). This type of role ambiguity is often the result of inadequate training and assimilation into the perspective role, or the lack of formal education brought about by misaligned or ineffective college preparatory and institutional certification and endorsement programs (Ollhoff \& Ollhoff, 1996, p. 6). A lack of clear institutional and individual expectations can result from structural inconsistencies that effect the perception of the role to the individual and other actors in the institution. These inconsistencies are a form of role ambiguity, and often initiate another type of role conflict called role frustration.

Role frustration is when an "individual is unable to fulfill a role in the way that he or she would like or others expect him or her to do. It occurs when situational factors are such as to make the playing of a role according to ideal expectations impossible" (Bertrand, 1972, p. 175). Examples of "situational factors" may include limited resources, inappropriate time constraints, or even inadequate structural components like space or equipment. These factors often are increased with the complexity of the occupation. In a study conducted by Bates in 1962, role frustration was identified as more likely to occur in certain occupations. Educational professions were one of the occupations identified by Bates as being more likely to identify feelings of role frustration.

Role problems are the result of inefficiencies and incongruencies in the structural frame of a social system. The administrative theory defined by Getzels and Guba (1954) defined these incongruencies as a lack of fulfillment of both of the nomothetic and 
idiographic dimensions of their social systems model. Role problems can be most accurately described through empirical studies that provide glimpses of their theoretical descriptions in a "real-world" social system. The results of these studies are useful in the manner in which they are applied to the existing structure in an attempt to make the system more efficient for the institution and the individual.

The purpose of this portion of the literature review is to examine role theory and the impact it has had in the area of educational administration. The Getzels and Guba (1954) model of administration has been frequently used as the theoretical framework in a number of studies of educational administration. This study examines the educational administrator in an organizational environment, and the role the administrator occupies within that institution. An examination of the role of the principal in the organizational environment may result in identifying any conflicts that exist within this social system. This type of information is useful in providing an understanding of the role of the principal, and principal autonomy within the public-school system in Oregon, which is a collective bargaining state.

\section{Principal Leadership}

Principals are the key factor in building and sustaining a school culture in which both teachers and students can succeed. Over the last decade, research has established the empirical link between school leadership and improved student achievement, and policy and practice have focused much attention on the role of the principal and what makes a principal effective (Chiang, Lipscomb, \& Gill, 2016). In addition to their role as instructional leaders helping to develop good teaching, effective principals are also 
collaborators, cultivating the leadership of teachers and others in their schools. The most difficult question facing building leaders is what is the most effective, but more important, how can all of the roles be balanced and managed in the current political, educational and economic reality of a public school.

Over the past two decades, and especially since the passage of the NCLB in 2002, federal and state policies have placed individual schools — and their leaders — at the center of education reform efforts. Lunenburg and Ornstein (2008) identified the demanding testing regiments and accountability requirements for schools designed to improve education, as a central theme of current educational policy:

States must identify adequate yearly progress (AYP) objectives and disaggregate test results for all students and subgroups of students based on socioeconomic status, race/ethnicity, English language proficiency, and disability. Moreover, the law mandates that 100 percent of students must score at the proficient level on state test by 2014. Furthermore, the No Child Left Behind Act requires states to participate every other year in the National Assessment of Educational Progress (NAEP) in reading and mathematics. (p. 12)

The message is clear: public schools will have strong academic standards, measured by standardized assessments, and the teachers and administrators, disincentivized by performance failure, are accountable for the results. According to Lunenburg and Ornstein (2008), “this assertion has strong economic, political and social appeal; its logic is clear. What teachers teach and students learn is a matter of public inspection and subject to direct measurement" (p. 12). On the contrary, the motivation for the politician is simple; supporting accountability measures represents a strong position in support of student achievement that, if effective, can generate significant public support. An ineffective accountability policy can always be blamed on the inability of our 
educators, leaving the policy-makers free from liability and any negative public perception.

School accountability has continued to exist at the forefront at the forefront of the legislative agenda. The Every Student Succeeds Act (ESSA) was signed by former President Obama in December of 2015, reauthorizing the 50-year-old Elementary and Secondary Education Act (ESEA) of 1965 demonstrating a further commitment to providing equitable access and improved educational outcomes for all students across the country. Although ESSA provided some modifications, it still mandates a statewide system of accountability that requires all states to report yearly progress using at least one indicator of school quality or student success and a separate indicator of student growth.

The mantra of "accountability for results" puts a premium on effective school leaders who are expected to marshal their schools' instructional, human, and financial resources toward the goal of raising student achievement. And understandably so; a quarter century of research confirms that the two most important school-linked variables in boosting achievement are teacher quality and principal leadership (Glasman, 1984; O’Donnell \& White, 2005; Waters \& Cameron, 2007).

The positive correlation between an effective principal and student achievement has been repeatedly identified in the educational literature. As Markow, Macia, and Lee (2013) noted, "Over the last decade, research has established the empirical link between school leadership and improved student achievement, and policy and practice have focused much attention on the role of the principal and what makes a principal effective" (p. 31). Principals are the second most important factor behind teacher effectiveness in 
building and sustaining a school culture in which both teachers and students can succeed (Seashore Louis, Leithwood, Wahlstrom, \& Anderson, 2010). In fact, Seashore Louis et al. did not find evidence of any school improving outcomes without a talented leader:

Efforts to determine how principal leadership affects student achievement have a rich, albeit recent, history. Our analysis provides the most extensive empirical test to date of whether instructional leadership, shared leadership, and trust in the principal, when considered together, have the potential to increase student learning. The answer is an unqualified yes. (p. 53)

In addition to their role as instructional leaders helping to develop good teaching, effective principals are also collaborators, cultivating the leadership of teachers and others in their schools. Several renowned scholars in the area of leadership and school improvement have noted the importance of teacher, student and principal relationships (Hattie, Birch, \& Masters, 2016; Waters, Marzano, \& McNulty, 2004). Fullan (2002) made a very strong conclusion, "The single factor common to successful change is that relationships improve. If relationships improve, schools get better. If relationships remain the same or get worse, ground is lost" (p. 18). Fullan has the belief that emotional intelligence is a characteristic necessary for leaders to be highly successful in a complex organization. Emotionally intelligent leaders are able to build relationships because they have a strong sense of awareness, the ability to self-regulate their emotions, and are sensitive and inspiring to others. Relationships are the "social capital" which can rebuild the culture and improve the performance of an entire school. The relationships are what make the whole greater than the sum of the parts.

The most powerful example of how relationships can impact schools, teachers, administrators and, most important, students, is through Collective Teacher Efficacy. Collective Teacher Efficacy refers to the "collective self-perception that teachers in a 
given school make an educational difference to their students over and above the educational impact of their homes and communities" (Tschannen-Moran \& Barr, 2004, p. 190). According to Hattie et al. (2016), Collective Teacher Efficacy (with an effect size of 1.57) is ranked as the number one factor influencing student achievement and can yield three years of student academic growth over the course of a single school year. Schools with the following identifying characteristics are more likely to have levels of Collective Teacher Efficacy:

1. High levels of teacher participation in school-wide decisions

2. Consensus on goals/vision

3. Knowledge of colleagues' practices

4. Staff alignment on fundamental educational beliefs

5. Effective systems of intervention

6. Responsiveness of leadership (Donohoo, 2017).

Hattie et al.'s research suggests the role of the principal is less about leading instruction, it is more about understanding what the principal can do to build capacity; offer appropriate professional development, aligned curriculum, provide collaboration time, etc., in support of improving quality instruction.

The most difficult question facing building leaders is where to focus their energies and how to balance and manage all of the roles in the current political, educational and economic reality of a public school. In 1988 Fullan described the then picture of the role of the building leader through a question that is the title of the first chapter: "How Bad are Things for the Principal?” (p. 1). Fullan discussed a study from 1984 that measured 150 principals and their roles over a 5 -year period. In $1984,90 \%$ of the principals 
indicated an increase in their role demands across 11 indicators. Fullan argued that the role of principals has drastically changed, "Indeed, it is no longer a matter of additive overloads; the definition of the very job of the principal has undergone fundamental change" (p. 2). Since then, a Markow et al. (2013) qualitative study of 500 public school principals concluded the following:

Most principals say that their responsibilities today have changed compared to five years ago and that the job has increased in complexity. Seven in $10(69 \%)$ principals disagree with the statement that a school principal's responsibilities today are very similar to his or her responsibilities five years ago. (p. 32)

See Figure 2 for a summary of attitudes principals have about their jobs.

Figure 2.1

Principal Attitudes about the Job of the Principal

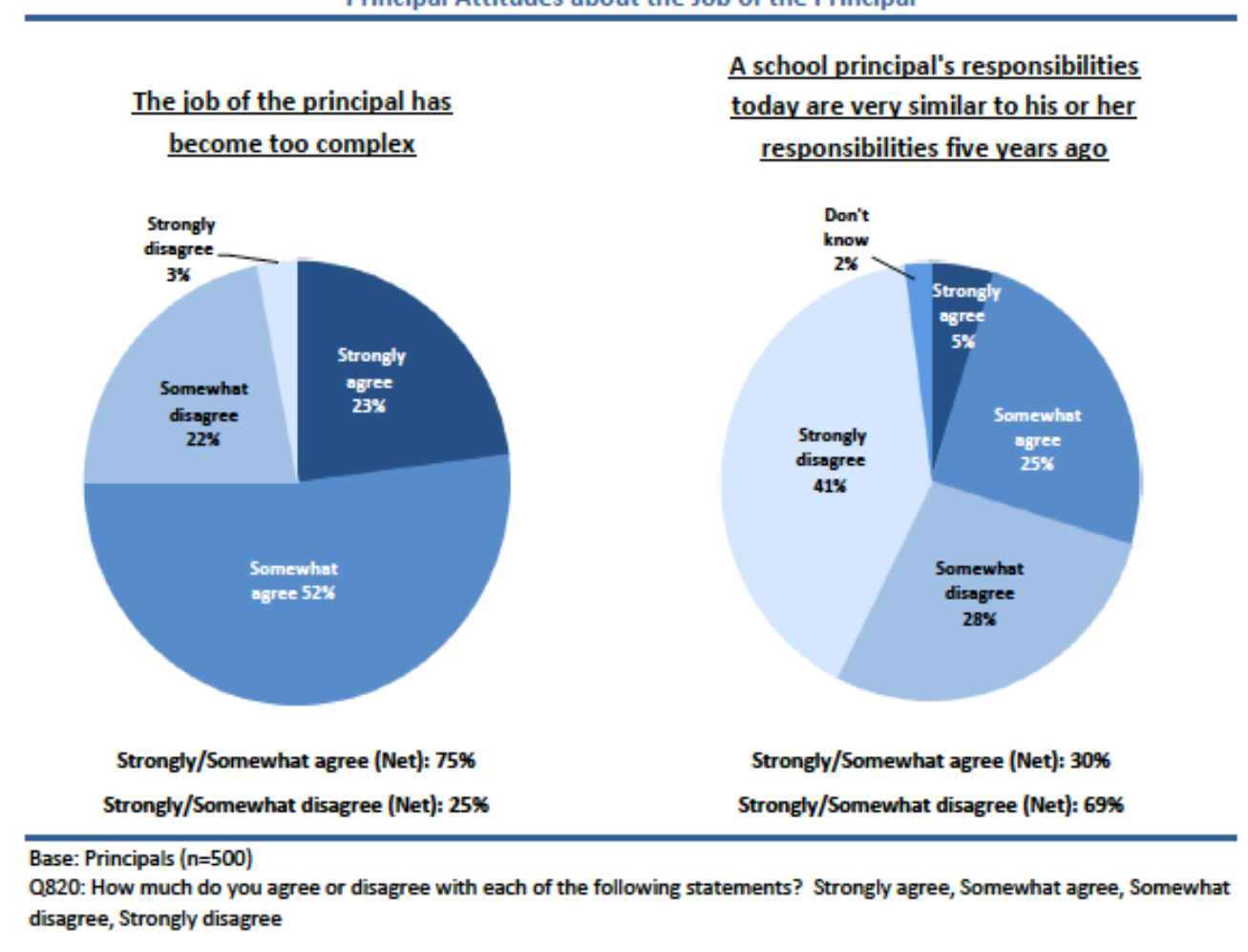

Figure 2. Visual summary of the qualitative data on principal attitudes about the job of the principal. Source: D. Markow, L. Macia, and H. Lee, 2013, MetLife Survey of the American Teacher: Challenges for School Leadership, p. 24. 
There is an extensive body of literature that is available for review in the area of the role of the principal. In my review of four decades of work, the prevalent conclusion in the studies is that the role of the principal as a school leader is constantly changing, is increasingly more complex, and perceived differently dependent upon the stakeholder. Almost 25 years ago, Whitaker (1995) came to the conclusion that, "given the increasingly complex nature of the principal's job due to changing conditions in the context of educational reform, districts must carefully examine the principal's role to retain quality principals" (p. 295), leading many to question not just whether it can be done, but also whether it is worth the cost. More recently, Federici and Skaalvik (2012) were able to specifically identify whether or not individual principals' feelings of selfefficacy were positively or negatively related to burnout, their overall job satisfaction, and their motivation to quit the position. The results of their study revealed that "principal self-efficacy was positively related to job satisfaction and motivation to quit and negatively related to burnout" (p. 1). Furthermore, Federici and Skaalvik concluded that the current complex and unpredictability of the role requires the need to continually support leadership:

Such work environments require principals to be updated at any time in order to act efficaciously. Self-efficacy contributes positively to this functioning, because it affects performance of the principals' through mechanisms like choice, effort and perseverance. Increasing principals' self-efficacy is therefore an important objective for those responsible for improving the quality of leadership in schools. Moreover, to provide self-efficacy is in our view an important goal in education of school principals. (p. 19)

Modern organizations themselves have increasingly become more complex as they try to adapt and keep pace in our current global society. In contrast, our publicschool systems have resisted significant organizational change. Current educational 
policy focuses on accountability and demands increases in student performance and achievement. In a stagnant and non-responsive, traditional and structural frame, principal leadership has emerged to the forefront of public and political conversations. According to Lunenburg and Ornstein (2008) "a number of observers have suggested that the increasing complexity of modern organizations puts a greater premium on leaders' possession of a repertoire of styles and strategies" (p. 26). These observations echo the thoughts of Bolman and Deal (2008) who argued that modern leadership is defined by the ability to reframe or view a problem or issue from a multitude of perspectives. In the organization of public education, such conclusions serve to emphasize the critical importance of effective educational leadership and the capacity of principals to implement reform inside an increasingly modern and complex organizational structure that is stringently defined by traditional industrial age policy.

Public education, however, has been traditionally, and almost uniformly, defined in an organizational frame mired in conflict between a "structural looseness," characterized by an inordinate lack of coordination, control, consensus, and accountability; and a centralized undemocratic bureaucracy that is highly rigid, stultifying and unresponsive (Ingersoll, 1994). Hill, Pierce, and Guthrie (1997) described the limitations of this traditional educational organizational:

Rule-bound, it discourages initiative and risk taking in schools and systems facing unprecedented problems. Politically driven, it allows decisions reached from on high that satisfy as many people as possible to substitute for the professional judgment and initiative of competent, caring professionals in the school and classroom. Emphasizing compliance, it defines accountability as adherence to process, when results are the only appropriate standard. Organized to manage institutions and minimize conflict, it ties up resources of permanent staff and the management of routine operations. (p. 40) 
The traditional educational organization limits the decision-making power of the principal. The MetLife Survey of the American Teacher: Challenges for School Leadership (Markow et al., 2013) provided data, indicated in Table 1, describing how much control that current K-12 principals feel they have in making decisions inside of their organizational structure.

Table 1

A Summary of Principal Ratings of How Much Control They Have in Making Decisions

\begin{tabular}{|c|c|c|c|}
\hline Principal Ratings of & $\begin{array}{l}2.4 \\
\text { ol They Hav } \\
\text { t deal) }\end{array}$ & in Making De & sions \\
\hline & \multirow[b]{2}{*}{ Principals } & \multicolumn{2}{|c|}{ School Level } \\
\hline & & Elementary & $\begin{array}{l}\text { Middle/ } \\
\text { High (Net) }\end{array}$ \\
\hline Teachers' schedules & $79 \%$ & $78 \%$ & $83 \%$ \\
\hline Hiring teachers & $74 \%$ & $72 \%$ & $79 \%$ \\
\hline Removing teachers & $43 \%$ & $42 \%$ & $45 \%$ \\
\hline Curriculum and instruction & $42 \%$ & $41 \%$ & $44 \%$ \\
\hline Finances & $22 \%$ & $23 \%$ & $19 \%$ \\
\hline
\end{tabular}

Source: D. Markow, L. Macia, and H. Lee, 2013, MetLife Survey of the American Teacher: Challenges for School Leadership, p. 29.

While principals report varying levels of control over decision making in key areas, they believe in their professional accountability. According to the MetLife Survey of the American Teacher: Challenges for School Leadership (Markow et al., 2013), "Principals take responsibility for the leadership of their schools. Nine in 10 (89\%) principals agree that, ultimately, the principal should be held accountable for everything 
that happens to the children in his or her school, including $45 \%$ who strongly agree with this view" (p. 27). Successful and effective principals are willing to accept the responsibility and accountability for their work, as long as they are provided the reciprocate level of authority to complete it; we need to increase school autonomy while at the same time preserving accountability (Ballou, 1999). Based on our observations, we believe that greater autonomy is needed in large bureaucratic school systems to increase the number of successful schools (Teske \& Schneider, 1999).

As opposed to the lack of depth in the research base on the impact of collective bargaining on school improvement, there is much larger body of work on the impact of how principal leadership can impact student achievement and school improvement. As a result of the significant size of the research devoted to this topic, I focused upon metaanalysis of the research. In 1998, Marzano worked with Mid-Continent Research for Education and Learning on a quantitative study measuring the effective sizes of school and leadership practices on student achievement and which was later described in the Association for Supervision and Curriculum Development publication, Classroom Instruction That Works (Marzano, Pickering, \& Pollock, 2001). In 2007 a number of researchers came together again to complete a meta-analysis that reviewed more than 5,000 studies on school-level leadership and the effect it had upon student achievement (Waters \& Cameron, 2007).

The findings from this study were published in the text, School Leadership that Works: From Research to Results, and are the results of a sample size consisting of leadership ratings for more than 2,800 principals and achievement scores from 1.4 
million students (Marzano, Waters \& McNulty, 2005). In all of the studies selected, the dependent variable was student achievement, the independent variable was principal leadership and their measures were both quantitative and standardized. One of the major findings of this study was that there was a statistically significant correlation between principal leadership and student achievement. According to the study, the statistical significance was equal to .25 , which equals a $10 \%$ increase in student achievement scores on a norm referenced standardized test per standard deviation increase in principal leadership behavior (Marzano et al., 2005).

In addition to the large-scale meta-analysis, an additional growing body of empirical evidence demonstrates that principals have an important impact on schools, teachers, and student achievement. One growing body of research is the impact principal retentions rates have on student achievement. There are two important variables associated with high principal retention rates. The first, schools with high levels of principal retention tend to have higher levels of teacher retention. Second, any school reform effort is reliant on the efforts of a principal to create a common school vision that focuses on implementing the reform effort over multiple years (Hallinger \& Heck, 1996; Heck \& Hallinger, 1999; Leithwood, 1994; Leithwood \& Jantzi, 2000). Fuller, Young, and Baker (2007) supported the idea that creating a common vision and thoroughly integrating reform efforts into the culture of a school takes a prolonged and sustained effort. The impact or results of these efforts are minimal and easily derailed with the turnover of a principal. Their research suggests:

Principal stability is positively associated with decreases in teacher attrition, increases in teacher quality, and increases in student achievement, the high 
turnover rates of principals is troubling. This is particularly true of high-poverty, high-minority and low-performing schools most in need of leadership and teacher stability. State and district policies makers certainly need to focus much greater attention on this issue if they want to improve schooling outcomes for all students and close the achievement gap. (Fuller et al., 2007, p. 18)

In the review of the literature in the area of principal leadership that I conducted, I found a recurring message that repeated itself over the course of almost 40 years. The role of a principal is consistently changing. The responsibilities of the position continue to increase over time as well as the level of accountability to local, state and federal stakeholders. The flexibility inside of the educational organization has become increasingly limited; however, the principal has a direct influence upon student achievement at the building level. These conclusions were consistent in all of the literature I reviewed.

In closing, I would like to leave the reader with a glimpse into the mind of current principals' courtesy of the research findings presented in The Autonomy Gap by Adamowski et al. (2007):

Despite having their hands tied over critical decisions, most district principals interviewed for this study appear content with the meager authority they possess ... They would like to have more control over personnel (especially hiring, firing, and transferring teachers) but they don't demand it. They don't expect it. They don't quit over it. They have learned to work the system, not change the system. They seek to do the best they can as managers, not revolutionaries. (p. 9)

\section{Collective Bargaining}

For the purposes of this paper, it is imperative to understand collective bargaining and the role it plays in public education. Collective bargaining is defined in the state of Oregon as

The performance of the mutual obligation of a public employer and the representative of its employees to meet at reasonable times and confer in good 
faith with respect to employment relations for the purpose of negotiations concerning mandatory subjects of bargaining, to meet and confer in good faith in accordance with law with respect to any dispute concerning the interpretation or application of a collective bargaining agreement, and to execute written contracts incorporating agreements that have been reached on behalf of the public employer and the employees in the bargaining unit covered by such negotiations. (ORS 243.650, 2017)

Currently, 31 states have mandatory bargaining; 14 permit bargaining, and 5 states prohibit bargaining. Regardless of whether a state is considered to be a collective (mandatory or permitted) or non-collective bargaining (prohibited) state, the practical applications in regards to negotiations, formal agreements and policies reveal few differences between the two methods (Hess \& Loup, 2008). The proposed study is specific to the state of Oregon, which is defined as a collective bargaining state.

In 2012, Winkler et al. authored a study published by the Thomas B. Fordham Institute titled, How Strong Are U.S. Teacher Unions? A State-by-State Comparison. This study focused on the role of teacher unions, and how well they look out for teacher interests in the American K-12 public education system. More specifically, the study identified how they use politics to do this, by measuring teacher union strength, state by state, by focusing on three questions:

1. What elements are potential sources of a union's strength (i.e., inputs)?

2. How might unions wield power in terms of behavior and conduct (i.e., processes and activities)?

3. What are signs that they have gotten their way (i.e., outcomes)? (p. 8)

The study ranked states based on the power and influence of the state's unions. In this study, Oregon was ranked as having the second most powerful teacher union (Oregon Education Association) in the United States. Additionally, the teacher union in Oregon 
was also ranked in Tier 1 (strong), in four of the five categories assigned: Resources and Membership, Involvement in Politics, Scope of Bargaining, and Perceived Influence. Oregon was ranked in Tier Four (weak) in the last category: State Policies.

This study intended to examine what principals and teacher leaders believe about the effect of CBAs on school performance and how principals and teachers in high performing schools describe authority and autonomy of the leadership in effective schools? Thus, in order to provide a more focused contextual understanding of collective bargaining for the purpose of this study, a historical review of the respective union relations and each of the districts from the five participant schools was conducted. The review produced information that identified strained union relationships in two of the five districts. To protect the identity of the subjects, I do not provide detailed information. However, it is important to note that these strained relationships range from being strained for more than 40 years to relatively recently (Magmer, 1983; Oregon Public Broadcasting, 2014).

The significance of this study in the literature review is that a significant portion of the rationale for the findings in this study was the lack of regional (West) representation in the original study, and no representation in the state of Oregon. The strength of the teacher unions in the state provides a further reason to examine the research question.

The body of educational research in respect to the influence of labor agreements on student achievement indicates a general lack of continuity. The most succinct 
explanation of the varied impacts labor agreements have on student achievement is provided by Eberts (2007):

The evidence on how unions affect student achievement leads to the general conclusion that there is no simple answer and that generalization is difficult. The average-achieving student does not appear to be harmed by attending union schools and may even fare slightly better, whereas low-achieving, at-risk students and high-achieving students tend to do better in nonunion (schools and districts with no labor agreements) schools. Even though some threads of evidence are promising, researchers have much to learn about how unions affect student outcomes. What is known with some certainty is that the productivity gains of unionization, if any, do not match the increase in cost, upward of fifteen percent, that unions place on education through higher compensation and their influence on resource allocation in schools. (p. 178)

The literature provides differing conclusions suggesting that CBAs are seen to have both negative and positive influences on student achievement, dependent upon the type of analysis and the variables studied. As a whole, longitudinal studies found that the process of collective bargaining and students inside of schools functioning under labor agreements reported higher overall student achievement. In educational studies where the individual student was the unit of analysis, the research indicated a positive trend for student performance. Most recently, Vachon and Ma (2015) examined the effects of two independent items commonly negotiated in teacher contracts against student standardized math assessment scores. Their conclusions echoed the work of Eberts and Stone (1984), Register and Grimes (1991), and Steelman, Powell, and Carini (2000) indicating individual students in unionized schools outperform individual students in nonunion schools on standardized assessments.

In educational studies where the individual school districts were used as the unit of analysis, the research indicated a negative trend for student performance. One seminal piece of literature was written by Hoxby (1996) titled, How Teacher Unions Affect 
Education Production. After controlling for district and economic characteristics, her study concluded that the restrictive CBA resulted in lower student achievement on the California state assessment and a 2.3\% increase in dropout rates (Moe, 2009). The disparity in the findings of how labor agreements impact student achievement can be partially explained by the standardizing effects of labor agreements on schools and school districts. Schools that are functioning inside of a CBA rely, to a greater intent, upon traditional classroom instruction, which work best for the average individual student (Eberts, 2007).

In educational studies where state level data were used as the unit of analysis, the research also indicated a negative trend for student performance. A recent study by Lott and Kenny (2013) examined the differences in student achievement dependent upon the strength (financial resource) of the individual teachers' union in 42 states, "studying the effects of the major contributions to state and federal elected officials provides important general knowledge about special interest influence" (p. 94). The researchers offered the following conclusion, "students in states in which the teachers' union has high dues and high spending have lower test scores than students in states with low dues and spending. Union strength matters and indeed matters more than any other variable in our regressions" (p. 102).

Adamowski et al. (2007) studied 33 principals from low, average, and high performing schools in five urban areas in different three states. In their study, they introduced the concept of autonomy as a barrier to effective school leadership. The researchers defined the discrepancy and distance between the authority educators 
(principals) need and the authority they have as the "Autonomy Gap" (Adamowski et al., 2007).

The principals that participated strongly agreed that they had moderately strong leadership capacity. They also identified 21 school level functions by importance that impacted their leadership capacity, citing hiring, assigning and discharging unsuitable teachers, along with allocating time for instruction, as the most important factors determining their effectiveness. Additionally, the principals identified union contracts, and state and federal policies as sources that weakened their authority. In conclusion, the principals described having a lack of authority over the functions they regarded as critical to raising student achievement. Specifically, the results indicated that principals of charter schools and in a right-to-work state enjoy more autonomy in most personnel matters than their public counterparts in collective-bargaining states (Adamowski et al., 2007). These findings support a need to continue the investigation of CBAs, their flexibility, and their impact, positive or negative, on student achievement.

In summary, the educational literature regarding the impact that labor agreements have on student performance is decidedly mixed and without a consensus. Additionally, the literature does not provide any conclusion regarding the appropriate measurement for studying the impact of labor agreements on student academic performance and has found standardized assessment results to be relatively similar in both mandatory and permissive bargaining states (Eberts, 2007). The literature available on the correlation between labor agreements and student achievement is simply not ideal. Previous educational research has not been able to overcome the difficulty of conducting statistically valid and 
significant studies that can effectively control the variables for individual students and school attributes, and to monitor and collect the data over an extended period of time. I expect the trend in the literature in this area to continue to move toward more valid statistical studies as a result of the current educational movement toward accountability and the amount of individual student data that is being collected in response to these new standards.

\section{Synthesis}

The literature reviewed for this study included an examination of role and role theory in relation to an organization, principal leadership, and collective bargaining defined in the context of public education. Role theory in summary is the individual struggle to self-identify in the context of an organization. In a symbiotic organization, the needs of the individual and the organization are in unison; however, there are often sources of conflict that prevent this balance. The literature reviewed for principal leadership collectively supports the importance of the role in regards to student achievement and school improvement. Additionally, there is a general consensus that the role is continuing to diversify, become more difficult, and that individuals are not only leaving the position, but fewer are aspiring to enter the role as well.

The literature on collective bargaining revealed information that was significant to the design of the study targeted to the state of Oregon. However, the literature did not provide a general consensus on the measurable effect of labor agreements, defined through collective bargaining or non-collective bargaining states, on student achievement. There are data that indicate that the impact of labor agreements produce 
both positive and negative effects for student learning. The only universal conclusion in the literature I read was that the cost of collective bargaining for the educational system (in dollars) far outweighs that resulting impact student achievement, be it positive or negative.

\section{Critique}

Recommendations for addressing the impact of CBAs on student achievement fall into two frames: immediate recommendations for local educators and future recommendations for state and federal policy makers. The current political and organizational realities surrounding collective bargaining and labor agreements do not provide for either a single or simple solution. The complexities surrounding this issue require creative, non-traditional reform described by Hess and Loup (2008):

New one-size-fits-all solutions invite implementation debacles and are likely to hurl us from one era of compliant management into another ... Rather there is a need to move on multiple fronts to promote flexibility for district and school leaders-and to ensure leaders are prepared for their roles and held accountable for using authority appropriately and effectively. (p. 30)

The true significance of the research question is to provide information about what impact labor agreements have on practitioners. What happens in our classrooms and in our buildings when theory becomes reality? There is a clear lack of research specific to Oregon that provides clarity around the impact of labor agreements on student achievement. With the knowledge that Oregon performs poorly in comparison to other states in both academic achievement and high school graduation rates yet is home to the second strongest teacher union in the country there may be a need for more research in this area. 


\section{Review of the Methodological Literature}

The application of conclusions drawn from traditional qualitative and quantitative research to the modern educational setting, especially in the area of collective bargaining, can provide difficulties for educational leaders looking to apply them in practice. Simply, there are too many independent variables unique to public schools and school systems to isolate and identify direct causal relationships. For example, every school district in the country that participates in collective bargaining has a separate and independent labor agreement negotiated in isolation from neighboring districts. Conclusions that are ascertained from educational research may provide general recommendations supported by data; however, it realistically cannot be applied universally to our public schools because of their inherent individuality.

Therefore, it can be inferred that successful leaders have to be able to understand how an effective practice, concluded from research, can be adapted to the specific needs of the individual setting. In the future it is my intention to refine an established and tested research tool to help practitioners evaluate their specific CBAs with the purpose of positively impacting student achievement. Only through continued investigation, possibly with a successful educational research tool or product, can we hope to collect additional information to understand the true impact local labor agreements have on student achievement.

\section{Summary of the Research Literature and Application to the Study}

The literature on collective bargaining and the impact on school performance is summarily fledgling and non-conclusive, resulting from the vast number of variables that 
impact student achievement. The investigation into collective bargaining practices has increased recently as a result of public pressure to address the underperformance of our schools coupled with the demand to increase shrinking state and local budget allocations. Although limited, there are some studies that have posed similar research questions. One such study was conducted in 2008 by a former professor of mine at the University of Virginia, Frederick Hess, now at the Thomas Fordham Institute and Cody Loup titled, The Leadership Limbo: Teacher Labor Agreements in America's Fifty Largest School Districts (Hess \& Loup, 2008). The research study examined how much flexibility district leadership held in key areas of identified best practice. More specifically, how frequently do the labor agreements negotiated by school districts and teacher unions contain provisions that make it harder for public schools to be smart, flexible, highperforming organizations? (p. 11).

My research adds to the educational literature by asking a number of questions that are not represented in any area of the extant research that I reviewed. First, there was a limited amount of research specifically focused around practices in public schools K-12 at the building level, either elementary or secondary. In addition, the research that was available focused specifically on leadership, not classroom teachers or the comparison between the two individual populations. Finally, I found no educational literature related to the research questions posed in this study that addressed topics specific to the needs of students, teachers, principals, schools and districts within our region or state.

None of the districts in the study conducted by Hess and Loup (2008) were located in the state of Oregon, and a statistically insignificant sample was from the 
Pacific Northwest. This lack of representation, specifically to Oregon, is inconsistent to the correlated strengths of the associated National Teachers Unions. A study written in 2012, by Winkler et al. indicated that a majority of the most influential unions are located in the West and Pacific Northwest. Specifically, the state of Oregon has the second strongest teachers' union in the United States (p. 36). Although the studies are significantly different in size, scope, design and method, it still offers the opportunity to examine the same questions under the variables specific to our educational setting in Oregon.

The relationship between CBAs and school improvement is highly politicized and produces considerable debate:

In recent years, debates over school reform have increasingly focused on the role of teacher unions in the changing landscape of American $\mathrm{K}-12$ education. On one hand, critics argue that these unions, using their powerful grip on education politics and policy to great effect, bear primary responsibility for blocking states' efforts to put into place overdue reforms that will drive major-league gains in our educational system. Such critics contend that the unions generally succeed at preserving teacher job security and other interests and do so at the expense of improved opportunities for kids. (Winkler et al., 2012, p. 1)

As a result of the inconclusiveness of the educational literature I read, I am selecting a set of high performing schools identified by the ODE to see what the teachers and leaders in these schools believe to be the relationship between CBAs and school performance. 


\section{Chapter 3: Methods}

\section{Introduction}

The literature on collective bargaining and the impact on school performance is summarily fledgling and non-conclusive, in part due to the vast number of variables that impact achievement. The research on labor agreements, specifically around flexibility, has increased recently, likely from the economic pressures forcing politicians to address the underperformance of our schools in lieu of shrinking state and local budget allocations. Researchers such as Hess and Loup (2008) have already conducted comparative studies of large school districts focused on the differences among their individual agreements. My research adds to the literature by providing a more local focus, specific to the state of Oregon, and draws a direct connection between specific school performance and contractual flexibility, which is not represented in any area of the extant research.

It is difficult for practitioners to apply the findings of traditional qualitative and quantitative research regarding collective bargaining to practice. Multiple independent variables unique to public schools and school systems make it difficult to isolate and identify direct causal relationships between CBAs and school performance. For example, every school district in the country that participates in collective bargaining has a separate and independent labor agreement negotiated in isolation from neighboring districts. Conclusions ascertained from educational research may provide general recommendations supported by data; however, findings cannot realistically be applied 
universally to our public schools because of the inherent individuality of each school district. Therefore, it can be inferred that successful leaders have to be able to understand how an effective practice, informed by research, can be adapted to the specific needs of the individual setting. While the data I have collected was intended to be used to inform CBAs to positively impact student achievement, the analysis of the data in this study, to be discussed in Chapter 4, indicate that CBAs are not consistently perceived to be a deterrent to raising student achievement.

\section{Research Methods}

For this study, I examined the relationship between the school's CBA, school leadership characteristics, the school culture, and the ability of school leaders to reduce educational disparities in their schools. Educational research is defined as a formal, systemic application of the scientific method to the study of educational problems with the goal of explaining, predicting, and controlling educational phenomena (Gay, Mills, \& Airasian, 2006). Research adds to our knowledge and existing information about issues, improves practice by offering new ideas or evaluating existing approaches, and informs policy debates by creating conversation about important issues (Creswell, 2005). The research process includes four main steps: (a) selection and definition of a problem, (b) execution of research procedures, (c) analysis of data, and (d) drawing and stating conclusions (Gay et al., 2006). Two major paradigms of educational research, qualitative and quantitative research, present unique methods that inform the overall strategy for collecting and analyzing data (Gay et al., 2006). It is possible for a research question to 
be addressed using either method, and sometimes the research question may be addressed using a combination of the two major paradigms in a mixed methods approach.

The first approach to inquiry, qualitative research, is the human attempt to bring meaning to events and phenomenon as they occur in their natural setting. Specifically, qualitative research is defined as process of understanding based on distinct methodological traditions of inquiry that explore a social or human problem. The researcher builds a complex, holistic picture, analyzes words, reports detailed views of informants, and conducts the study in a natural setting (Creswell, 1997). Qualitative methods of research typically place more emphasis on description, observation and exploration over explanation and data that indicate causal links. Finding meaning is the essential purpose of qualitative research and is often conducted through one of several approaches: case studies, grounded theory design, narrative and ethnographic research. These approaches provide descriptions of the participants' perspectives and are used to create general explanations for a process, action or interaction (Creswell, 2005; Gay et al., 2006). I used the qualitative process with data collected through online surveys to describe the characteristics of successful school leaders and any possible constraints of a CBA.

The second process of inquiry, quantitative research, is the analysis of numerical data to answer a specific question. One definition is an inquiry into a social or human problem based on testing a theory composed of variables, measured with numbers, and analyzed with statistical procedures, in order to determine whether the predictive generalizations of the theory hold true (Creswell, 1994). According to Gay et al. (2006), 
quantitative methods of research intend to describe current conditions, study cause-effect phenomena, and investigate relationships through a view of the world that is relatively stable, uniform and coherent. Critical to the quantitative process is the hypothesis, which predicts the results of the research; control of contextual factors, data collection from significant samples of participants, and the use of statistical methods to analyze the data. There are two major ways to conduct quantitative research: experiments and surveys. Experiments include "true" experiments with the random assignment of subjects to treatment conditions and quasi experiments that use nonrandomized designs; surveys include cross-sectional and longitudinal studies using questionnaires or structured interviews for data collection with the intent for generalizing from a sample to a population (Creswell, 1994).

I did not select the quantitative process as the method for this study for several reasons. The first is that the study is not generalizable, due to the limited sample size. The total number of schools that were identified by using purposive sampling was only seven, five of which became participants. The surveys and the study were also not longitudinal in design. Finally, the intention of the qualitative process, according to Gay et al. (2006), requires the investigation of relationships through a view of the world that is relatively stable, uniform and coherent. In the context of this study, the "world" of public education is neither stable, uniform nor coherent.

\section{Participants}

Participants included five high schools recognized by ODE in 2014-2015 as successful Oregon high schools, based upon significant improvement in their overall 
graduation rates or reducing the graduation rates between targeted student groups (ODE, 2016b). All of the schools are comprehensive high schools, located in independent school districts, and are a representative sample of state student enrollment and geographic locations. The principals of each high school were participants in this study as were 23 teachers; four of the schools had five teacher leader participants and one school had three teacher leader participants.

In order to protect the anonymity of the participating schools, I am not going to describe them independently. As a group, there were some similarities between the schools: they all had student populations that were highly mobile (more than 14\%), all but one with high English learner populations (4 ranging from 14-53\%), high poverty (ranging from 46-100\%), and highly diverse (ranging from 22-64\% students of color), when compared to other Oregon high schools (ODE, 2016c).

The identification of the participating schools and their respective principal was selected through a method called purposive sampling (Creswell, 1994; Etikan, Musa, \& Alkassim, 2016). Purposive sampling "is typically used in qualitative research to identify and select the information-rich cases for the most proper utilization of available resource" (Etikan et al., 2016, pp. 2-3). Although the sample size of the study was small, the strength of the methodology is supported by the sampling techniques used to select participants that are proficient and well informed with "a phenomenon of interest" (Etikan et al., 2016, pp. 2-3) and is typically used in qualitative research to identify and concentrate on people with particular characteristics who will better be able to assist with the relevant research (pp. 2-3). Unlike random studies, which deliberately include a diverse 
cross section of ages, backgrounds and cultures, the idea behind purposive sampling is to concentrate on people with particular characteristics who will better be able to assist with the relevant research.

In each of the participant schools, only five teachers were selected to participate in the study. The sample consisted of teachers that hold leadership positions in the school, such as department chairpersons, site council or leadership team members. The rationale for this purposive sampling is that in their more prominent role as teacher-leaders, they might be able to provide more informed and comprehensive responses to the interview questions regarding leadership. The relatively small number of teacher leader participants, per school and overall, selected in the study is supported by an additional method of sampling called convenience sampling. Miles and Huberman (1984) suggested sampling data can be evaluated through six pedagogical criteria. In 2000, these criteria were interpreted into a list of attributes:

1. The sampling strategy should be relevant to the conceptual framework and research questions addressed by the research.

2. The sample should be likely to generate rich information on the type of phenomena which need to be studied.

3. The sample should enhance the "generalizability" of the findings.

4. The sample should produce believable descriptions/explanations.

5. Is the sample strategy ethical?

6. Is the sampling plan feasible? (Curtis, Gesler, Smith, \& Washburn, 2000, p. 1003)

Although the sample size is small, survey respondents provide a focused look at CBAs, the context in which successful leaders lead, and how they respond to leadership issues 
that allow some principals to be more successful, as measured by ODE school performance data, than others in Oregon high schools.

\section{Procedures}

The data collection procedures for this research study are theoretically and practically grounded in qualitative methods (Creswell, 2005) using a survey developed by the researcher in support of the research questions specific to this study. Prior to conducting the study, I completed a Portland State University approved course on the Responsible Conduct of Research/Human Subjects, the NIH Subjects Protections Training. Approval to complete the research and the amended protocol \#163753 for the study entitled, "The Relationship Between Labor Agreements and School Performance" was obtained from the Institutional Review Board at Portland State University on April 3, 2017.

The study involves collecting data around the characteristics of successful leaders in Oregon high schools from the perspectives of teacher leaders and principals. I obtained data from the principal of each of the identified 5 high performing high schools using an online questionnaire consisting of the seven approved questions. Principal interviews or data collection were conducted via an online media or qualitative tool. Additionally, I obtained data from teacher participants using an online questionnaire consisting of the seven approved study questions which intended to include five teachers at each of the identified five high performing high schools.

To solicit participants, I contacted the superintendent of each district for the seven schools recognized in the 2014-2015 research study on successful Oregon high schools 
(ODE, 2016b). During the initial contact, I spoke with the superintendent of each school district and informed them of the purpose of the research and the protocol required to complete the study. I informed them that the testing is non-invasive, requires a minimal amount of time from employees, and would not interfere with the functioning of the school district. Upon approval to conduct the study, I contacted the principal of each of the identified schools.

I contacted each principal individually via email. Three of the principals requested text messaging, and one spoke directly with me on the telephone. Upon contact with each potential participant, I explained the goals of this study, selection criteria for participants, and asked for permission to include them in the study.

Data collection was conducted starting in the spring of 2017 and concluded in the summer of 2017. The length of the survey depended upon the participant, however, I provided an estimate of 20 minutes for principal participants, and 15 minutes for teacher participants. The benefit to the participant of an online instrument is the ability to control the confidentiality of the location, as well as to provide a greater deal of overall convenience. Each individual interview began with a review of either the Principal/ Teacher Consent Form, assuring them of confidentiality of both their responses, the reporting of the data, and which contained all of the required elements defined in the Portland State University Institutional Review Board Standard Operating Procedures Manual. In order to continue participation in the study, individuals provided their consent by indicating so electronically. Participants could also exit the survey at any time if they so choose. 


\section{Instruments and Measures}

This study included two qualitative instruments, one for building principals and one for the building teachers. Each instrument consisted of seven questions, and the seven questions were each the same for both participant groups, relative to position and/or any obvious grammatical corrections. The questions for the instrument were developed over time, in collaboration with my advisor and committee, in an attempt to ascertain as much information from the participant/respondents around the research questions. The two instruments, one specific to principals and one to teachers respectively, are presented below:

Principal Questions:

1. To what do you attribute your improved graduation rates and reduction in the achievement gap?

2. Can you identify any barriers that exist(ed) for your school in order to achieve your success in these areas?

3. What strategies do you use to overcome the barriers you currently face?

4. Please describe what the school culture (academic, social, and emotional characteristics) is like for students and for staff.

5. What do you believe are the characteristics of an effective school administrator?

6. To what extent do you as a principal have the authority to do what is necessary to ensure that your school meets the expectations for student achievement and improving graduation rates?

7. Is there anything else you believe is important for me to know about what helped you achieve student success and/or any barriers you face when working to reduce educational disparities? 
Teacher Questions:

1. To what do you attribute your improved graduation rates and the reduction in the achievement gap?

2. Can you identify any barriers that exist(ed) for your school in order to achieve your success in these areas?

3. What strategies do you (does your principal) use to overcome the barriers you (your school) currently school face?

4. Please describe what the school culture (academic, social, and emotional characteristics) is like for students and for staff.

5. What do you believe are the characteristics of an effective school administrator?

6. To what extent does your principal have the authority to do what is necessary to ensure that your school meets the expectations for student achievement and improving graduation rates?

7. Is there anything else you believe is important for me to know about what helped your school administrator achieve student success and/or any barriers your school leader faces when working to reduce educational disparities?

In addition, there was also an individualized consent agreement for both principal and teacher participant groups respectively.

\section{Role of the Researcher}

As a current public-school administrator, I need to guard against any personal regarding this study. I work with and under the provisions of a district and teacher union negotiated labor agreement, which is relevant in my role as a former principal and current central office administrator. It is important to recognize this bias as a researcher and to take steps to limit bias. Maxwell (2013) recommended securing multiple data sources. 


\section{Data Collection and Analysis}

The main objective of this study was to determine what impact CBAs have on the ability of high school principals to reduce educational disparities and close the achievement gap from both the perspective of themselves and teacher-leaders. Furthermore, under the context of CBAs, what are the characteristics and types of leadership that allow some principals to be more successful as measured by school performance than others in Oregon high schools. The two major research questions of the study are:

1. What do principals and teacher leaders believe about the effect of CBAs on school performance?

2. How do principals and teachers in high performing schools describe authority and autonomy of leadership in effective schools?

As previously identified, the data were collected using a qualitative instrument for all participants. The participants were not limited to one response per question, and many participants provided multiple responses to each of the seven questions. Therefore, the number of total responses was far greater than one response per participant, per question. The overall data collection was intended to result in a total of 30 completed qualitative instruments as explained below:

Data Collection (30 Participants) Example:

- School A: Principal (1) Teachers (5)

- School B: Principal (1) Teachers (5)

- School C: Principal (1) Teachers (5)

- School D: Principal (1) Teachers (5)

- School E: Principal (1) Teachers (5) 
In order to analyze the data, responses were initially identified as either principal or teacher participants. Each participant group, principal and teacher, was further organized by individual questions one through seven, which were identified as P1-P7 for principals and T1-T7 for teachers respectively. Once completed, I followed the same process to thematically classify and label the individual responses (outlined below) for both the principal and teacher groups, and to code the data collected.

For each participant group, only one research question was coded at a time, and all of the responses were reviewed independently, not as a collective group. Participant responses were classified and labeled into themes using colored markers. There were no limitations set on the number of responses per participant or on the number of classifications per question. The classification and labeling of the qualitative data provided me the ability to "code" responses as individual pieces of data and place them into the themes that were identified from the participant responses. Coding the quantitative data provided a way to count responses in a qualitative method, granting the opportunity for a more aligned analysis of the participant data. This specific process was applied to each of the seven research questions for both the principal and teacher participant groups. Upon completion of the coding process for both participant groups, the total number of responses per question, per theme was now available.

Analysis of the data required looking at responses from the principal and teacher groups as a collective whole, but also independently from both groups at each of the five independent high schools. In order to organize the data for analysis, the following labels were used: 
Collective Principal Responses: P1-P7

Principal Responses Per Building:

School A: PA1-PA7

School B: PB1-PB7

School C: PC1-PC7

School D: PD1-PD7

School E: PE1-PE7
Collective Teacher Responses: T1-T7 Teacher Responses Per Building:
School A: TA1-TA7
School B: TB1-TB7
School C: TC1-TC7
School D: TD1-TD7
School E: TE1-TE7

The overall data collected from the quantitative instrument were organized by theme for each question, for each participant group, and for each building. Additional data sets representing responses from the participant groups as a whole were also organized in the same manner. The data are included with the presentation of the results in Chapter 4. 


\section{Chapter 4: Results and Analysis}

\section{Introduction}

The current educational environment is defined by organizational accountability practices intended to increase the level of student achievement in our public-school system. The Every Student Succeeds Act (ESSA) of 2015, replacing NCLB passed in 2002, represents the latest federal legislation from the United States Department of Education that will require states to design, follow and achieve a new set of accountability measures. The state of Oregon recently received approval of the ESSA plan (ODE, 2016a). Currently, Oregon is one of the lowest ranked states in the country for producing high school graduates, ranked 47 out of 50. It is also known for having the second strongest teacher union in the country (Winkler et al., 2012). In the convergence between increasing accountability, low school and student performance and one of the most influential teachers' unions in the country, some question if there is a relationship between student outcomes and teacher union strength (Winkler et al., 2012).

The purpose of this research is to understand the impact of CBAs on the ability of successful school leaders to increase student achievement. Therefore, this study examines the impact of CBAs on school performance in five high performing schools in Oregon. Specifically, this study examines the characteristics of successful principals' and what strategies they use to increase student achievement within the requirements of CBAs. The 
purpose of the research was answered by examining the research questions identified below:

1. What do principals and teacher leaders believe about the effect of CBAs on school performance?

2. How do principals and teachers in high performing schools describe authority and autonomy of leadership in effective schools?

The data collected for the study were obtained using both purposive and convenience Sampling. Through purposive sampling, I identified five high performing Oregon high schools using the criteria of graduation rates and demographics reflecting diverse populations through a previously conducted research study by the ODE (2016b). The schools' identity is protected as per the approval of this study by Institutional Review Board \#163753.

At each school, I used convenience sampling to secure participation from five teachers that hold leadership positions in the school. The teachers selected at each school completed an online survey consisting of seven preapproved study questions. The principal at each school also participated in their own individual survey.

\section{Analysis of Data and Presentation of the Results}

The data collected via the process identified in Chapter 3: Data Collection and Analysis were converted to a graphic and/or chart to provide a visual representation of the information. All visual data contained the specific numerical responses as well. Each data set was analyzed both individually and collectively by question, by school, and by participant group (teachers and principals). The initial stage of the data analysis consisted of internally reviewing the individual collections for any identifiable similarities or 
relationships among the responses. The second stage of the analysis consisted of comparing any identified relations among each of the individual questions between participant groups, comparing them across schools, and looking for similarities, differences and relationships at a much larger level. In the presentation of the data, there is an individual chart and comment for each of the 84 individual response items. The presentation of the data below is organized in the following manner: collective principal responses per question, collective teacher responses per question, collective principal responses per school, and collective teacher responses per school.

Collective principal responses per question. The results from Question 1 indicate that as a group, the principals consistently identified four areas that were important to increasing overall school performance: early identification and intervention for students needing academic support, relationships with students built upon respect, effective teachers and instruction, and a clear school vision supported by school-wide systems. Responses also indicate that while other practices or strategies may be a contributing factor suggested by some principals, they may be dependent upon the individual characteristics of the variables that exist at each building. Examples of these are school size and location, student demographics, and socio-economic status (see Figure 3 for a visual representation of these data). 


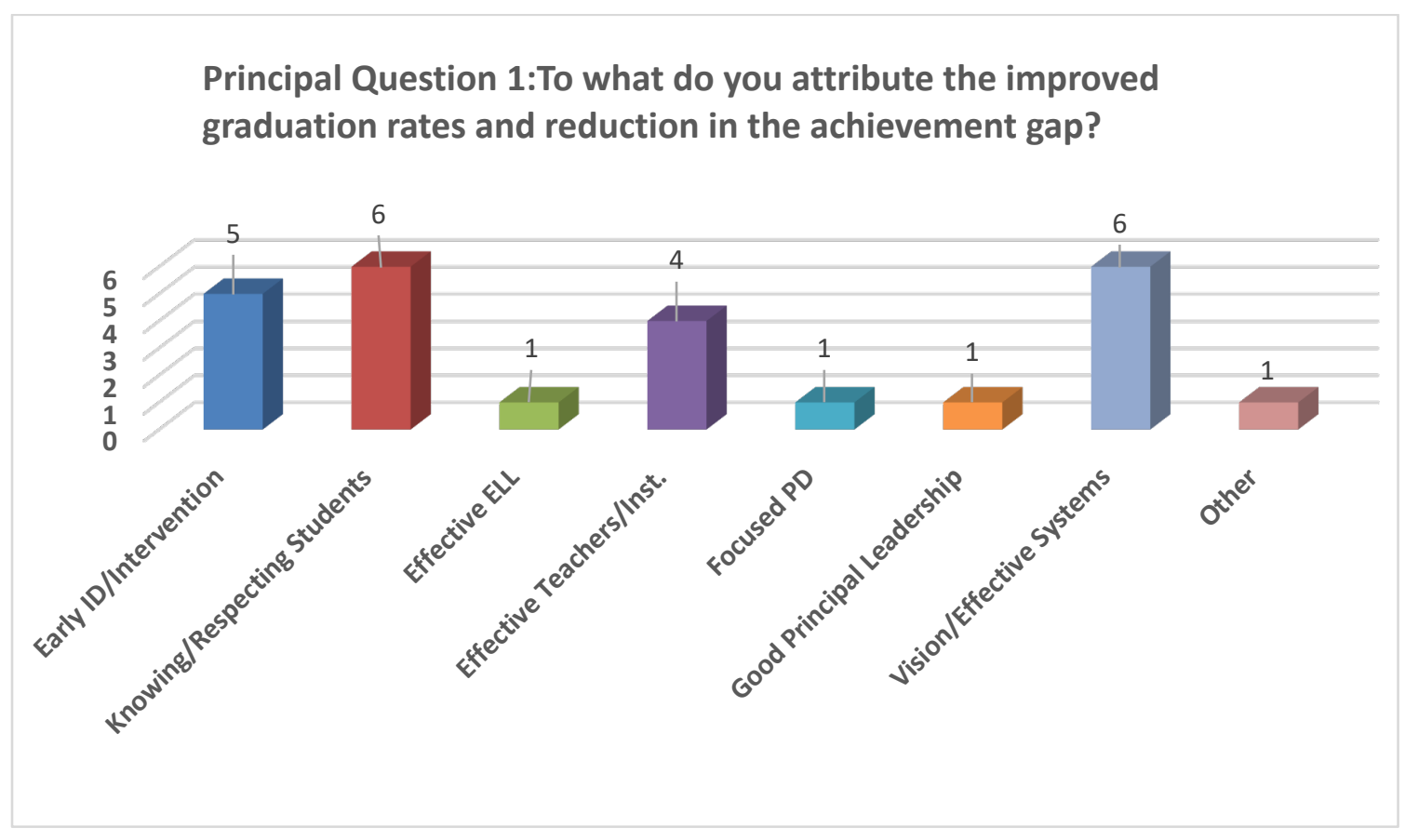

Figure 3. Summary of collective principal responses to question 1 . The number of principals attributing the above factors to improving student achievement.

The responses from the principals as a group to Question 2 presented a lack of agreement around what they identified as barriers to improving school performance and closing the achievement gap. The only response gathering more than one response was the inability of school leaders to provide their teaching staff with more opportunities to collaborate. The lack of agreement suggests that the perceived barriers in existence for school leaders (principals) is not easily identifiable, and again may be dependent upon independent variables that exist for each school. As previously indicated in Chapter 3: Data Collection and Analysis, there was no limitation to the number of responses for each individual question on the survey instrument. Question 2 is of additional significance in that when offered an open opportunity to identify any impediments to improving 
outcomes for students, school leaders provided little feedback (see Figure 4 for a visual representation of these data).

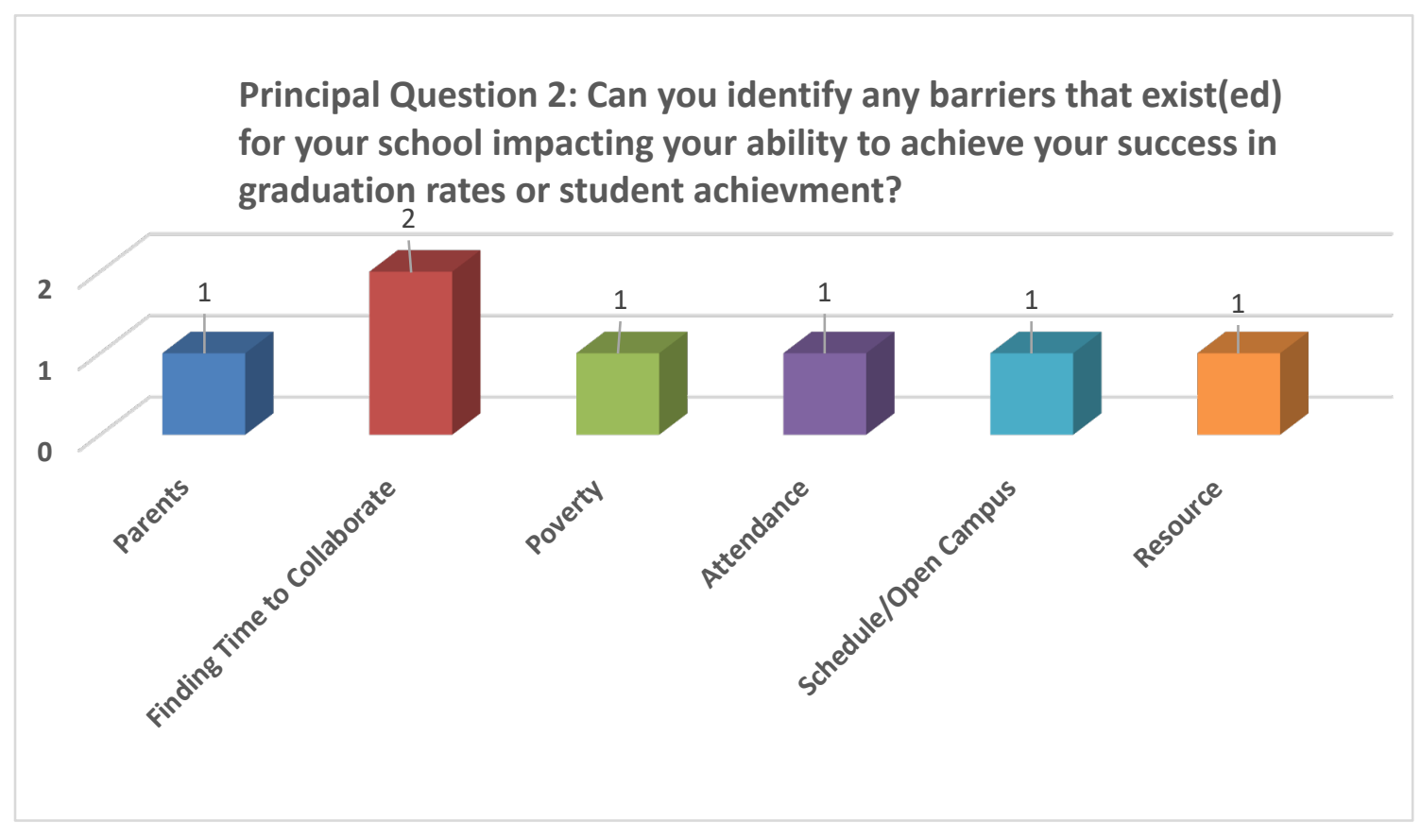

Figure 4. Summary of collective principal responses to Question 2. The number of principals identifying the above factors as barriers to student achievement.

In similar fashion to the previous question, principals had diverse responses in their responses to Question 3, "What strategies do you use to overcome the barriers you currently face?" Additionally, the principals provided limited feedback to this question as well. The mirroring between the two questions indicates a strong and valid relationship between the questions and the responses. This relationship is examined further in the interpretation of the results (see Figure 5 for a visual representation of these data). 


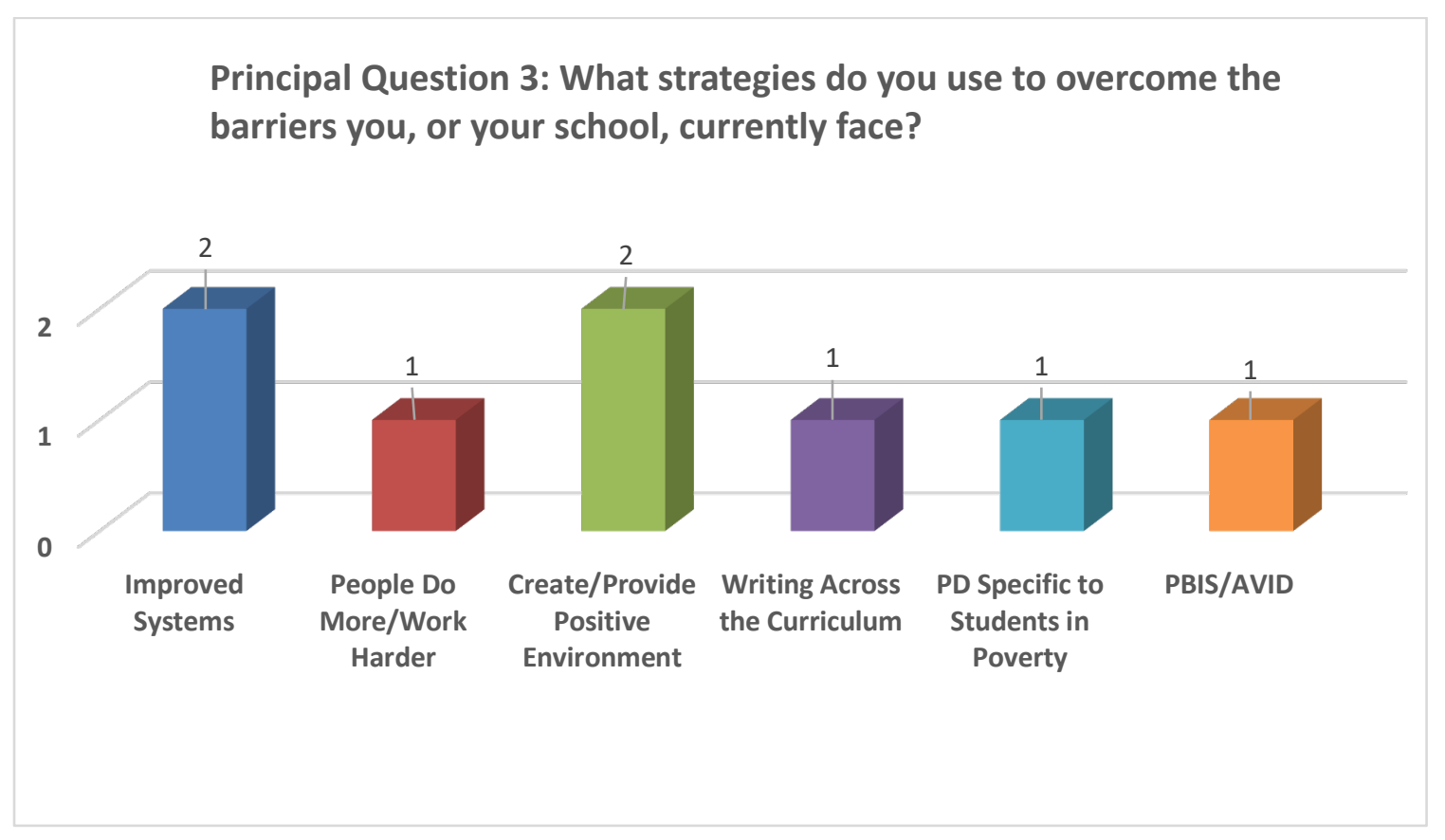

Figure 5. Summary of collective principal responses to Question 3. The number of principals utilizing the above factors to overcome barriers to student achievement.

The overall attributes the principal participant group identified as necessary for a successful school in Question 1 are all similarly identified in responses as aspects of the individual school cultures at multiple buildings. Student interventions, positive relationships, and effective instruction (high expectations), were recognized as a significant part of the school culture across all the buildings in the study. One point that was significant in the review of the responses to this question was that of the 17 responses provided by principals, only two (poverty and high need students) would be considered "barriers" in an educational environment (see Figure 6 for a visual representation of these data). 


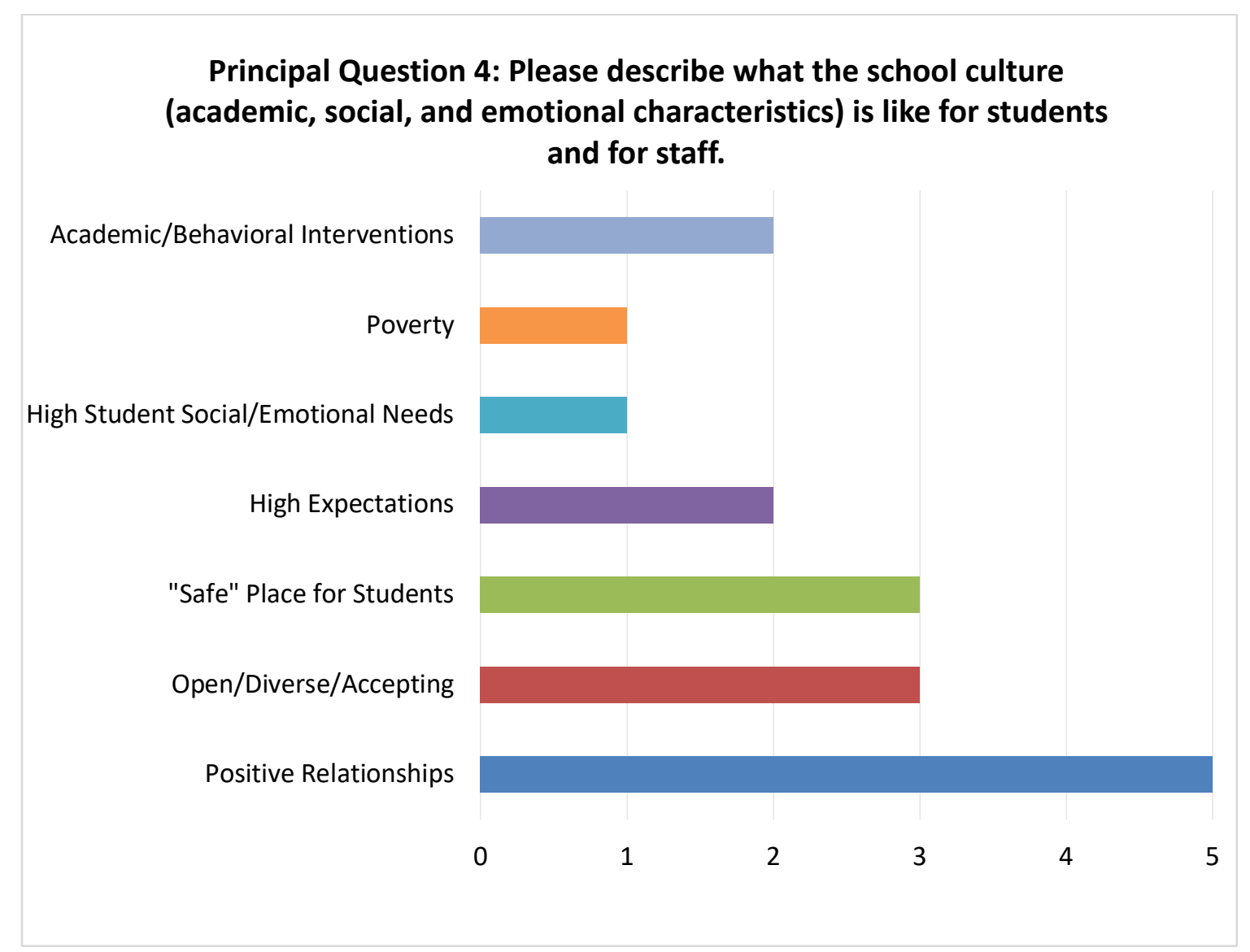

Figure 6. Summary of collective principal responses to Question 4. The number of principals indicating the following characteristics as being descriptive of their school culture.

When asked about their own perceptions of an effective school leader (Question 5), the collective principal participant group provided the largest number of different response themes among the seven questions they were asked. In addition, principal respondents also provided the largest total number of total collective responses for this question as well. The distribution of the responses, viewed in Figure 7, shows almost an equal distribution among all of the nine characteristics of an effective school leader identified by the principal participants. The data suggest that from the perspective of a 
principal, an effective school leader requires a multifaceted skill set, regardless of the variables specific to individual buildings, and the ability to identify and apply them appropriately as necessary.

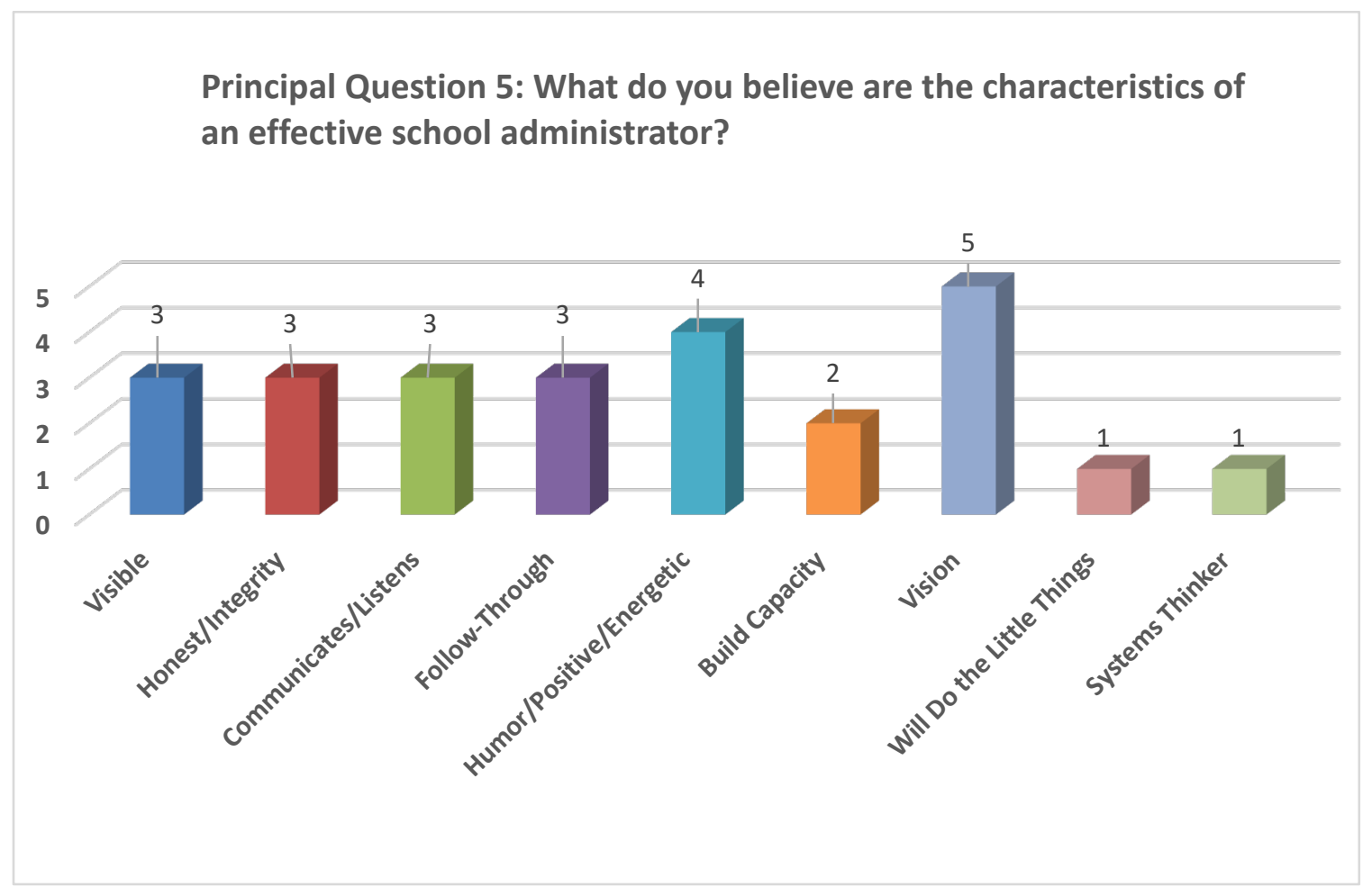

Figure 7. Summary of collective principal responses to Question 5. The number of principals indicating the above factors as characteristics of an effective school administrator.

The major research question in this study surrounds the relationship between contextual variables and the ability of school leaders to reduce educational disparities in their schools, and to improve educational outcomes for all students. Principal Question 6 asked the participants to identify what level of autonomy they had as school leaders, "To what extent do you have the authority to do what is necessary to ensure that your school meets the expectations for student achievement and improving graduation rates?" Every 
respondent felt that they had the appropriate and necessary level of authority as a building leader to improve student outcomes (see Figure 8 for a visual representation of these data).

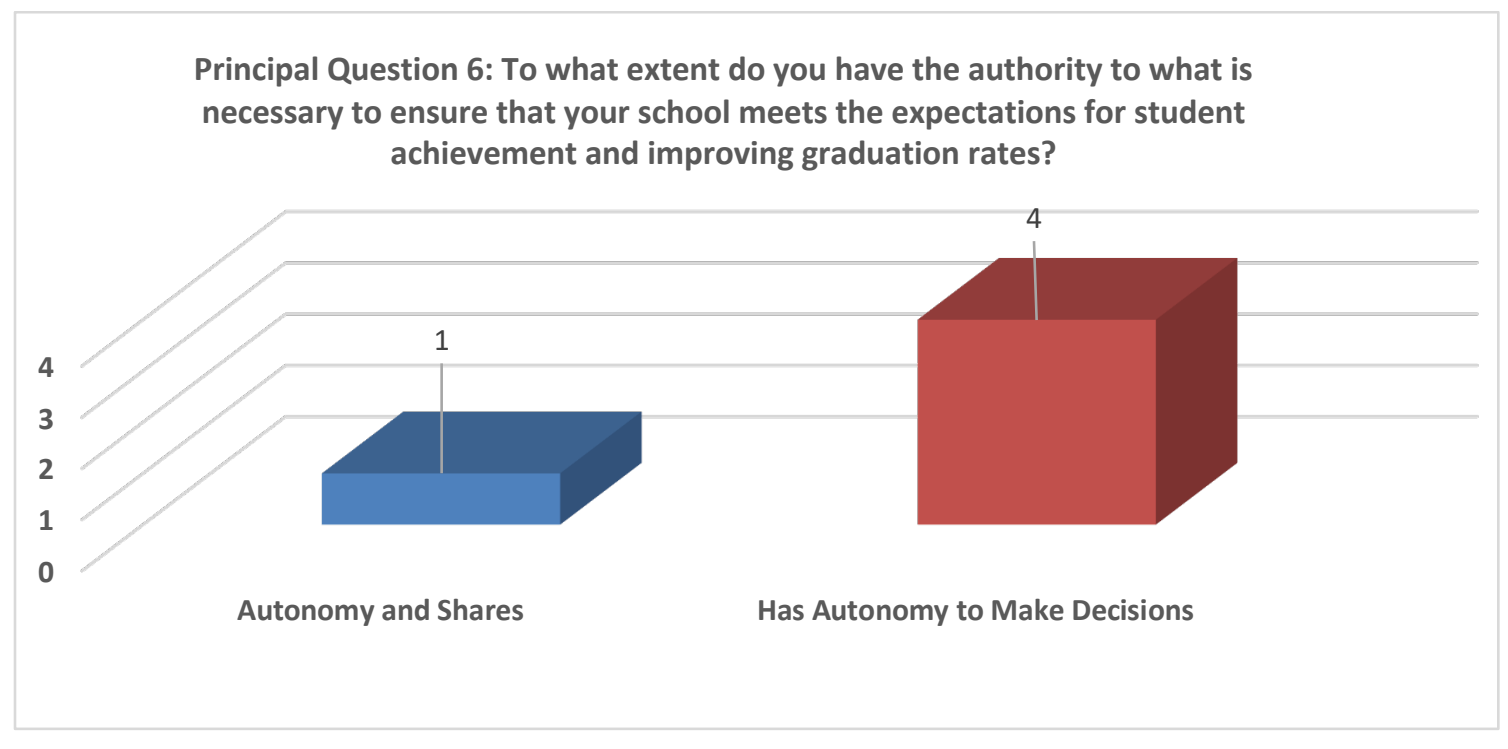

Figure 8. Summary of collective principal responses to Question 6. The number of principals describing their level of authority and autonomy in decision making with respect to ensuring their school meets the expectations for student achievement and graduation rates.

The last question in the survey provided respondents an open-ended opportunity to provide any last-minute reflections or to emphasize previous statements around any factors that individually impacted them in their position as a school administrator working to reduce educational disparities. The responses they provided were extremely similar to those that they provided as a collective group, specifically Question 5, which asks for the "Characteristics of an effective school administrator." In the total of all responses, only two were new and had not been previously submitted for any question. The first was that experience or longevity in a building was a contributing factor to 
success to more than one building administrator. The second was that having good teachers and the ability to hire excellent teachers was imperative to success as well. These two new categories equaled "Belief in Students" in receiving the most responses from the collective principal participants (see Figure 9 for a visual representation of these data).

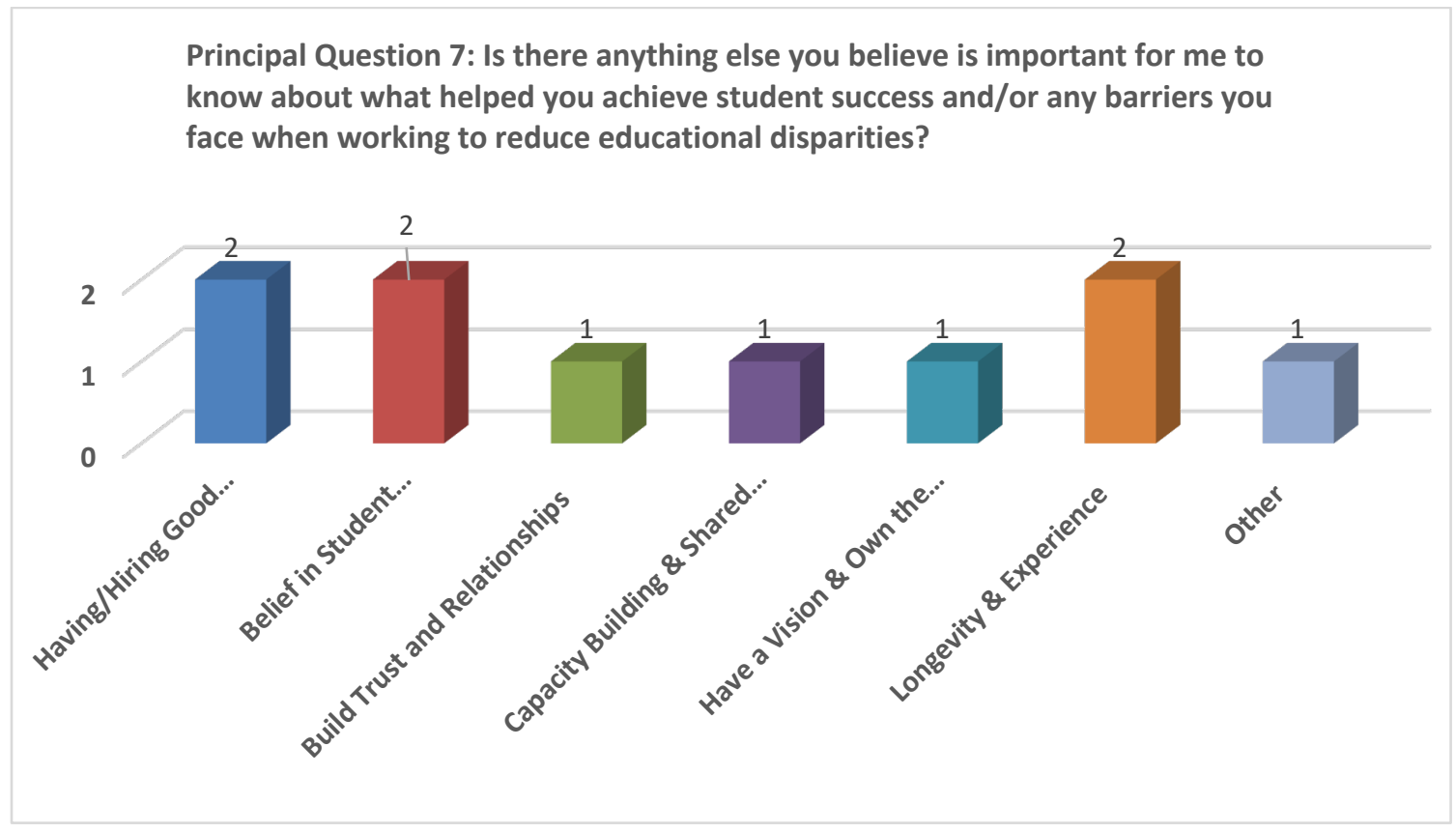

Figure 9. Summary of collective principal responses to Question 7. The number of principals describing additional factors they deemed important in ensuring their school improve student success and reduce educational disparities.

Collective teacher responses per school (A-E) per question (1-7). The set of collective responses from the teacher participants to Question 1 indicates that according to the respondents, there are three distinct attributes that have the strongest effect on improving graduation rates and reducing the achievement gap: academic interventions, student relationships, and effective school-wide systems (see Figure 10). These factors 
were clearly more significant to teachers than other variables such as clean data, activities, and resources. There were two other items that stood out in the data collection. The first is that, although not among the top three responses, school administration was identified multiple times by teacher respondents as important to school success. Second, there were two responses indicating that school success was achieved as a result of lowered student and teacher expectations. A breakdown of the individual building data may provide more insight to these items.

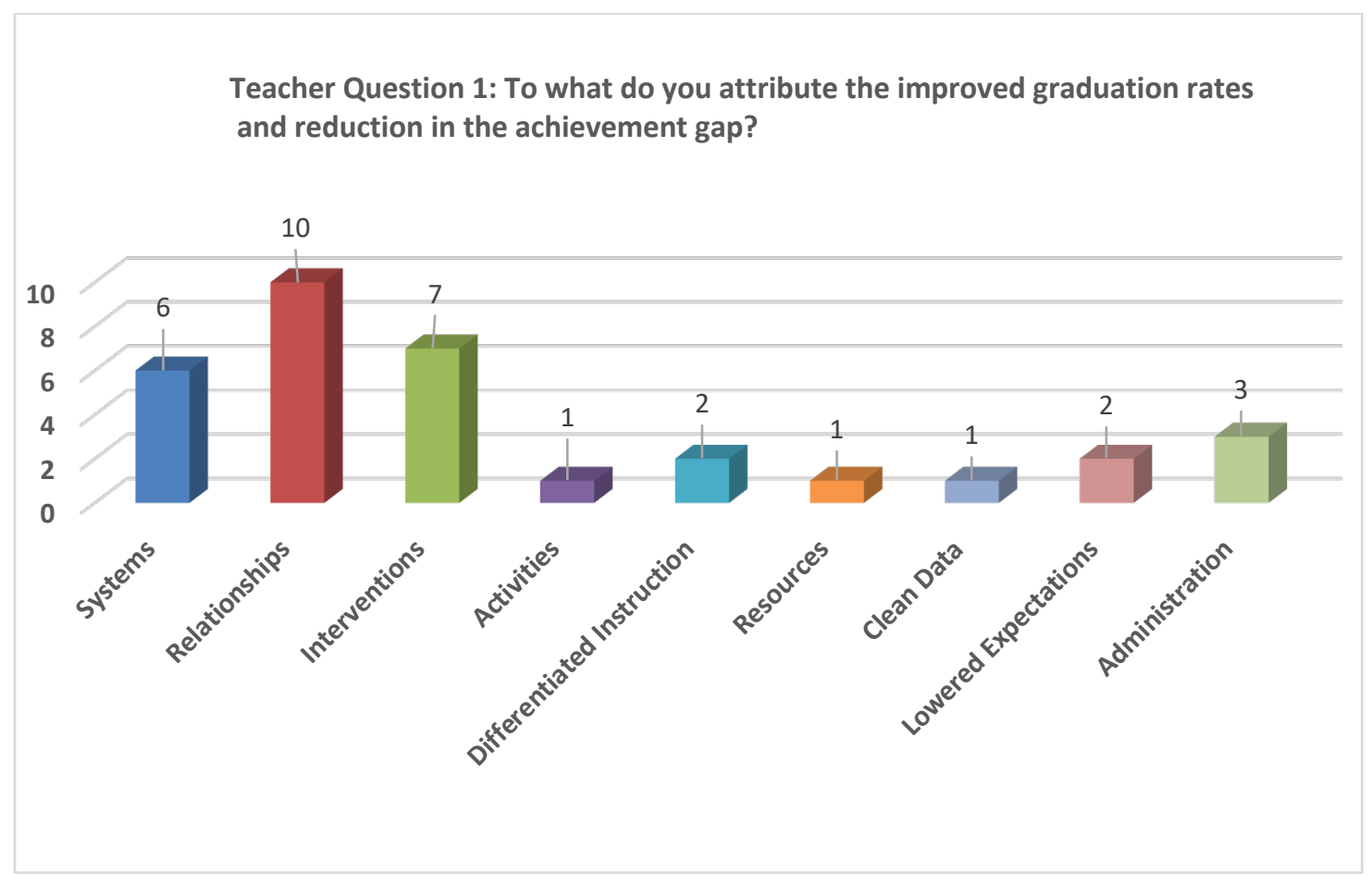

Figure 10. Summary of collective teacher responses from Buildings A-E to Question 1. The number of teachers attributing the above factors to improving student achievement.

The responses from the teacher participants as a group to Question 2 identified student demographics and poverty, by more than twice the next response, to be the biggest barrier to improving student achievement at their schools. The next set of factors 
identified as barriers, although to a lesser extent, was clustered into a group containing: student attendance, a lack of connections and commitment from the community, and school resources (see Figure 11). It is likely that these variables are all correlated with one another. Though not the only variable at play, poverty may create more strain on the student, teacher, and school, negatively impacting attendance, and minimizing resources. Lack of community connections may be a mirror to the lack of networks and supports at home available to continue the education of students outside of the school setting.

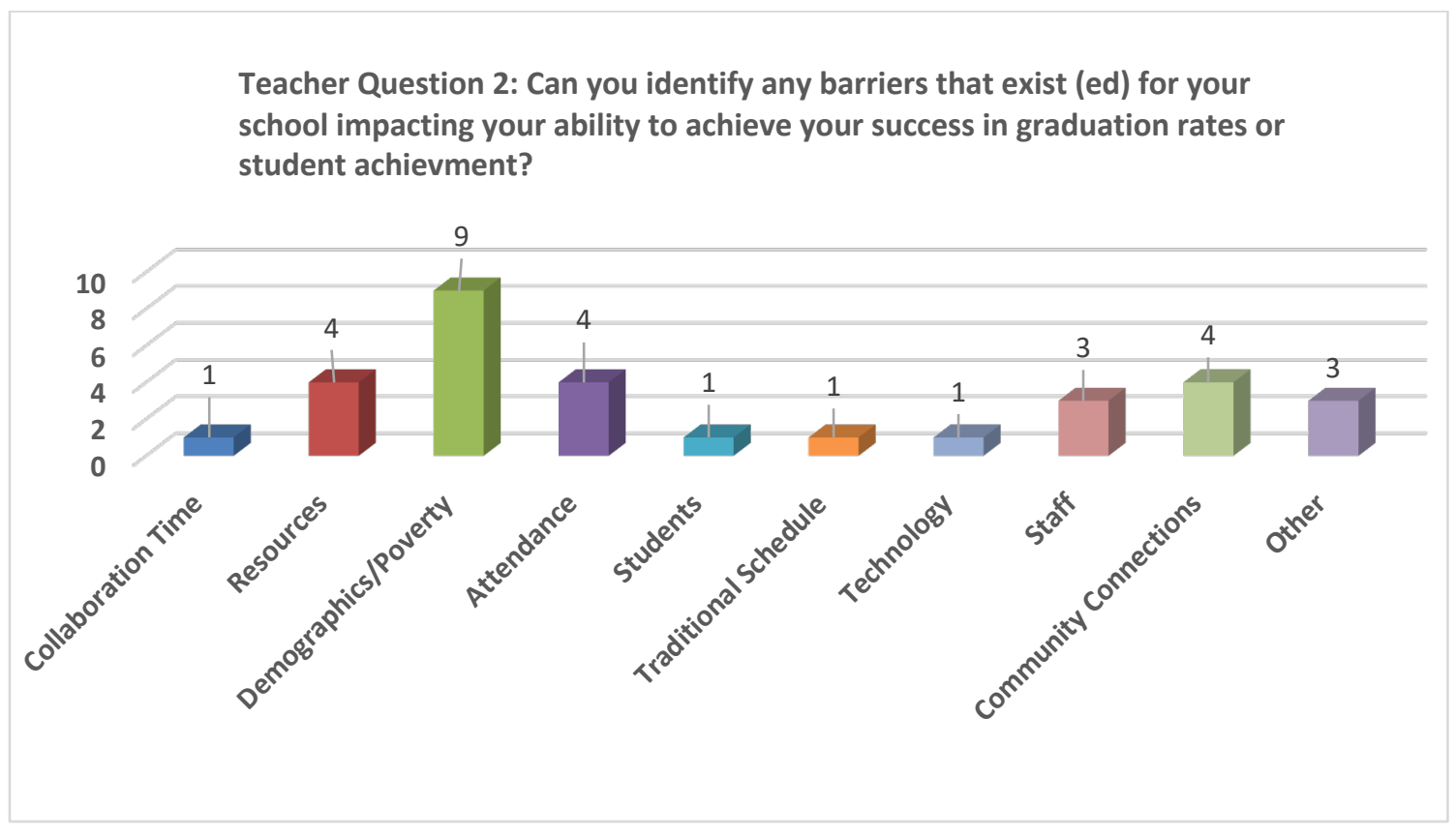

Figure 11. Summary of collective teacher responses from Buildings A-E to Question 2. The number of teachers identifying the above factors as barriers to student achievement.

Relationship building and afterschool interventions ranked among the highest sited strategies used by teachers to overcome barriers to student achievement in their schools. While a wide variety of strategies were being employed, from afterschool activities, changes in instructional practices, and modified expectations, afterschool 
intervention programs were felt to have the greatest impact on shifting student achievement. The large number of responses across a number of different categorical areas suggests that strategies may be dependent upon variables specific to the individual schools. These factors may include specific demographics, limited availability of afterschool activities or athletics, location and socio-economic status. However, it is significant, regardless of those factors, three areas gathered the majority of the responses (see Figure 12).

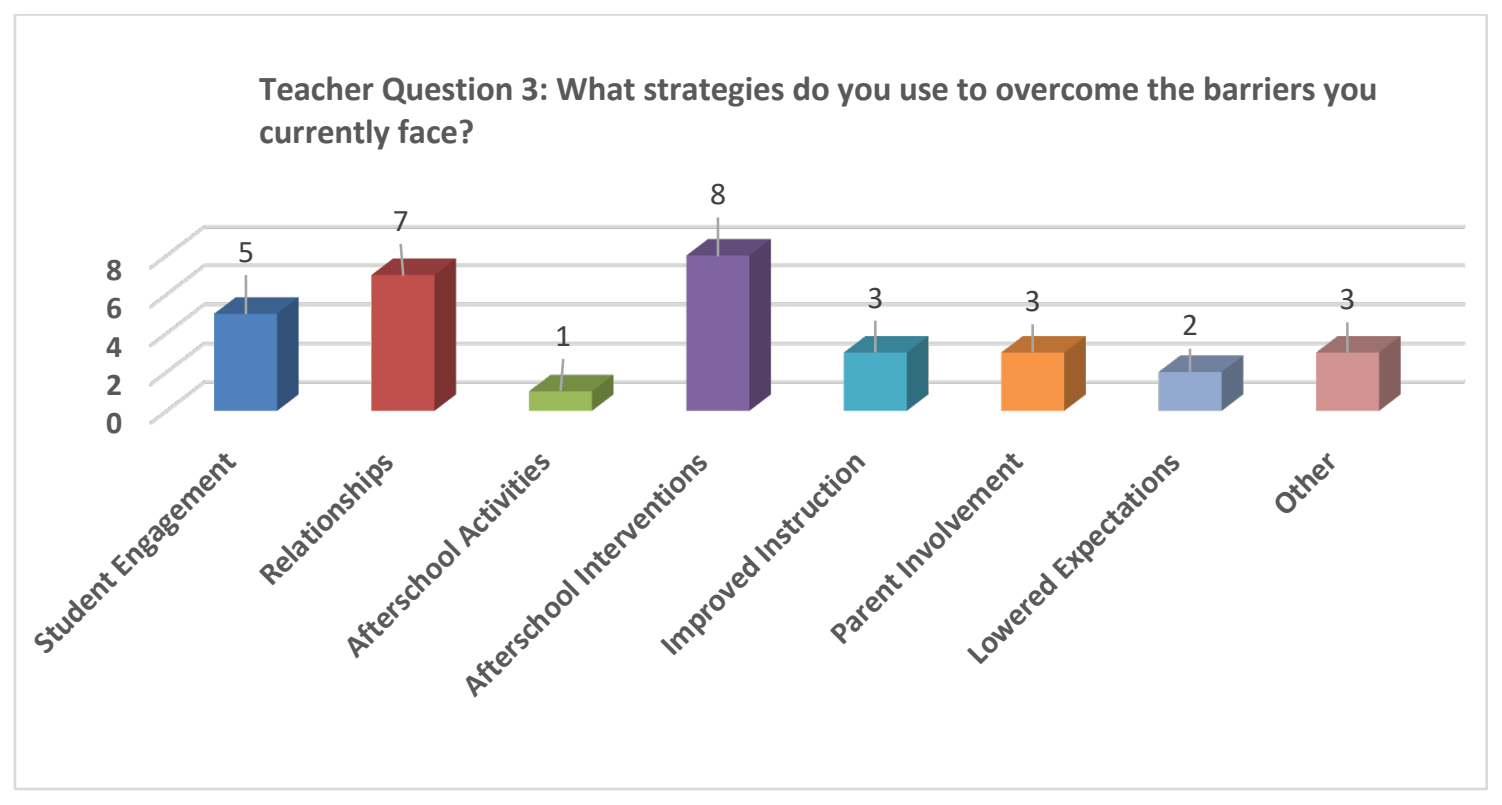

Figure 12. Summary of collective teacher responses from Buildings A-E to Question 3. The number of teachers identifying the following strategies used to overcome barriers to student achievement.

The participant responses to Question 4 (see Figure 13) confirm the importance of relationships in schools as most teachers from these model programs described their school culture as one that was "relationship oriented." While 39\% of teachers described their schools as relationship oriented, $26 \%$ also described their school's climate as open, 
diverse, and accepting of others. This open environment would likely contribute to the opportunity for students and staff to create positive relationships with one another.

Interestingly, teachers had mixed views with respect to school culture and administrative support. While just $22 \%$ of the respondents described their school's leadership as supportive, the same number of teachers found that district level administration was less connected and less supportive of their needs in schools. This may represent a disconnect that exists in the relationship and communication between administration and leadership at the building and district levels. Finally, while poverty was a major factor sited as a barrier to achievement in Teacher Question 2 (Figure 11), it did not seem to have a significant impact on collective teacher perception of culture at their schools.

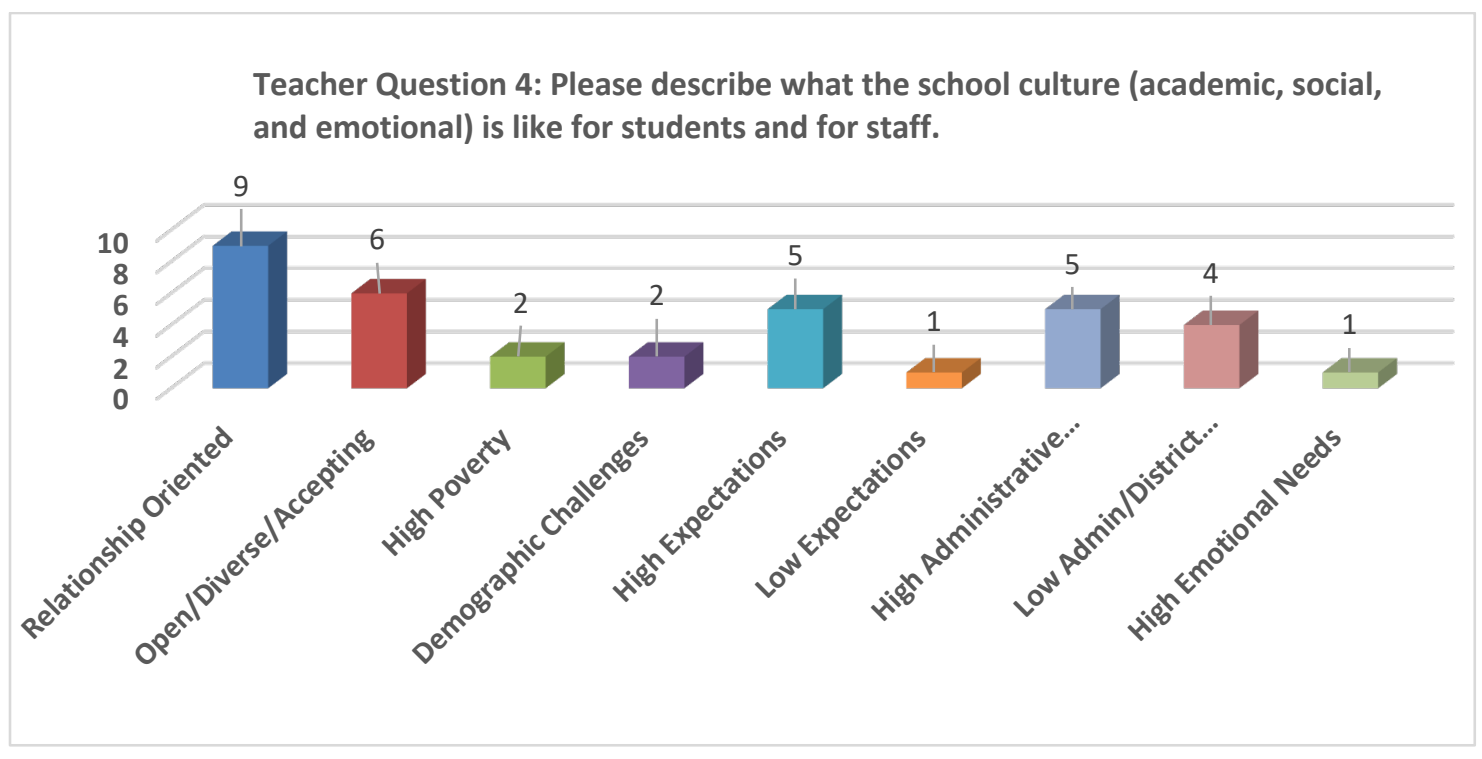

Figure 13. Summary of collective teacher responses from Buildings A-E to Question 4. The number of teachers indicating the following characteristics as being descriptive of their school culture. 
When asked about what characteristics were most important in an effective school administrator, four behaviors were identified by the respondents: administrators who valued and built capacity in their staff, accepted feedback, demonstrated decisiveness in decision-making, and who believed in and was able to build school culture. Although there were some responses that represented requests for a school administrator that was positive, a communicator and consistent, these characteristics were not identified as significant or desirable factors compared to the overall values demonstrated in the reflections of the teacher-leader participant group. The fact that these characteristics are the most preferred to a group of teacher leaders may suggest that in a building with a strong school culture, a decisive school administrator who accepts and values their feedback and supports their ability to grow, a combination of those variables provides enough space for teachers to help students enough to achieve the desired change outcomes (see Figure 14).

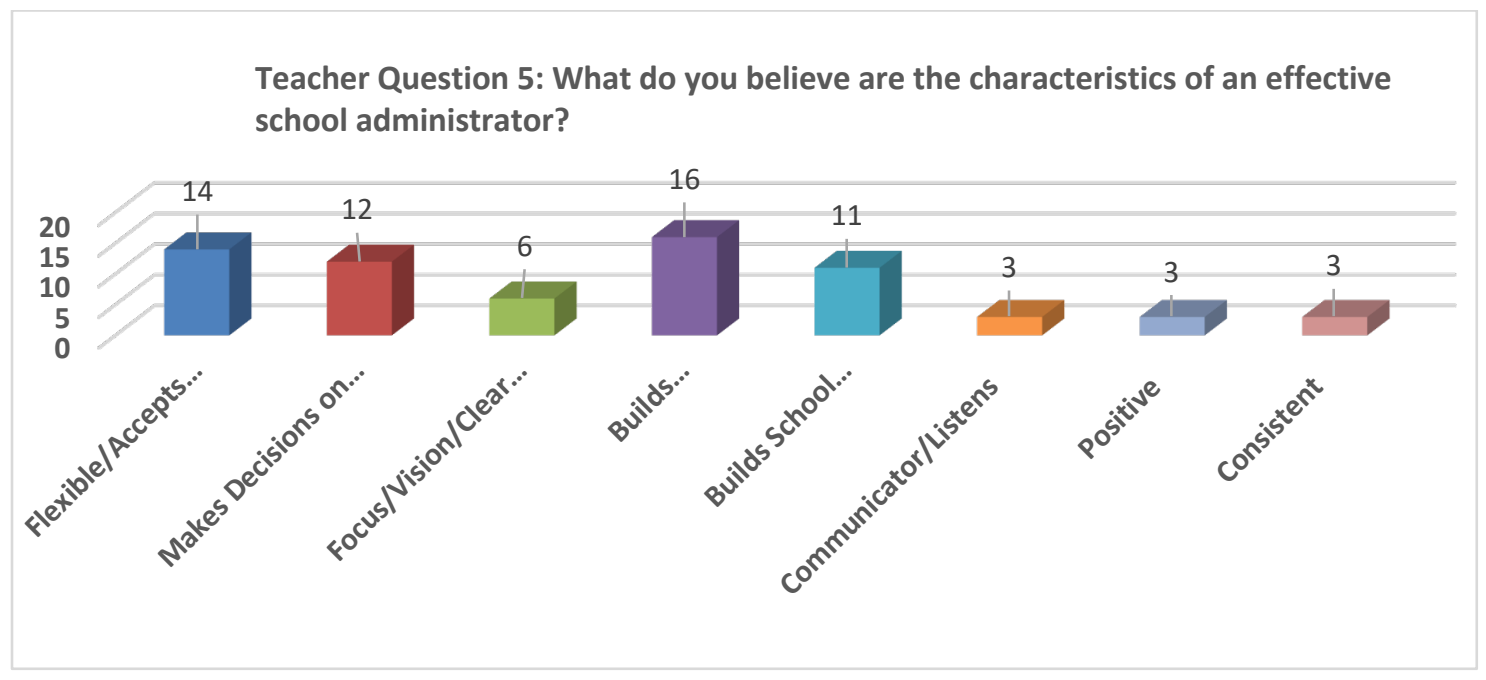

Figure 14. Summary of collective teacher responses from Buildings A-E to Question 5. The number of teachers indicating the following characteristics as being descriptive of an effective school administrator. 
The responses from the teacher participants to Question 6 are extremely important in helping discern the difference between the reported level of autonomy and authority they perceive their school administrator has to make decisions to ensure student achievement expectations from the actual levels reported by the administrators themselves (see Figure 15). The responses included everything from no autonomy, "their principal's hands were tied by the district," to completely autonomous in their ability to make decisions and the authority to execute them. The variability of these responses may indicate a lack of understanding or misconception by teacher participants of the system level variables at work in designing and implementing large-scale changes in school culture and student achievement interventions, the school and district administrative relationship, the socio-political context, or maybe all three.

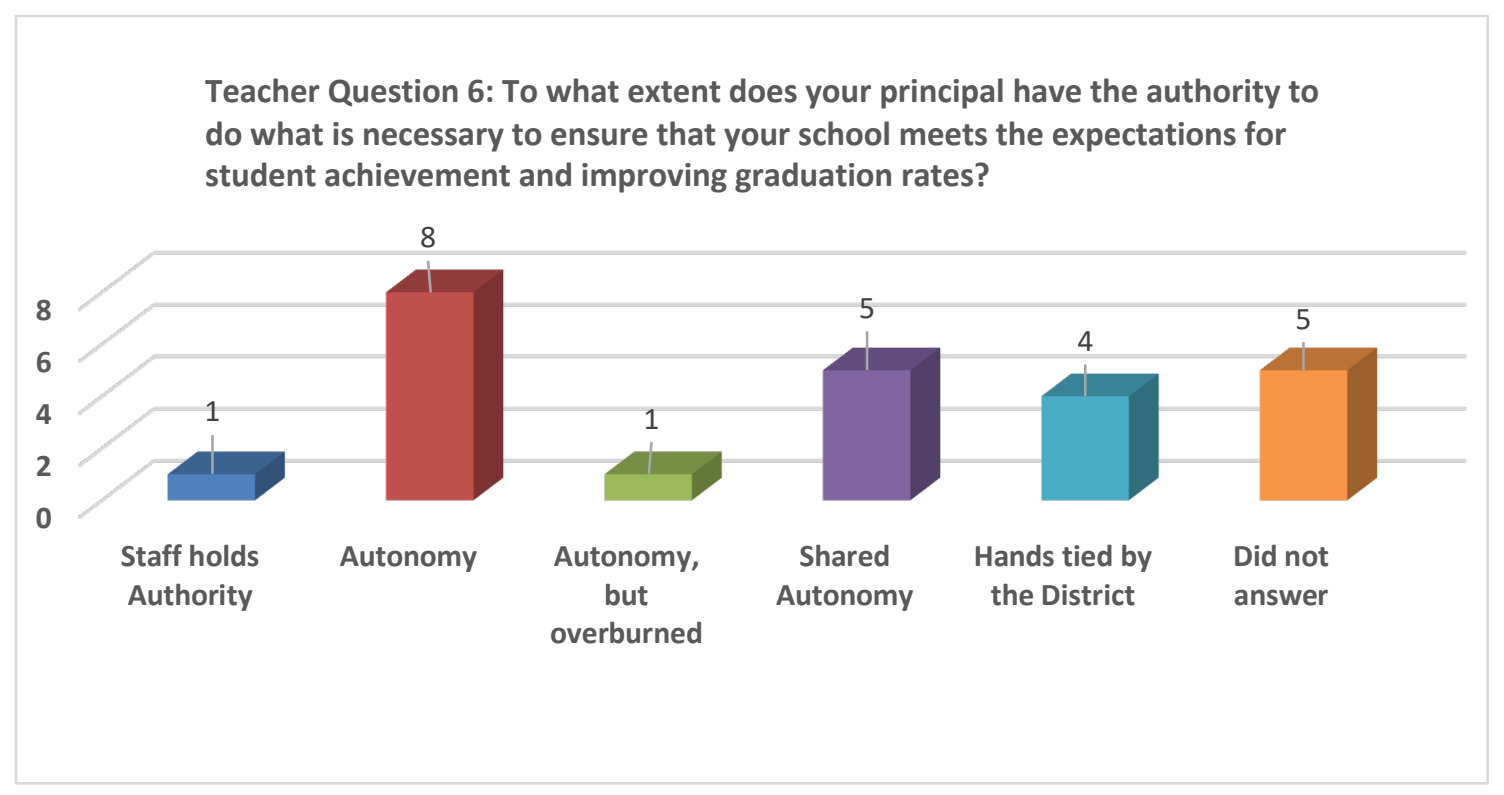

Figure 15. Summary of collective teacher responses from Buildings A-E to Question 6. The number of teachers indicating the level of perceived authority and autonomy in their principal's decision making with respect to ensuring their school meets the expectations for student achievement and graduation rates. 
Question 7 reciprocated the open-ended opportunity to provide any last-minute reflections or statements the teacher participants believed were attributes of their school administrator that helped, or barriers that prevented, work toward reducing educational disparities. There were four that represented the majority of the responses. Among the top four categorical responses were; building a strong team, belief in student success, having/hiring high quality teachers, and "other factors." Five teachers did not respond to the question nor had nothing additional to add to their previous survey responses. Of the top categories of teacher responses for Question 7 (see Figure 16), three were similar to the previously identified qualities of an effective school administrator: values staff and team, is flexible/shares authority, and a belief in students. Four teacher participants indicated that having good teachers and the ability to remove poor ones was a significant factor in achieving successful outcomes, as shown in Figure 16. Multiple responses in this category indicate that teacher leaders have high expectations for their colleagues and expect a school administrator to do the same. The fifth area that represented the most responses was the number of participants that chose not to respond to the question. 


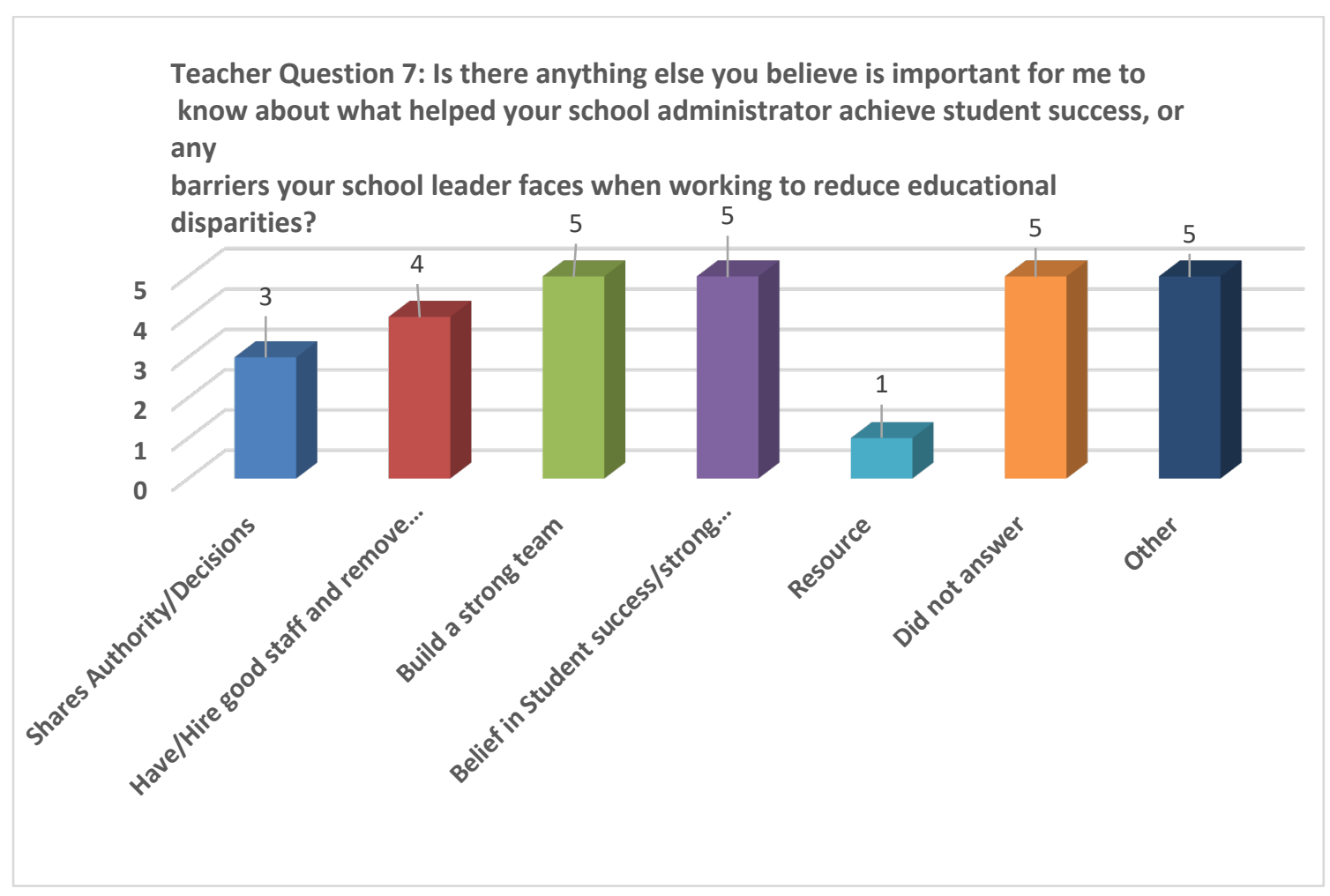

Figure 16. Summary of collective teacher responses from Buildings A-E to Question 7. The number of teachers describing additional factors they deemed important in ensuring their school improve student success and reduce educational disparities.

Building A: Individual teacher responses questions (1-7). A review of the individual teacher responses specific to Building A revealed a distinct lack of cohesiveness or agreement among what actual factors played a role in improving student achievement and graduation rate. Participants were unclear of how much authority the building principal had in making decisions and struggled to identify what strategies the principal used to overcome any perceived barriers to improvement. There was also clear division on how the culture of the school was identified, with a little more than half of the responses describing it as having a student body with significant needs, and others as a place of acceptance built on relationships. Similarly, less than half of the participants 
even chose to respond to the final open-ended question offering the opportunity to provide any feedback on principal leadership.

The teacher participant group in Building A did have a strong collective response for two of the seven research questions. The first is that in order to be an effective school administrator, the administrator needs to be both flexible and willing to accept criticism. The second is that according to the participants in Building A, the two greatest barriers that exist against school improvement are poverty and lack of connections and commitment from the community, both variables that would be considered external to the school. Figures 17-23 show teacher responses to the survey questions.

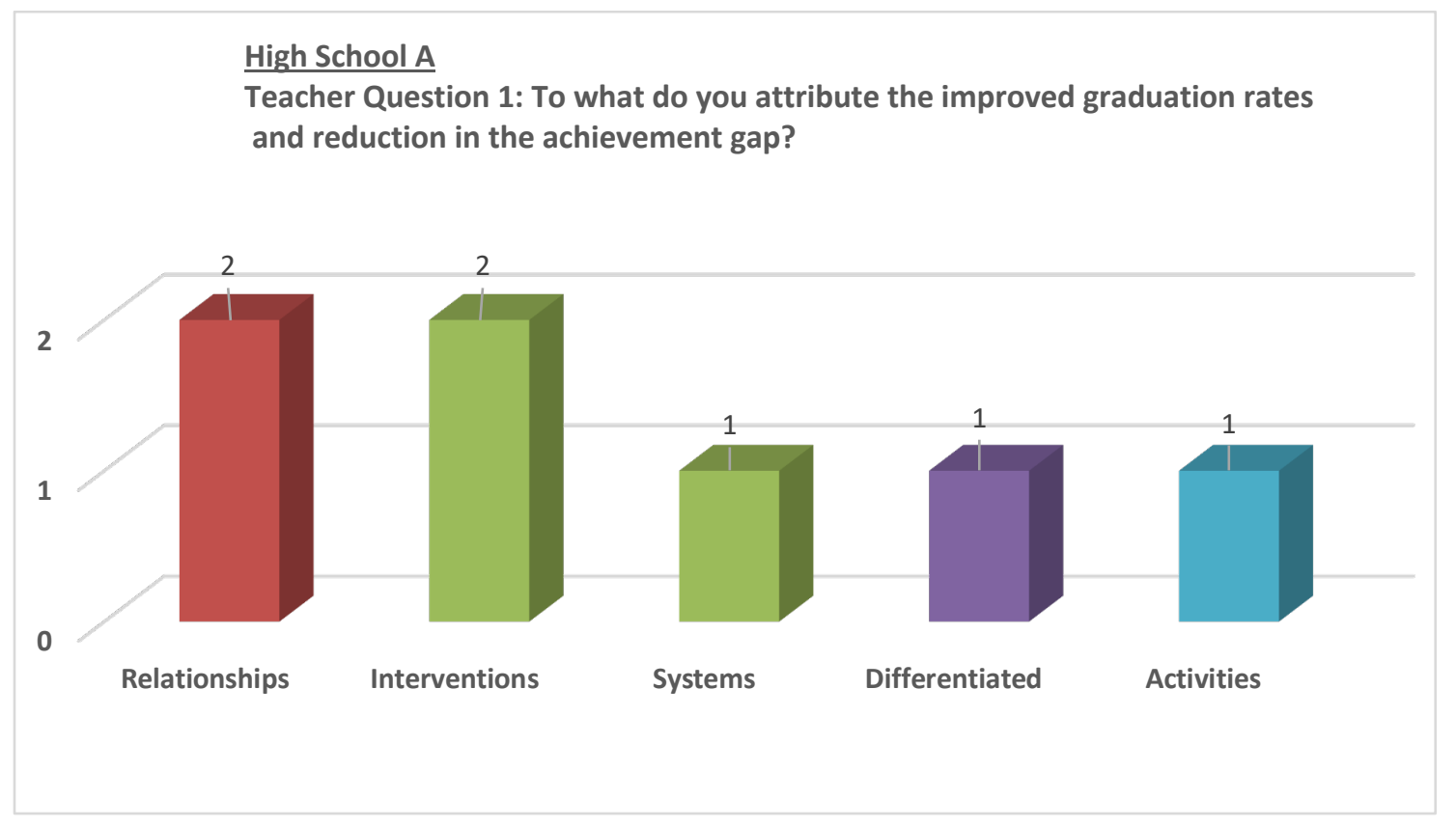

Figure 17. Summary of teacher responses from Building A to Question 1. The number of teachers attributing the above factors to improving student achievement. 


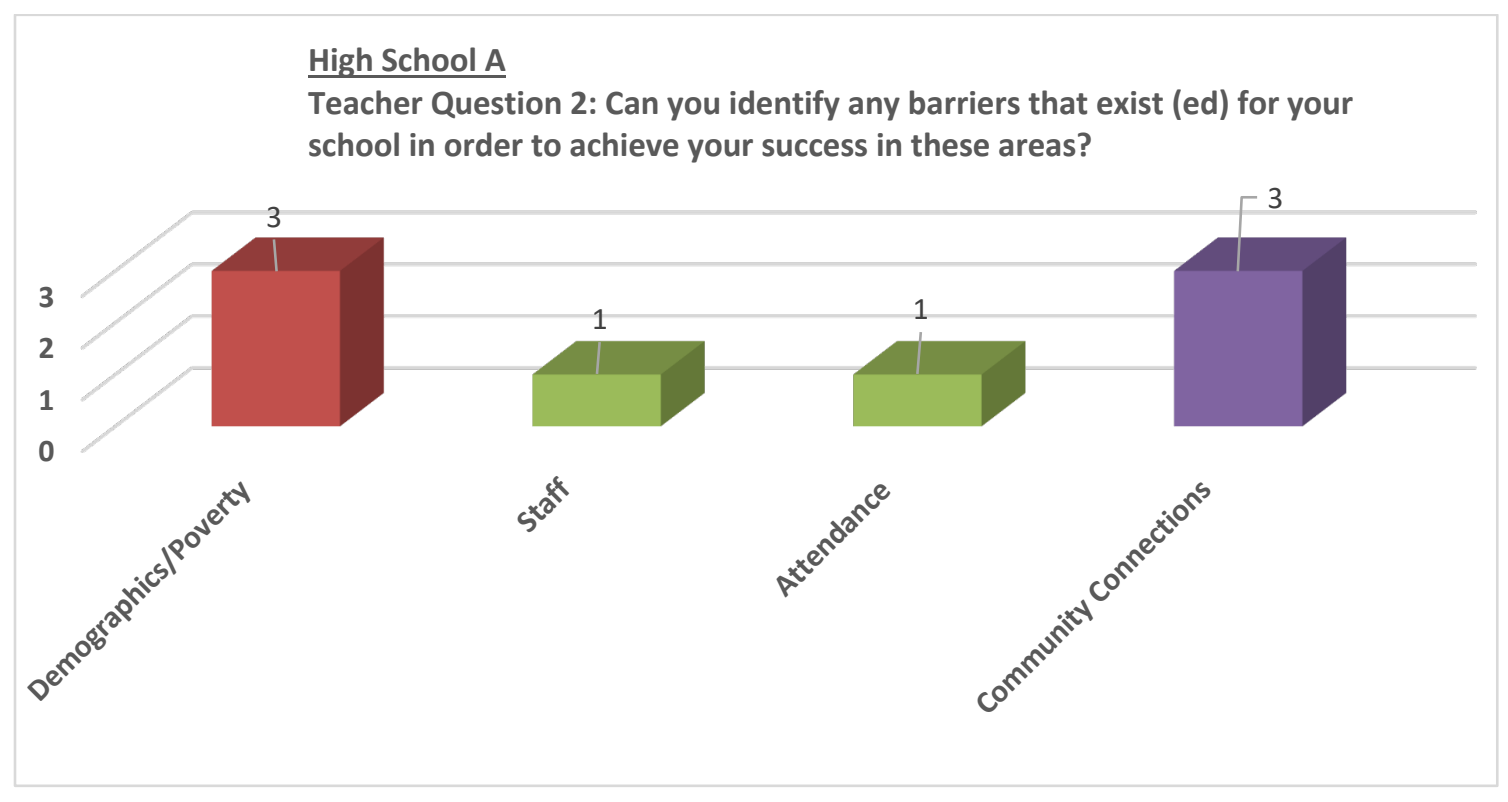

Figure 18. Summary of collective teacher responses from Building A to Question 2. The number of teachers identifying the above factors as barriers to student achievement.

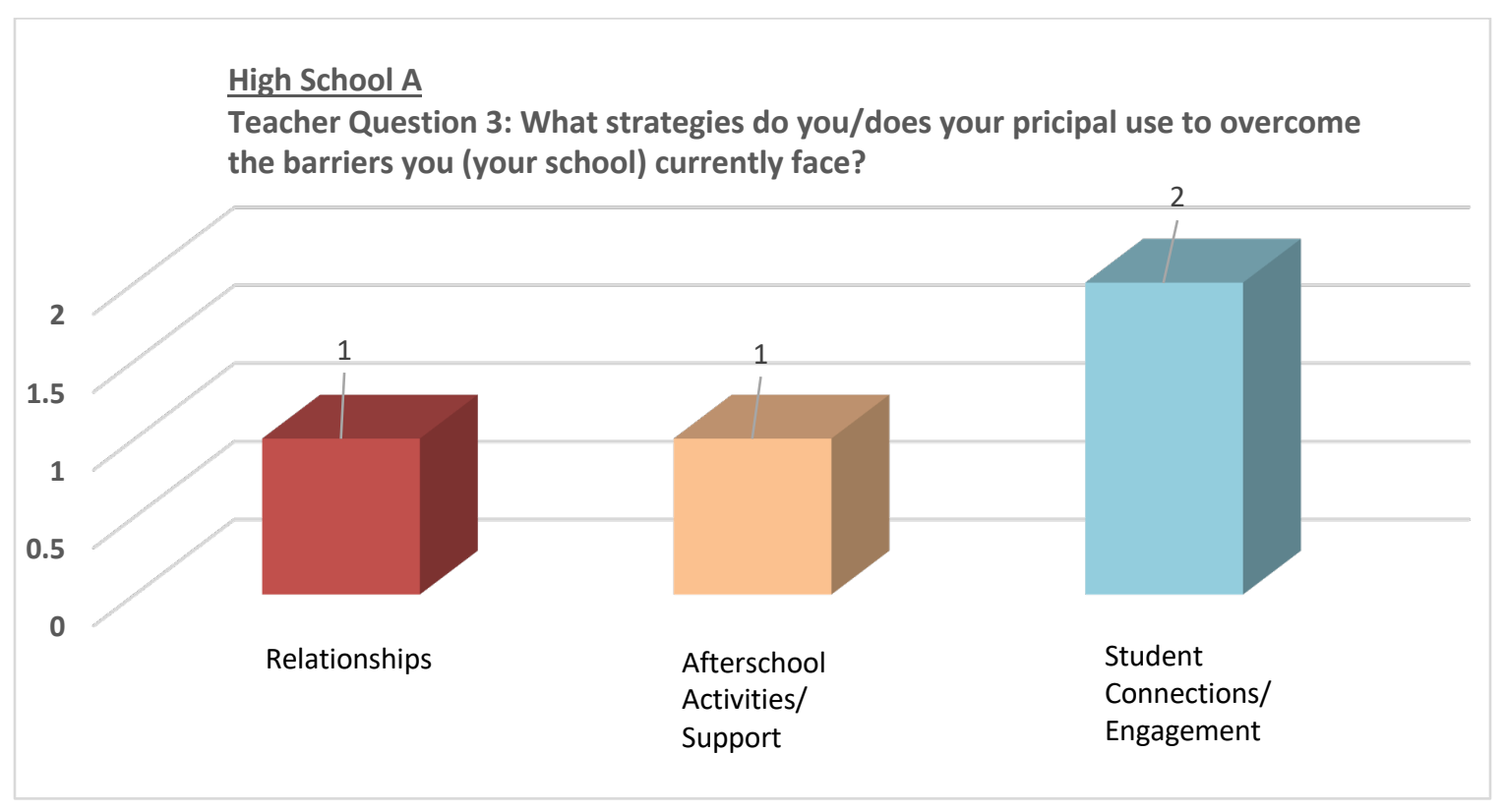

Figure 19. Summary of collective teacher responses from Building A to Question 3. The number of teachers identifying the following strategies used to overcome barriers to student achievement. 


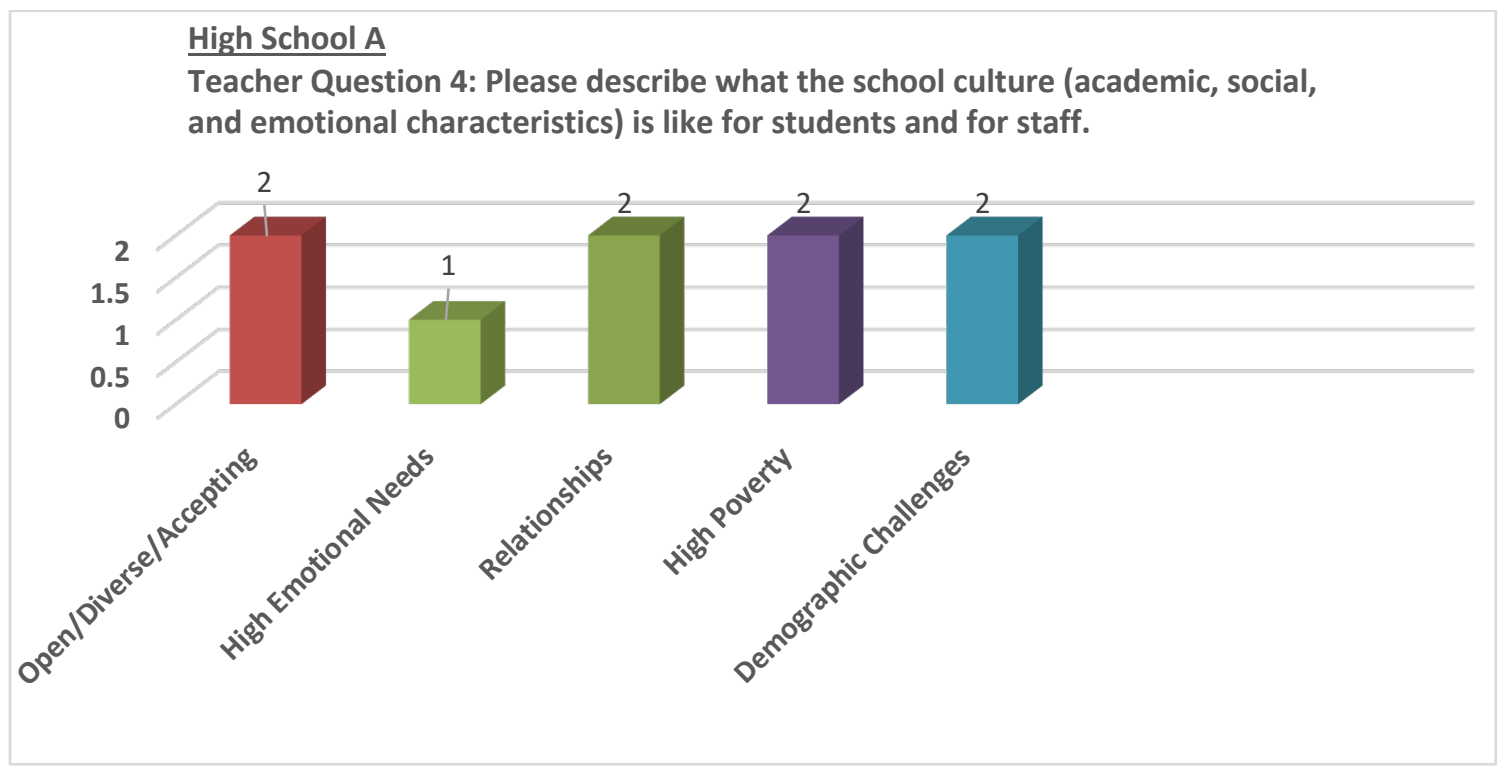

Figure 20. Summary of collective teacher responses from Building A to Question 4. The number of teachers indicating the following characteristics as being descriptive of their school culture.

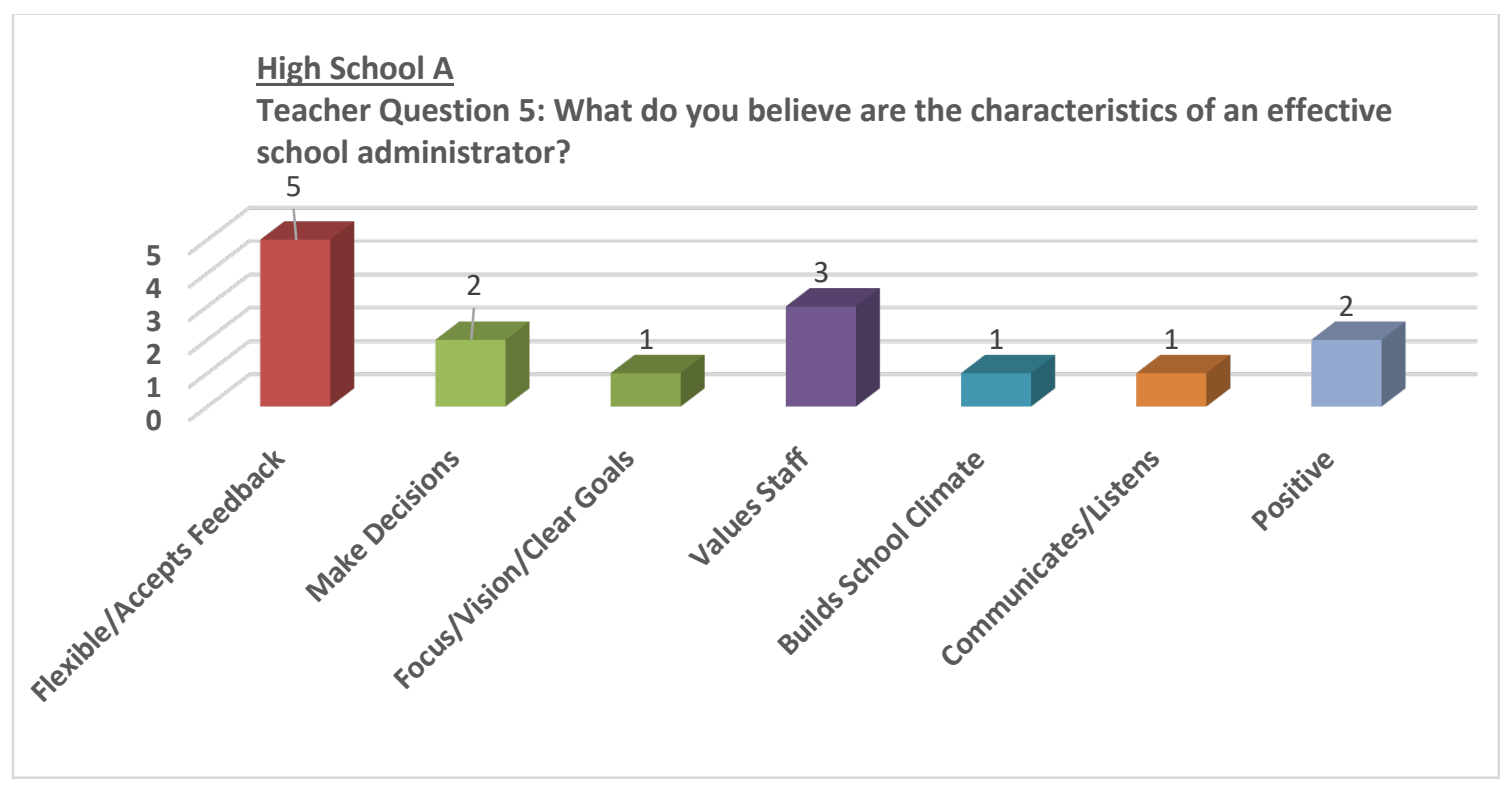

Figure 21. Summary of collective teacher responses from Building A to Question 5. The number of teachers indicating the following characteristics as being descriptive of an effective school administrator. 


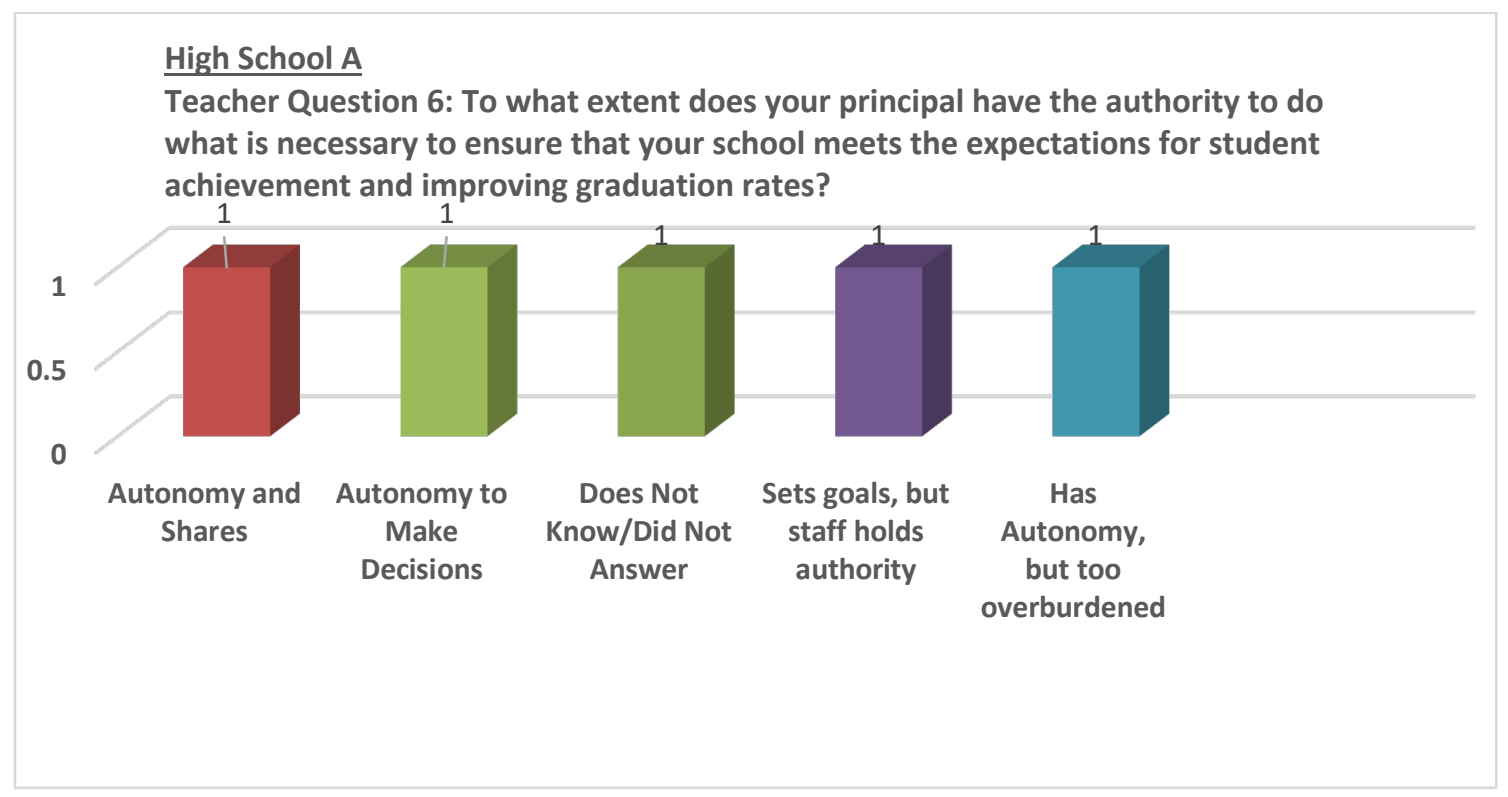

Figure 22. Summary of collective teacher responses from Building A to Question 6. The number of teachers indicating the level of perceived authority and autonomy in their principal's decision making with respect to ensuring their school meets the expectations for student achievement and graduation rates.

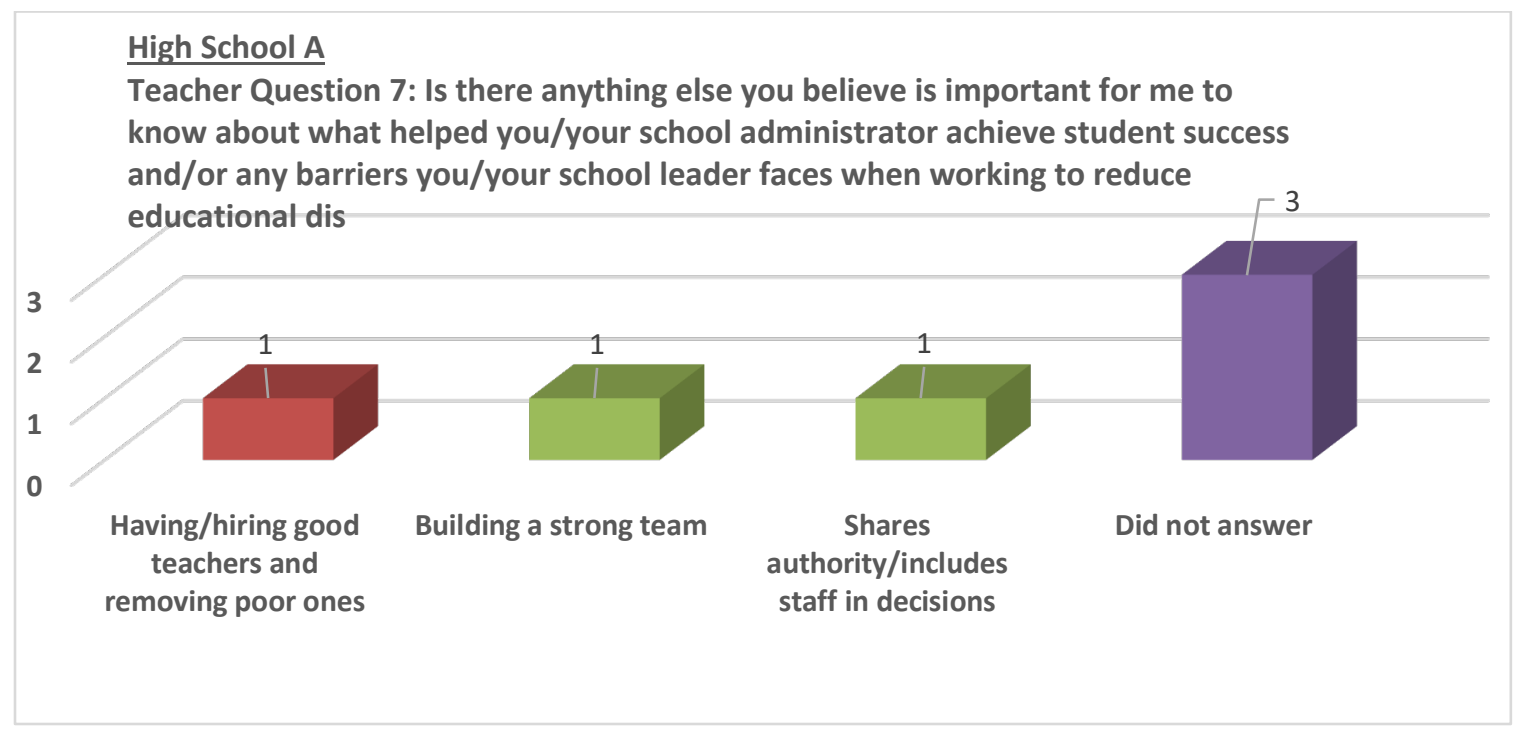

Figure 23. Summary of collective teacher responses from Building A to Question 7. The number of teachers describing additional factors they deemed important in ensuring their school improve student success and reduce educational disparities. 
Building B: Individual teacher responses questions (1-7). Overall, the responses from the teacher participant group from Building B broke into the distinct concepts. The first was their strong collective belief that the greatest barrier existing in their efforts toward school improvement is poverty. Attendance and resources were also identified, all external variables, and largely student dependent. Second, the responses to questions one, three and seven indicate that they are aware as to what strategies are in place and that are having a positive impact in the building. Finally, over the next three questions, the five teacher participants produced between four and seven responses for each category. The respondents could not agree on what the school culture, the characteristics of an effective administrator or what level of authority their own principal had in the building. See Figures 24-30 for teacher responses in Building B.

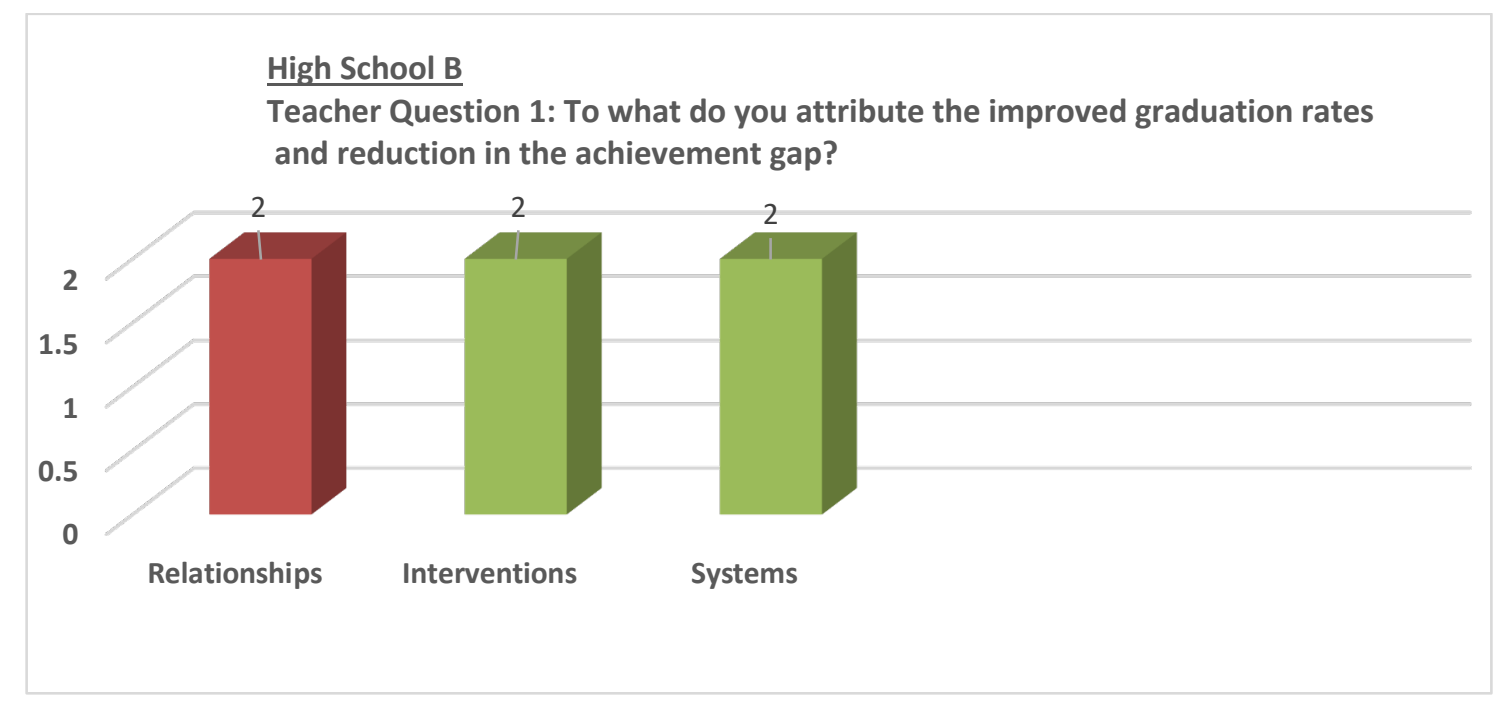

Figure 24. Summary of collective teacher responses from Building B to Question 1. The number of teachers attributing the above factors to improving student achievement. 


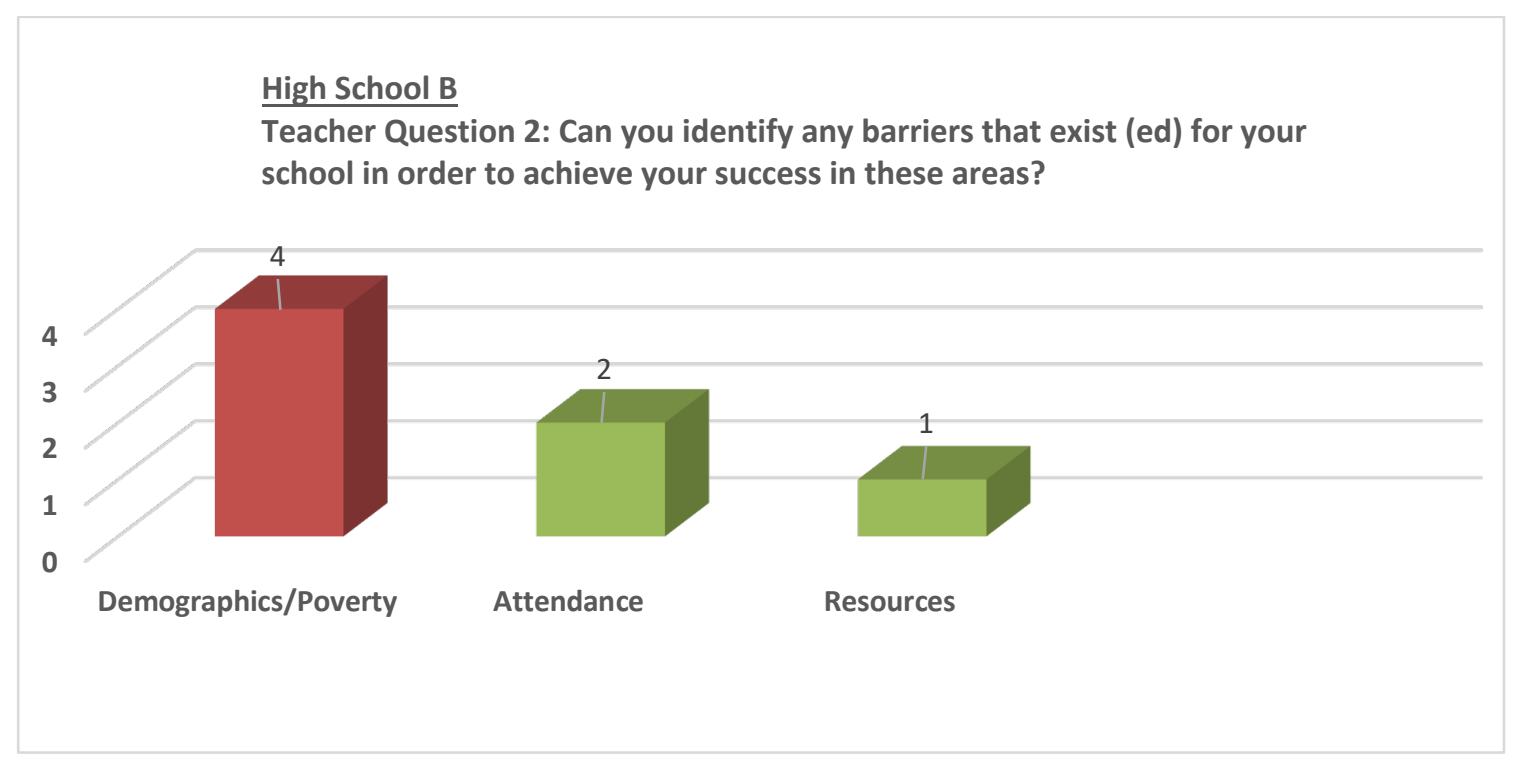

Figure 25. Summary of collective teacher responses from Building B to Question 2. The number of teachers identifying the above factors as barriers to student achievement.

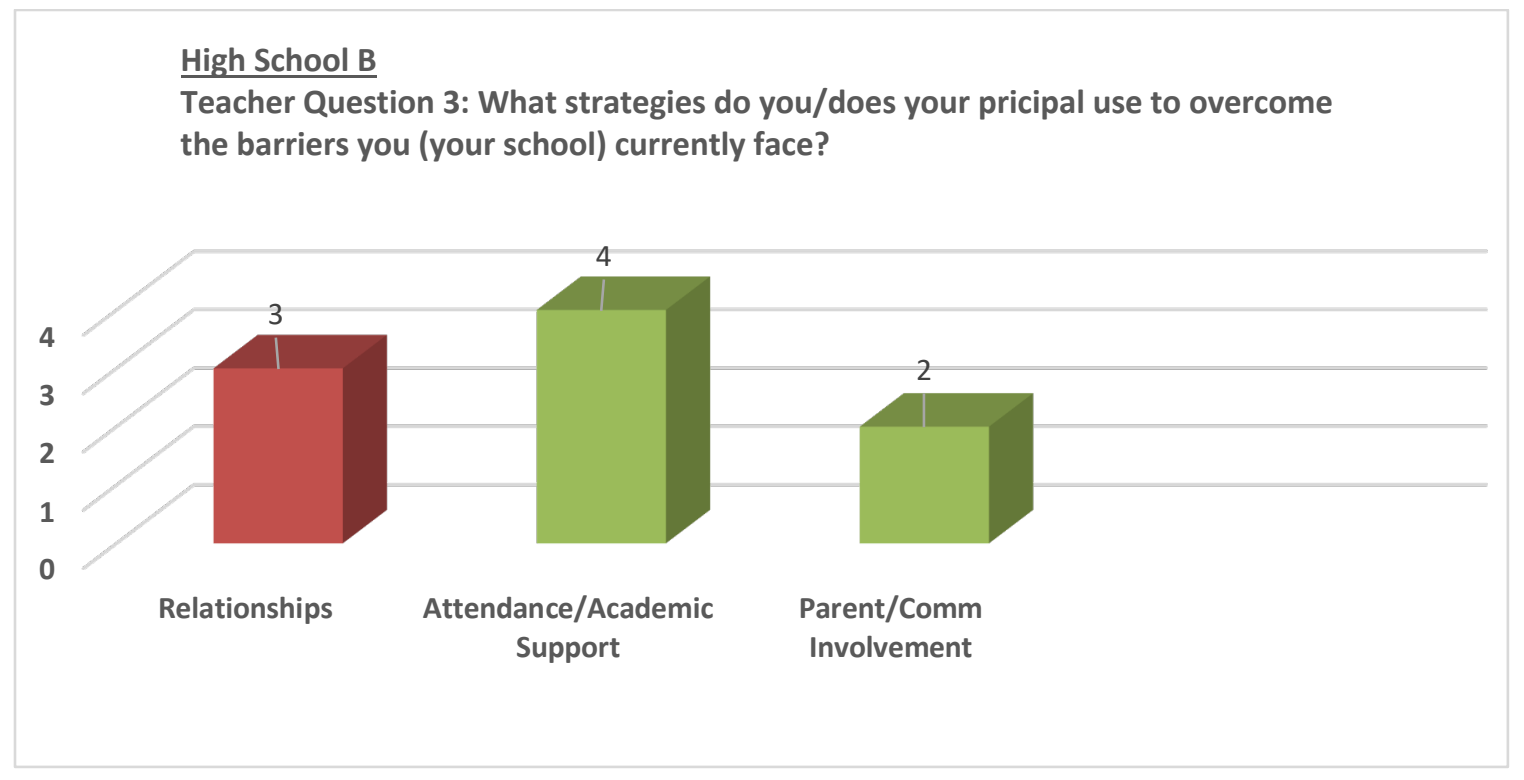

Figure 26. Summary of collective teacher responses from Building B to Question 3. The number of teachers identifying the above strategies used to overcome barriers to student achievement. 


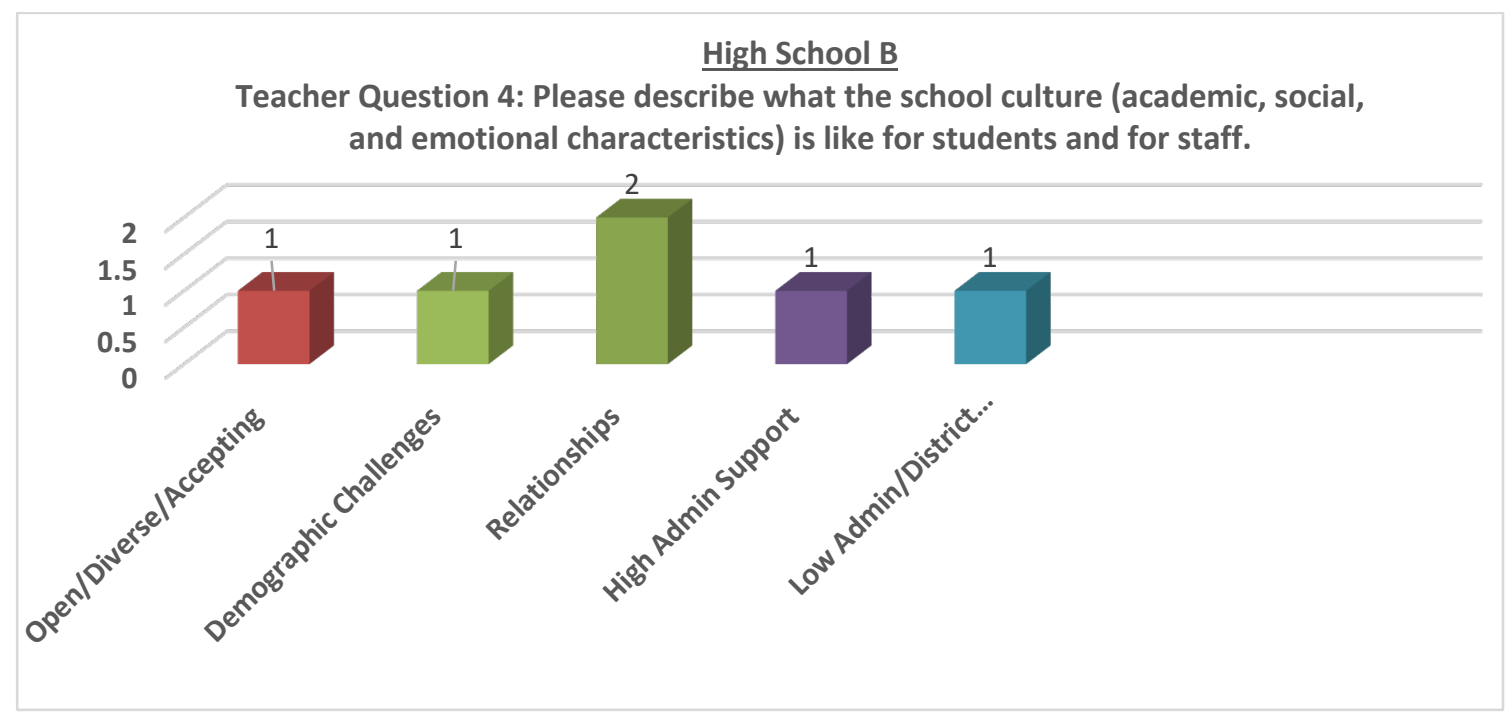

Figure 27. Summary of collective teacher responses from Building B to Question 4. The number of teachers indicating the following characteristics as being descriptive of their school culture.

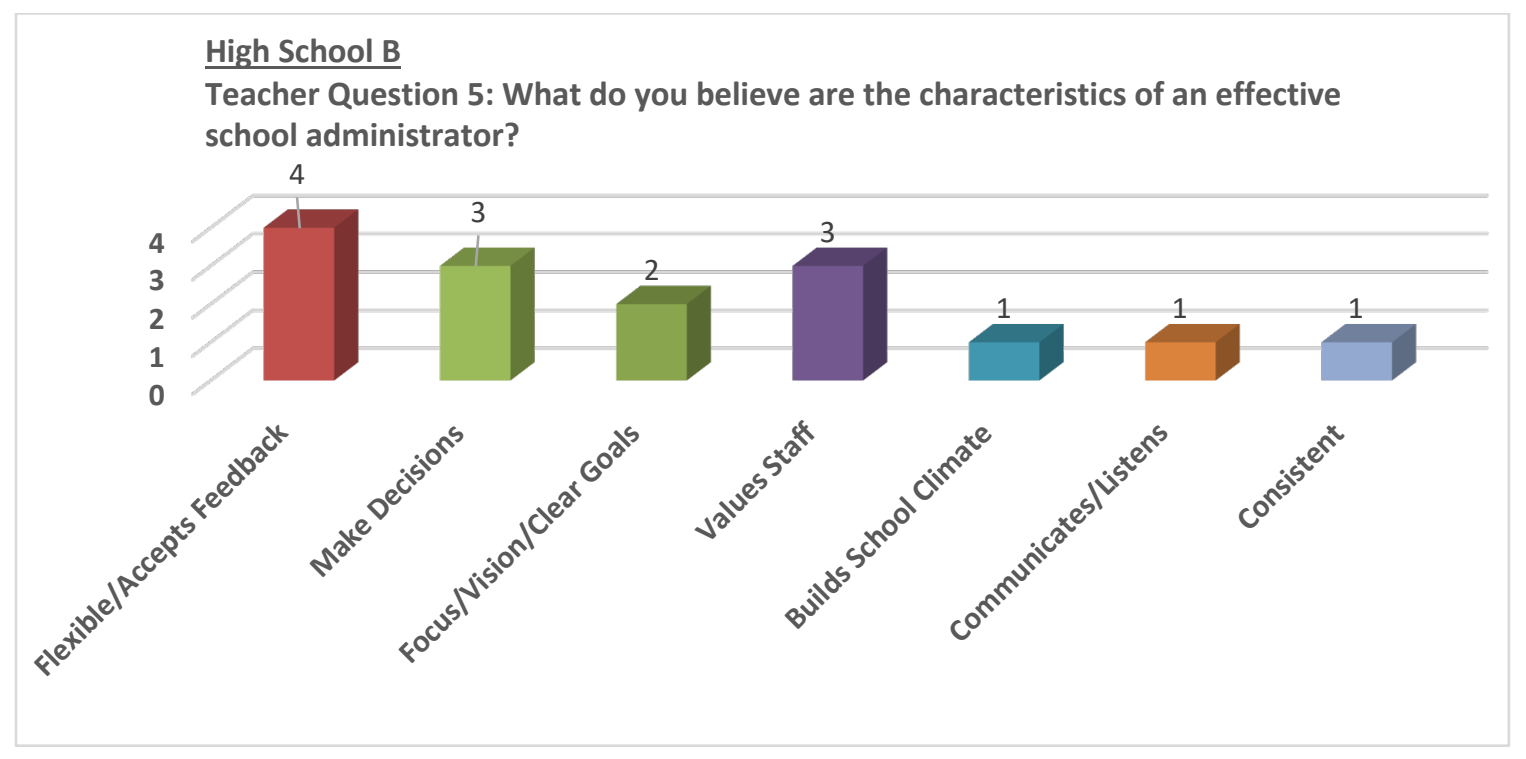

Figure 28. Summary of collective teacher responses from Building B to Question 5. The number of teachers indicating the following characteristics as being descriptive of an effective school administrator. 


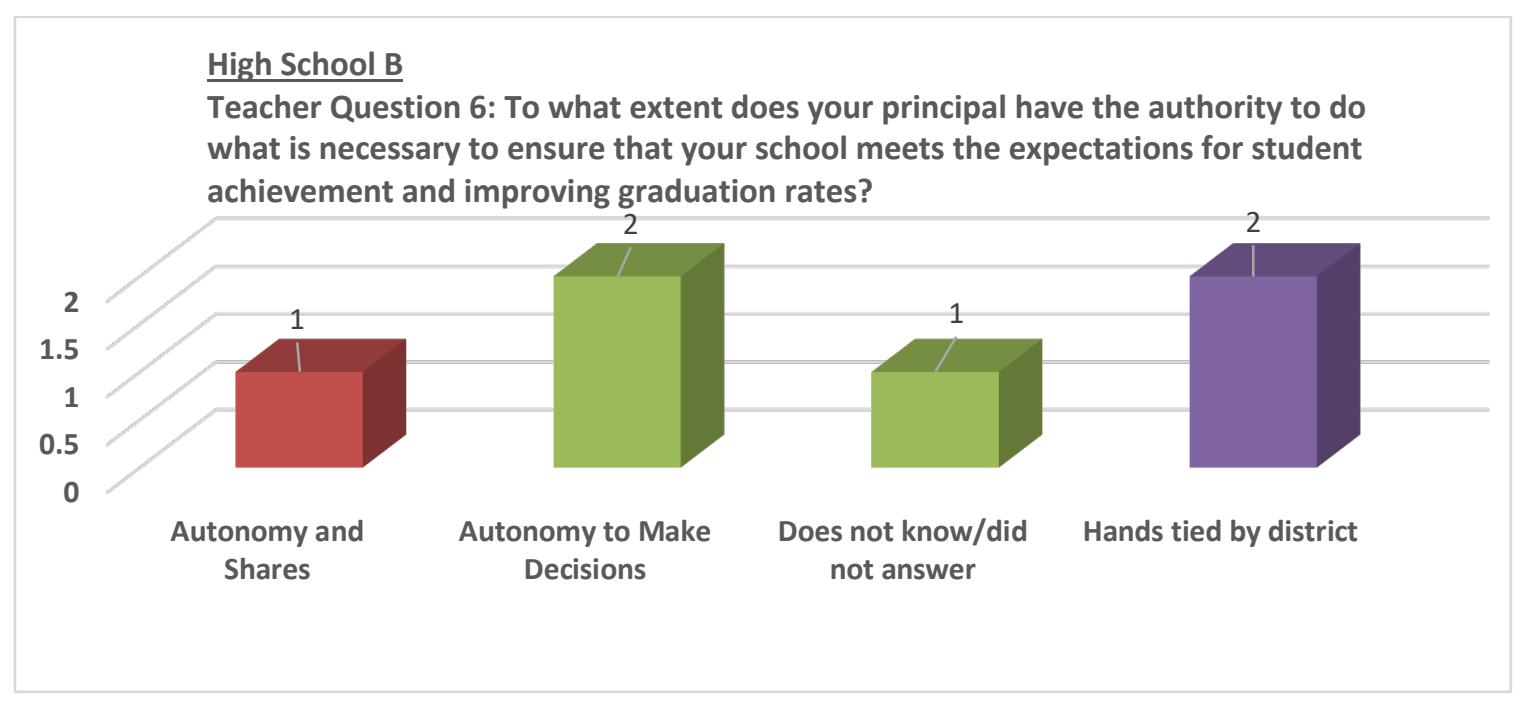

Figure 29. Summary of collective teacher responses from Building B to Question 6. The number of teachers indicating the level of perceived authority and autonomy in their principal's decision making with respect to ensuring their school meets the expectations for student achievement and graduation rates.

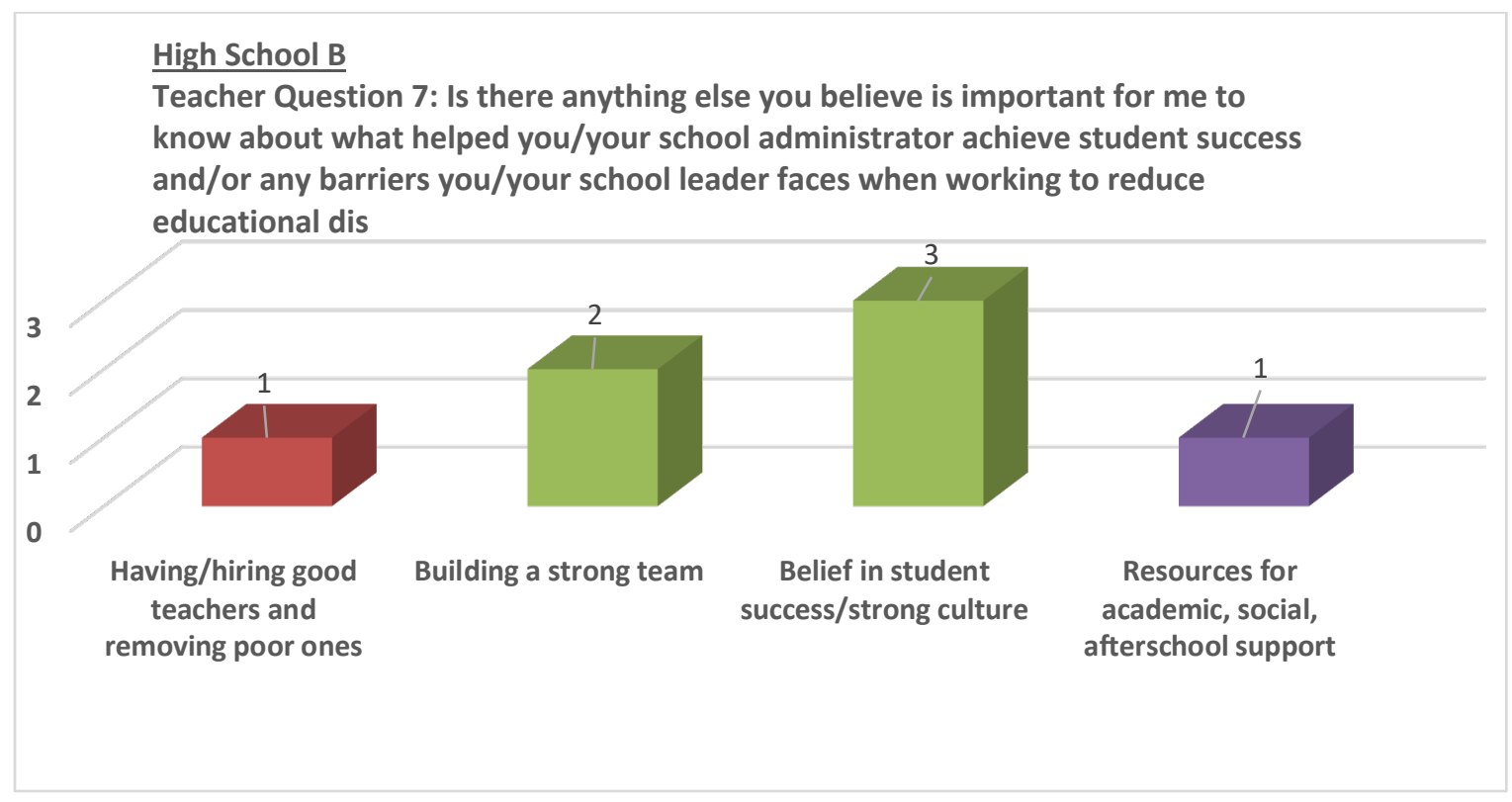

Figure 30. Summary of collective teacher responses from Building B to Question 7. The number of teachers describing additional factors they deemed important in ensuring their school improve student success and reduce educational disparities. 
Building C: Individual teacher responses questions (1-7). A review of the individual responses specific to Building $\mathrm{C}$ revealed a participant group that appeared to have a universal idea about the challenges they faced, the strategies they employed to address them, and the belief in a highly-supportive, relationship-oriented school administrator with the authority to make decisions. According to the responses from Question 2, the greatest barrier that exists against school improvement is a lack of resources. One limitation of the study is that the coding of responses minimizes the specificity attached to a word like "resource" that would be helpful in this context. The strategy most identified by the group as the key variable they attributed to improving graduation rated and reducing the achievement gap was building healthy relationships with students. The word "relationships" was provided as a positive response for five of the seven questions. Lastly, the group of teacher-leaders appeared to have a clear understanding of what they wanted (or had) in a school administrator. The five respondents provided similar answers over multiple categories describing the characteristics of an effective administrator, as well as specifically identifying "high administrative support" in Question 4. See Figures 31-37 for teacher responses in Building C. 


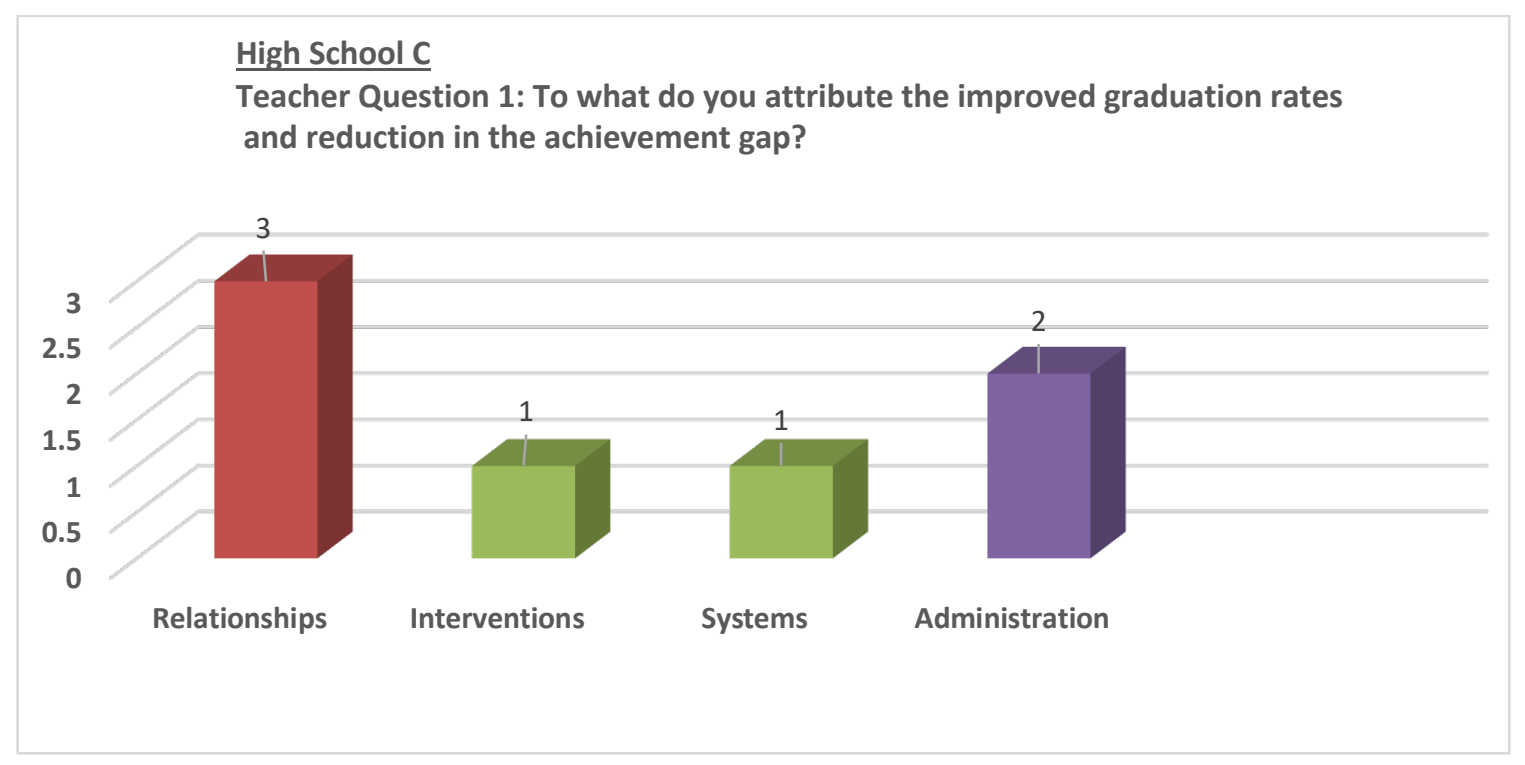

Figure 31. Summary of collective teacher responses from Building C to Question 1. The number of teachers attributing the above factors to improving student achievement.

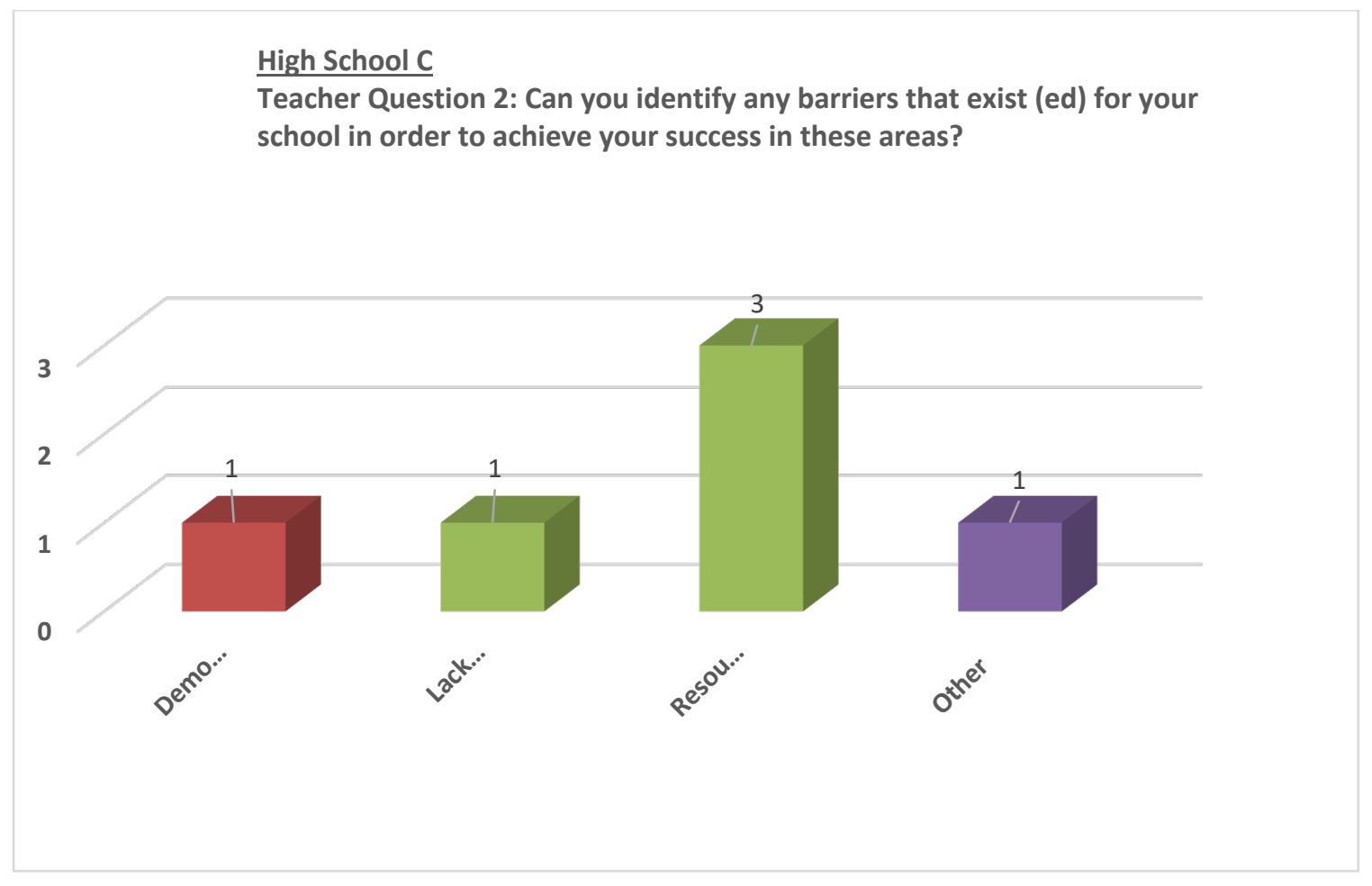

Figure 32. Summary of collective teacher responses from Building C to Question 2. The number of teachers identifying the above factors as barriers to student achievement. 


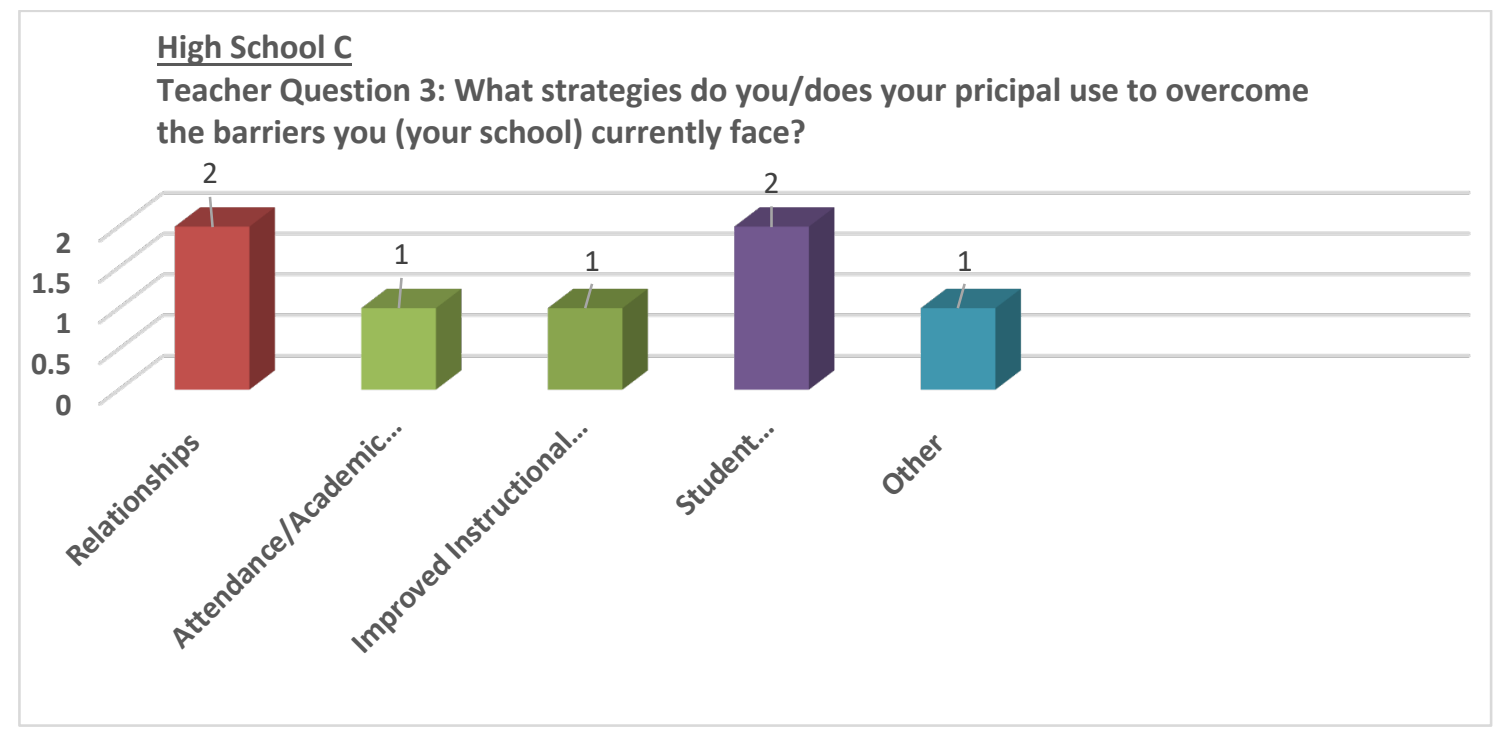

Figure 33. Summary of collective teacher responses from Building C to Question 3. The number of teachers identifying the following strategies used to overcome barriers to student achievement.

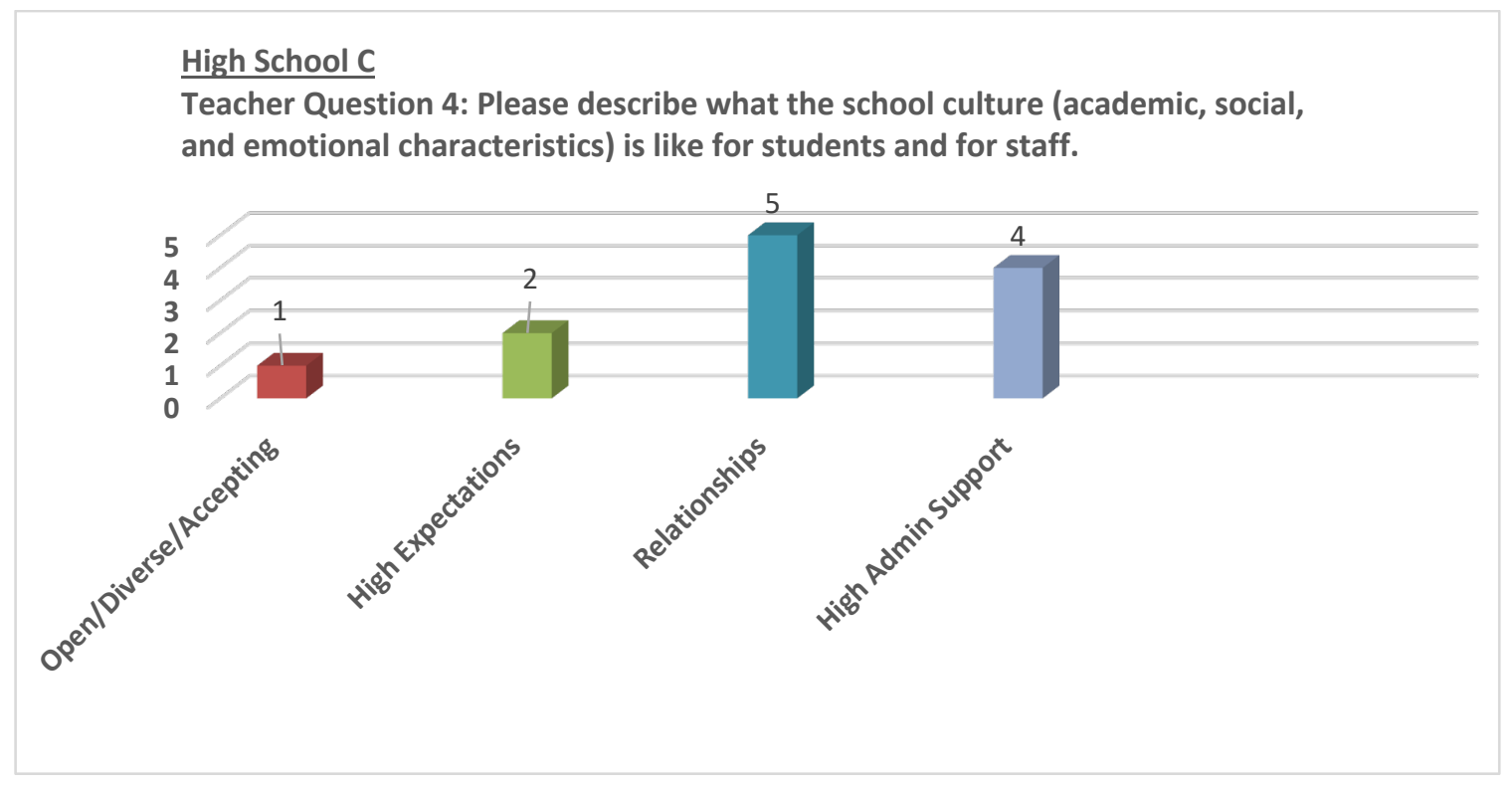

Figure 34. Summary of collective teacher responses from Building C to Question 4. The number of teachers indicating the following characteristics as being descriptive of their school culture. 


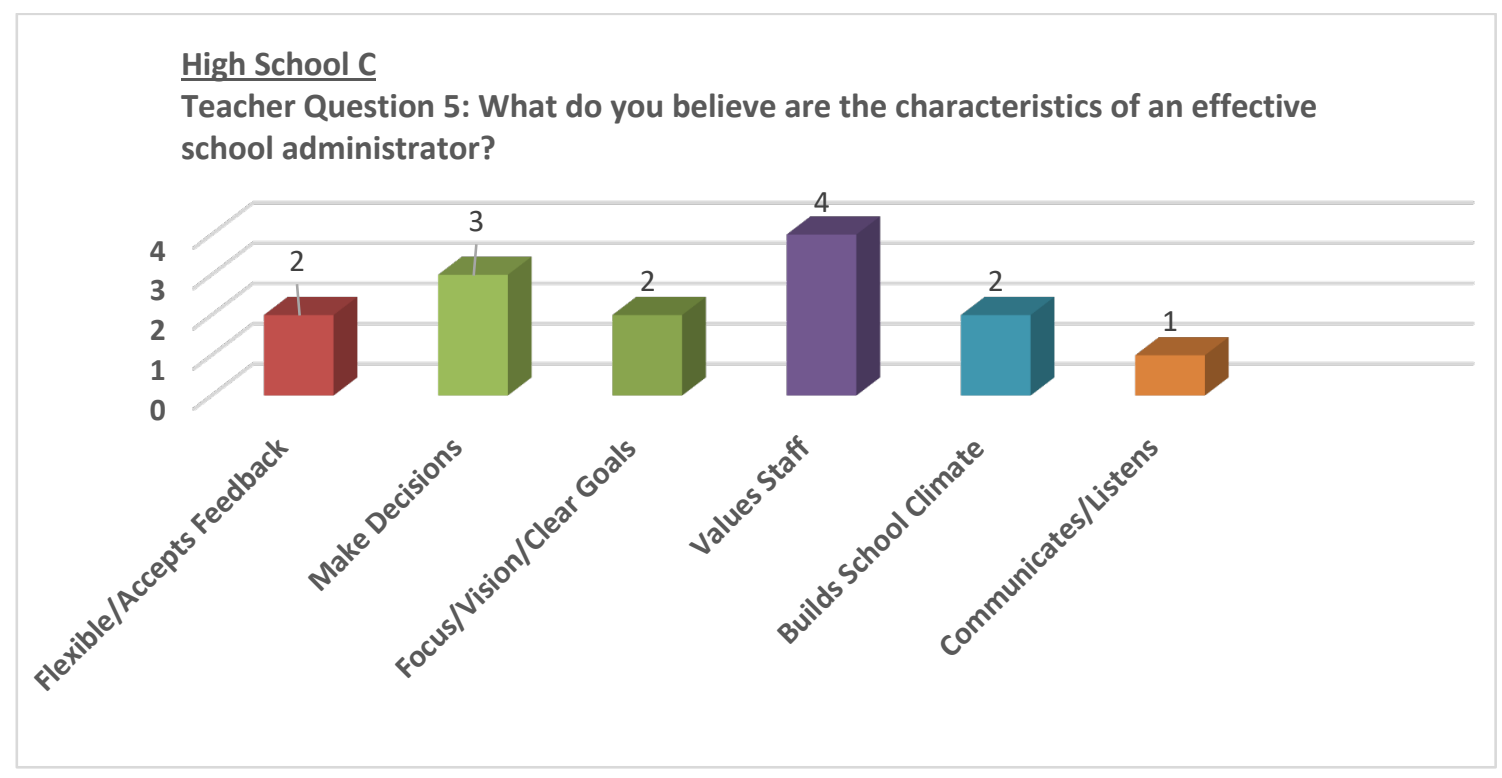

Figure 35. Summary of collective teacher responses from Building C to Question 5. The number of teachers indicating the following characteristics as being descriptive of an effective school administrator.

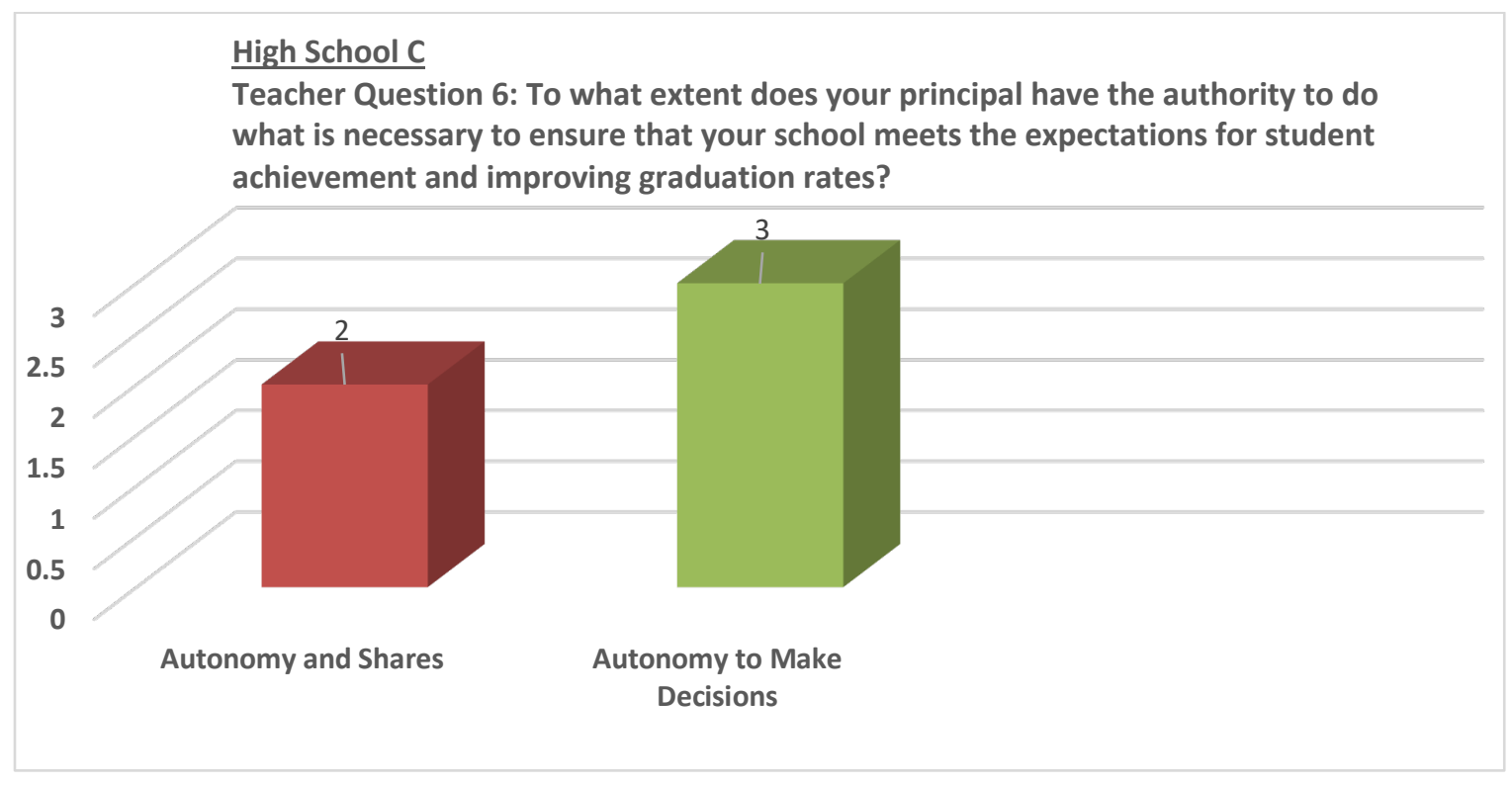

Figure 36. Summary of collective teacher responses from Building C to Question 6. The number of teachers indicating the level of perceived authority and autonomy in their principal's decision making with respect to ensuring their school meets the expectations for student achievement and graduation rates. 


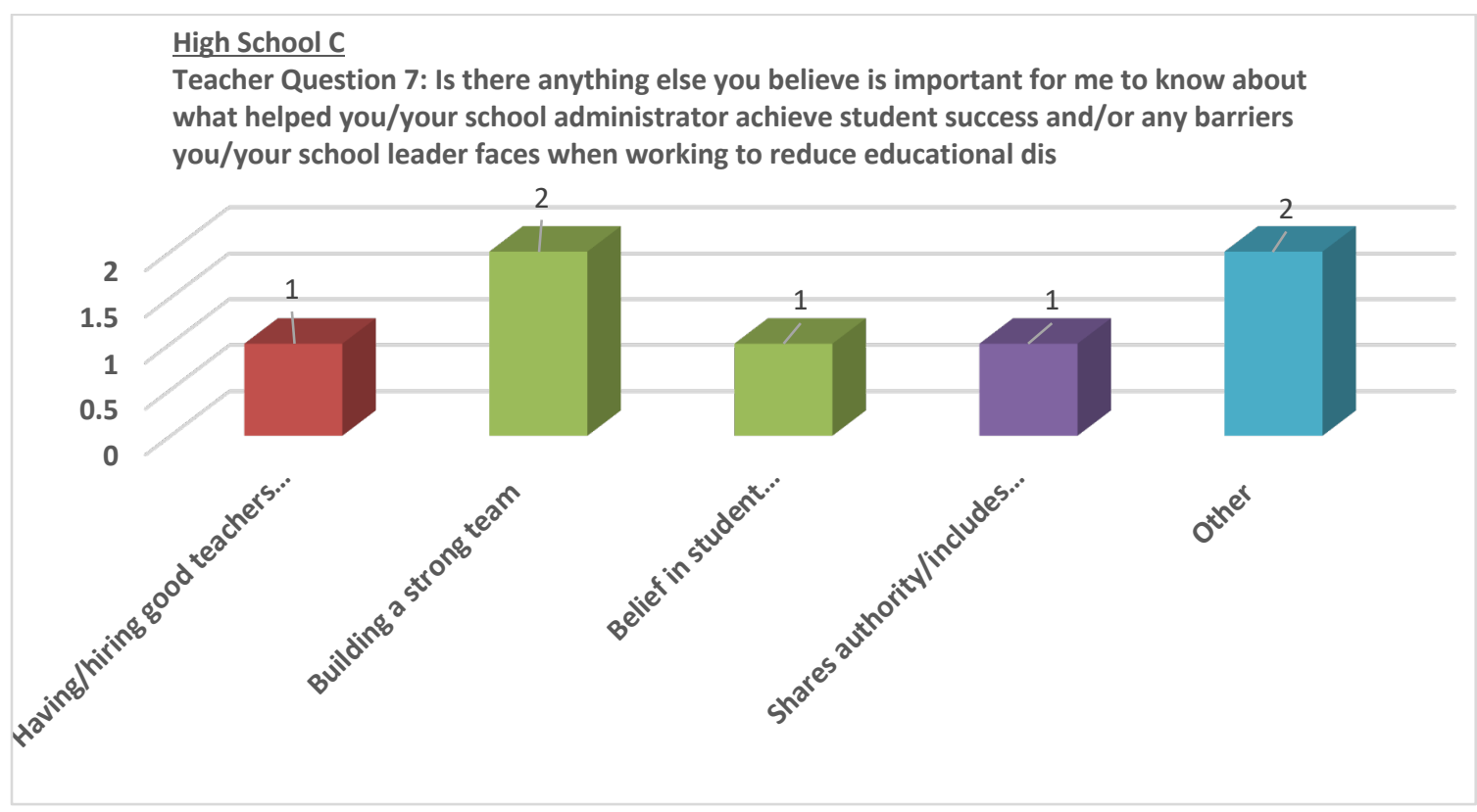

Figure 37, Summary of collective teacher responses from Building C to Question 7. The number of teachers describing additional factors they deemed important in ensuring their school improve student success and reduce educational disparities.

Building D: Individual teacher responses questions (1-7). The teacher participant group in Building D showed the most diversified responses to each of the seven research questions. There was no consensus among surveyed staff on key variables contributing to school success, barriers to success, or effective leadership strategies. The strongest collective response was that according to three participants in Building D, the greatest interventions against barriers to student success were attendance and academic intervention programs. The lack of consensus and clear trends from this group may indicate success at this school was due to programs and strategies that were not universally agreed upon. Another explanation may be that teachers were largely unaware of administrative and system level interventions that improved student success. See Figures 38-44 for teacher responses in Building D. 


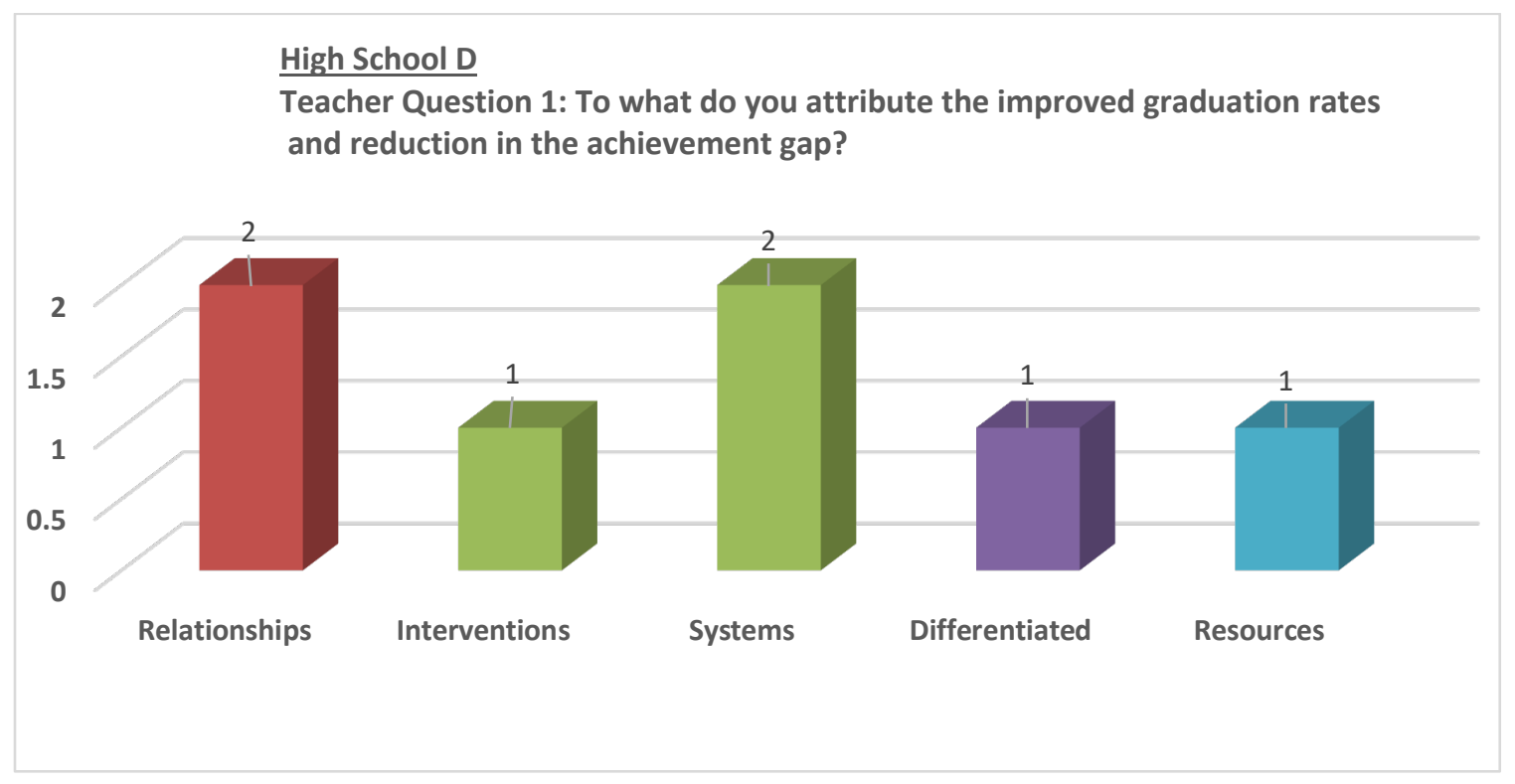

Figure 38. Summary of collective teacher responses from Building D to Question 1. The number of teachers attributing the above factors to improving student achievement.

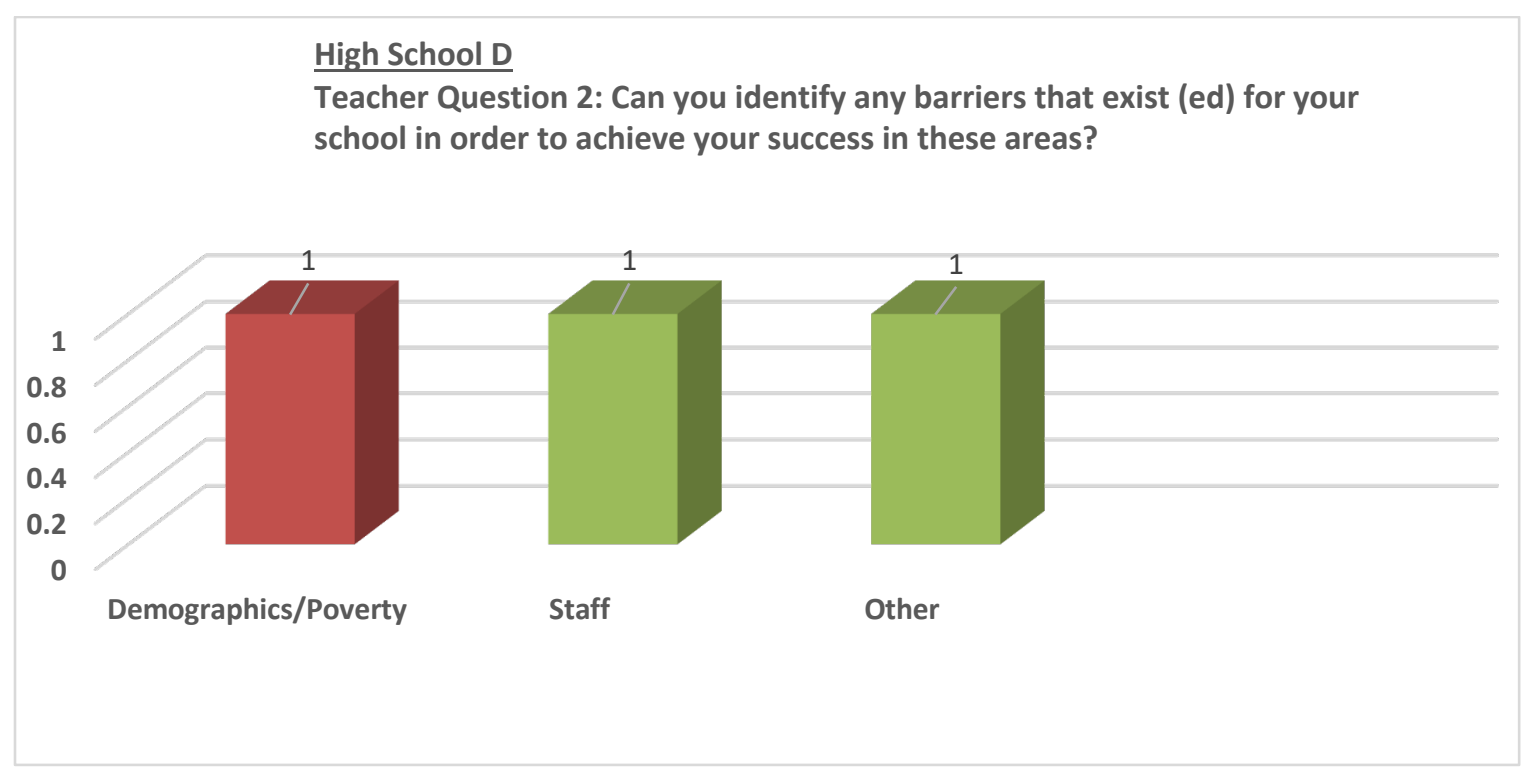

Figure 39. Summary of collective teacher responses from Building D to Question 2. The number of teachers identifying the above factors as barriers to student achievement. 


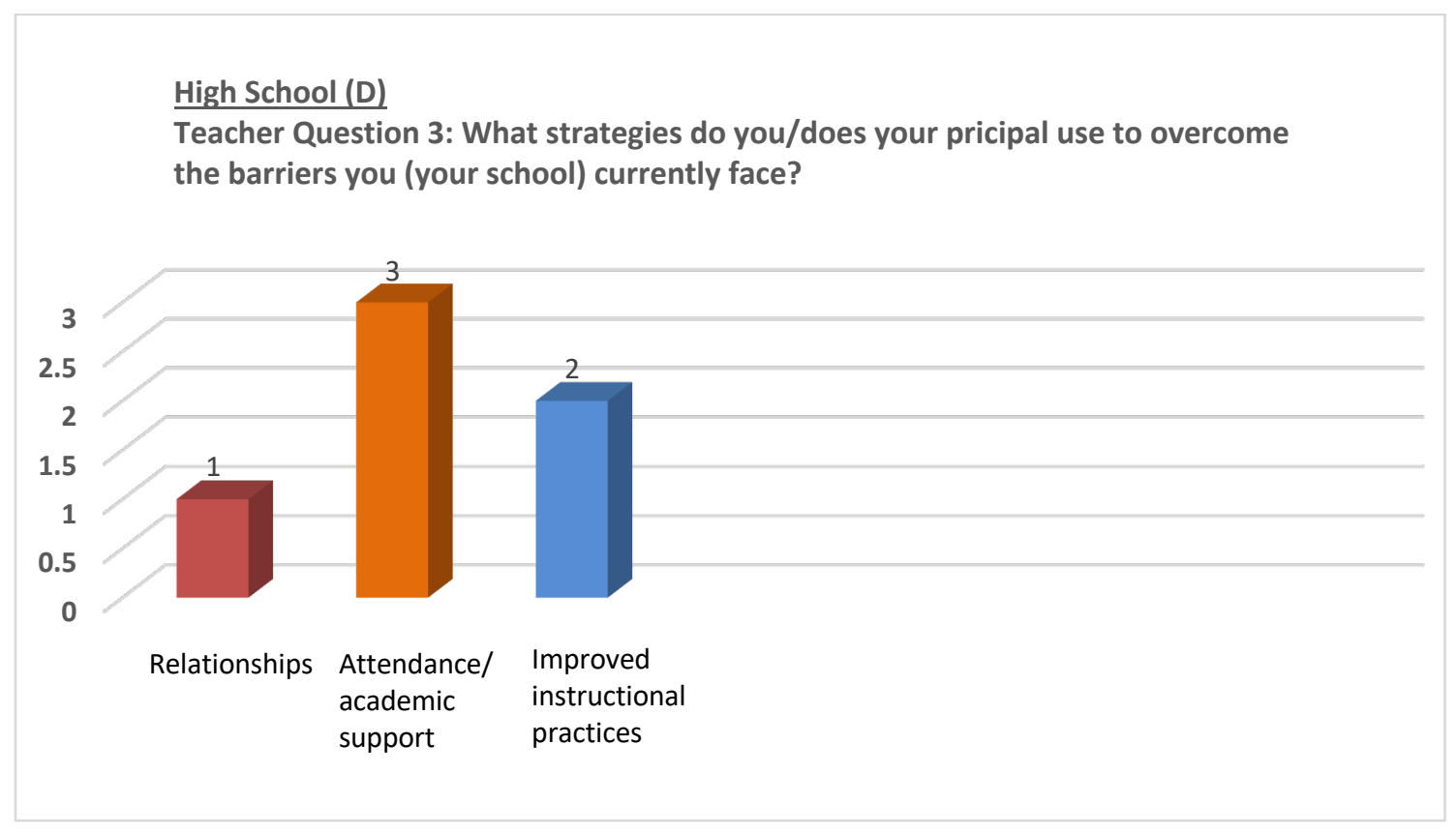

Figure 40. Summary of collective teacher responses from Building D to Question 3. The number of teachers identifying the following strategies used to overcome barriers to student achievement.

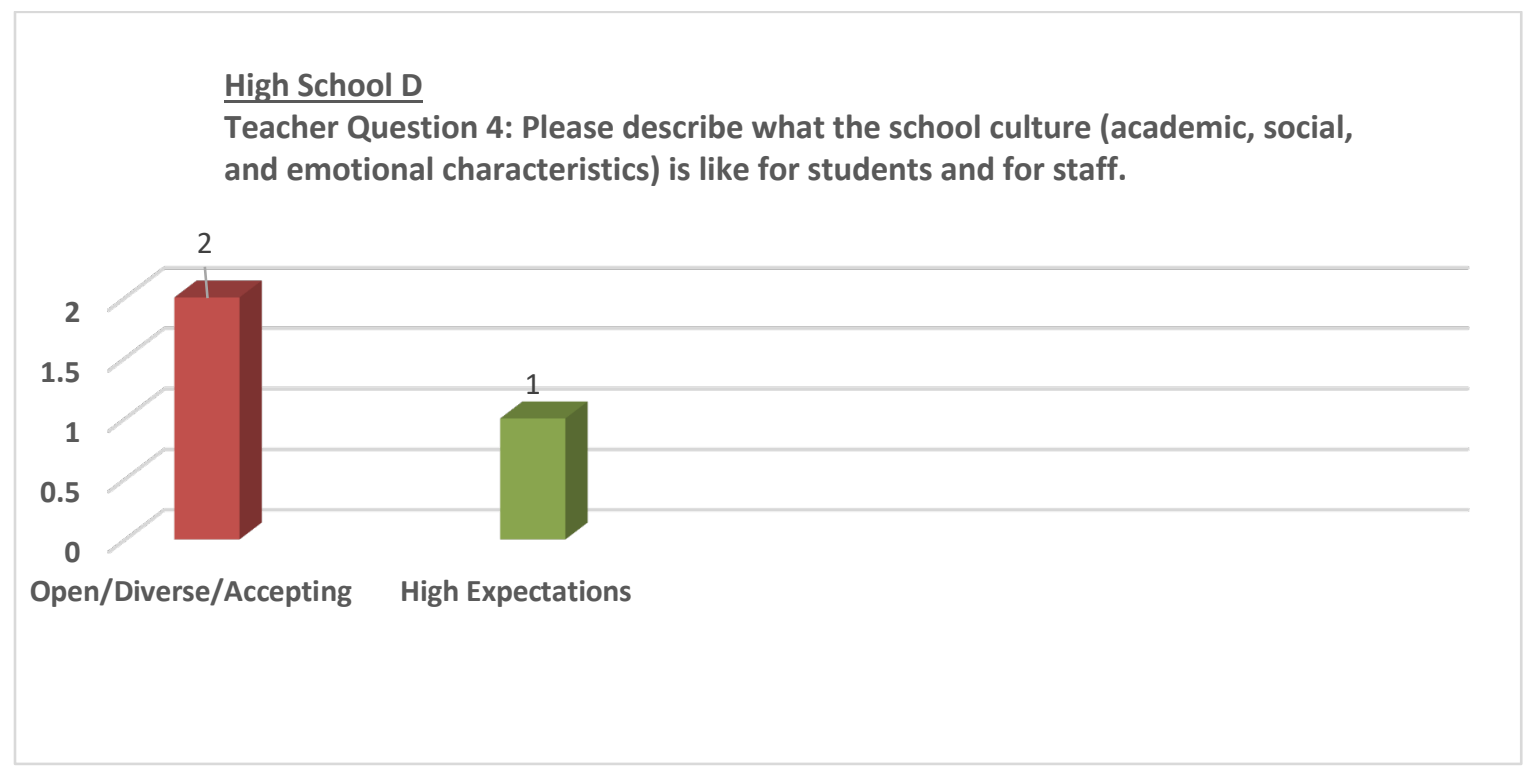

Figure 41. Summary of collective teacher responses from Building D to Question 4. The number of teachers indicating the following characteristics as being descriptive of their school culture. 


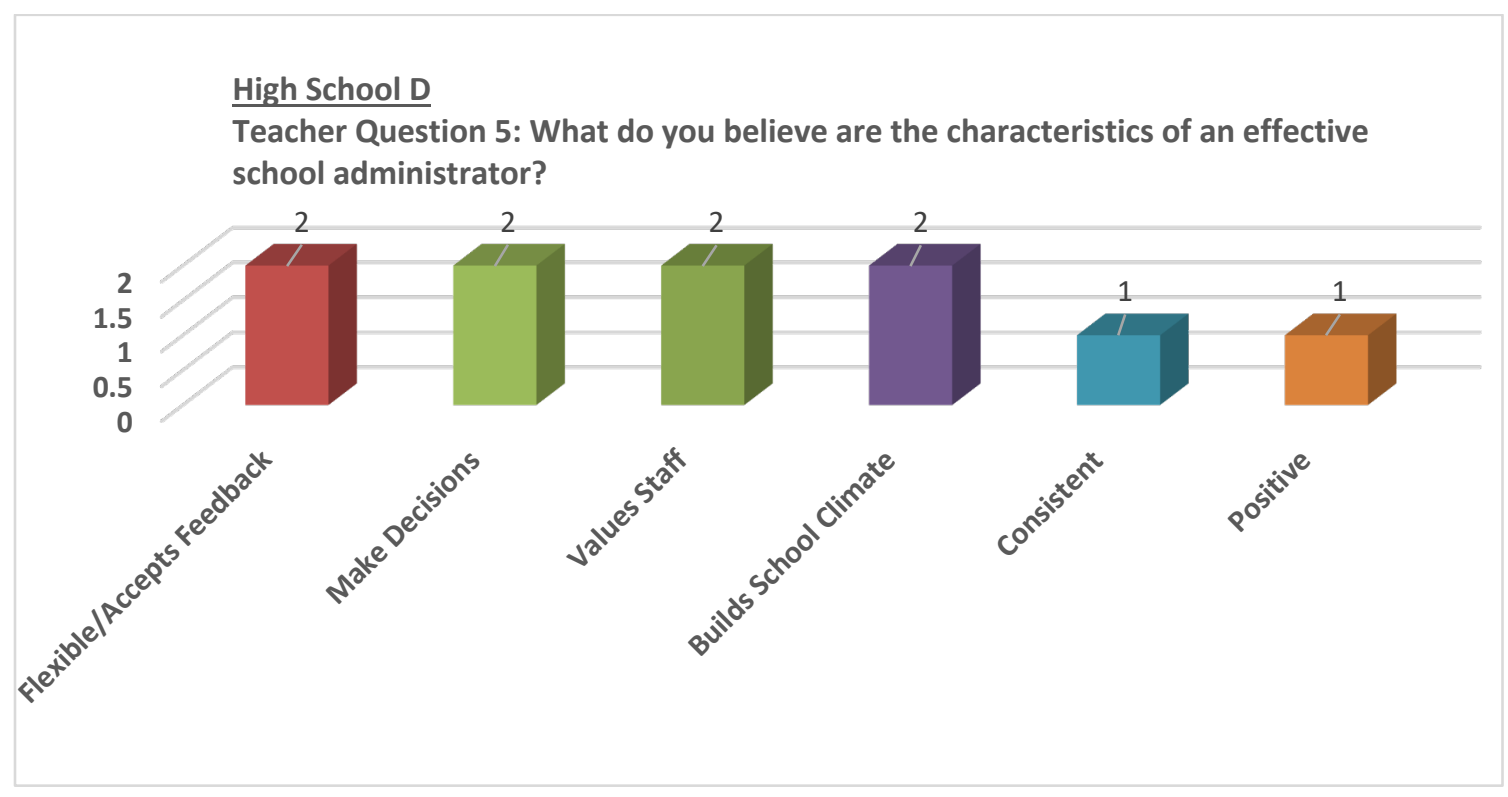

Figure 42. Summary of collective teacher responses from Building D to Question 5. The number of teachers indicating the following characteristics as being descriptive of an effective school administrator.

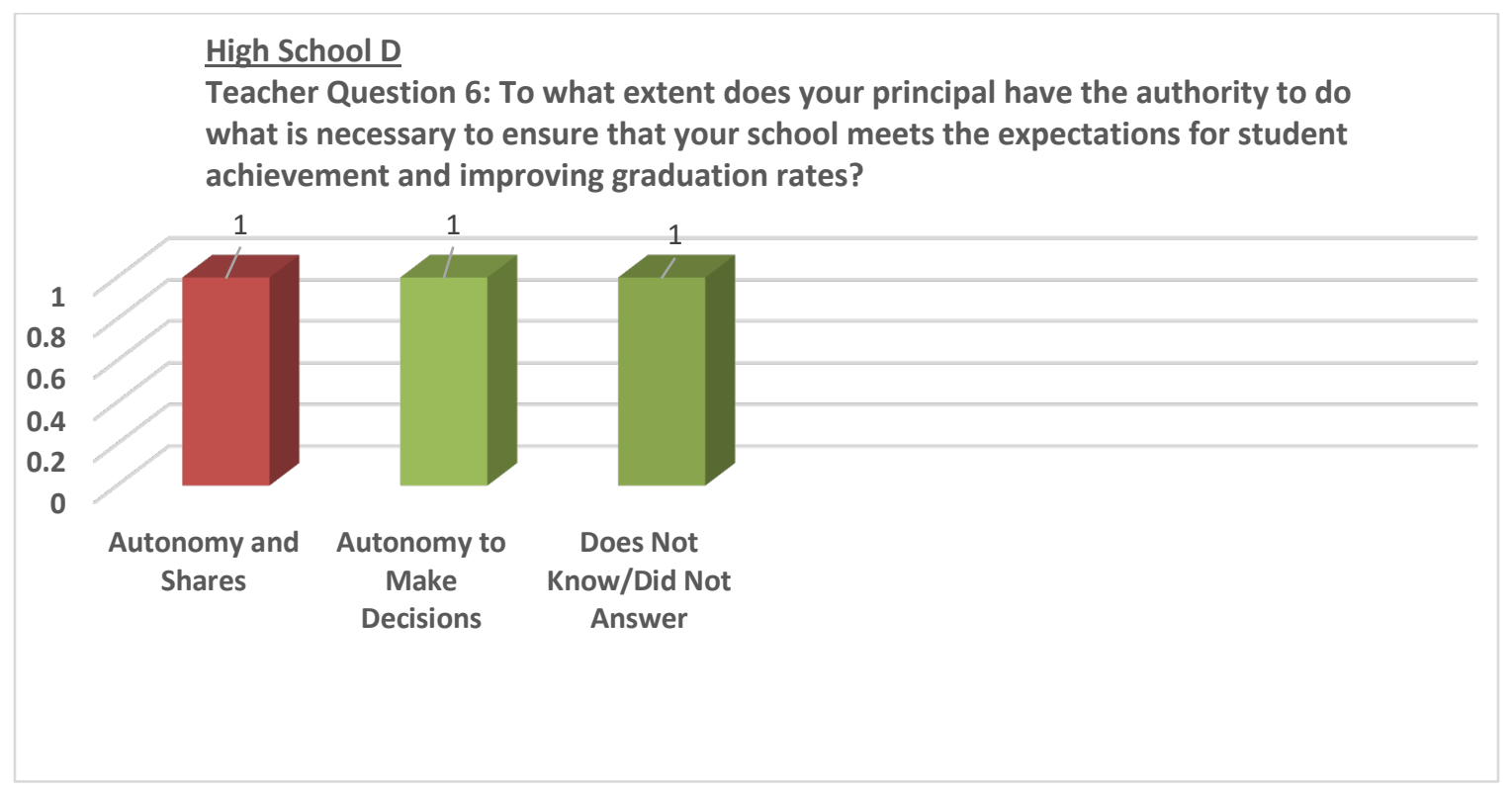

Figure 43. Summary of collective teacher responses from Building D to Question 6. The number of teachers indicating the level of perceived authority and autonomy in their principal's decision making with respect to ensuring their school meets the expectations for student achievement and graduation rates. 


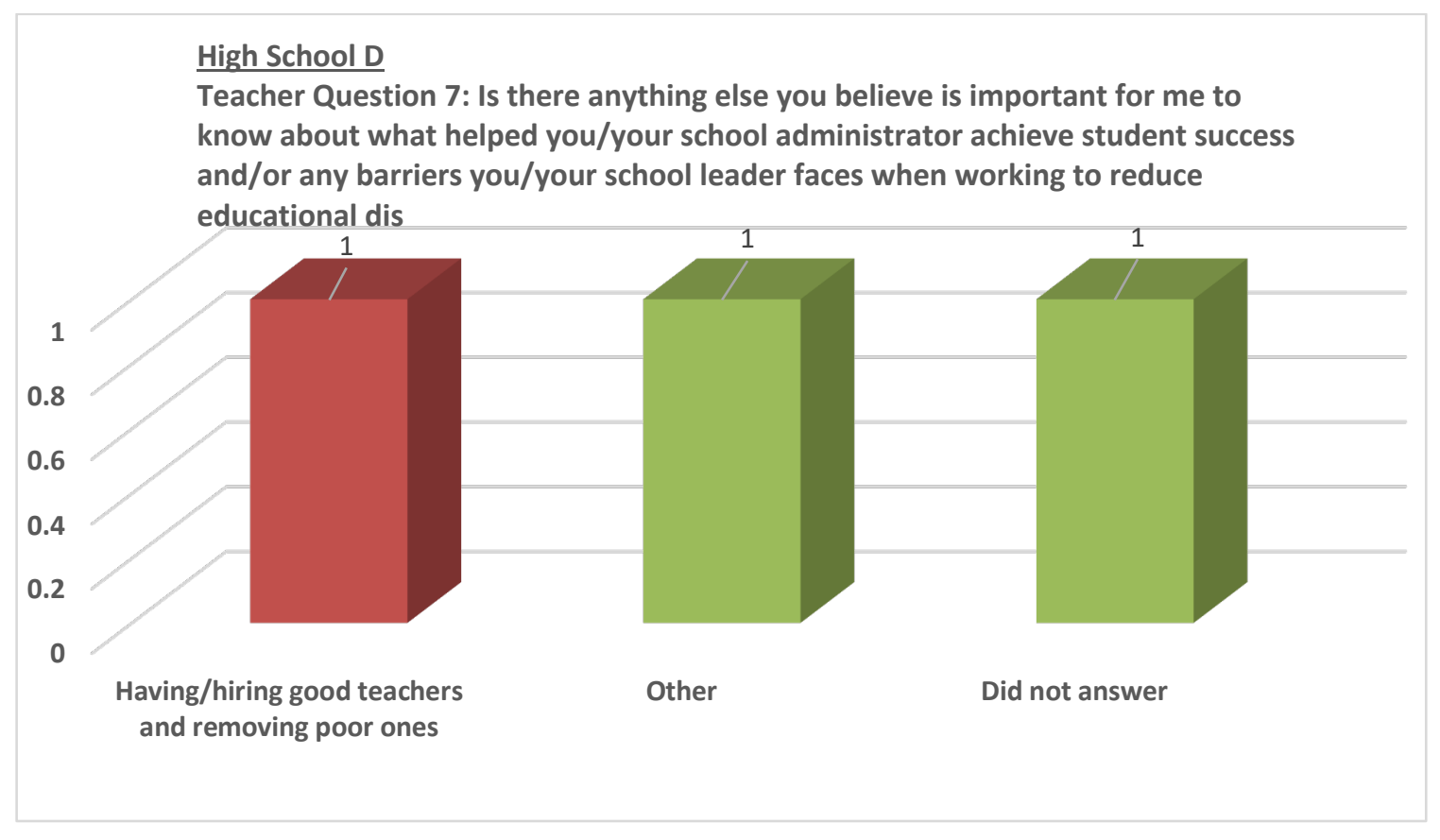

Figure 44. Summary of collective teacher responses from Building D to Question 7. The number of teachers describing additional factors they deemed important in ensuring their school improve student success and reduce educational disparities.

Building E: Individual teacher responses questions (1-7). The responses from the teacher group presented a set of responses that at first seemed counterintuitive to the inclusive of Building E as a sample school. Teachers indicated the administrator lowered academic expectations which contributed to the improvement at Building E. They indicated they had a multitude of barriers and a non-supportive administrator with low expectations for students and little authority to make effective decisions. In contrast to low expectations, of the administration the teachers had high expectations for students and clearly identified a desire for an administrator who would build school culture and value and support the current staff. It appears that there is a clear disconnect between administration and the staff; however, the current increase in graduation rates and 
increased student achievement indicate that high teacher expectations may be the key to student achievement in this school. This finding is directly supported in research by Charlotte Danielson in her 2009 publication, Talk About Teaching! Leading Professional Conversations, where she concludes that classroom teachers have the most statistically significant impact on overall individual student achievement. See Figures 45-51 for teacher responses in Building E.

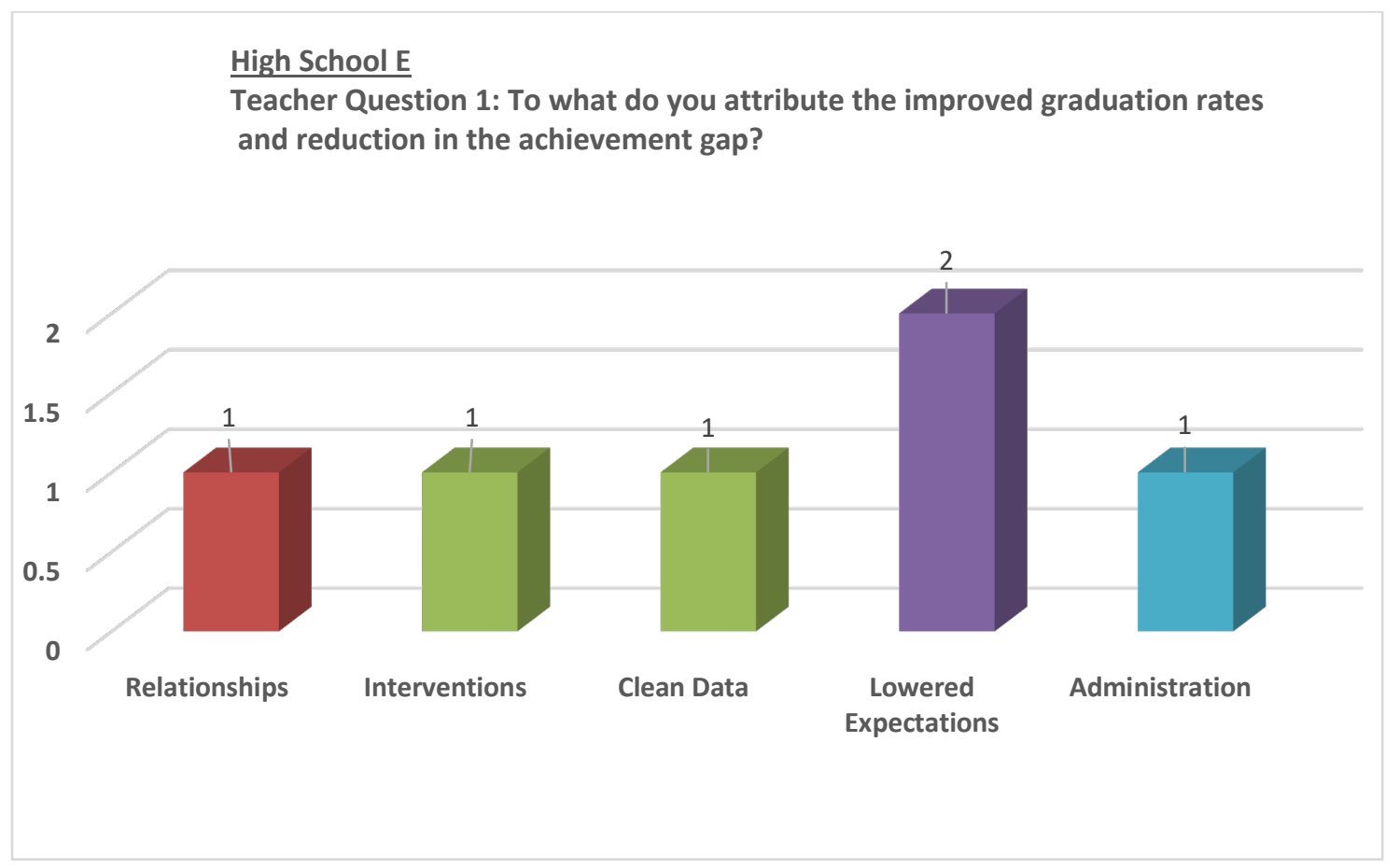

Figure 45. Summary of collective teacher responses from Building E to Question 1. The number of teachers attributing the above factors to improving student achievement. 


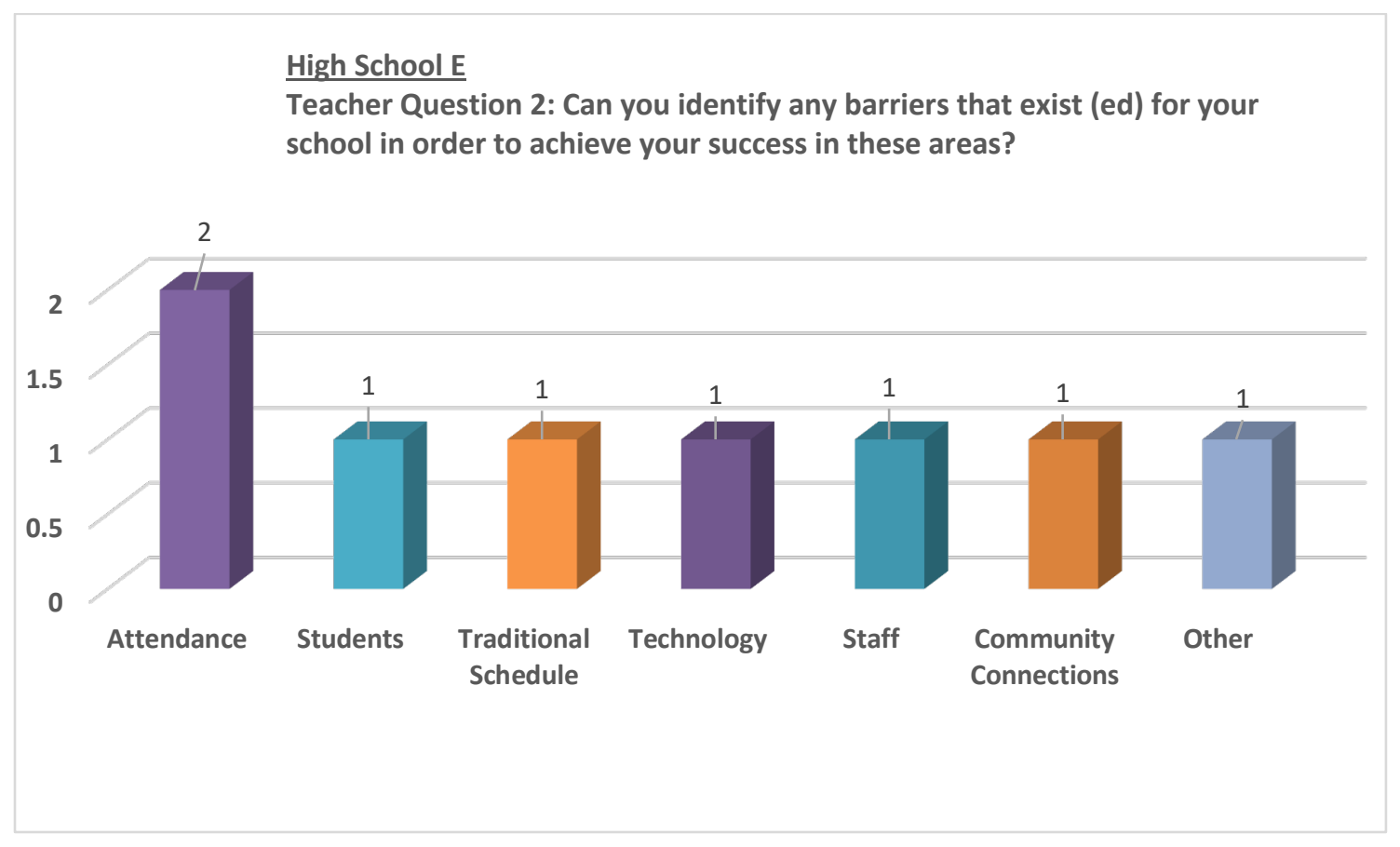

Figure 46. Summary of collective teacher responses from Building E to Question 2. The number of teachers identifying the above factors as barriers to student achievement.

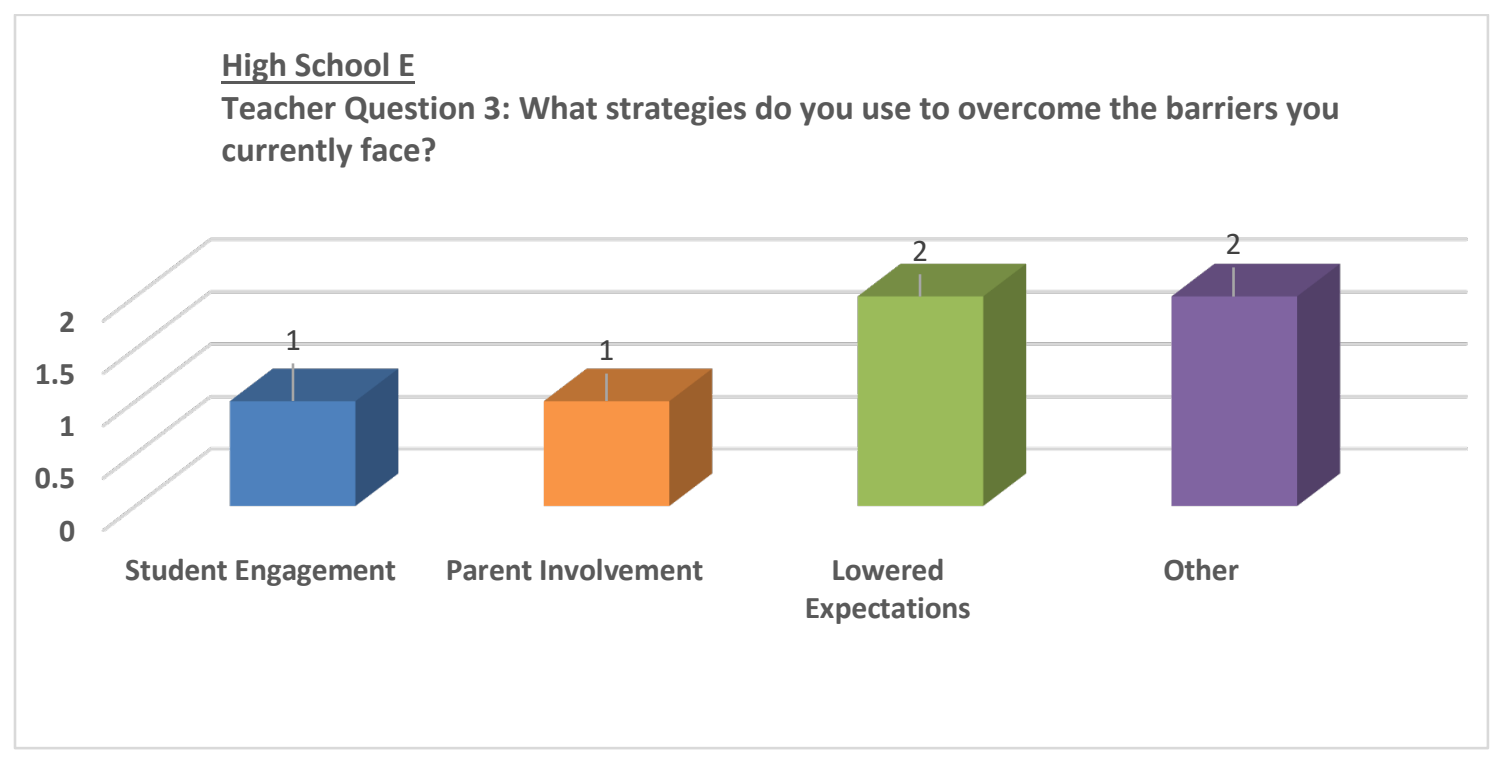

Figure 47. Summary of collective teacher responses from Building E to Question 3. The number of teachers identifying the above strategies used to overcome barriers to student achievement. 


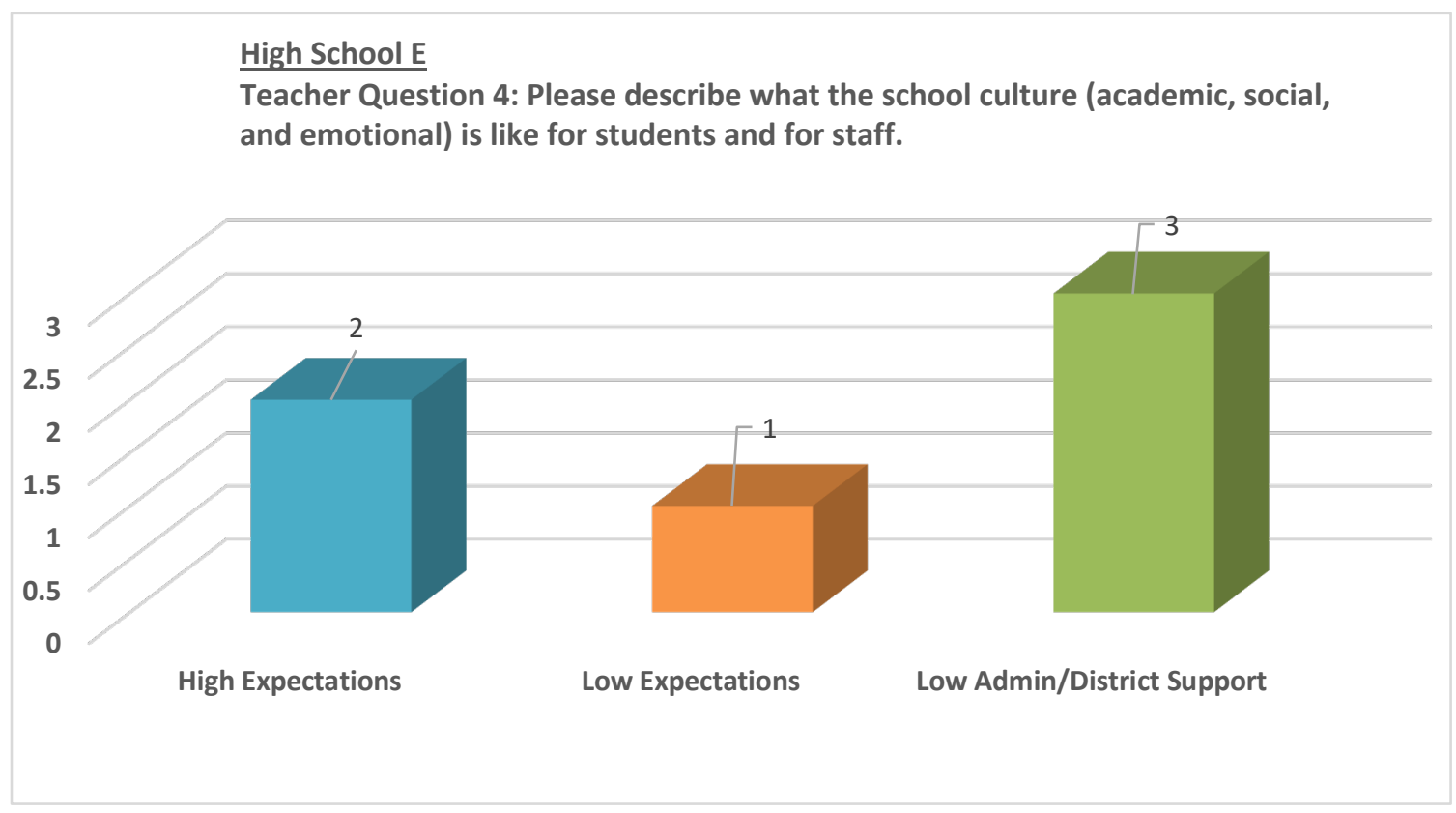

Figure 48. Summary of collective teacher responses from Building E to Question 4. The number of teachers indicating the following characteristics as being descriptive of their school culture.

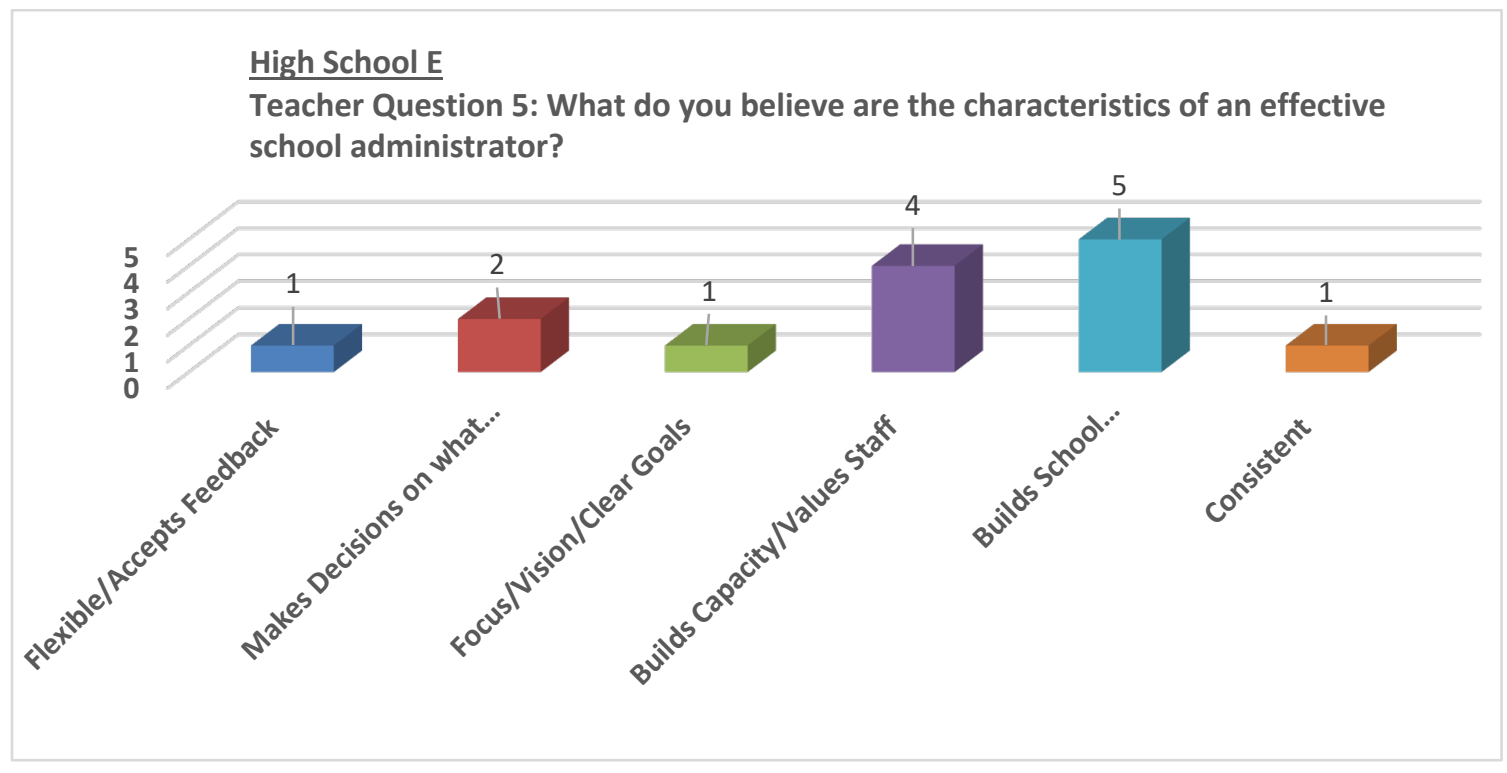

Figure 49. Summary of collective teacher responses from Building E to Question 5. The number of teachers indicating the following characteristics as being descriptive of an effective school administrator. 


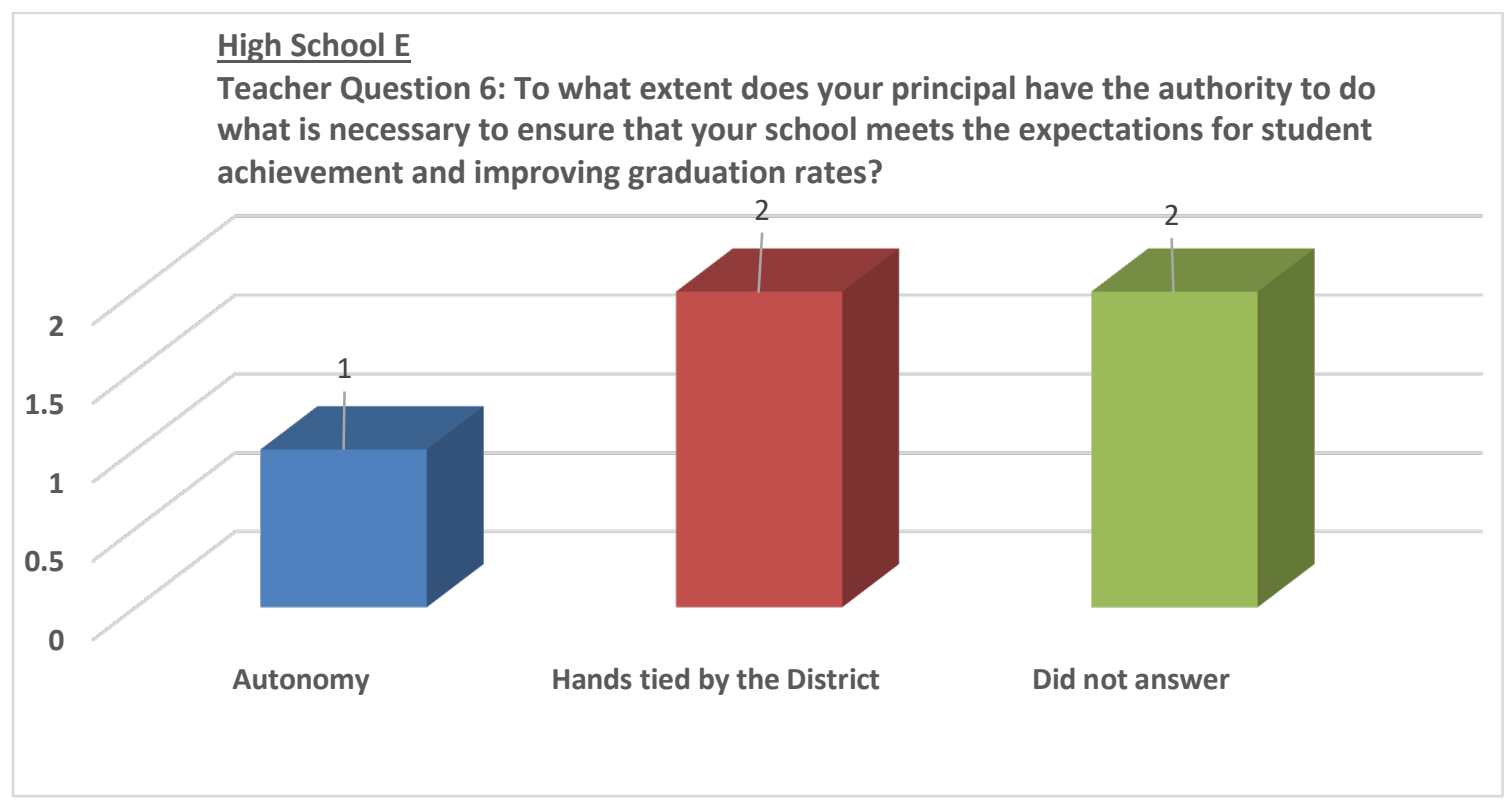

Figure 50. Summary of collective teacher responses from Building E to Question 6. The number of teachers indicating the level of perceived authority and autonomy in their principal's decision making with respect to ensuring their school meets the expectations for student achievement and graduation rates.

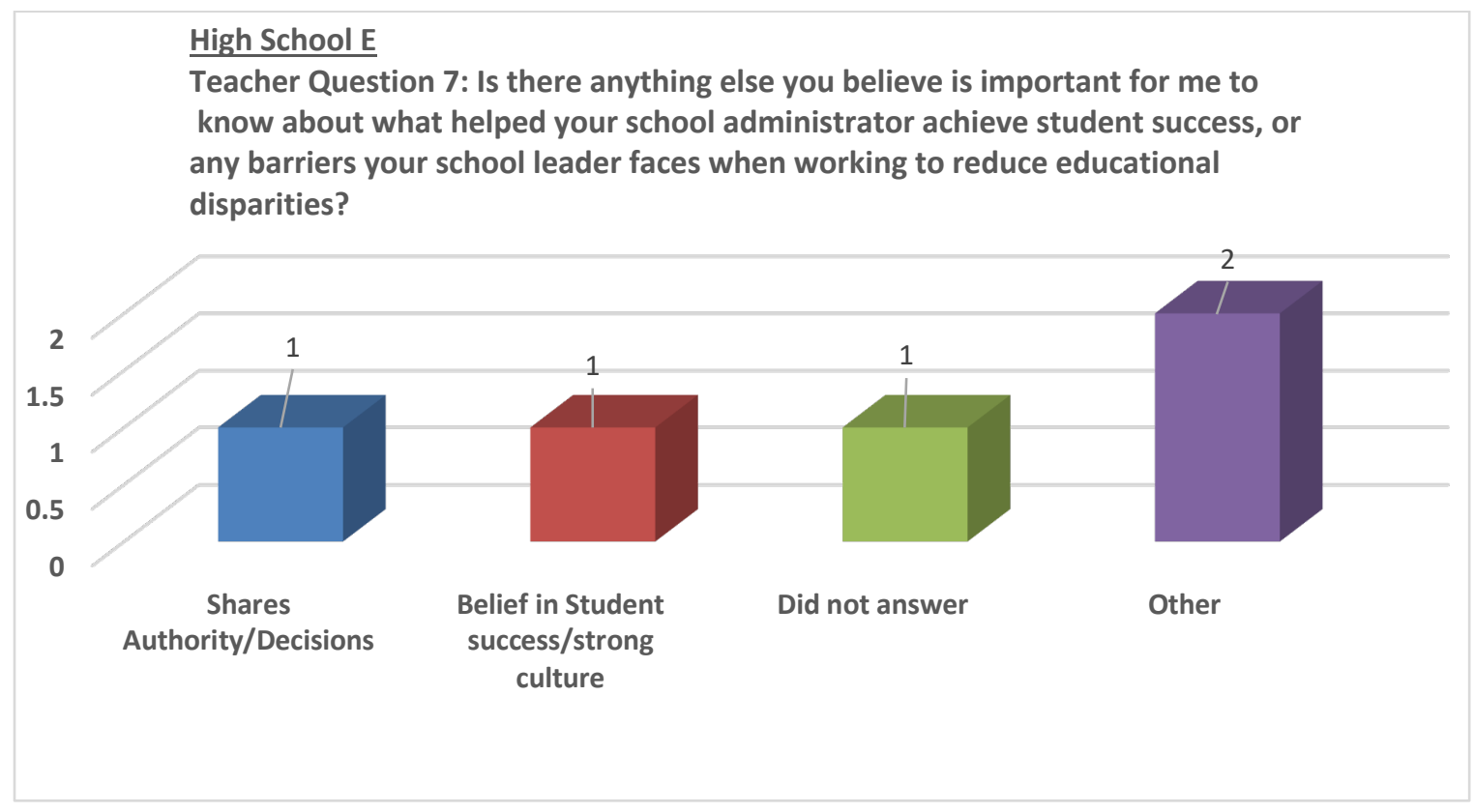

Figure 51. Summary of collective teacher responses from Building E to Question 7. The number of teachers describing additional factors they deemed important in ensuring their school improve student success and reduce educational disparities. 
Building A: Individual principal responses questions (1-7). The principal of Building A identified two main factors they attributed to improved graduation rates and the reduction of the achievement gap: knowing their students and managing effective school systems through a strong central vision. Principal A identified a lack of resources as their main barrier to student achievement but noted in Question 3 that staff works harder to compensate for these externally derived factors. Principal A described their school as having strong relationships among the students, staff and administration as well as an open, diverse, and accepting school climate. Principal A believes that they operate with complete autonomy within their building. Principal A believes an effective administrator demonstrates integrity, has a clear vision, builds capacity in their staff, maintains a growth-mindset, and is willing to step in and do the little things to support students and staff. Principal A reinforced all of these characteristics when provided an open-ended response in Question 7, demonstrating a firm commitment and belief to the traits previously identified as belonging to an effective school administrator. See Figures 52-58 for visual summaries of responses from Principal A. 


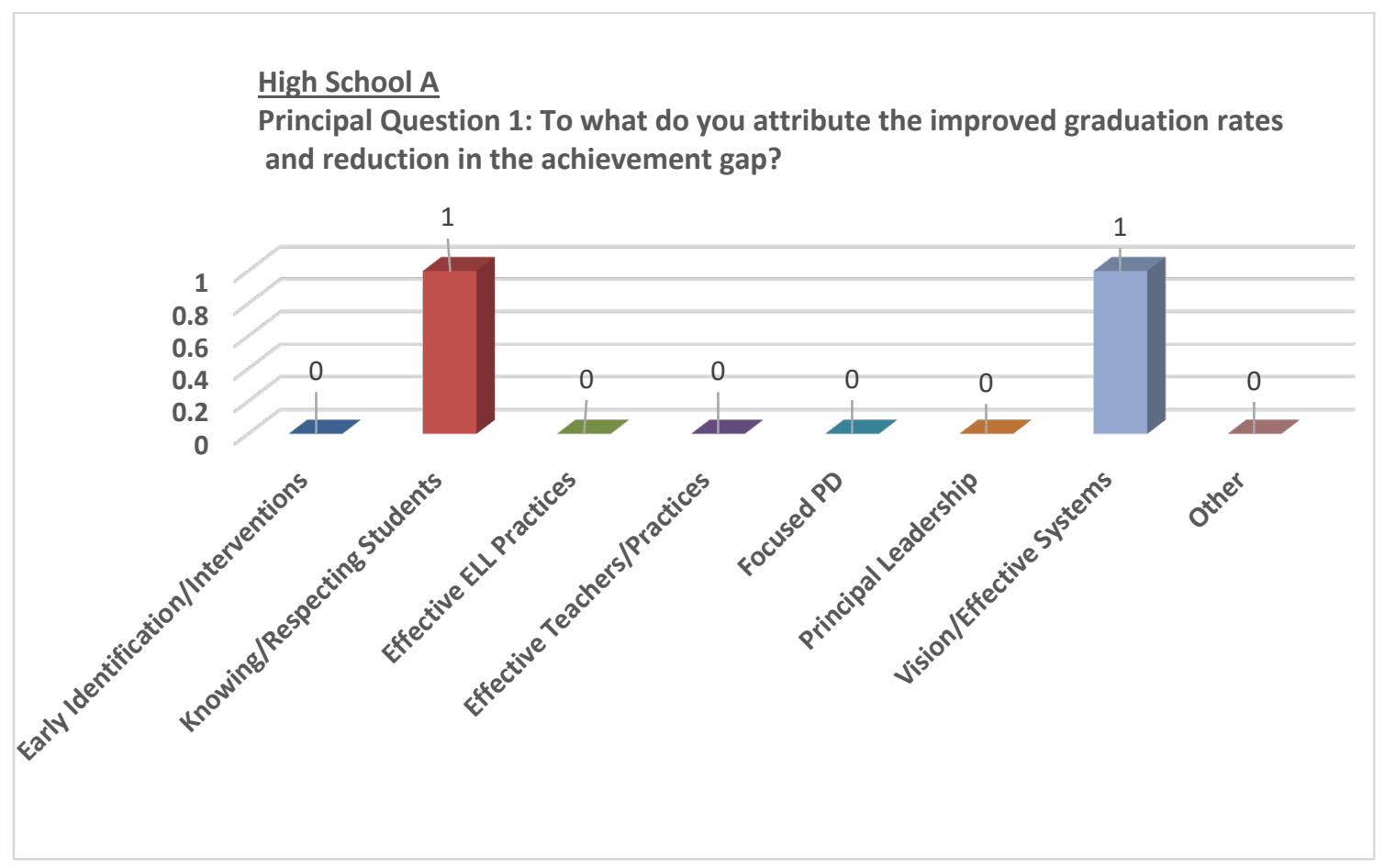

Figure 52. Summary of Principal A's responses to Question 1. The number of times a principal attributed the above factors to improving student achievement.

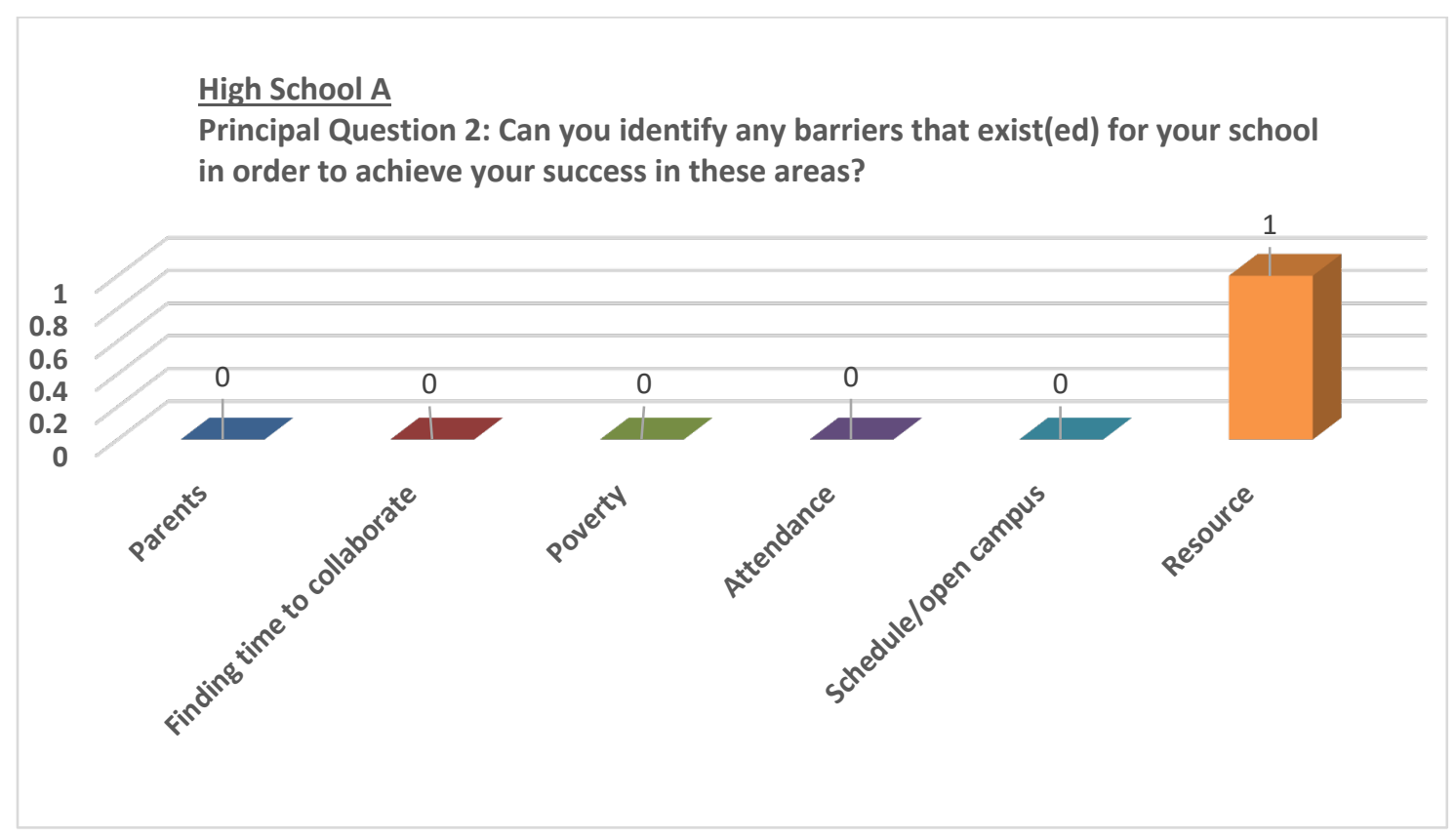

Figure 53. Summary of Principal A's responses to Question 2. The number of times a principal identified the above factors as barriers to student achievement. 


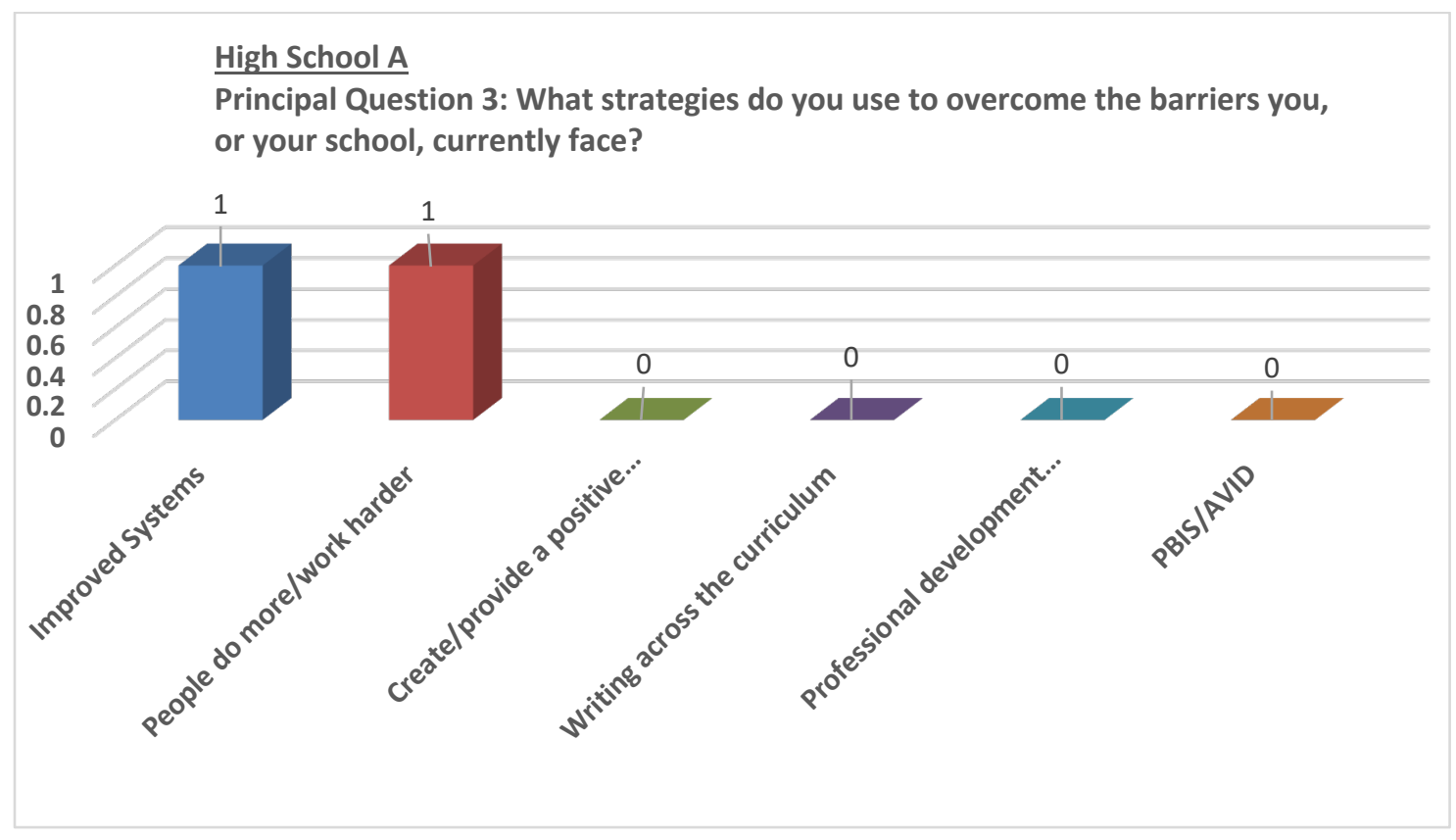

Figure 54. Summary of Principal A's responses to Question 3. The number of times a principal utilized the above factors to overcome barriers to student achievement.

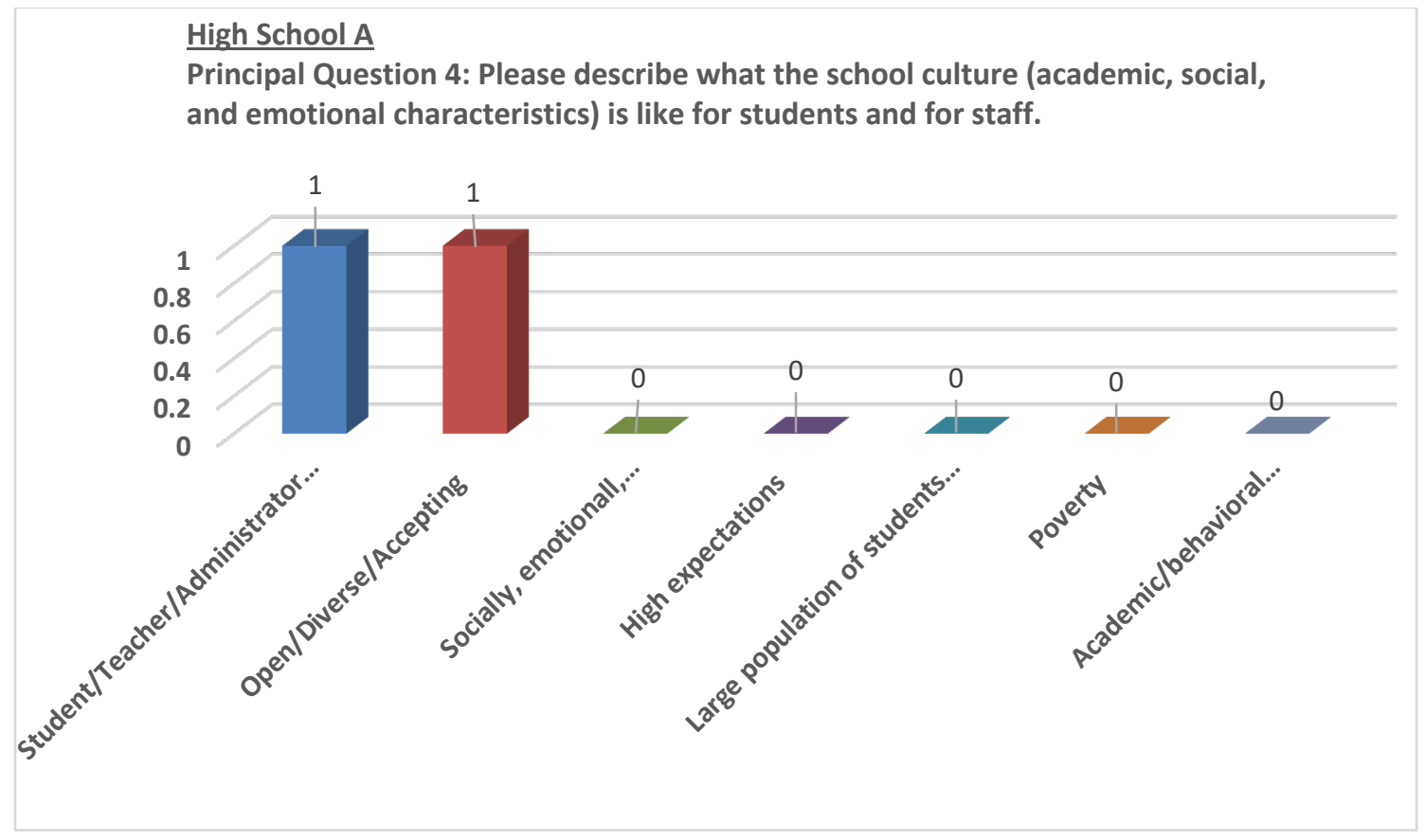

Figure 55. Summary of Principal A's responses to Question 4. The number of times a principal indicated the above characteristics as being descriptive of their school culture. 


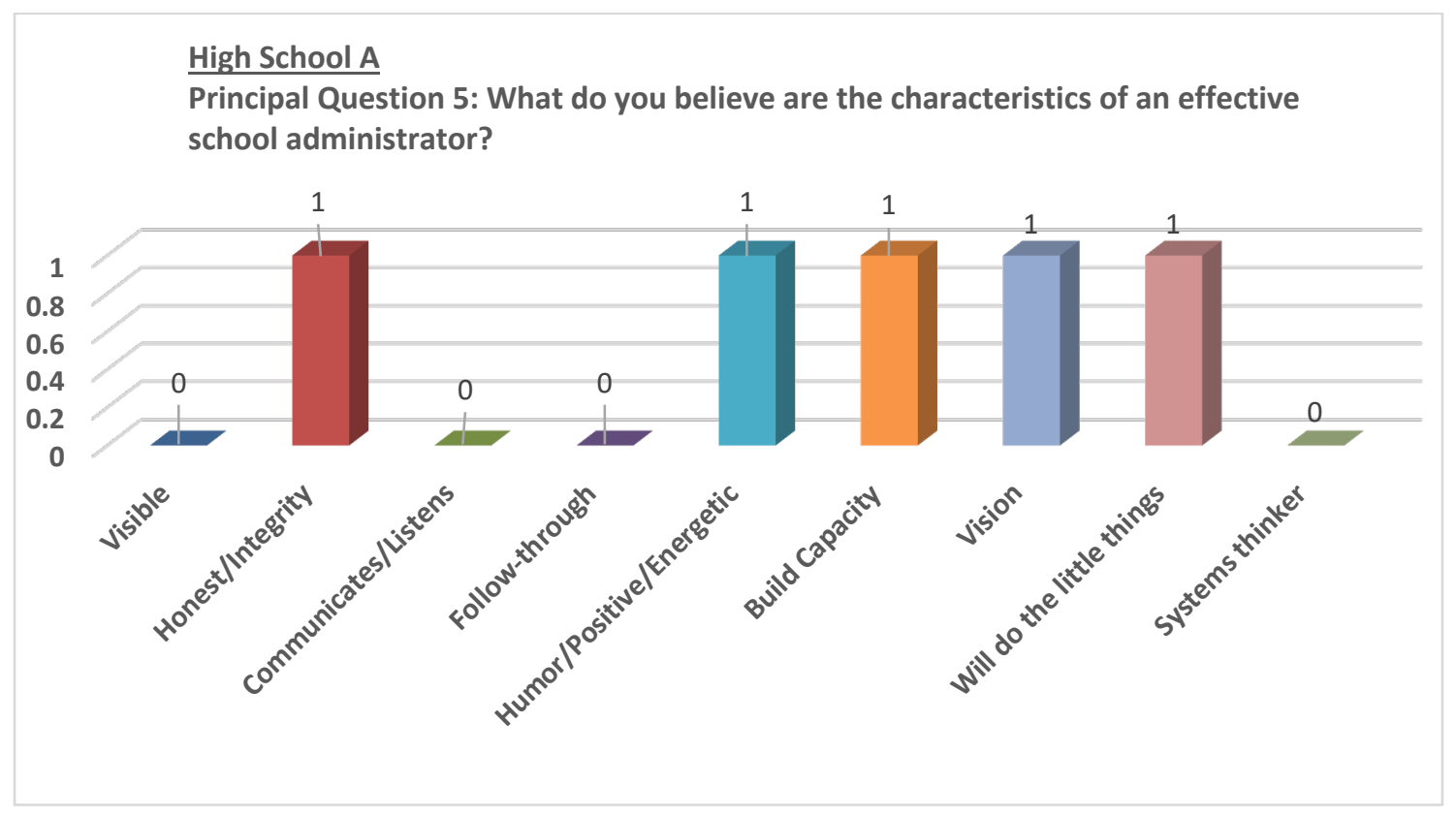

Figure 56. Summary of Principal A's responses to Question 5. The number of times a principal indicated the above factors as characteristics of an effective school administrator.

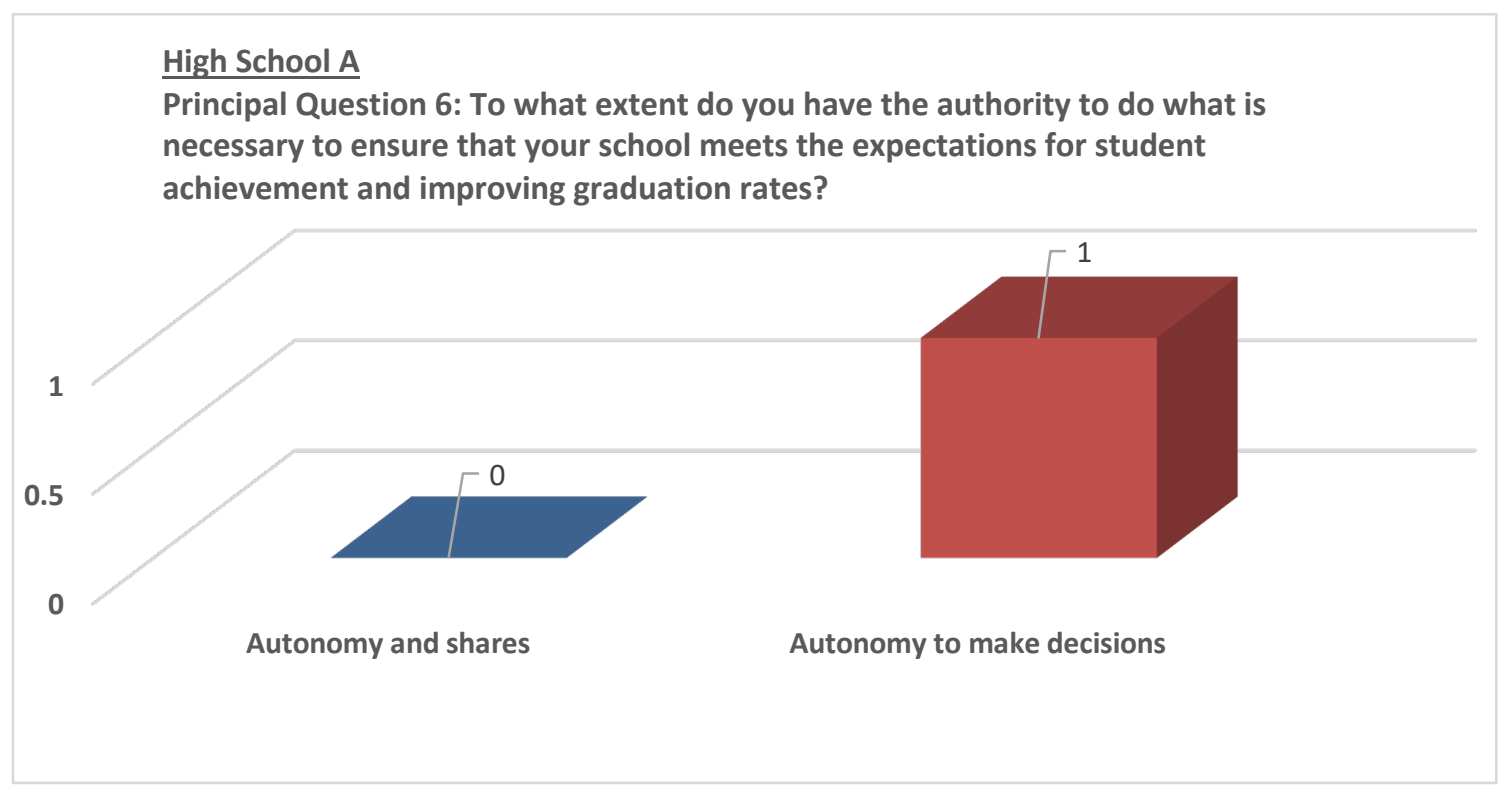

Figure 57. Summary of Principal A's responses to Question 6. The number of times a principal described their level of authority and autonomy in decision making with respect to ensuring their school meets the expectations for student achievement and graduation rates. 


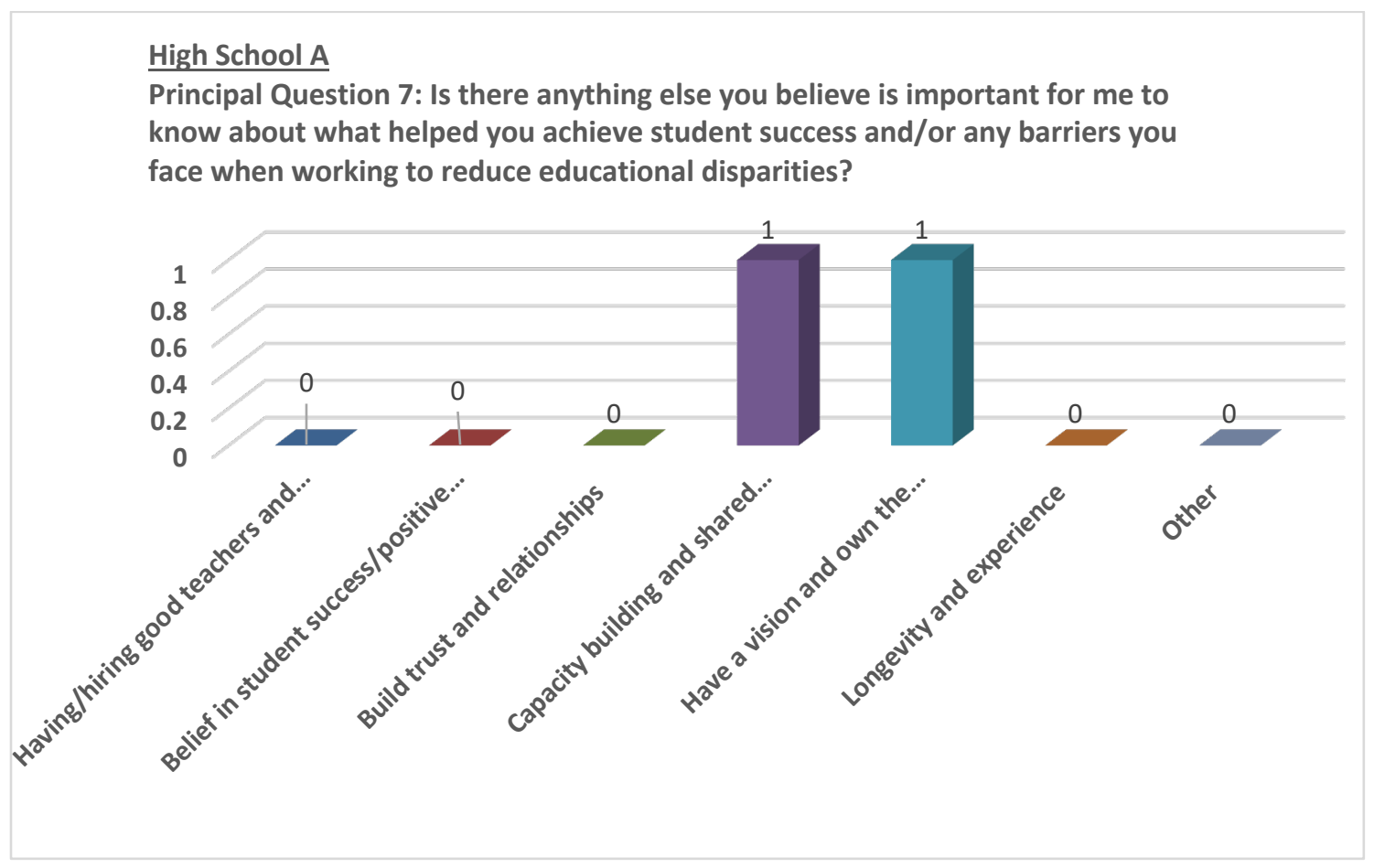

Figure 58. Summary of Principal A's responses to Question 7. The number of times a principal described additional factors they deemed important in ensuring their school improve student success and reduce educational disparities.

\section{Building B: Individual principal responses questions (1-7). Principal B}

attributed the success of their school to a wide range of variables; however, they specifically identify the primary barrier to student success as poor parental involvement or support at home. In order to address these external barriers, Principal B focused on creating a positive school culture and stable environment throughout the school and every classroom. Principal B attributed the strong school culture to the strong relationships among the students, staff and administration as well as an open, diverse and accepting cultural atmosphere. Principal B indicated the value of being a visible leader, acting with integrity, maintaining a growth mindset, effectively communicating, and providing 
follow-through with every interaction. Principal B sees principals as having complete autonomy to make decisions but shares some of those decisions with staff leadership. This strategy aligns with the principal's last comments on Question 7, where the principal indicated that building trust and capacity in staff and implementing shared decision making may have ultimately contributed to their recent increases in student success. See Figures 59-65 for visual summaries of responses from Principal B.

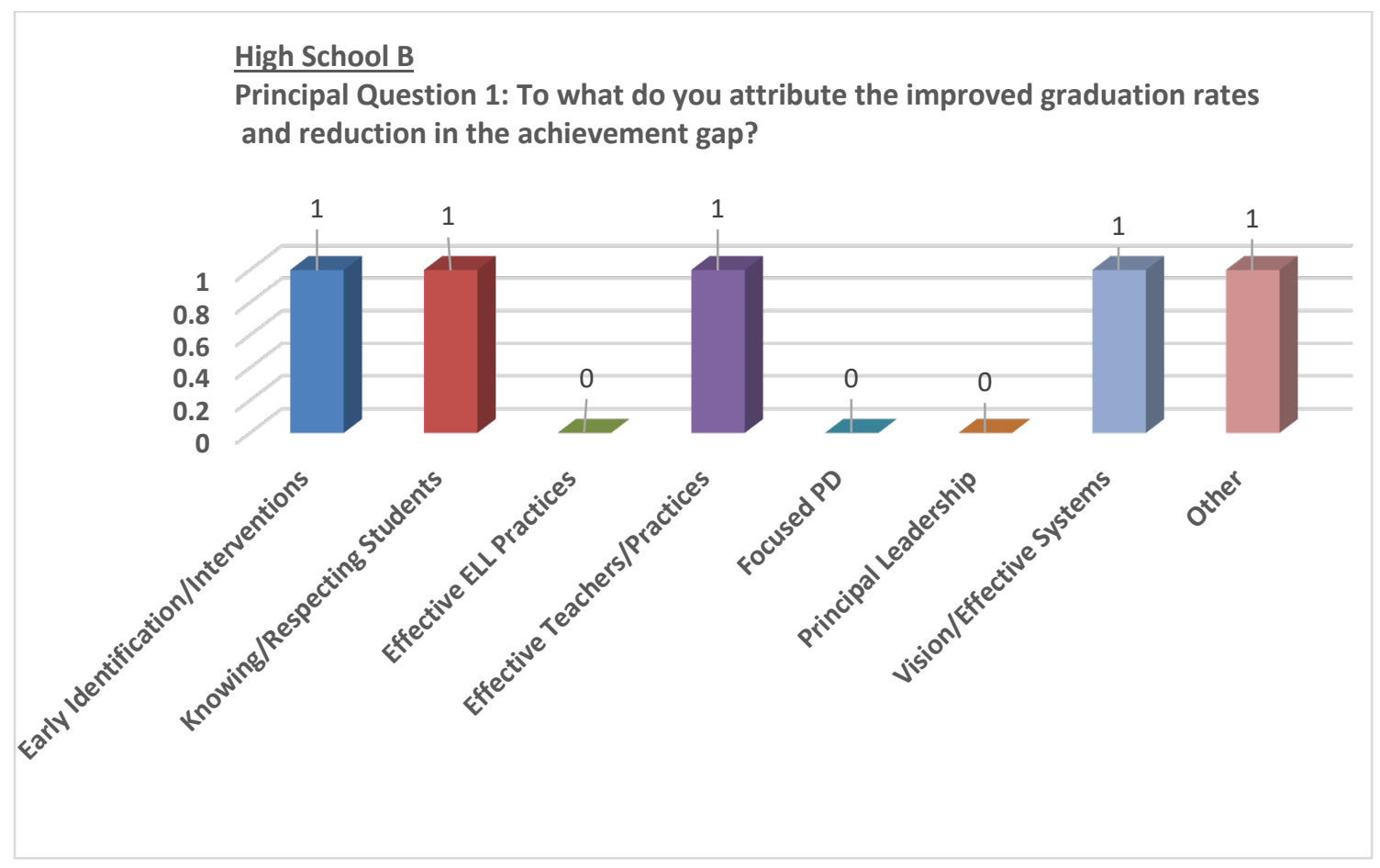

Figure 59. Summary of Principal B's responses to Question 1. The number of times a principal attributed the above factors to improving student achievement. 


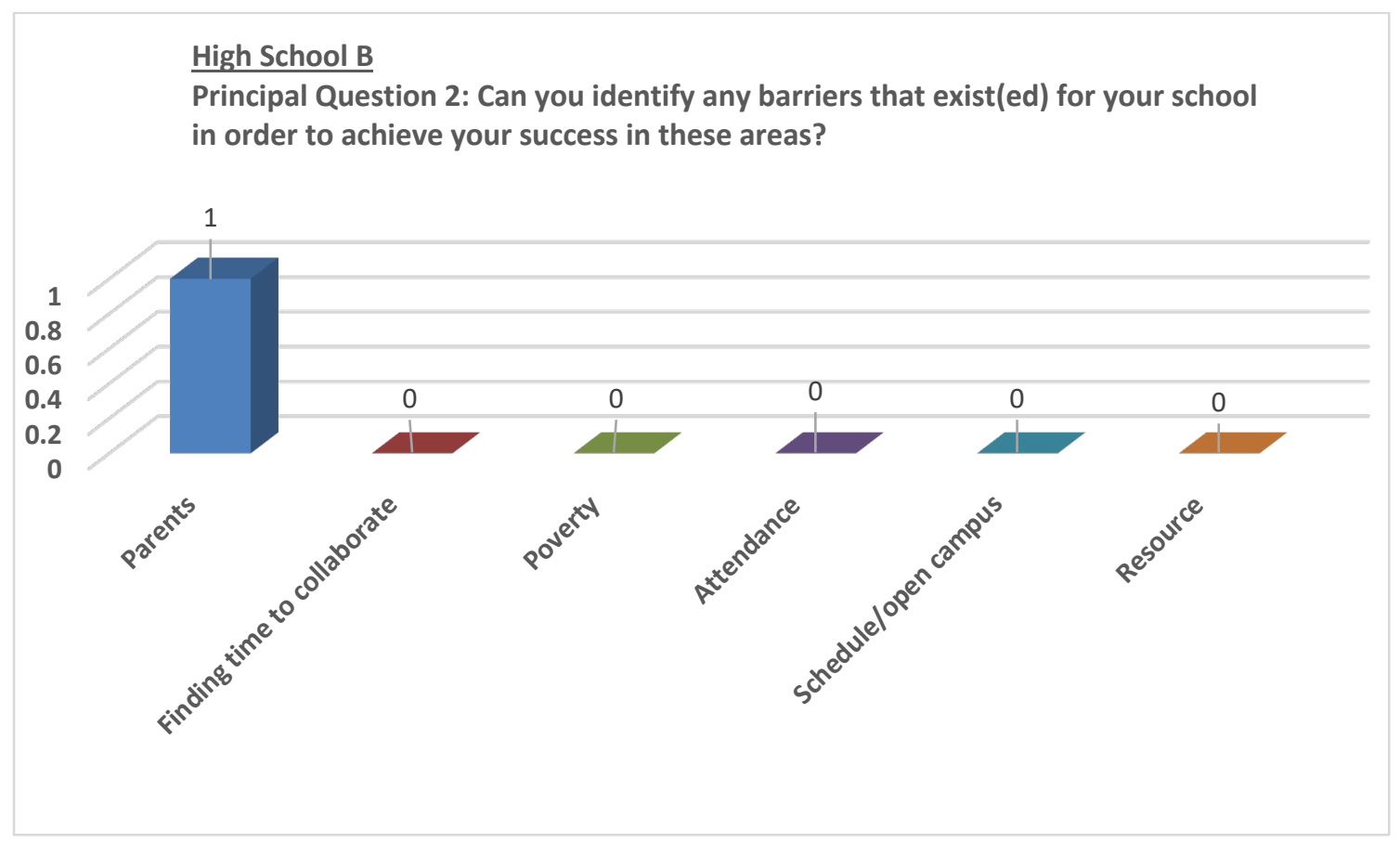

Figure 60. Summary of Principal B's responses to Question 2. The number of times a principal identified the above factors as barriers to student achievement.

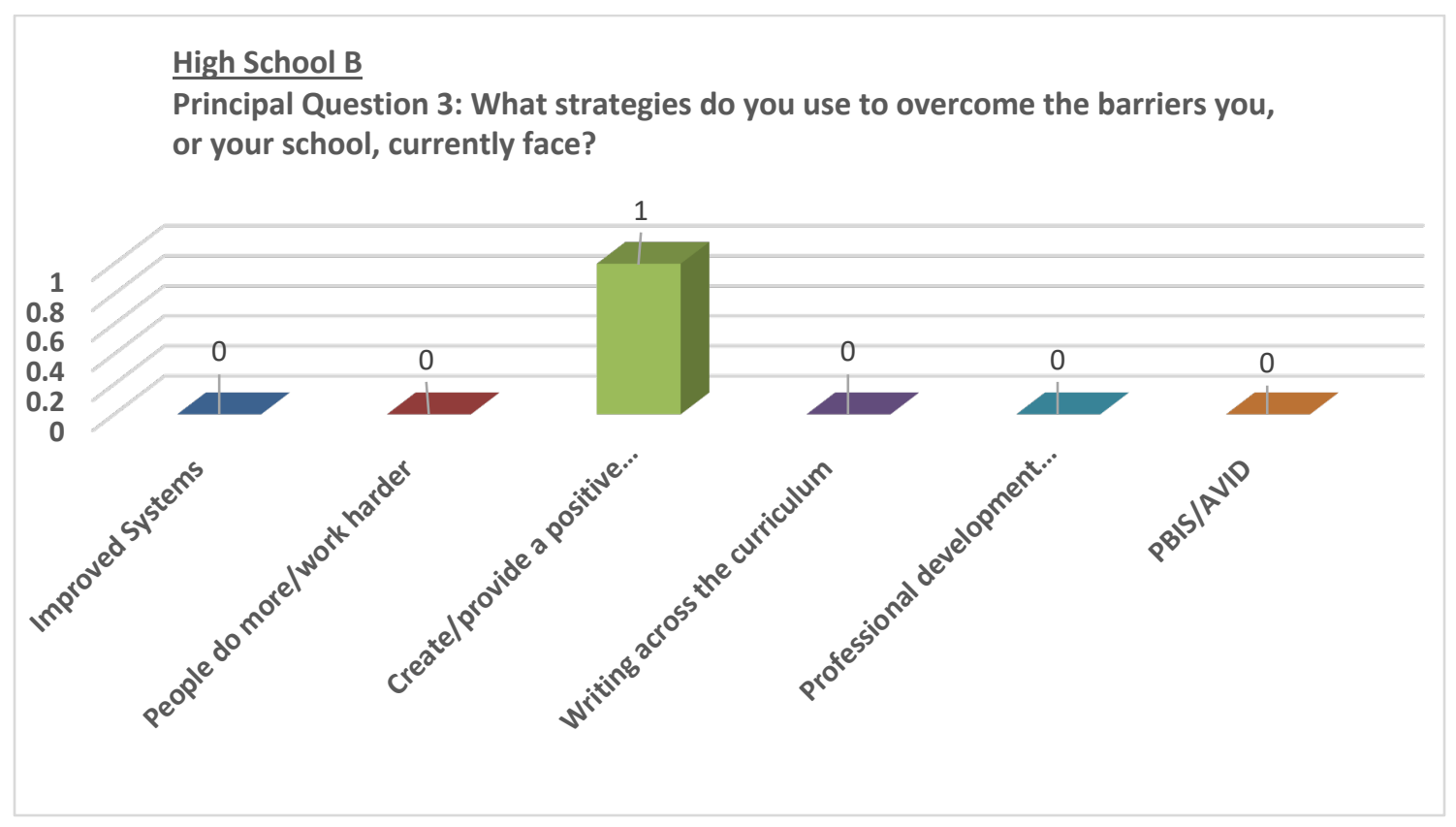

Figure 61. Summary of Principal B's responses to Question 3. The number of times a principal utilized the above factors to overcome barriers to student achievement. 


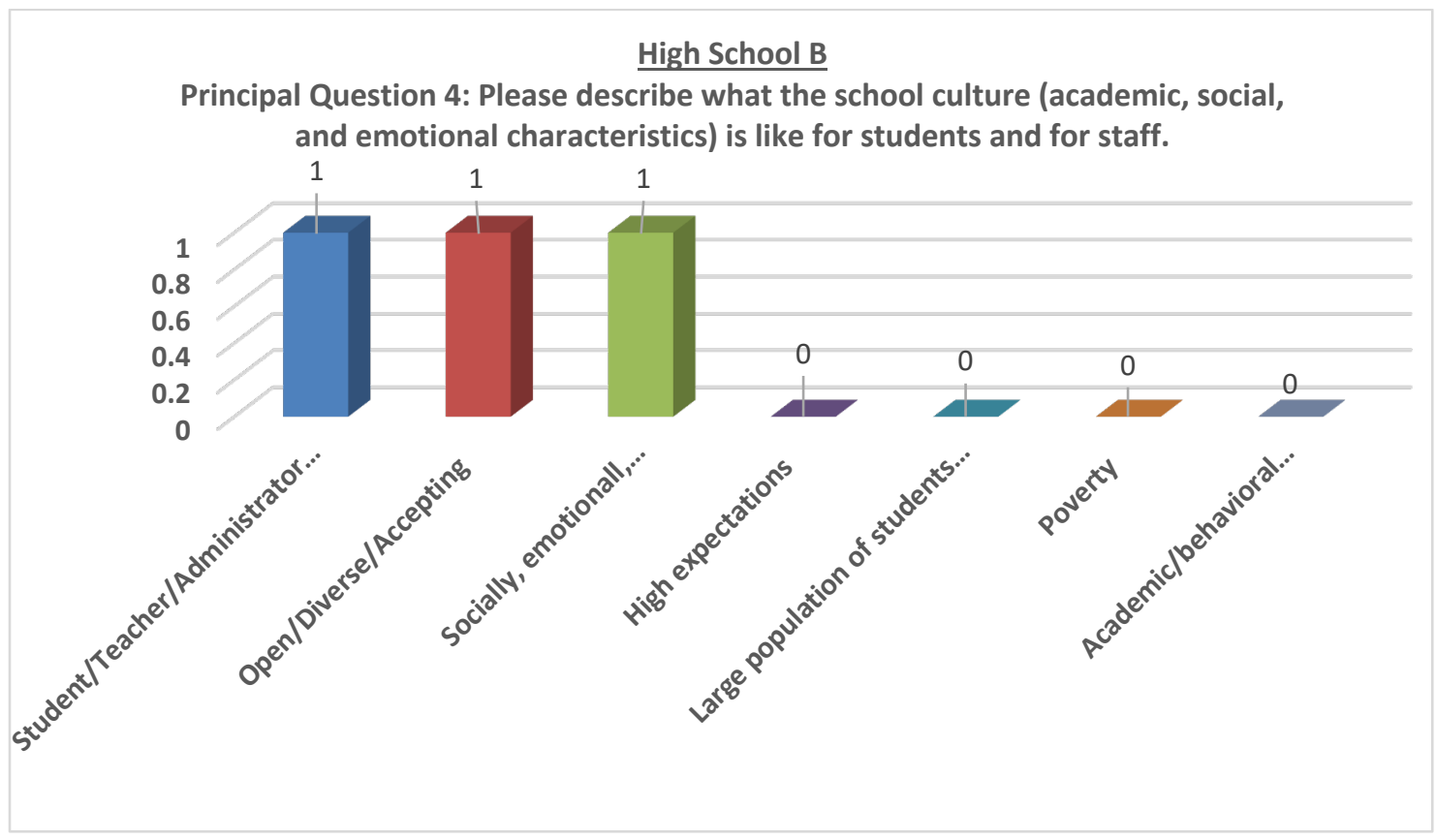

Figure 62. Summary of Principal B's responses to Question 4. The number times a principal indicated the following characteristics as being descriptive of their school culture.

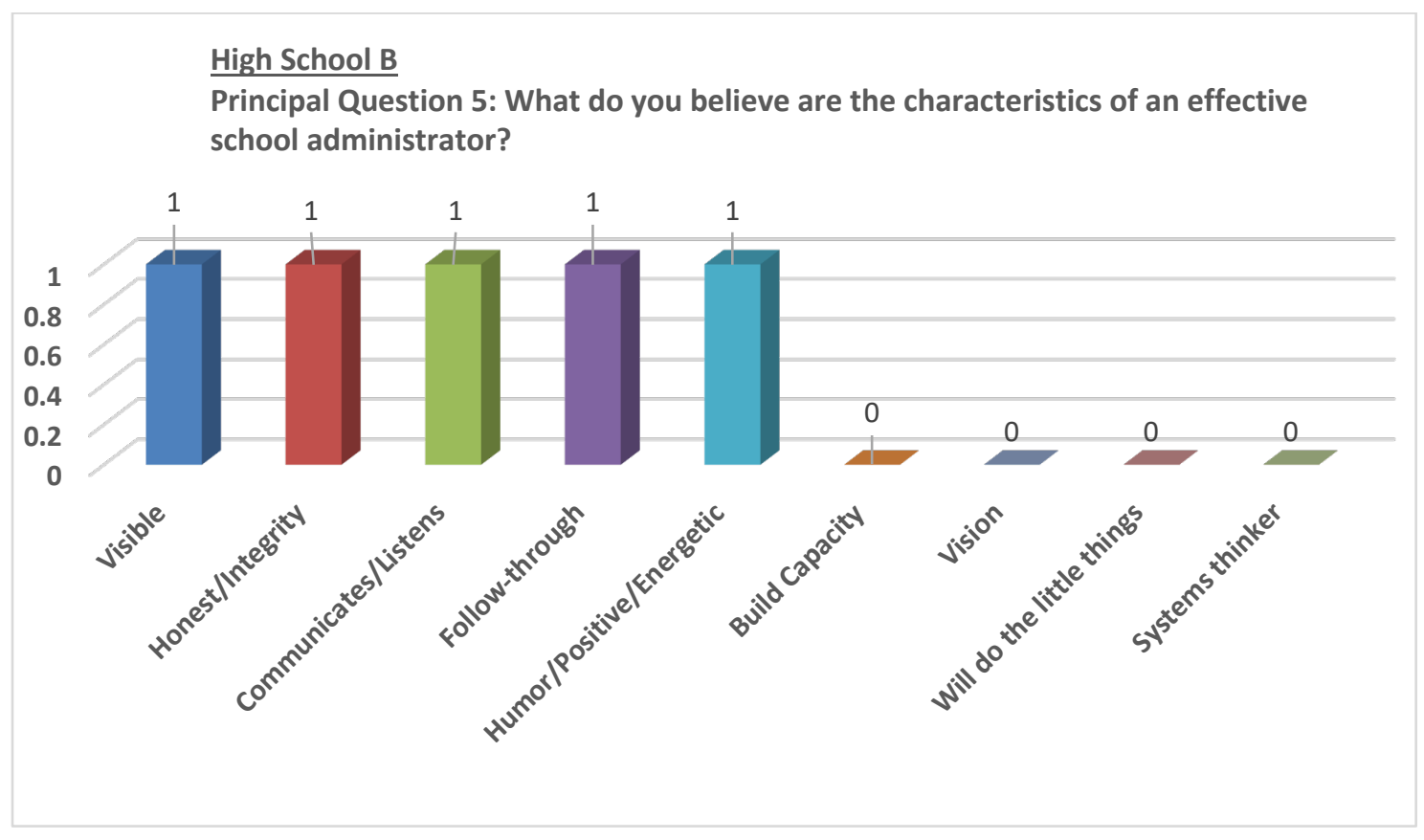

Figure 63. Summary of Principal B's responses to Question 5. The number of times a principal indicated the above factors as characteristics of an effective school administrator. 


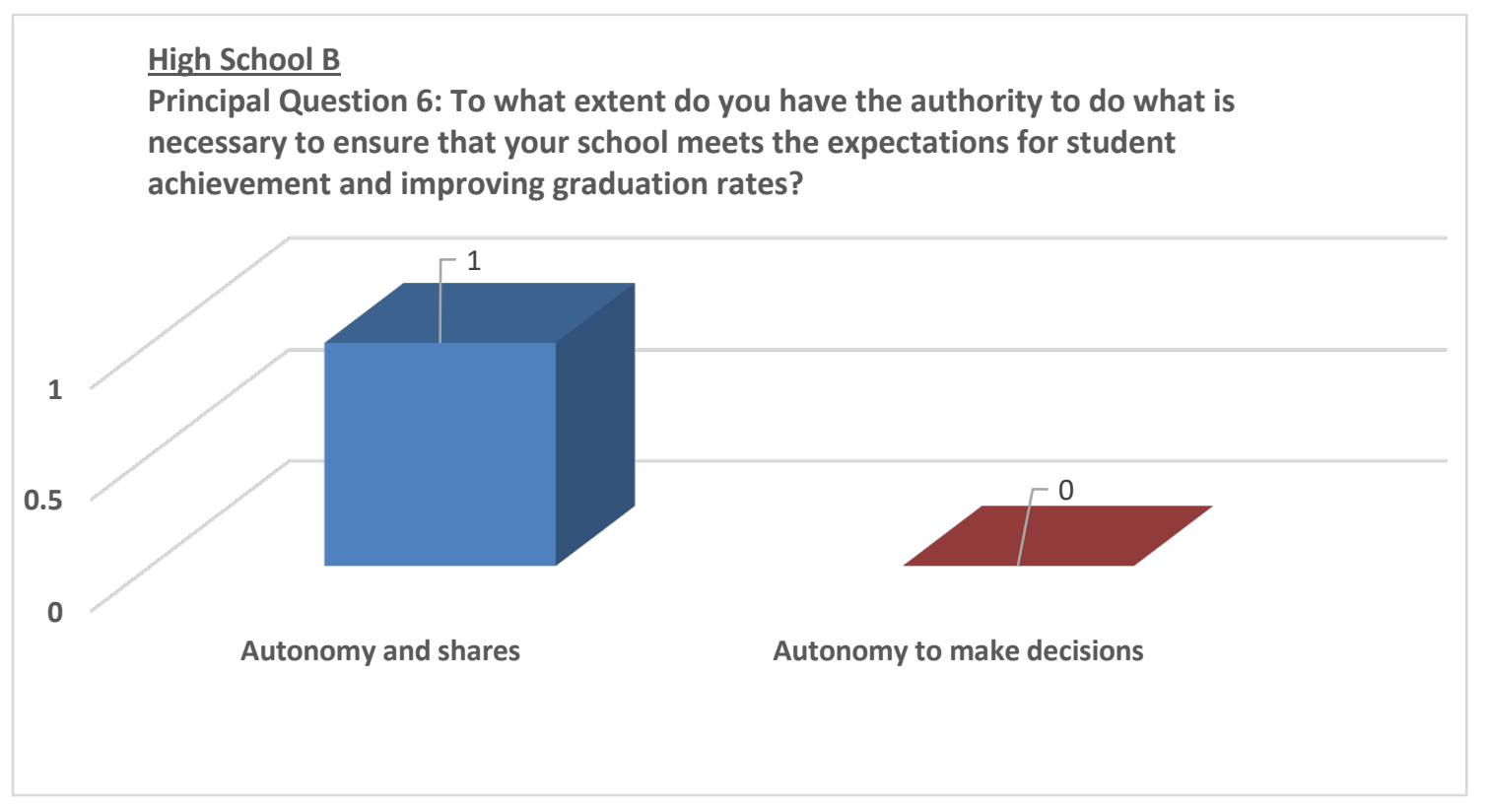

Figure 64. Summary of Principal B's responses to Question 6. The number of times a principal described their level of authority and autonomy in decision making with respect to ensuring their school meets the expectations for student achievement and graduation rates.

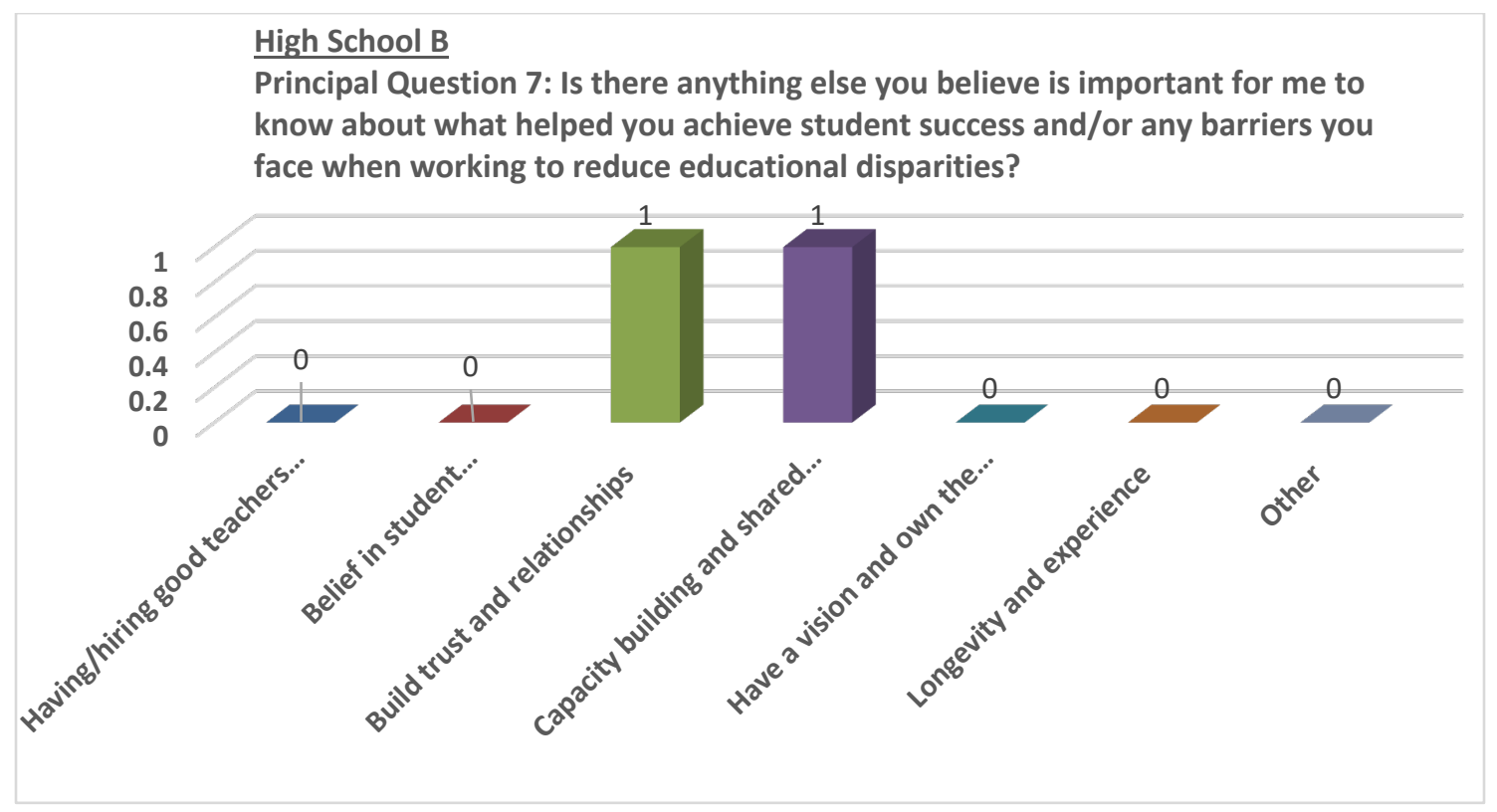

Figure 65. Summary of Principal B's responses to Question 7. The number of times a principal described additional factors they deemed important in ensuring their school improve student success and reduce educational disparities. 
Building C: Individual principal responses questions (1-7). Providing early academic interventions and knowing and respecting the student population are the factors Principal $\mathrm{C}$ identified as contributing to the overall increase in student achievement. Socio-economic status (poverty) and a lack of collaboration time are identified as the primary barriers to student success at Building C. Although Principal C clearly identified two barriers to success, the teacher leaders identify only one strategy, targeted professional development aimed at targeting the needs of students in poverty, as an attempt to overcome those barriers. It could be perceived that Principal C chose not to focus on addressing teacher collaboration time because it is a variable that is reliant upon a change in the schedule and not in the prevue of their authority. Principal C identified strong communication skills, follow through, visibility and presence, and a strong central vision to be important qualities in an effective administrator. Additionally, Principal C indicated that strong hiring practices and having good teachers contributes significantly to the ability of a school to reduce the achievement gap and increase student success, and they have the autonomy and authority to make those decisions. See Figures 66-72 for visual summaries of responses from Principal C. 


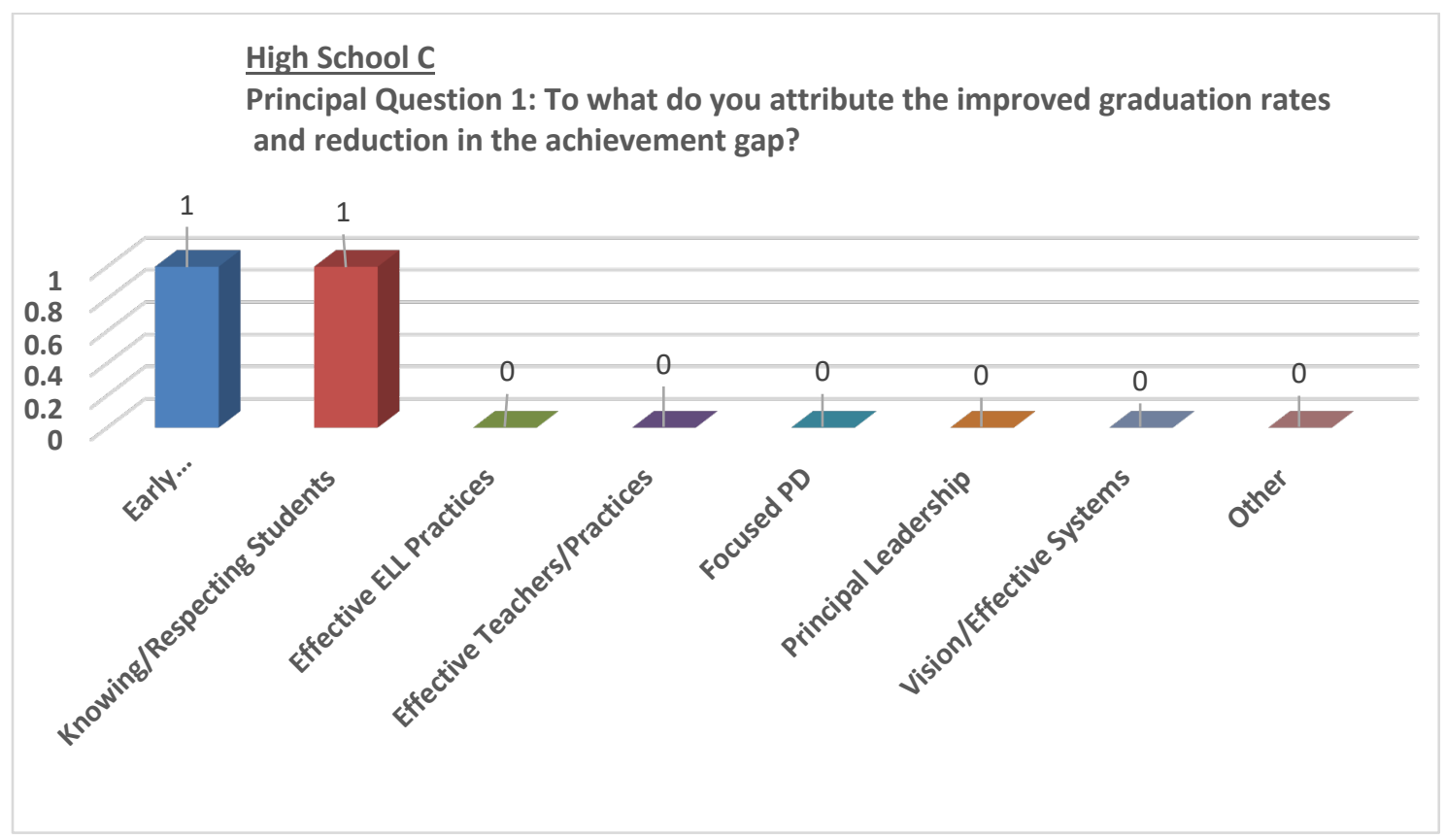

Figure 66. Summary of Principal C's responses to Question 1. The number of times a principal attributed the above factors to improving student achievement.

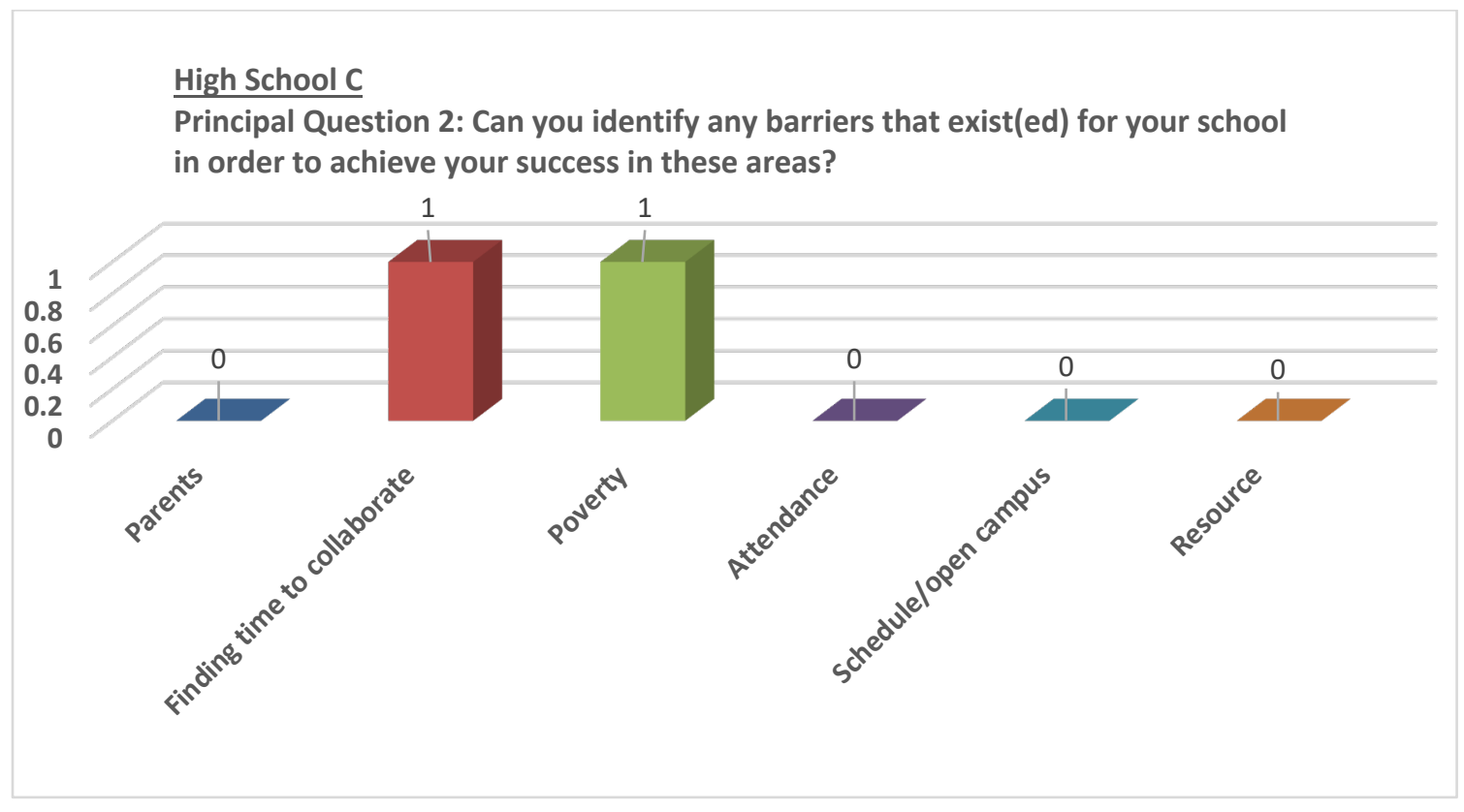

Figure 67. Summary of Principal C's responses to Question 2. The number of times a principal identified the above factors as barriers to student achievement. 


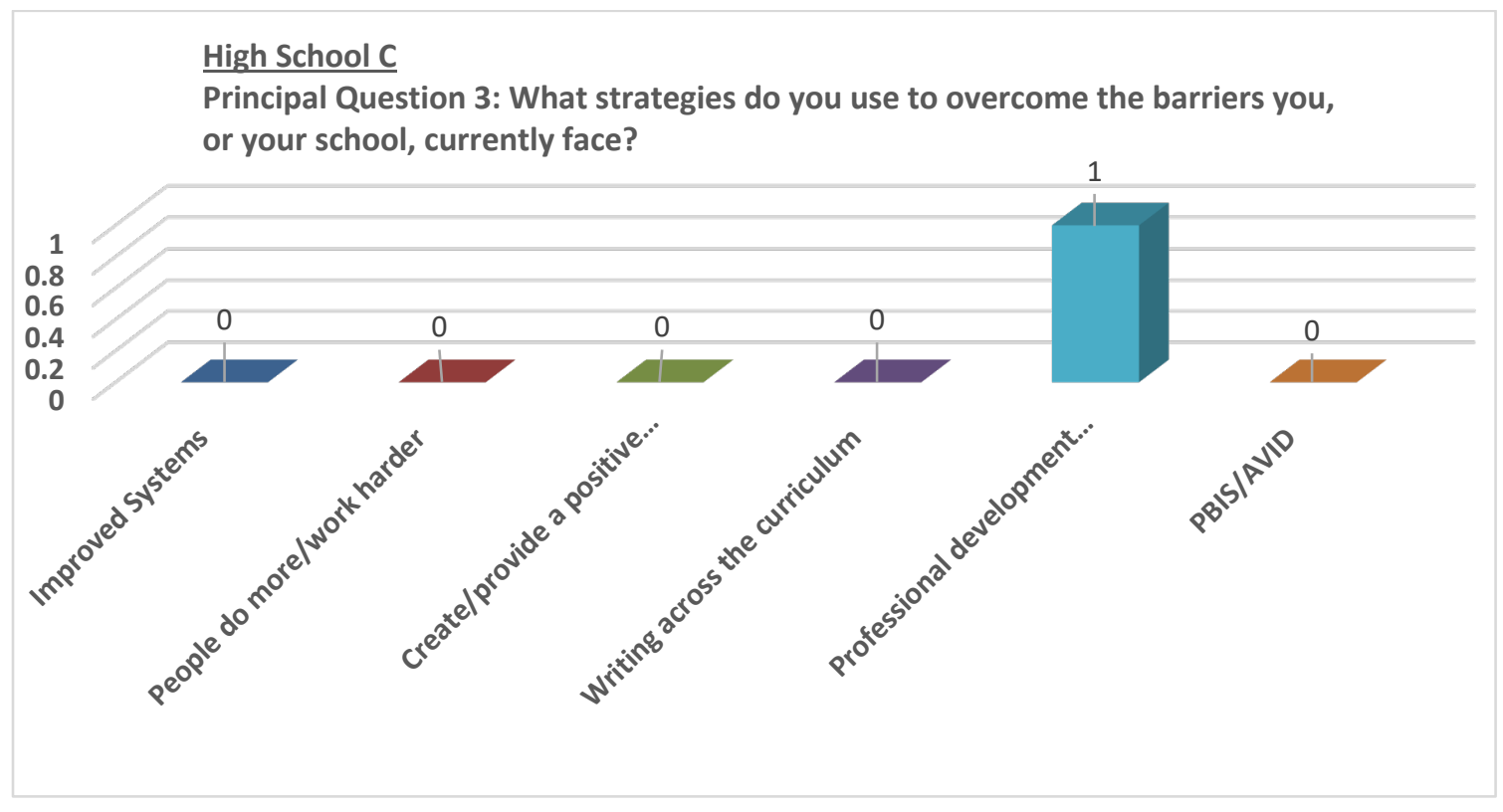

Figure 68. Summary of Principal C's responses to Question 3. The number of times a principal utilized the above factors to overcome barriers to student achievement.

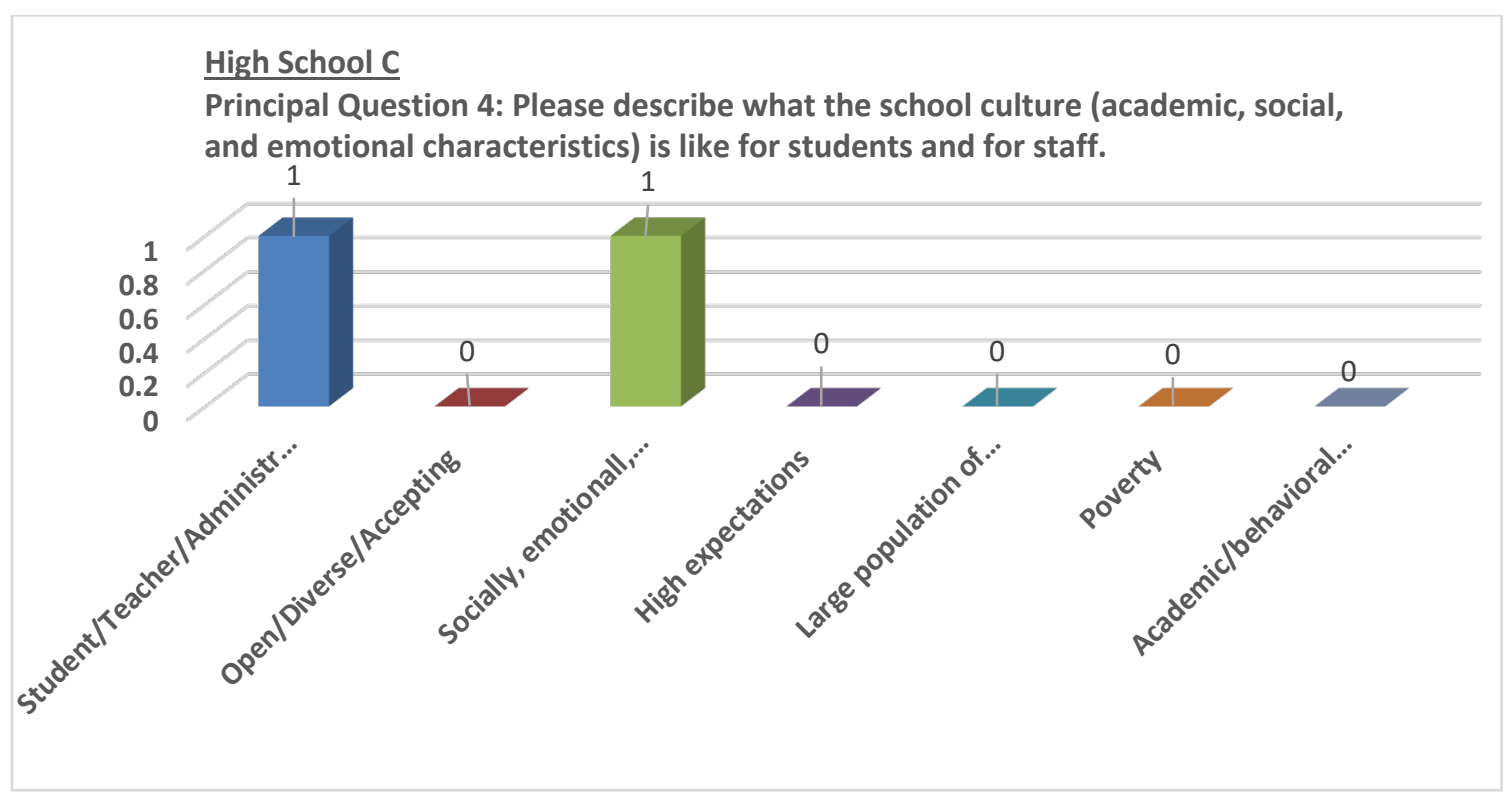

Figure 69. Summary of Principal C's responses to Question 4. The number times a principal indicated the above characteristics as being descriptive of their school culture. 


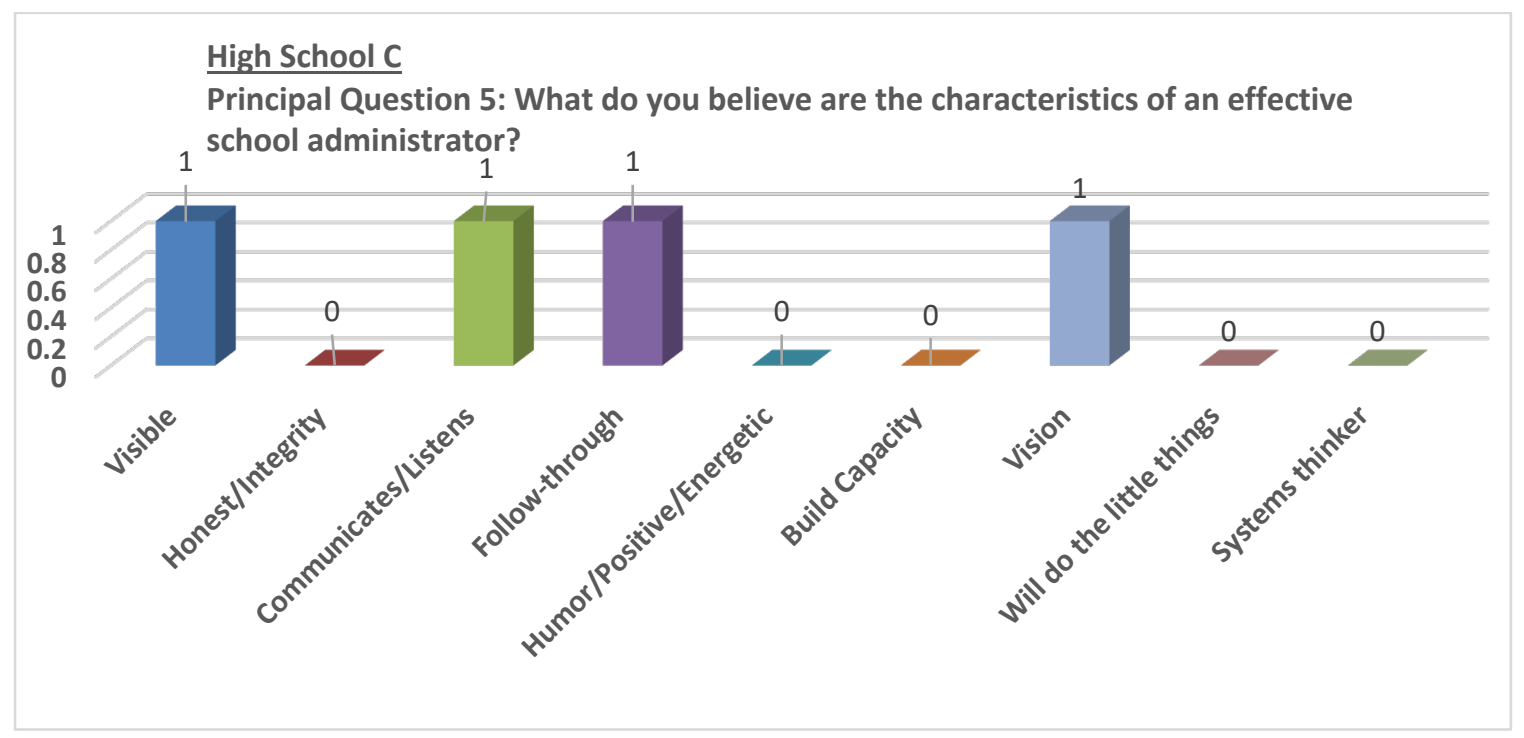

Figure 70. Summary of Principal C's responses to Question 5. The number of times a principal indicated the above factors as characteristics of an effective school administrator.

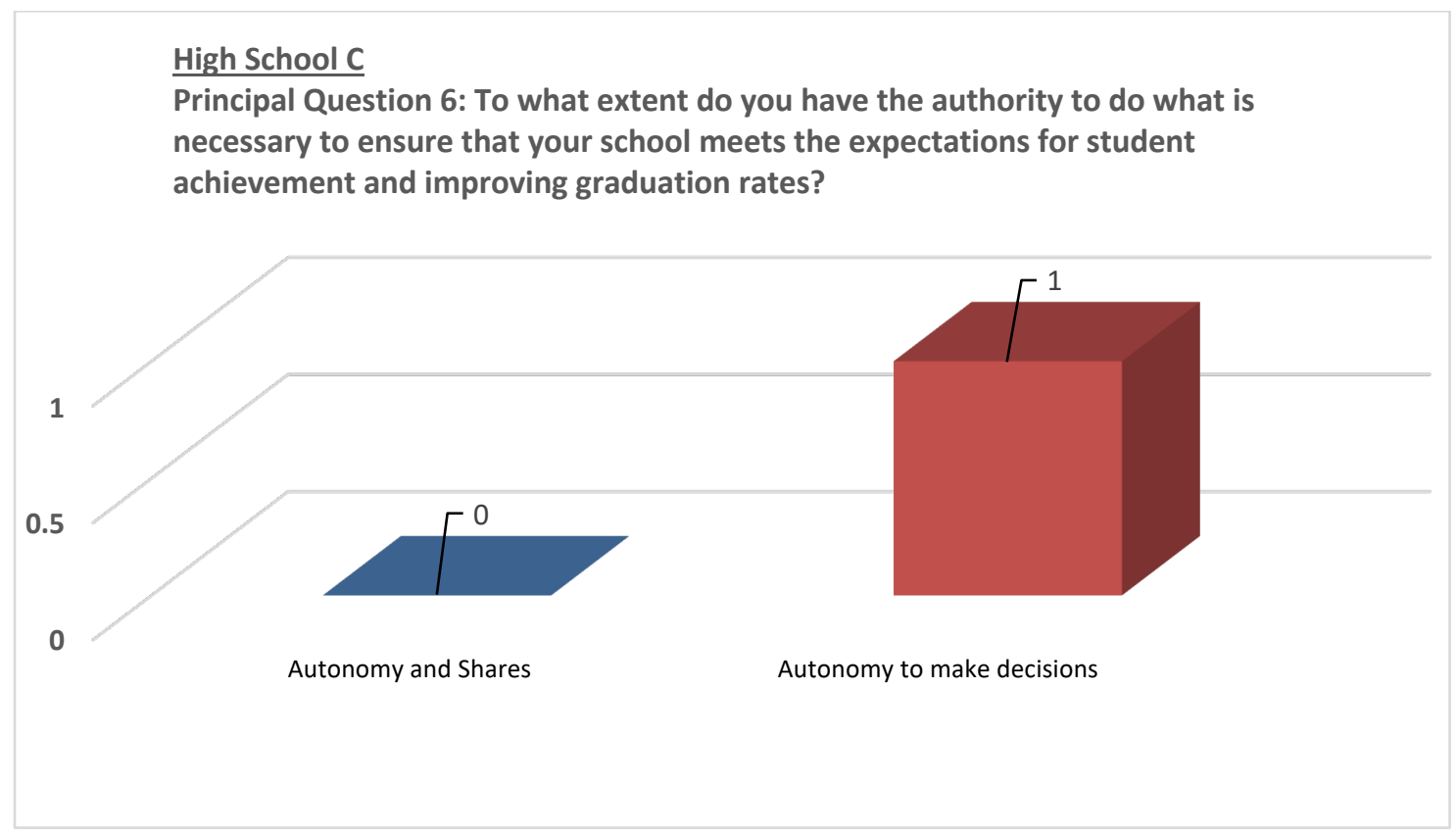

Figure 71. Summary of Principal C's responses to Question 6. The number of times a principal described their level of authority and autonomy in decision making with respect to ensuring their school meets the expectations for student achievement and graduation rates. 


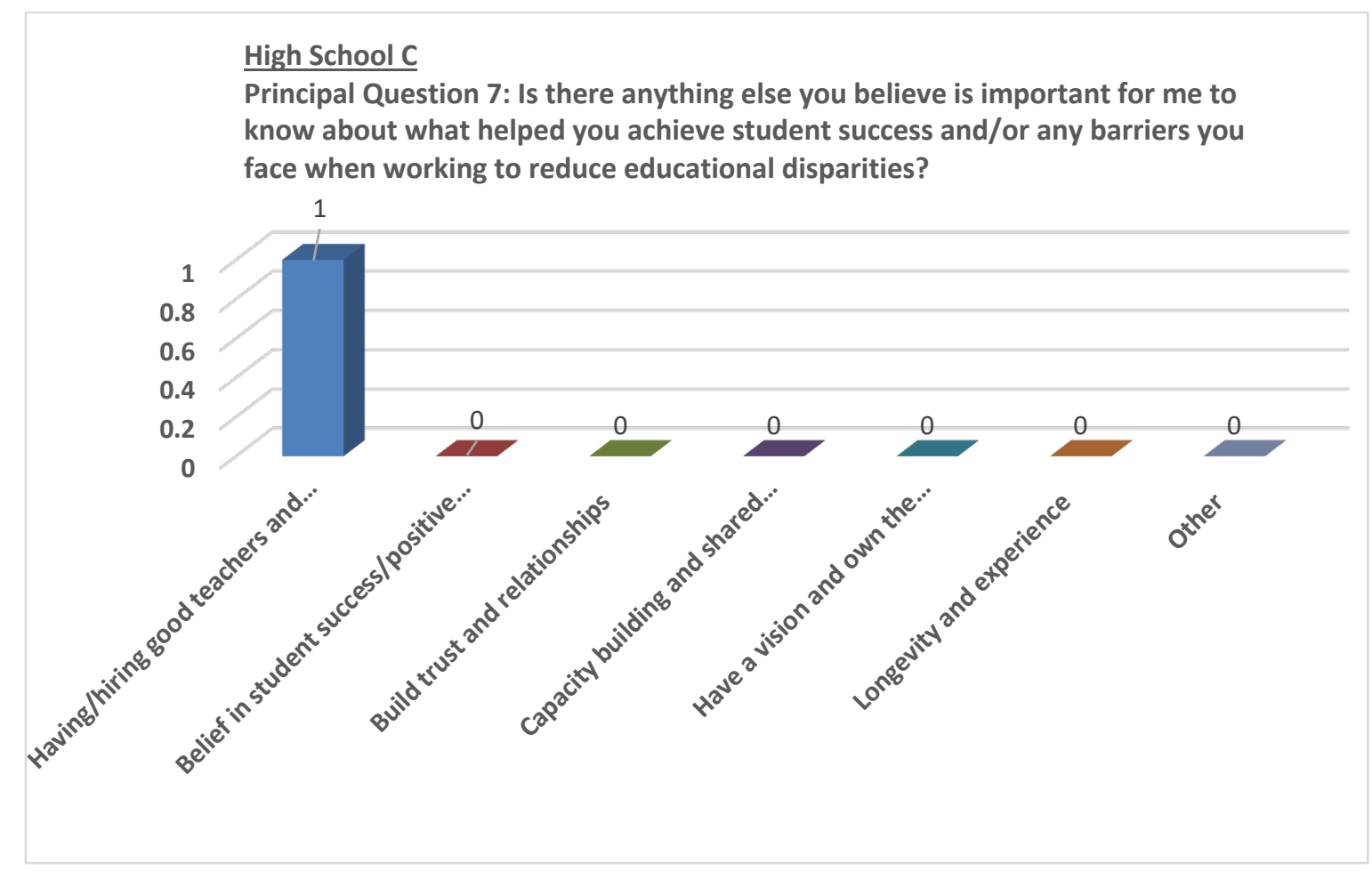

Figure 72. Summary of Principal C's responses to Question 7. The number of times a principal described additional factors they deemed important in ensuring their school improve student success and reduce educational disparities.

\section{Building D: Individual principal responses questions (1-7). Principal D}

contributes focused professional development, highly effective teaching practices and strong principal leadership as the primary reasons behind their improved graduation rates and reduction in the achievement gap. The major barrier to improving student success according to Principal D was finding time for teachers to collaborate. The strategy identified as having the most success in addressing the identified barrier was the implementation of "writing across the curriculum." This strategy may be effective in supporting the needs of the students which Principal D described as being deeply impacted by poverty with high social, emotional, and academic needs. Building does 
provide an internal school cultural with high expectations, academic and behavioral supports, targeted intervention systems, and strong interpersonal relationships between the students, staff and administration. According to Principal D, a successful administrator must have a wide range of abilities including being a positive, visible leader that acts with integrity and follows through on their decisions. Effective characteristics of a school administrator were also identified as an experienced, systems-level thinker with a vision that includes building staff capacity. Principal D enjoyed complete autonomy in decision making and acknowledged the ability to hire effective teachers and remove poor performing teachers as a critical factor in improving school performance. See Figures 7379 for visual summaries of responses from Principal D.

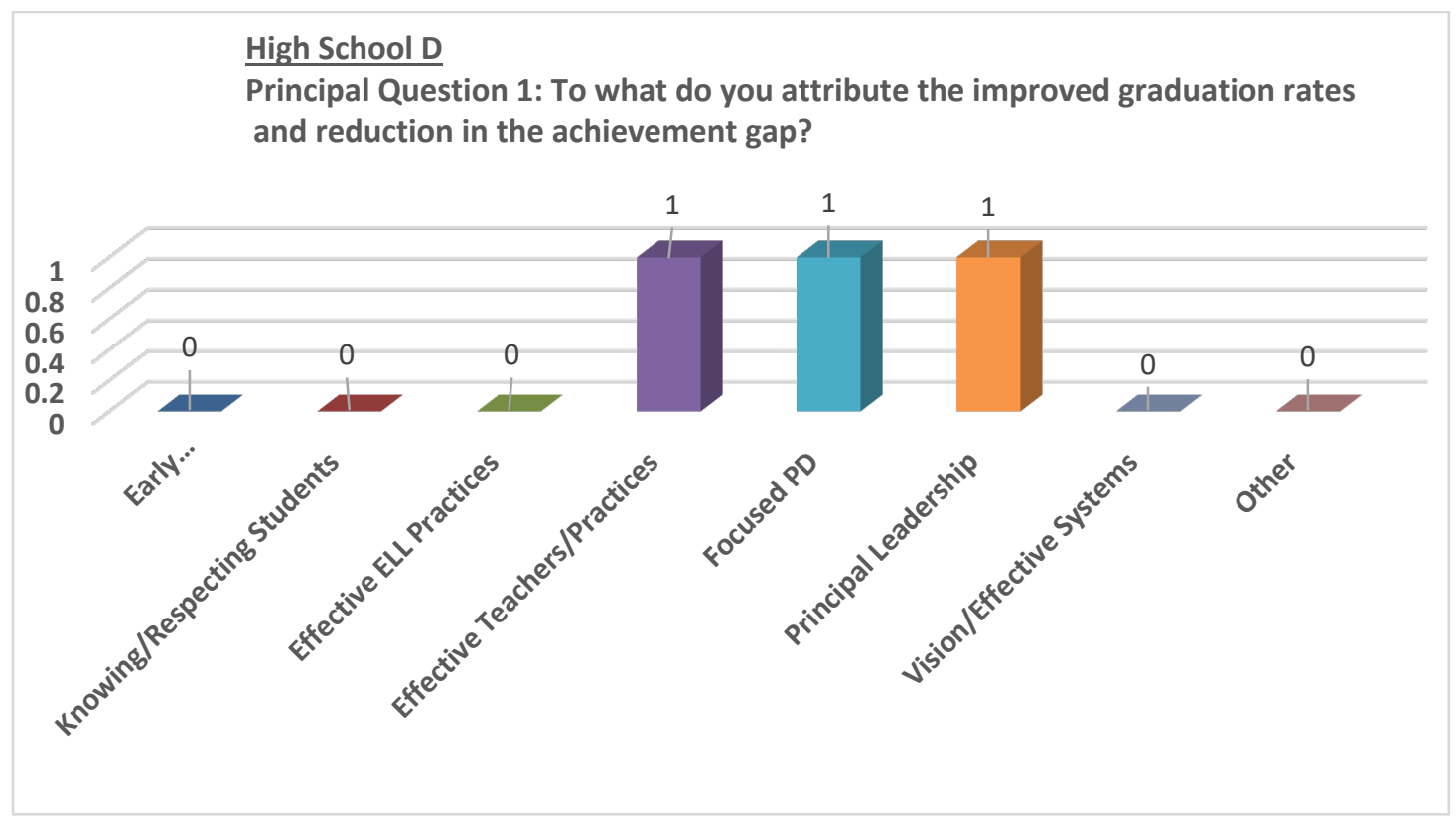

Figure 73. Summary of Principal D's responses to Question 1. The number of times a principal attributed the above factors to improving student achievement. 


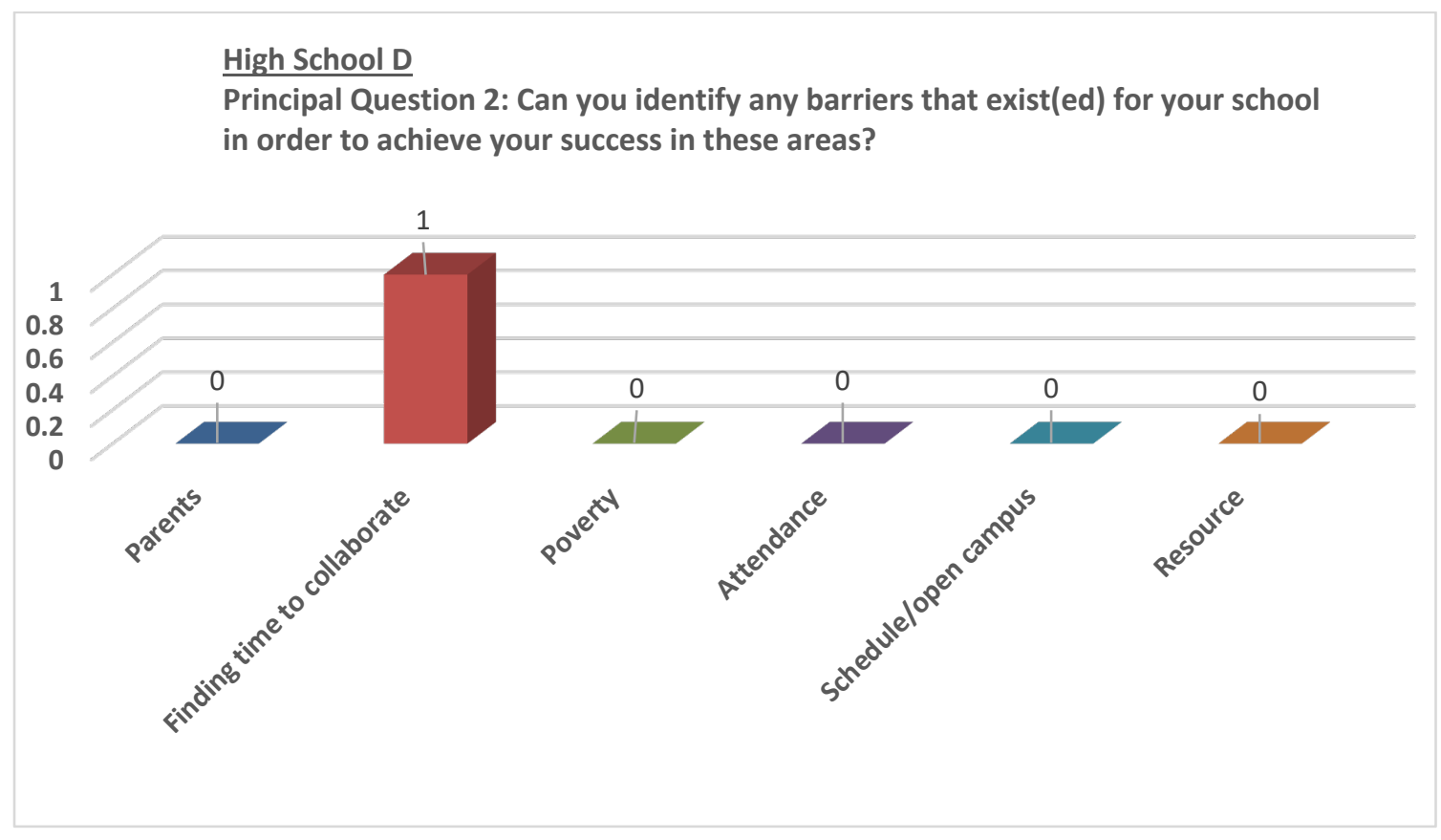

Figure 74. Summary of Principal D's responses to Question 2. The number of times a principal identified the above factors as barriers to student achievement.

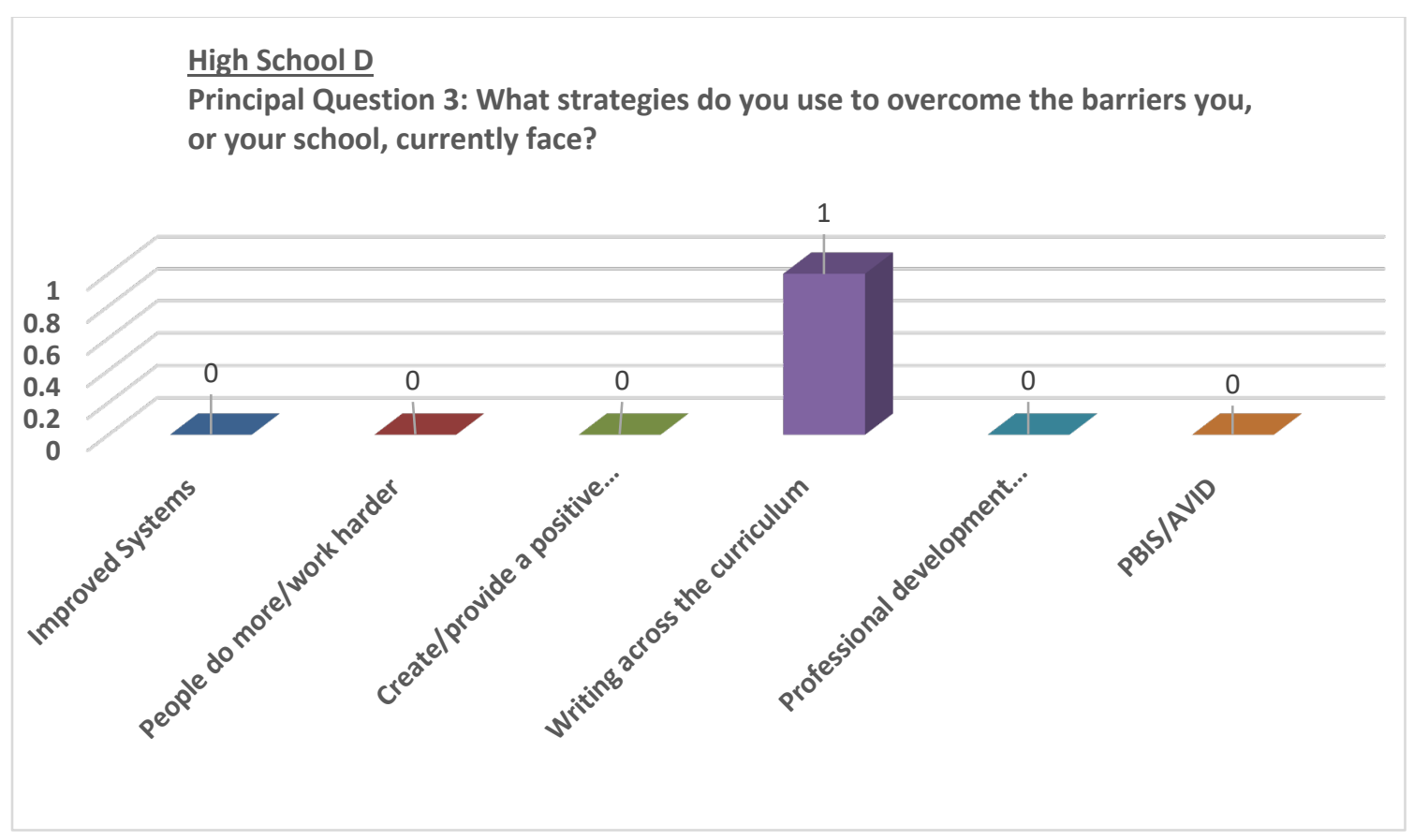

Figure 75. Summary of Principal D's responses to Question 3. The number of times a principal utilized the above factors to overcome barriers to student achievement. 


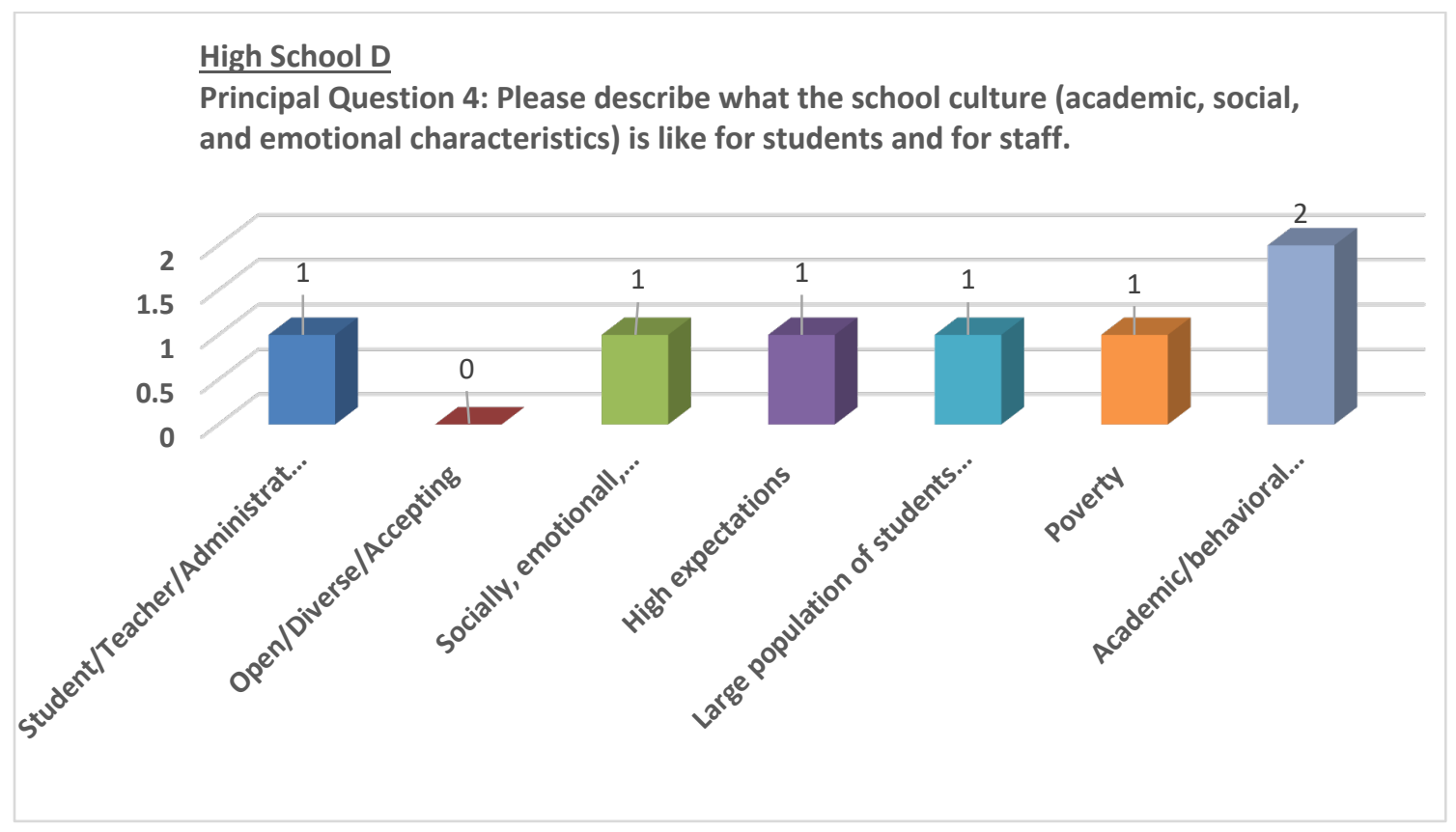

Figure 76. Summary of Principal D's responses to Question 4. The number times a principal indicated the following characteristics as being descriptive of their school culture.

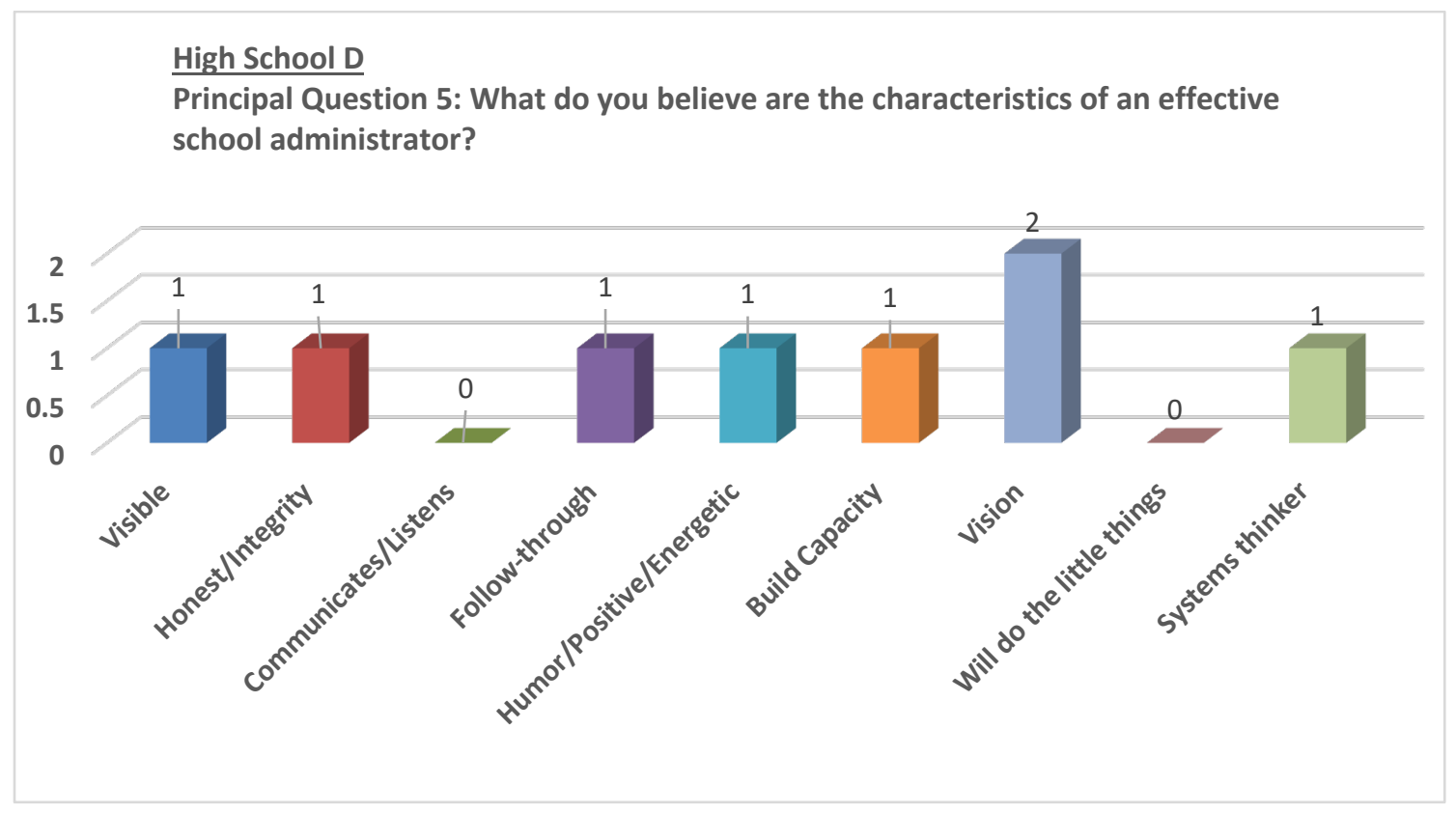

Figure 77. Summary of Principal D's responses to Question 5. The number of times a principal indicated the above factors as characteristics of an effective school administrator. 


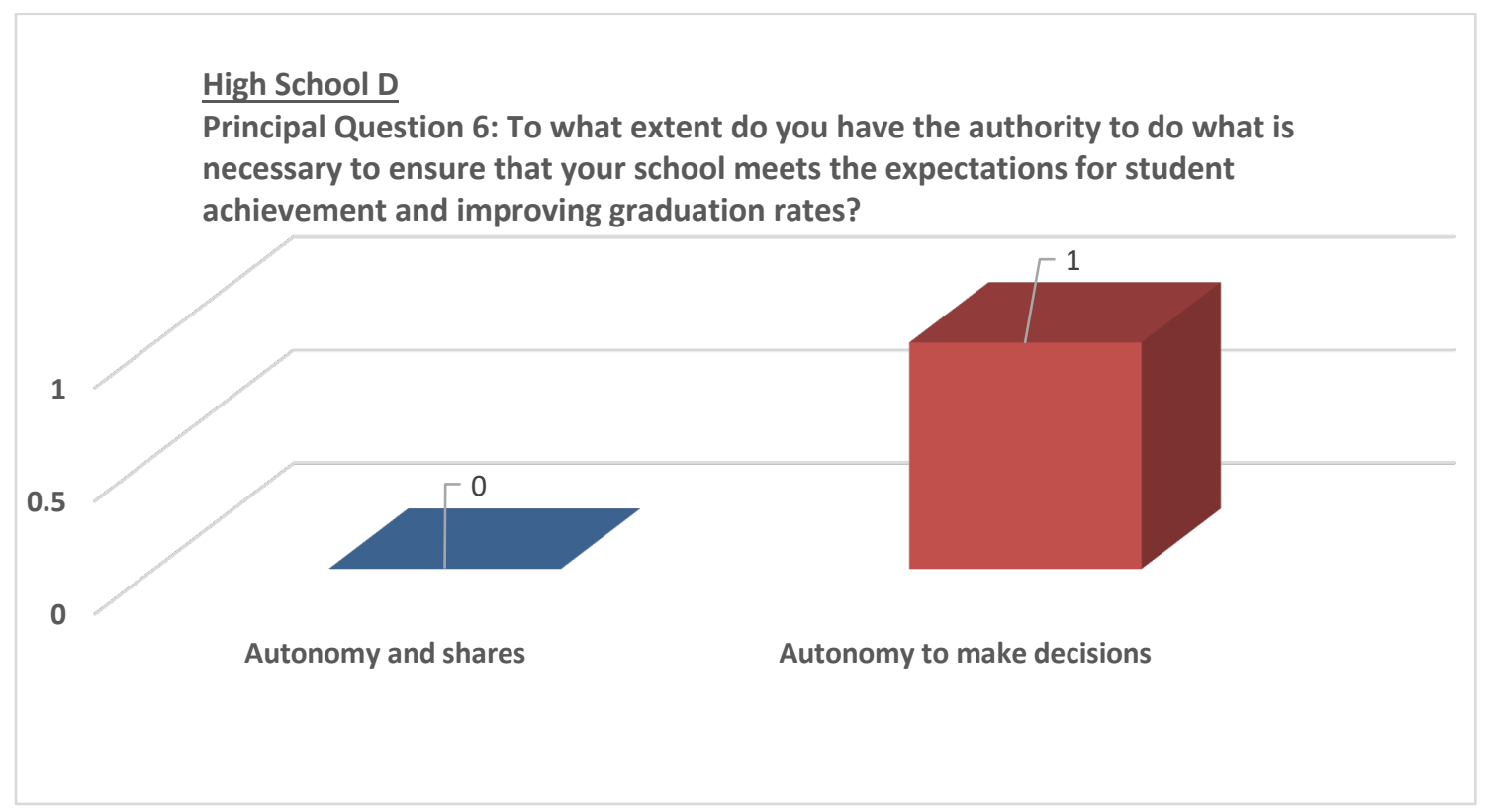

Figure 78. Summary of Principal D's responses to Question 6. The number of times a principal described their level of authority and autonomy in decision making with respect to ensuring their school meets the expectations for student achievement and graduation rates.

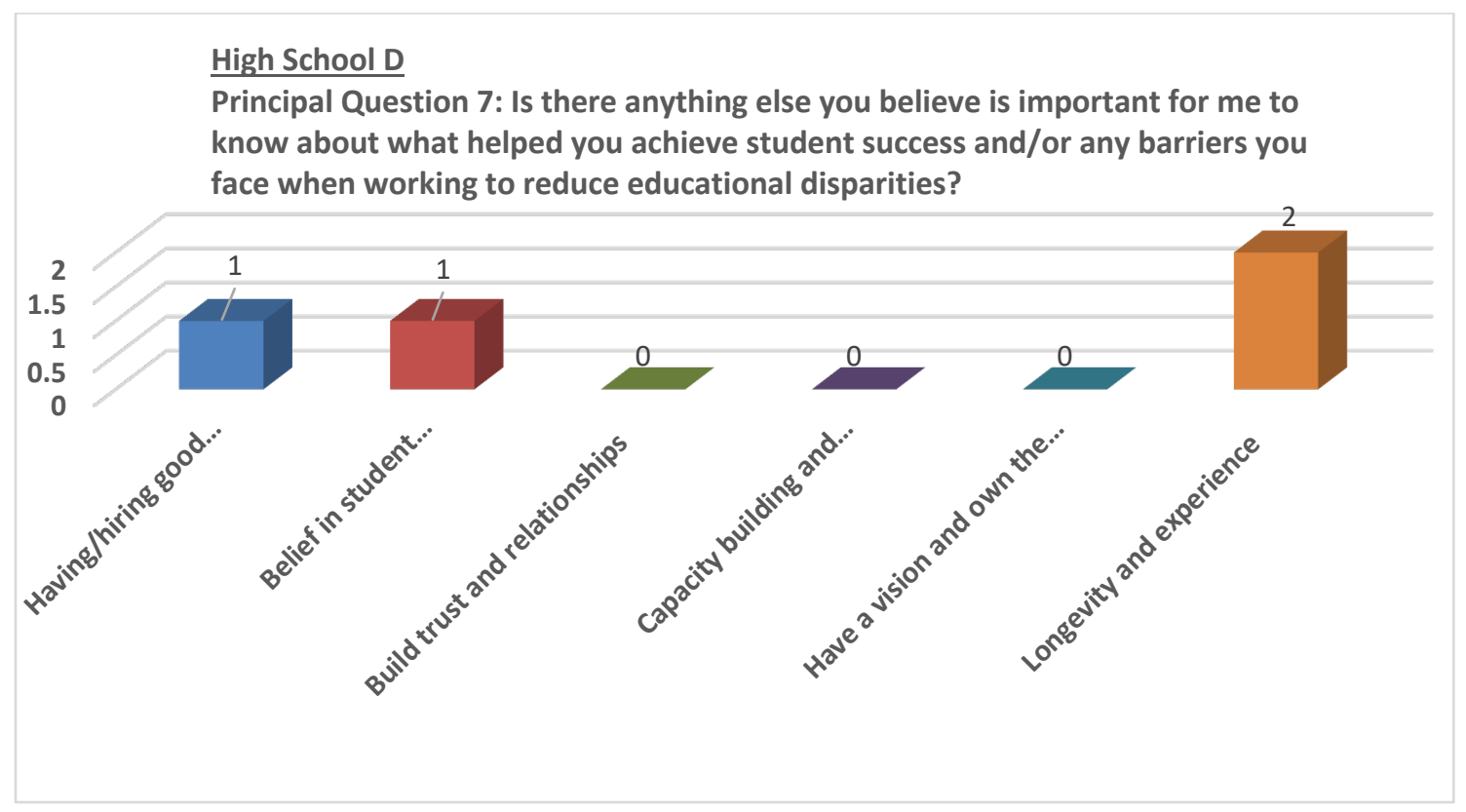

Figure 79. Summary of Principal D's responses to Question 7. The number of times a principal described additional factors they deemed important in ensuring their school improve student success and reduce educational disparities. 
Building E: Individual principal responses questions (1-7). Principal E

attributes effective ELL practices as the most significant factor in the improvement of their school's graduation rate and overall student achievement. The identified barriers were external and system-level variables, such as attendance rates and open schedules. In response to these concerns, Principal E improved internal building systems, promoted a positive and welcoming school climate, and implemented multi-tiered systems of support for students using Advancement Via Individual Determination and Positive Behavioral Interventions and Supports. Principal E described their school culture as open and diverse, relationship focused, with high academic expectations for all students. Principal E cited only three primary variables as critical to effective school leadership; a clear vision, an effective communicator, and approaching everything with a growth mindset. Principal E enjoyed complete autonomy in decision-making and when asked to provide their final thoughts in Question 7 described the most significant barrier in school improvement is poor instruction. Furthermore, the time needed in the formal process of evaluating and removing sub-par teachers is extremely difficult. See Figures $80-86$ for a visual summary of Principal E’s responses. 


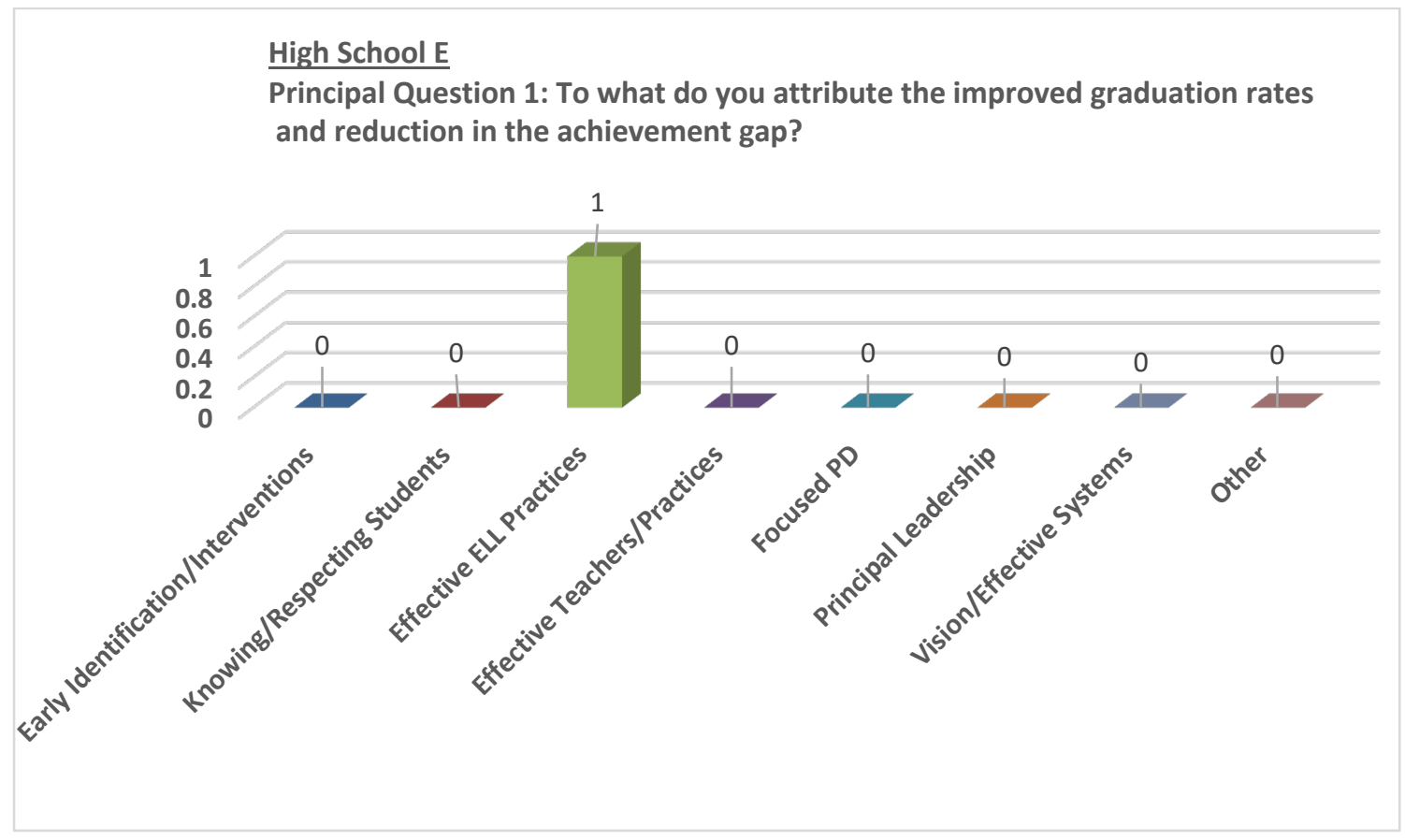

Figure 80. Summary of Principal E's responses to Question 1. The number of times a principal attributed the above factors to improving student achievement.

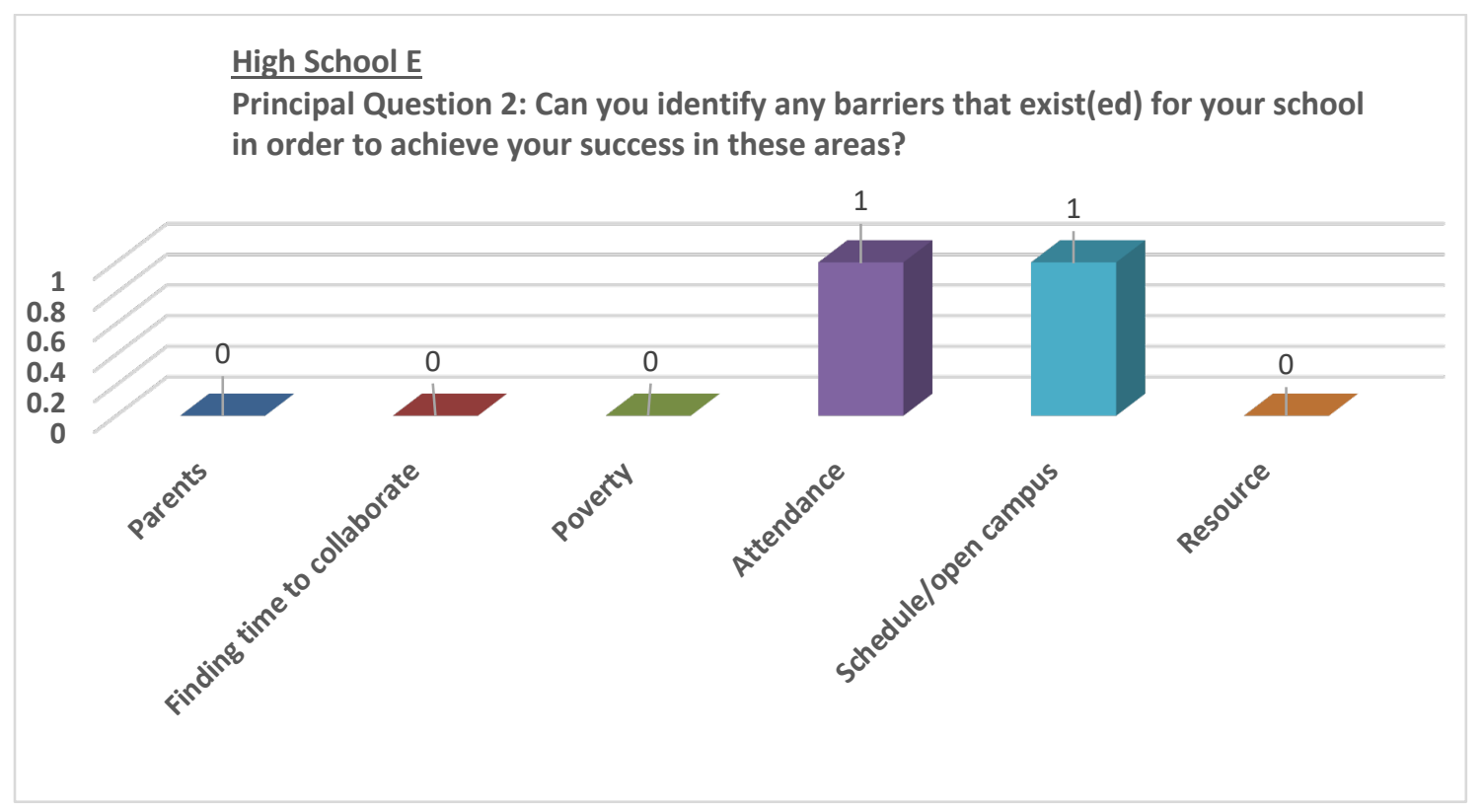

Figure 81. Summary of Principal E's responses to Question 2. The number of times a principal identified the above factors as barriers to student achievement. 


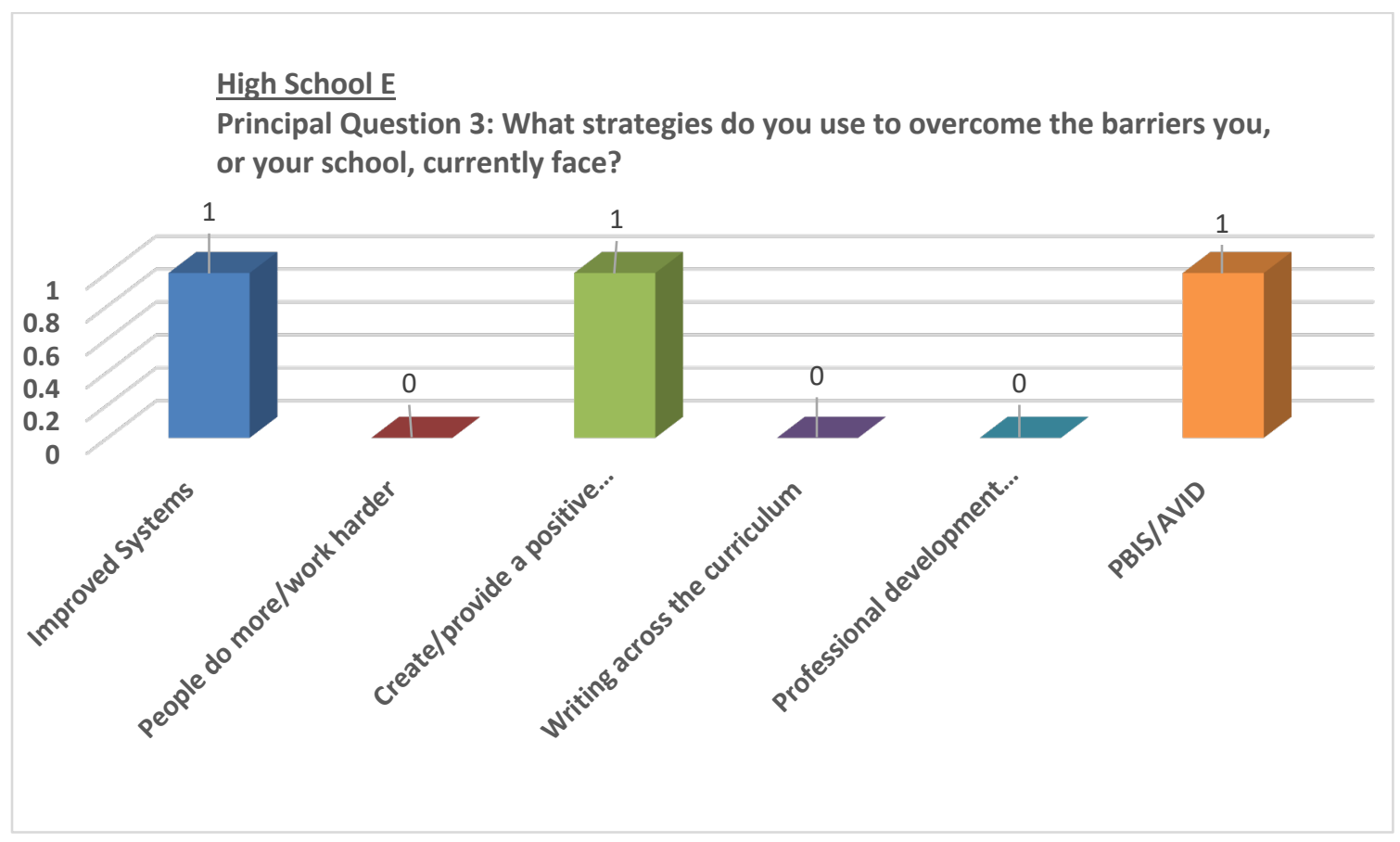

Figure 82. Summary of Principal E's responses to Question 3. The number of times a principal utilized the above factors to overcome barriers to student achievement.

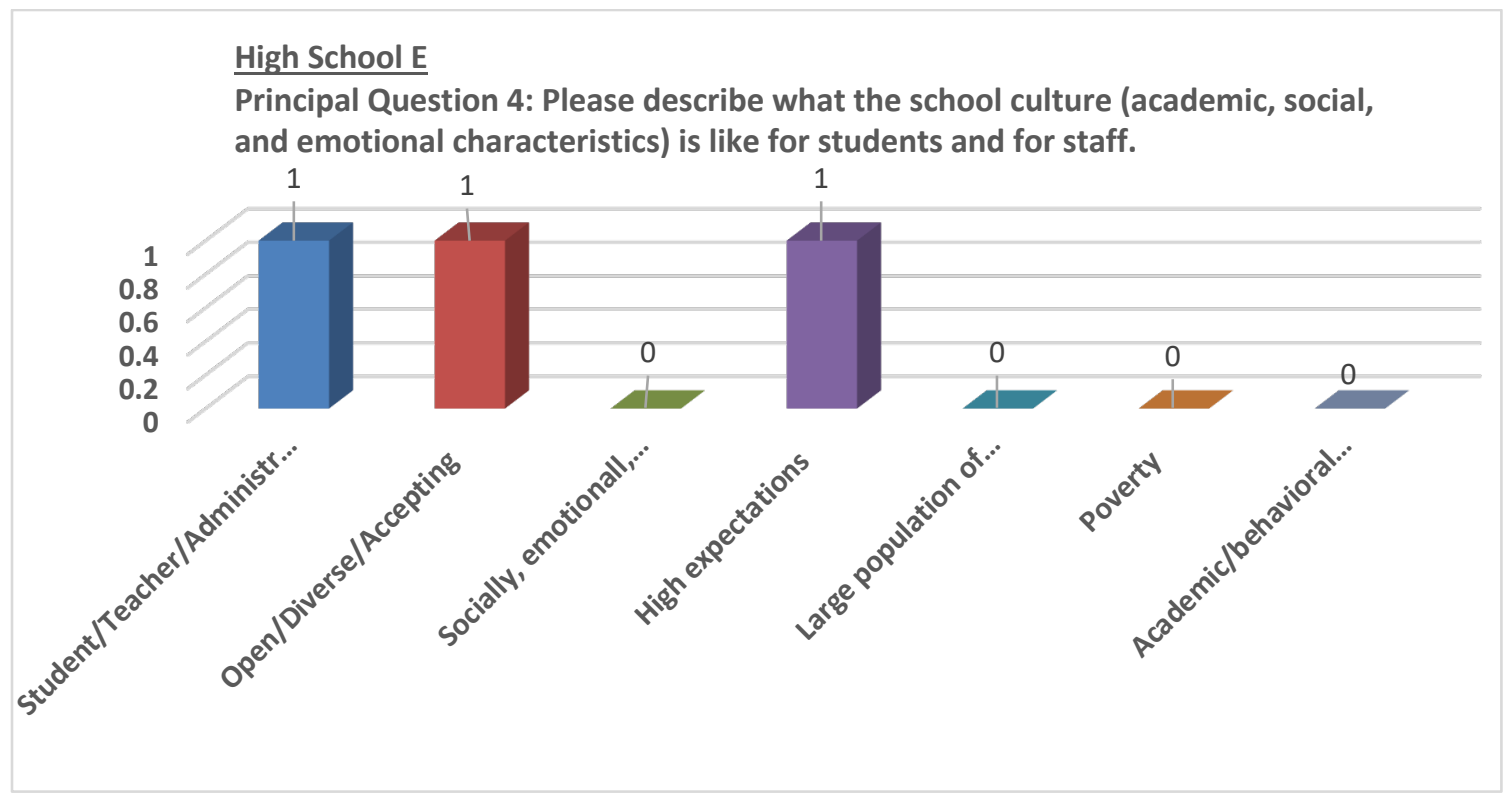

Figure 84. Summary of Principal E's responses to Question 4. The number times a principal indicated the above characteristics as being descriptive of their school culture. 


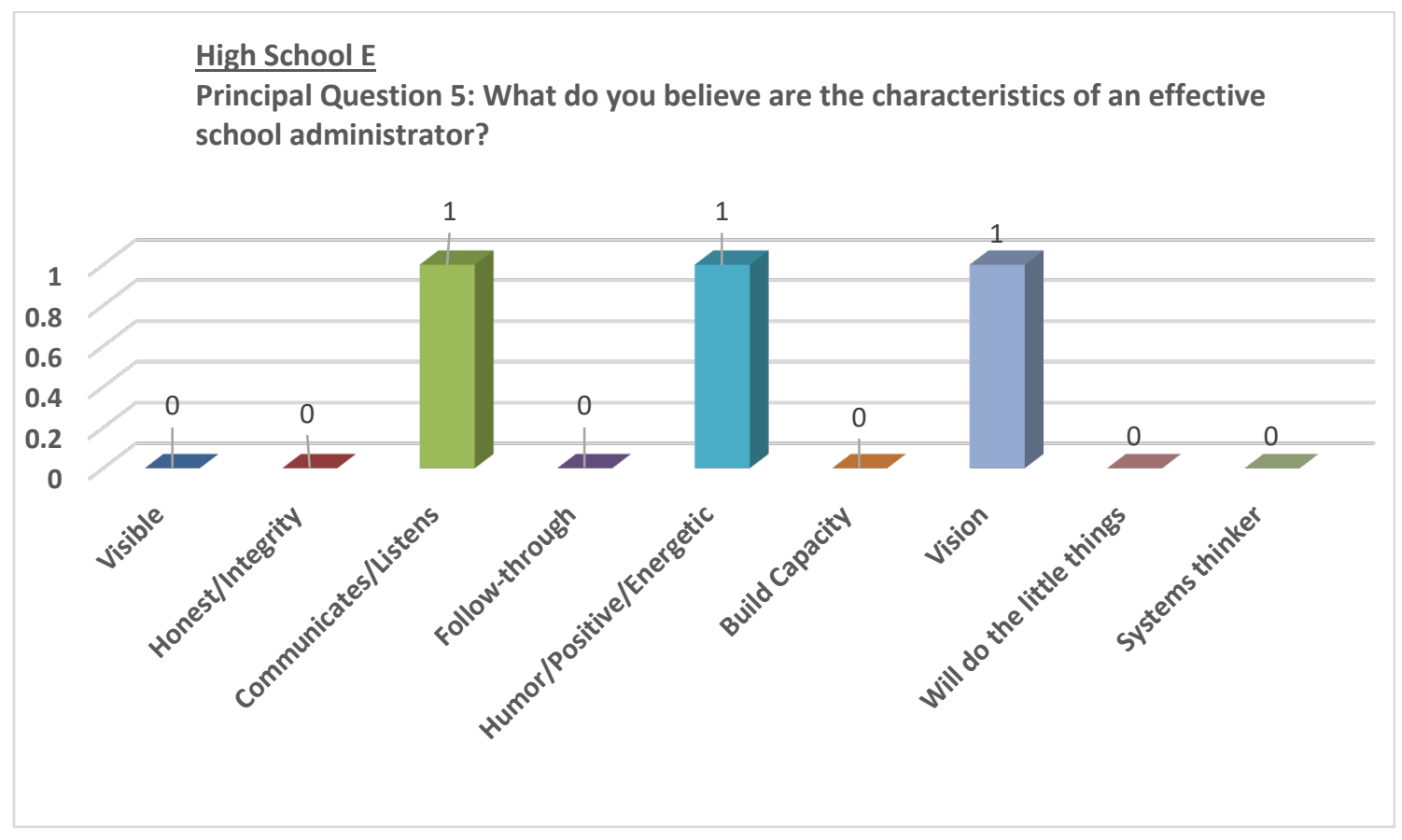

Figure 84. Summary of Principal E's responses to Question 5. The number of times a principal indicated the above factors as characteristics of an effective school administrator.

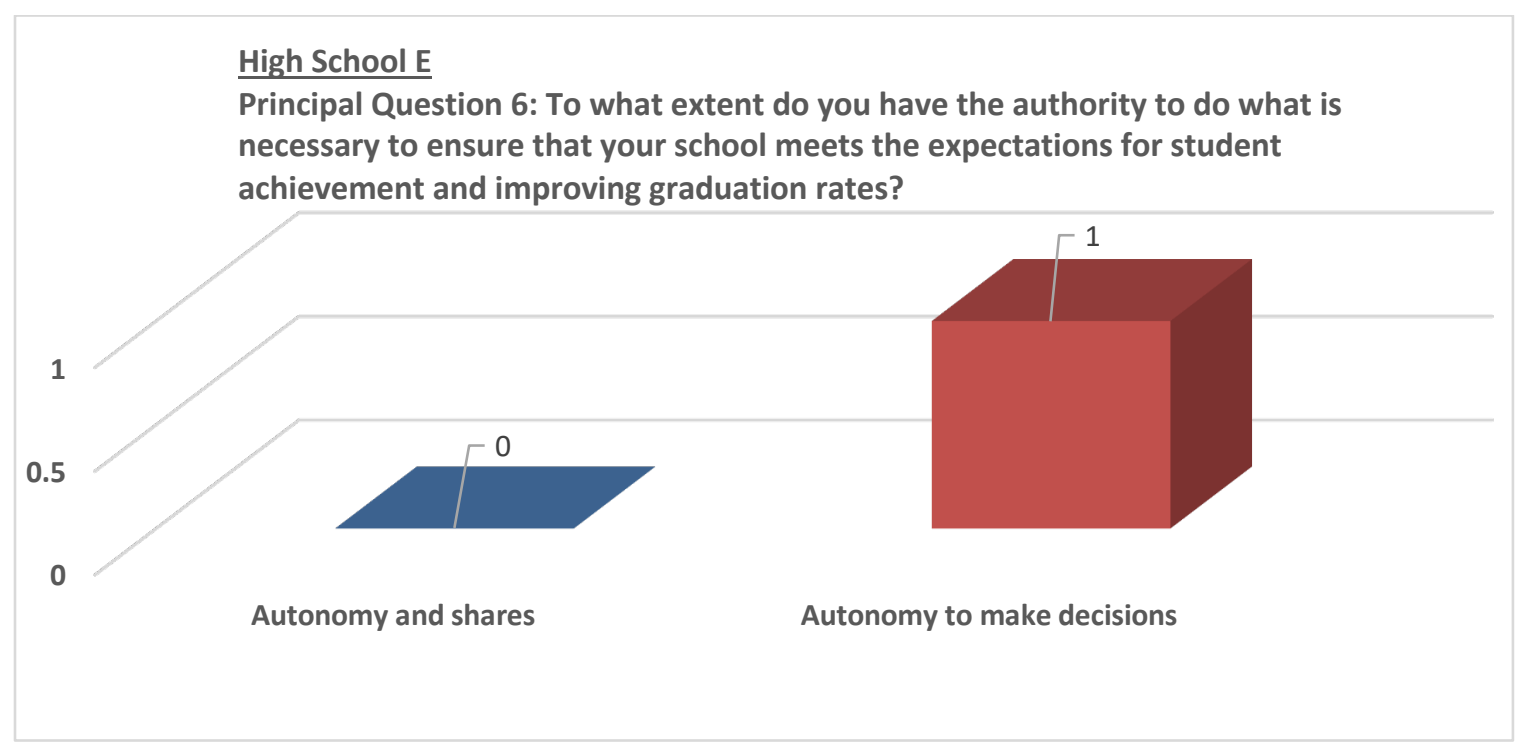

Figure 85. Summary of Principal E's responses to Question 6. The number of times a principal described their level of authority and autonomy in decision making with respect to ensuring their school meets the expectations for student achievement and graduation rates. 


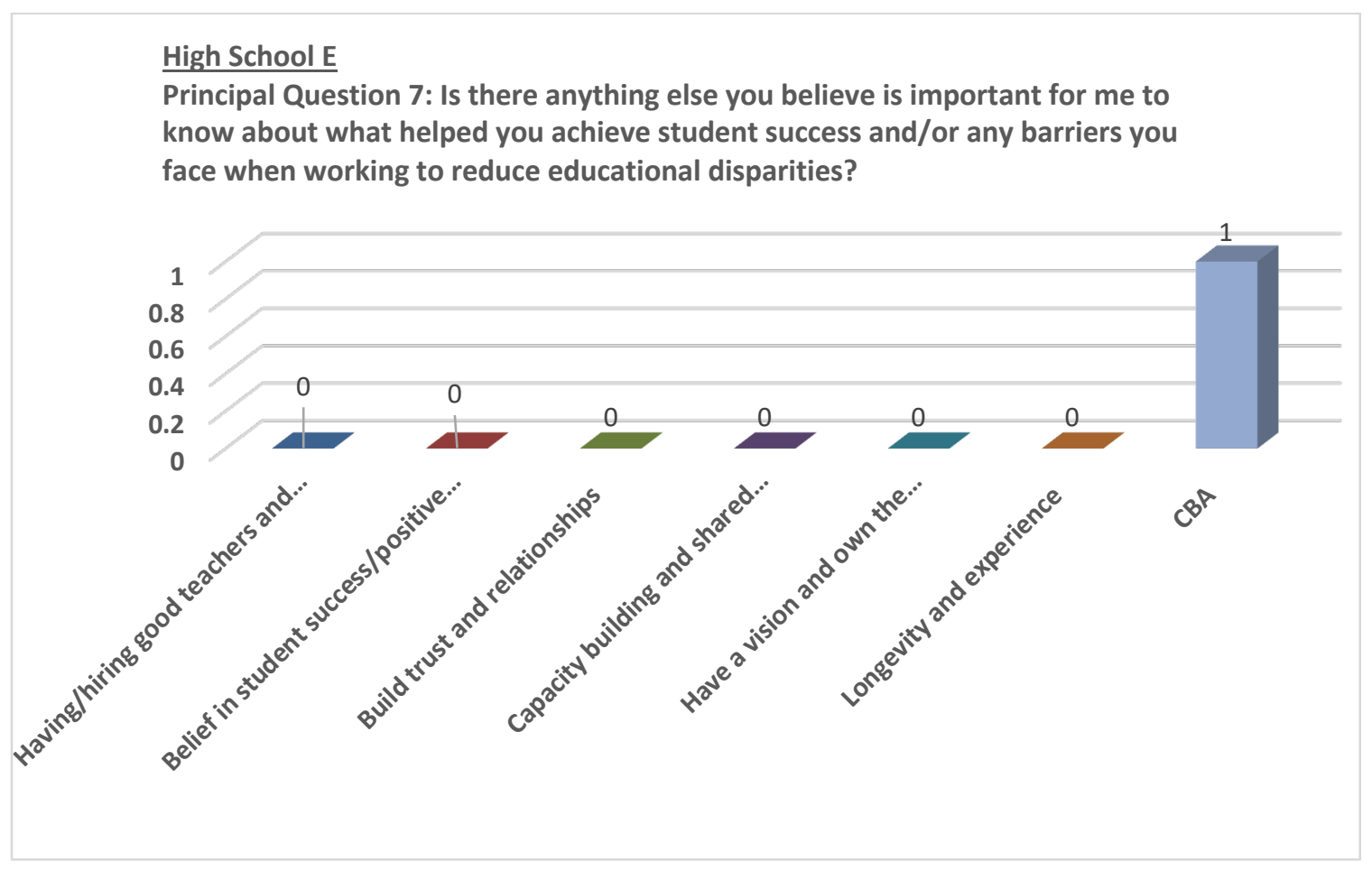

Figure 86. Summary of Principal E's responses to Question 7. The number of times a principal described additional factors they deemed important in ensuring their school improve student success and reduce educational disparities.

\section{Interpretation of Findings}

The findings from the study are based upon the review of the data collected, coded and graphically represented in 84 separate charts created from the responses from the principal and teacher participant groups as a collective whole, but also independently, from both groups at each of the five independent high schools. A comparison between the collective responses of the principal and teacher participant groups for each of the seven research questions is provided below.

Interview Question 1: To what do you attribute your improved graduation rates and reduction in the achievement gap? The four main themes identified by administrator and teacher respondents as having the strongest effect on improving graduation rates and 
reducing the achievement gap are as follows: academic interventions, student relationships, effective school-wide systems and strong relationships.

Interview Question 2: Can you identify any barriers that exist(ed) for your school in order to achieve your success in these areas? There was a distinct difference in the perspectives between the two participant groups around barriers that were prohibitive in making positive individual and collective student growth. The responses from the principals provided no clarity as to what they felt was a true indicator, identifying a number of different variables, none with any particular underlying theme. The teacher responses universally identified poverty as the largest barrier to student success, a variable that was not entered as a response by the principal participants. Conversely, the lack of collaboration time, the only indicator garnering more than one response from the principals, received the lowest number of responses from the teachers. The data indicate a large gap in the perception between the two groups around what variables they considered educational barriers.

Interview Question 3: What strategies do you use to overcome the barriers you currently face? The overall responses from the two participant groups were not entirely congruent; however, they did align within the traditional scope of respective job responsibilities. The principal participants identified creating or improving the overall school climate and building efficient and effective organizational systems as their top priorities to address barriers to success. These strategies are reflective of the large-scale, building-wide responsibilities for a school administrator. The teacher participants identified student relationships and academic interventions as the strategies they find 
most effective and are more clearly aligned with individual classroom and instructional practices.

Interview Question 4: Please describe what the school culture (academic, social, and emotional characteristics) is like for students and for staff. The set of collective responses from both the teacher and principals identified the same attributes of a school culture as their top two responses: an open, diverse and accepting school environment and culture built on positive student relationships. The school administrators identified a "safe" school environment, physically and socio-emotionally, as their third highest response while teachers identified strong administrative support as their third highest response. According to the responses, both the teacher and school administrator participants from the high performing schools have open, diverse and accepting environments built on positive student relationships. The importance of having a cohesive vision around school culture and community is an essential element to improving school performance, and to ensure that the growth is sustainable. This conclusion is supported by Waters and Cameron (2007), who called this a Purposeful Community:

A Purposeful Community as one with the "collective efficacy" and the capability to use all available assets to accomplish purposes and produce outcomes that matter to all community member through agreed upon processes . . . after reviewing hundreds of studies on school improvement, we have concluded that everything in a school occurs within the context of a community ... the more this diverse community is able to coalesce around shared purposes, the more sustainable and effective a school's change efforts will be. (pp. 45-46)

The role and the importance the building leader places on a school community and culture is critical to their success or failure. Cetin, Kinik, and Sehkar (2016) concluded that the development of an organized and focused community is necessary if schools want to achieve student success. 
Interview Question 5: What do you believe are the characteristics of an effective school administrator? The data collected from the two participant groups describing the characteristics of an effective administrator provided responses that were completely conflicting in nature. Although there was not a large discrepancy between the number of responses per category, the school administrators self-identified having a long-term vision and demonstrating an overall positive attitude as the two most important characteristics of being effective. Conversely, the data collected from the teachers indicated four characteristics that were highly valued above all other others: the ability to be flexible and accept feedback, to make decisions on what is best for students, someone who values and builds capacity in their staff, and someone who builds strong student and school culture. This finding indicates a need for further study in order to determine implications for school leaders.

Interview Question 6: To what extent do you as principal/does your principal have the authority to do what is necessary to ensure that your school meets the expectations for student achievement and improving graduation rates? As a group, the principal responses indicated that they felt they had the authority to do what was necessary to improve student achievement. A limitation of the study was identifying what "authority" actually meant to them in the context of their position. The teacher responses were much more diversified, and many indicated simply, "I don't know." The data indicate a perceived lack of understanding of how much authority the school administrator truly does have to make autonomous decisions, and furthermore, in what areas and in what context they have decision making authority. 
Interview Question 7: Is there anything else you believe is important for me to know about what helped you (your school administrator) achieve student success and/or any barriers you face when working to reduce educational disparities? When both participant groups were offered an open-ended opportunity to provide additional factors or barriers that respectively contributed or inhibited their successes, four categories emerged as representative of the majority of the responses shared by both groups, all of which were contributing factors, not barriers, to success: a valued staff and team; a flexible administrator who shares and distributes authority; a school, staff and administration with a strong belief in students; and having good teachers and the ability to remove poor ones.

Synthesis of High School A. The principal and teacher participants from Building A respectively, offered differing insights as to what factors contributed most to improved graduation rates and a reduction in the achievement gap. The principal clearly identified two main factors: positive student relationships and having a strong central vision. In this school staff opinions showed little congruency and were split among five different response categories. Nonetheless, both respondent groups were in agreement that external factors such as resources, poverty, and community involvement, were the most significant barriers to student achievement. Although in agreement, the two participant groups identified alternative methods which they felt were effective in overcoming the previously acknowledged barriers. The teachers selected strategies that were student-centered: building strong relationships, providing afterschool activities and programs, and improving student connections/engagement strategies. The principal 
identified targeted improvements in building systems and indicated that, "people are just working harder as well.”

All of the study participants have a similar view of the culture at High School A. It is described as an environment that is open, built on interpersonal relationships, and strongly supportive of students with significant needs. However, the principal and teacher respondents did not share a common understanding around the characteristics of an effective school leader, nor did they agree on how much authority they perceived the principal had in the role. In fact, the responses to Question 5, "the characteristics of an effective leader" produced the most variance and the greatest number of categorical responses as compared to all of the other questions and responses in High School A. The responses clearly indicate that what the teachers perceive and what the principal perceives as an effective school administrator are not the same thing. These data provide a number of questions that are addressed in the discussion section of Chapter 5.

Synthesis of High School B. Overall, all the respondents from High School B largely identified student dependent, external variables (poverty, parenting, and attendance) as those that negatively impact student success. The principal identified strategies that were systemic and non-academic as the primary methods to addressing these barriers; strong school culture, student-staff relationships, and a stable school environment. Although the staff could not completely agree upon a singular strategy they felt was entirely responsible, responses still echoed a belief that relationships and academic interventions had an impact on improving graduation rates and overall student achievement. Overall, the responses from the principal and teacher participants were 
fairly congruent with one another. The only area in which the two groups differed was in what they believed were the characteristics of an effective administrator. The teachers in High School B want an administrator willing to accept criticism, be flexible and who values them as professionals. The principal believed visibility, honesty, integrity, quality communication and follow-through are the most important qualities for success.

Synthesis of High School C. The collective respondent data from High School C showed strong and consistent parallels in the identification of the variables contributing to student success, what types of barriers inhibit success, and what interventions and/or strategies were used to overcome the obstacles they identified as a school. According to all of the respondents, High School $\mathrm{C}$ faces barriers associated with poverty. The principal and teachers believe that academic interventions and focusing on student relationships are the factors that improved their outcomes. In addition, they also indicated that the things they believed resulted in positive student outcomes are still the things that they are currently doing and continue to focus on in their building. In High School C, three of the four characteristics of effective leadership self-identified by the principal were also identified as highly valued by the teachers, a level of congruency not matched in any of the other buildings included in the study. The responses from High School C made it easy to identify there was a shared common commitment to cultivating supportive and respectful relationships between students, staff, and administration.

Synthesis of High School D. The respondents from High School D all agree that academic intervention programs were important strategies used to address the various barriers to student success in their school, with both the teachers and principal identifying 
"writing across the curriculum," as one specific high impact strategy. Additionally, both participant groups described the school population as one of high emotional, social, economic and academic need. Successful academic intervention plans and the varied individual responses noted by teachers would have even greater impact if more collaboration time could be provided, according to the principal. The apparent multivariate approach and foci of teachers to improving student success, as well as the collective staff commitment to targeted academic interventions, indicate that while teachers and administrators work closely together on addressing primary variables, they are potentially unaware of each other's impact at system and individual classroom levels respectively.

Though specific qualities describing culture sited by administration and staff varied, many shared a common theme of building strong relationships and expectations between staff, students, and administration. This belief was shared by Principal D, who indicated a great deal of success was attributed to their dedication to building staff capacity and to hiring strong instructional leaders. This was reinforced by the agreement from both sets of respondents that leadership had the authority to make the decisions necessary to improve student outcomes.

Synthesis of High School E. Building E teachers and administrators disagreed on multiple research questions. With respect to strategies they felt attributed most strongly to increased student achievement and graduation rates, administrators identified changes in ELL programming while teachers felt lowered expectations were the cause of shifting performance. Teachers thought administration had little authority to make decisions 
where administration described a feeling of complete autonomy. Administration maintained a system-level perspective on barriers to student success identifying attendance gaps and open schedules as areas of primary concern where teachers were more concerned about non-supportive administration and lowered expectations.

Furthermore, administration was concerned with the negative impact of poor instruction on student success and stressed the importance of intentional hiring and the ability to remove ineffective teachers. As a result, the educators in High School E disagreed upon the qualities of effective leadership. The principal felt strong leadership required vision, communication, levity, and humor while the teachers in High School E wanted voice in the process, to feel valued, and spoke to the desire for a principal that builds their existing capacity.

Although High School E experienced solid growth in graduation rates and overall student achievement, it seems clear that staff there have diverging impressions as to how that happens. It may be that both groups contributed to student improvement in distinct and different ways but lack the perspective to see each other's contributions. It is also possible that this building is showing evidence of recent efforts of administration to change staff performance leading to more effective teachers with high expectations feeling safe to identify past practices of low expectations as the residual predominant issue impacting students in classrooms.

\section{Limitations of Study}

There are a number of limitations that exist within this research study. Research limitations are characteristics that exist within the areas of the study that can alter the 
interpretation of the findings or analysis from the research. Typically, limitations exist as a result of the study design or the research methodology, restricting the how generalizable the findings are, how applicable they may be to practice, and how much they may add to the current body of educational literature (Price \& Murnan, 2004).

A significant limitation in the design of the study is the small sample size. The purposive sample included only five identified high schools, in five different school districts in only one state. In addition, there were only 28 participants total: the 5 principals of each high school and a total of 23 teachers; four of the schools had 5 teacher participants and one school had 3 teacher participants. The small sample size makes this study not generalizable; however, the findings may be applicable to practice because the sampling method, convenience sampling, supports the selection of a relatively small number of teacher leader participants, per school and overall for the design of this study (Curtis et al., 2000, p. 1003).

A second limitation of the study was the inability to control the research environment. The data collection process was conducted electronically via email that connected participants to a survey instrument that was accessible anywhere the participant could connect to Wi-Fi. The participants could answer the questions in any environment that they selected, and under any conditions. Additionally, the researcher could not respond to responses from the participants with any follow-up questions. One example where additional questioning from the researcher would have provided much more significant information is a response from Principal C to survey Question 3, asking what strategies the principal used to address the identified barriers of student poverty and 
the inability to find time for teachers to collaborate, to improve school performance. In his response, Principal C provided only one intervention, providing professional development specific to working with students in poverty. A follow-up question would have allowed insight as to why only one strategy was provided when there were two barriers identified. The worst example of this limitation is that in some circumstances, the inability to ask follow-up questions resulted in a number of non-responses to survey items.

A more significant limitation of the study may exist in the actual design of the seven interview questions. Table 2 provides a breakdown of the number of response categories provided by the principal and teacher participants for each of the seven research questions. A review of Table 2 indicates a significant variation in the number of categories of responses produced for each question between the principals and teacher participants. There are fewer types of responses (i.e., fewer suggestions of factors at play for some questions versus others). This could indicate a difference in question clarity or ambiguities in the language on behalf of the participants, indicating a need for improvement in the wording of the research questions.

It is also a possibility that some particular responses have more significance to the participants, specifically if both the principal and teacher identify the same factors. Therefore, other responses may actually not matter as much in terms of student success, like perceived leadership skills and school culture. What may be more important are the categories that the principal and teacher participants agree upon, like the identification of the barriers and the interventions used to improve school performance? It is also possible 
that the needs for each building and for each staff are independent of one another dependent upon their individual circumstances and specific challenges. Another variable that may be considered a limitation and have an impact upon the teacher responses and in some buildings are the independent differences of the teachers based upon their levels of experience, content area, and overall ability.

Table 2

Number of Categories of Responses Per Question

\begin{tabular}{|l|c|c|c|c|c|c|c|}
\hline & Q1 & Q2 & Q3 & Q4 & Q5 & Q6 & Q7 \\
\hline Teacher A & 5 & 4 & 3 & 5 & 7 & 5 & 4 \\
\hline Principal A & 2 & 1 & 2 & 2 & 6 & 1 & 2 \\
\hline Teacher B & 3 & 3 & 3 & 5 & 7 & 4 & 4 \\
\hline Principal B & 5 & 1 & 1 & 3 & 5 & 1 & 2 \\
\hline Teacher C & 4 & 4 & 5 & 4 & 6 & 2 & 5 \\
\hline Principal C & 2 & 2 & 1 & 2 & 4 & 1 & 1 \\
\hline Teacher D & 5 & 3 & 3 & 2 & 6 & 3 & 3 \\
\hline Principal D & 3 & 1 & 1 & 6 & 7 & 1 & 3 \\
\hline Teacher E & 5 & 7 & 4 & 3 & 6 & 3 & 4 \\
\hline Principal E & 1 & 2 & 3 & 3 & 3 & 1 & 1 \\
\hline
\end{tabular}

An additional limitation of this study is researcher bias. As a researcher, I bring a significant amount of practical building experience to the study. This year is my twentieth year serving as a public educator, all at the high school level. I have worked in both collective bargaining and non-collective bargaining states, and in a combination of small, large, urban, rural, wealthy and impoverished school districts. Professionally, this topic was generated from my personal experiences as a high school administrator coming from 
a non-collective bargaining state with a wealth of resources (Virginia), to a mandatory bargaining state (Oregon) to eventually serve as a principal at two Oregon high schools. 


\section{Chapter 5: Discussion and Conclusion}

\section{Introduction}

The purpose of this research study was to specifically examine what principals and teacher leaders believe about the effect of CBAs on school performance. More specifically, how do principals and teachers in high performing schools describe authority and autonomy of leadership in effective schools, and the ability of building leadership to do what is necessary to ensure that the (their) school meets the expectations for student achievement and improving graduation rates as required under new state and federal accountability legislation?

A review of educational literature was conducted in the following areas: role theory, organizational theory, and principal leadership. Further literature was reviewed in the areas of collective bargaining and labor agreements, specifically in the context of an educational organization and/or environment. The research study provides findings, specific to Oregon Public High Schools, where very little information exists to assist educational leaders in the process of decision-making around educational reform in support of student achievement. The research questions studied were:

1. What do principals and teacher leaders believe about the effect of CBAs on school performance?

2. How do principals and teachers in high performing schools describe authority and autonomy of leadership in effective schools? 


\section{Synthesis of Findings}

This section provides a brief summary of the collective findings resulting from a thorough review of the qualitative data gathered from the principal and teacher participants in the study. Each individual finding is discussed independently to provide clarity on the process that ultimately resulted in a final conclusive outcome. The section is organized by addressing each of the major research questions from the individual perspective of each of the two participant groups.

Research Question 1: What do principals and teacher leaders believe about the effect of CBAs on school performance? As a participant group, the principals identified six existing barriers that impacted school performance and only two of them, the ability to build in teacher collaboration time for staff and the school schedule, were directly related to the CBA. As a group, the principals identified eight key factors that contributed to improved school performance and an additional six more intentional strategies they used to overcome the existing barriers. Cumulatively, of the 14 responses regarding successful improvement and/or intervention strategies that have worked in highly successful schools only one, the ability to provide time within the school day for academic intervention, could be a limitation imposed by a CBA. No principals identified any limitations imposed by CBAs on school culture. The data collection tool allowed respondents a final opportunity to provide any additional comments regarding their ability to impact school performance, and out of 10 total responses 2 specifically identified the ability to address issues in teacher quality as a significant barrier. 
In an educational environment defined by accountability, principals are under intense pressure to demonstrate student success through multiple measures of student data that can have significant consequences without meeting the prescribed levels of performance. When given an anonymous platform to provide input regarding building level practices and feedback from the field, principals from highly successful schools identified CBAs as having almost no impact on their ability to reduce educational disparities and close the achievement gap. In fact, not once was a CBA mentioned by name in a response from a principal participant. The items coded as definitive aspects of a CBA would to have had been identified in one of two ways: either by an individual with significant background knowledge or experience of how a CBA functions inside of an educational organization or by examining each response against a summary of items gathered from a representative sample of CBAs matching the participant schools.

The teacher participant group identified 10 existing barriers that impacted school performance, 3 of them which were directly related to the CBA: the ability to build in teacher collaboration time for staff, the school schedule, and the quality of the staff. In the cumulative 17 responses provided around successful improvement and/or intervention strategies that have worked in highly successful buildings, 3 were identified as possible limitations imposed by the CBA: the ability to provide time within the school day for academic interventions, the ability to provide paid time to support both afterschool activities and to support academic interventions. Congruent to their co-participants, the teachers also specifically identified the ability to address teacher quality as a significant 
barrier when provided the opportunity for any additional comments. However, they identified it at twice the rate, with four total responses.

The responses from the teacher participants offered information that affirmed some findings identified in the response data provided by the principal participants. However, the perspectives of the teacher participants provided a significantly different lens on some unexpected outcomes, as well as provided focus in areas that would not have been addressed without the clear differences in perspective between the respective job responsibilities of the two participant groups. In response to the research question, and congruent to that of the principal participants finding, is that teachers from the highly successful schools studied did not identify the CBA as a barrier for their principal or the school to improve overall student performance.

A significant finding from the data collection was that the teacher participant responses identified and/or addressed the CBA as a current barrier to school improvement at a much higher response rate than the principal participants. This included a greater number of overall total responses as well as the total number of coded categories that reflected or referenced a factor that was governed or protected in some capacity by a typical CBA (i.e., teacher schedule or workday). In addition to the specific barriers previously identified by the principals, the teacher participants specifically identified ineffective teachers and the inability to remove them as a barrier to achieve successful or desired outcomes. Although significant, a limitation of this study was that further clarifying questions were not asked. Therefore, it is difficult to truly understand what the response may be referring to when noting "a barrier." It is unclear if "barrier" refers to 
the characteristic of an ineffective leader and their inability to effectively hire good teachers or remove ineffective ones?

Research Question 2: How do principals and teachers in high performing schools describe authority and autonomy of leadership in effective schools? A review of the data collected from the principal participants when asked if they felt that they had the appropriate and necessary level of authority as a building leader to improve student outcomes provided one representative response indicating that they had complete authority, and the ability to share it if desired, to make autonomous decisions in an effort to improve overall school performance.

A review of the data collected from the principal participants when asked if they felt that they had the appropriate and necessary level of authority as a building leader to improve student outcomes provided one representative response. The building leaders were completely aligned, each of them indicating that they had complete authority, and the ability to share it if desired, to make autonomous decisions in an effort to improve overall school performance. It seems there is a relationship between the level of authority building principals hold to the level of overall school performance and student outcomes they are able to directly influence. A closer review of the overall responses provided by the principal participants shows they are also closely aligned around the factors that they identify as highly responsible for improved outcomes. The factors they identify are all strategies that are not controlled by the umbrella of typical CBAs such as positive teacher-student relationships, implementing effective and efficient building systems, and focused professional development around strong instructional practices. In the schools 
represented by this study, the high levels of authority and autonomy that leaders have in their buildings seem to provide the flexibility needed to implement the appropriate strategies to address the supports teachers need in each specific context or building.

As a group, the teacher participants did not believe their principals had the appropriate and necessary level of authority as a building leader to improve student outcomes. Furthermore, the teachers demonstrated an inability to identify who did have that authority by providing a spectrum of responses including: the district office, the teachers, the principal, the principal "but [they are] too overburdened to do anything with it," shared authority; or they did not know or were not willing to answer. Regardless of how much authority the teacher participants perceived their building administrator to possess, they were strongly in alignment with their principals around what attributes were responsible for improved school performance, and what barriers currently existed to achieve that success.

Although it is difficult to generalize the findings because there are so few individuals in the study, the teachers consistently identified a number of strategies that were important to them, and are supported by educational literature, as having a positive impact on school performance. The first finding was the need for building leadership to be supportive of teachers' work (Fullan, 2002; Hattie et al., 2016; Wahlstrom \& Louis, 2008). O'Donnell and White (2005) similarly note the importance of principal-teacher relationships, noting "effective principals display caring attitudes toward staff members, students, and parents" (p. 68). Fullan and Pinchot (2018) also confirmed the importance of principal-teacher relationships as did Waters et al. (2004). 
In addition, this study identified the importance of leadership trust in teachers, a concept echoed by Soehner and Ryan (2011), as well as by Wahlstrom and Louis (2008). Effective leaders in this study seem to value the importance of vision (Gunal \& Demirtasil, 2016; Seashore Louis et al., 2010) and the autonomy to hire well (Adamowski et al., 2007; Hess \& Loup, 2008) and leave teachers to bear primary responsibility for student outcomes, which is supported by Seashore Louis et al. (2010):

High-scoring (Effective) principals have the ability and interpersonal skills to empower teachers to learn and grow according to the vision established for the school, these principals seek out and provide differentiated opportunities for their teachers to learn and grow. In contrast, teachers reported, low-scoring principals seldom suggested or supported professional growth opportunities. (p. 87)

While the leaders in Schools C, D, and E believe they had hired good teachers, those good teachers want support from their administrators and want to feel valued by them (Marzano et al., 2005).

The major differences between the responses from the two groups of participants were in what strategies were implemented to overcome the existing barriers, and what each group believed were the characteristics of an effective school administrator. A closer look at the data provides an important finding of the study. In buildings where the teachers and the school administrator had similar perceptions around what characteristics defined an effective school administrator, both groups identified the same implementation strategies necessary to overcome the existing barriers to school improvement. In buildings where the two participant groups had differing perceptions, the implementation strategies were only partially aligned. It can be reasonably concluded that an effective staff that does not believe in the quality of their building administrator will choose to implement strategies they feel are more effective in their classrooms- 
regardless of the stated vision of the school leader. It can also be concluded that in highly successful buildings, like the purposive sample used for this study, a highly effective teacher has the greatest impact on student achievement. Additionally, it might be possible to conclude that at some point if there are enough highly effective teachers in a building, then they can have enough independent impact on student achievement, regardless of belief and alignment with their building administrator to turn any building into a highly effective school (Danielson, 2009).

The findings of this study contradict the literature that indicates that CBAs are restrictive and constrain decision making (Eberts, 2007). The subjects in this study, indicate that the successful principals find ways, within the CBAs, to ensure that teachers are able to effectively teach, and the leaders can provide the supports that teachers need in order to be effective. Successful building leaders understand and accept CBAs as a natural part of the context of the educational organizational. They recognize that building relationships and working within the CBA collaboratively is the most efficient and effective way to build positive school culture, capacity in staff, and improve overall school performance, concepts also endorsed by Fullan (2002) and Hattie et al. (2016). The level of autonomy was directly correlated to the level of outcomes for the building. The more authority the principal had from central office to make decisions, the higher the outcomes for students.

\section{Implications}

There are several implications for practice regarding the findings of this study, particularly in the area of principal understanding of CBAs, the context of their school, 
and agreement about strategies that work. While it would have been natural to ask explicitly how the union or the contractual agreements hinder the school leader's ability to lead in their school, I chose not to ask this question in order to see if leaders identified the CBA on their own. In other words, I did not want to lead the subject in the direction of identifying a problematic CBA and skew the subjects' responses. The successful leaders in this study employed strategies that are not hindered by the CBA. For example, building positive relationships with students is not covered by the CBA. In addition, a positive school culture is not controlled by CBAs. Thus, one implication is that principals and teachers need to take the time to identify, with teachers, what is working in their school and what the barriers are to success in each school because the context in each school is different. Another implication for practice is that teachers and leaders need to identify the strategies that they agree on. Principals need to understand what the staff need their leader to be, not what the leaders wants to be for the school. This aligns with concepts of servant leadership.

Finally, school districts should work to hire, train, and retain leaders who do not view the CBA as a barrier to student success, rather as an opportunity to cultivate and build capacity, and trust with their staff. CBAs are important in that they help build relationships with and provide respect for professional teachers; they ensure structures for teacher success, and thus student success. If building administrators view CBAs as a chance to build relationships with teachers and a framework within which to support teachers, this mindset will contribute to student success. Viewing CBAs as negative may 
diminish the success of the school leader and will not contribute to a successful learning environment for students. 


\section{References}

Adamowski, S., Therriault, S. B., \& Cavanna, A. P. (2007). The autonomy gap: Barriers to effective school leadership. Washington, DC: Thomas B. Fordham Foundation and Institute.

Ballou, D. (1999). The New York City teachers' union contract: Shackling principals' leadership. New York, NY: Manhattan Institute, Center for Civic Innovation.

Barkley, R. (2005, December 7). Letter to the editor: Teacher contracts, student needs. Education Week, p. 38.

Bates, F. L. (1962). Some observations concerning the structural aspect of role conflict. The Pacific Sociological Review, 5(2), 75-82.

Bertrand, A. L. (1972). Social organization: A general systems and role theory perspective. Arlington Heights, IL: AHM Publishing.

Biddle, B., \& Thomas, E. (1966). Role theory: Concepts and research. New York, NY: John Wiley.

Bolman, L. G., \& Deal, T. E. (2008). Reframing organizations: Artistry, choice, and leadership. San Francisco, CA: Jossey-Bass.

Cetin, M., Kinik, F., \& Sehkar F. (2016). Effects of leadership on student success through the balanced leadership framework. Universal Journal of Educational Research, $4(4), 675-682$.

Chiang, H., Lipscomb, S., \& Gill, B. (2016, Summer). Is school value-added indicative of principal quality? Education Finance and Policy, 11(3), 283-309.

Creswell, J. W. (1994). Research design: Qualitative and quantitative approaches. Thousand Oaks, CA: Sage.

Creswell, J. W. (1997). Qualitative inquiry and research design: Choosing among the five traditions. Thousand Oaks, CA: Sage.

Creswell, J. W. (2005). Educational research: Planning, conducting, and evaluating quantitative and qualitative research. Upper Saddle River, NJ: Merrill Prentice Hall. 
Curtis, S., Gesler, W., Smith, G., \& Washburn, S. (2000). Approaches to sampling and case selection in qualitative research: Examples in the geography of health. Social Science and Medicine, 50, 1001-1014.

Danielson, C. (2009). Talk about teaching! Leading professional conversations. Thousand Oaks, CA: Corwin Press.

Donohoo, J. (2017). Collective efficacy: How educators' beliefs impact student learning. Thousand Oaks, CA: Corwin.

Drucker, P. (1954). The practice of management. New York, NY: Harper and Row.

Eberts, R. W. (2007). Teacher unions and student performance: help or hindrance? The Future of Children, 17(1), 175-200.

Eberts, R. W., \& Stone, J. A. (1984). Unions and public schools: The effect of collective bargaining on American education. Lexington, MA: Lexington Books.

Elementary and Secondary Education Act (ESEA) of 1965 (1965).

Etikan, I., Musa, S. A., \& Alkassim, R. S. (2016). Comparison of convenience sampling and purposive sampling. American Journal of Theoretical and Applied Statistics, 5(1), 1-4. doi:10.11648/j.ajtas.20160501.11

Every Student Succeeds Act (ESSA), S. 1177, 114th Con. (2015). Retrieved from https://www2.ed.gov/policy/elsec/leg/essa/index.html

Federici, R. A., \& Skaalvik, E. M. (2012). Principal self-efficacy: Relations with burnout, job satisfaction and motivation to quit. Social Psychology of Education, 15(3), 295-320.

Figlio, D., \& Ladd, H. F. (2008). School accountability and student achievement. In H. F. Ladd \& E. B. Fiske (Eds.), Handbook of research in education finance and policy (pp. 166-182). New York, NY: Routledge.

Flynn, R. J., \& Lemay, R. A. (1999). A quarter-century of normalization and social role valorization: Evolution and impact. Ottawa, Canada: University of Ottawa Press.

Fullan, M. (1988). What's worth fighting for in the principalship? Strategies for taking charge in the elementary school principalship. Andover, MA: The Regional Laboratory for Educational Improvement of the Northeast and Islands., NY:

Fullan, M. (2002). The change leader. Educational Leadership, 59(8), 6-20.

Fullan, M., \& Pinchot, M. (2018). The fast track to sustainable leadership. Educational Leadership, 75(6), 48-54. 
Fuller, E. J., Young, M. D., \& Baker, B. (2007, April). The relationship between principal characteristics, principal turnover, teacher quality, and student achievement. Paper presented at the annual meeting of the American Educational Research Association, Chicago, IL.

Gay, L. R., Mills, G. E., \& Airasian, P. (2006). Educational research: Competencies for analysis and applications ( $5^{\text {th }}$ ed.). Upper Saddle River, NJ: Merrill Prentice Hall.

Getzels, J. W. (1952). A psycho-sociological framework for the study of educational administration. Harvard Educational Review, 22, 235-246.

Getzels, J. W., \& Guba, E. (1954). Role, role conflicts and effectiveness. American Sociological Review, 19, 164-175.

Getzels, J. W., \& Guba, E. (1957). Social behavior and the administrative process. School Review, 65, 423-441.

Getzels, J. W., Lipham, J., \& Campbell, R. (1968). Educational administration as a social process. New York, NY: Harper.

Glasman, N. S. (1984). Student achievement and the school principal. Educational Evaluation and Policy Analysis, 6(3), 283-296.

Goode, W. J. (1960). A theory of role strain. American Sociological Review, 25(4), 483-496.

Gross, N., Mason, W. S., \& McEachern, A. W. (1958). Explorations in role analysis: Studies of the school superintendency role. New York, NY: John Wiley and Sons.

Gunal, Y., \& Demirtasil, R. N. (2016). A pathway to educational accountability: The relationship between effective school characteristics and student achievement. Universal Journal of Educational Research, 4(9), 2049-2054.

Hallinger, P., \& Heck, R. H. (1996). Reassessing the principal's role in school effectiveness: A review of empirical research, 1980-1995. Educational Administration Quarterly, 32(1), 5-44.

Hattie, J., Birch, K., \& Masters, D. (2016). Visible learning into action: International case studies of impact. New York, NY: Routledge.

Heck, R. \& Hallinger, P. (1999). Conceptual models, methodology, and methods for studying school leadership. In J. Murphy \& K. Seashore-Louis (Eds.), The second handbook of research in educational administration (pp. 141-162). San Francisco, CA: McCutchan. 
Hess, F. M., \& Loup, C. (2008). The leadership limbo: Teacher labor agreements in America's fifty largest school districts. Washington, DC: The Thomas Fordham Institute.

Hess, F. M., \& West, M. R. (2006). A better bargain: Overhauling teacher collective bargaining for the $21^{\text {st }}$ century. Cambridge, MA: Harvard University Program on Educational Policy and Governance.

Hill, P., Pierce, L. C., \& Guthrie, J. W. (1997). Reinventing public education: How contracting can transform America's schools. Chicago, IL: University of Chicago Press.

Hoxby, C. M. (1996). How teachers' unions affect education production. The Quarterly Journal of Economics, 111(3), 671-718.

Ingersoll, R. M. (1994, Summer). Organizational control in secondary schools. Harvard Educational Review, 64(2), 150-172.

Leithwood, K. (1994). Leadership for school restructuring. Educational Administration Quarterly, 30(4), 498-518.

Leithwood, K. \& Jantzi, D. (2000). Principal and teacher leader effects: A replication. School Leadership and Management, 20(4), 415-434.

Lieberman, M. (1999). The teacher unions: How they sabotage educational reform and why. San Francisco, CA: Encounter Books.

Lott, J. \& Kenny, L. (2013). State teacher union strength and student achievement. Economics of Education Review, 35, 93-103.

Lunenburg, F. C., \& Ornstein, A. C. (2008). Educational administration: Concepts and practices $\left(5^{\text {th }}\right.$ ed.). Belmont, CA: Thompson Learning.

Magmer, J. (1983). Strike planning: A management team review. Retrieved from https://eric.ed.gov/?id=ED251928

Markow, D., Macia, L., \& Lee, H. (2013). The MetLife survey of the American teacher: Challenges for school leadership. Retrieved from https://www.metlife.com/assets/ cao/foundation/MetLife-Teacher-Survey-2012.pdf

Marzano, R. J., Pickering, D. J., \& Pollock, J. E. (2001). Classroom instruction that works: Research-based strategies for increasing student achievement. Alexandria, VA: Association for Supervision and Curriculum Development 
Marzano, R. J., Waters, J. T., \& McNulty, B. A. (2005). School leadership that works: From research to results. Alexandria, VA: Association for Supervision and Curriculum Development.

Maslow, A. H. (1954). Motivation and personality. New York, NY: HarperCollins.

Maxwell, J. (2013). Qualitative research design. Thousand Oaks, CA: Sage.

McEachin, A., \& Strunk, K. O. (2011, August). Accountability under constraint: The relationship between collective bargaining agreements and California schools' and districts' performance under no child left behind. American Educational Research Journal, 48(4), 871-903.

McGuinn, P. (2010). Ringing the bell for K-12 teacher tenure reform. Washington, DC: Center for American Progress.

Miles, M. B., \& Huberman, A. M. (1984). Qualitative data analysis: A sourcebook of new methods. Thousand Oaks, CA: Sage.

Moe, T. M. (2002). Politics, control and the future of school accountability. Paper presented at the conference on Taking Account of Accountability, Kennedy School of Government, Harvard University, MA.

Moe, T. M. (2006). Union power and the education of children. In J. Hannaway \& A. Rotherham (Eds.), Collective bargaining in education: Negotiating change in todays' schools (pp. 229-266). Cambridge, MA: Harvard Educational Press.

Moe, T. M. (2009). Collective bargaining and the performance of the public schools. American. Journal of Political Science, 53(1), 156-174.

National Commission on Excellence in Education. (1983). A nation at risk: The imperative for educational reform. Washington, DC: U.S. Government Printing Office.

No Child Left Behind Act of 2001 (2002).

O’Donnell, R., \& White, G. (2005). Within the accountability era: Principals' instructional leadership behaviours and student achievement. NASSP Bulletin, 89(645), 56-71.

Ollhoff, J., \& Ollhoff, L. (1996). School-age care from the perspective of social role theory. St. Paul, MN: Minnesota Department of Children, Families, and Learning.

Oregon Department of Education. (2014a). Efforts to close achievement gaps: Secretary of State audit report (Report No. 2014-10). Salem, OR: Author. 
Oregon Department of Education. (2014b). Priority, focus and model school guidance. Salem, OR: Author.

Oregon Department of Education. (2016a). Draft framework for Oregon's ESSA state plan. Salem, OR: Author.

Oregon Department of Education. (2016b). Oregon's on-time high school graduation rate shows strong growth in 2014-2015. Salem, OR: Author.

Oregon Department of Education. (2016c). Report card download: School and district report cards [Data file]. Retrieved from https://www.ode.state.or.us/data/ reportcard/reports.aspx

Oregon Public Broadcasting. (2014). School strikes and labor disputes. Retrieved from https://www.opb.org/news/series/school-strikes-and-labor-disputes/

Oregon Revised Statute (ORS) 243.650 (2017). Retrieved from https://www.oregonlaws. org/ors/243.650

Parsons, T. (1951). The social system. Glencoe, IL: Free Press.

Peterson, P. E., \& West, M. (Eds.). (2003). No child left behind? The politics and practice of school accountability. Washington, DC: Brookings Institution.

Price, J. H., \& Murnan, J. (2004). Research limitations and the necessity of reporting them. American Journal of Health Education, 35, 66-67.

Register, C. A., \& Grimes, P. W. (1991). Collective bargaining, teachers, and student achievement. Journal of Labor Research, 12(2), 99-109.

Seashore Louis, K., Leithwood, K., Wahlstrom, K., \& Anderson, S. (2010). Investigating the links to improved student learning. Washington, DC: Wallace Foundation.

Senge, P. M. (1990). The fifth discipline: The art and practice of the learning organization. New York: Doubleday/Currency.

Soehner, D., \& Ryan, T. (2011). The interdependence of principal school leadership and student achievement. Scholar-Practitioner Quarterly, 5(3), 274-289.

Steelman, L. C., Powell, B., Carini, R. (2000). Do teacher unions hinder educational performance? Lessons learned from state SAT and ACT scores. Harvard Educational Review, 70(4), 437-466.

Taylor, F. W. (1911). The principles of scientific management. New York, NY: Harper. 
Teske, P., \& Schneider, M. (1999). The importance of leadership: The role of school principals. New York, NY: State University of New York, The PricewaterhouseCoopers Endowment for the Business of Government.

Tschannen-Moran, M., \& Barr, M. (2004). Fostering student achievement: The relationship between collective teacher efficacy and student achievement. Leadership and Policy in Schools, 3, 189-209.

U.S. Department of Education, Office of Secondary and Elementary Education. (2011). Student achievement and school accountability programs. Washington, DC: Author.

Vachon, T. E., \& Ma, J. (2015). Bargaining for success: Examining the relationship between teacher unions and student achievement. Social Forum, 30, 391-414. doi:10.1111/socf.12168

Wahlstrom, K., \& Louis, K. (2008). How teachers experience principal leadership: The roles of professional community, trust, efficacy, and shared responsibility. Educational Administration Quarterly, 44(4), 458-495.

Waters, T., \& Cameron, G. (2007). The balanced leadership framework: Connecting vision with action. Denver CO: Mid-Continent Research for Education and Learning (McREL).

Waters, J., \& Marzano, R., \& McNulty, B. (2004). Leadership that sparks learning. Educational Leadership: Journal of the Department of Supervision and Curriculum Development, 61(7), 48-51.

Whitaker, K. (1995). Principal burnout: Implications for professional development. Journal of Personnel Evaluation in Education, 9, 287-296.

Winkler, A. M., Scull, J., \& Zeehandelaar, D. (2012). How strong are U.S. teacher unions? A state-by-state comparison. Washington, DC: Thomas B. Fordham Institute. 